CLAUDIA IWASHITA

\title{
NOVAS ESTRATÉGIAS DE PURIFICAÇÃO DOS FATORES DE COAGULAÇÃO FATOR VIII E PROTEÍNA C A PARTIR DE \\ PLASMA HUMANO EMPREGANDO CROMATOGRAFIA LÍQUIDA
}

Dissertação apresentada ao Programa de Pós-Graduação Interunidades em Biotecnologia USP/ Instituto Butantan/ IPT, para obtenção do Título de Mestre em Biotecnologia. 


\title{
CLAUDIA IWASHITA
}

\author{
NOVAS ESTRATÉGIAS DE PURIFICAÇÃO DOS FATORES DE \\ COAGULAÇÃO FATOR VIII E PROTEÍNA C A PARTIR DE \\ PLASMA HUMANO EMPREGANDO CROMATOGRAFIA LÍQUIDA
}

Dissertação apresentada ao Programa de Pós-Graduação Interunidades em Biotecnologia USP/ Instituto Butantan/ IPT, para obtenção do Título de Mestre em Biotecnologia.

Área de concentração: Biotecnologia

Orientadora: Dra. Elisabeth Cheng

Versão original 
DADOS DE CATALOGAÇÃO NA PUBLICAÇÃO (CIP)

Serviço de Biblioteca e Informação Biomédica do

Instituto de Ciências Biomédicas da Universidade de São Paulo

reprodução não autorizada pelo autor

Iwashita, Claudia.

Novas estratégias de purificação dos fatores de coagulação Fator VIII e Proteína $\mathrm{C}$ a partir de plasma humano empregando cromatografia líquida / Claudia Iwashita. -- São Paulo, 2012.

Orientador: Elizabeth Cheng.

Dissertação (Mestrado) - Universidade de São Paulo. Instituto de Ciências Biomédicas. Programa de Pós-Graduação Interunidades em Biotecnologia USP/IPT/Instituto Butantan. Área de concentração:

Biotecnologia. Linha de pesquisa: Purificação de proteínas do plasma humano

Versão do título para o inglês: New strategies of purification of coagulation Factor VIII and Protein C from human plasma using liquid chromatography.

Descritores: 1. FVIII 2. Proteina C 3. IMAC 4. Cromatografia 5.Purificação de Proteínas I. Cheng, Elizabeth II. Universidade de São Paulo. Instituto de Ciências Biomédicas. Programa de Pós-Graduação Interunidades em Biotecnologia USP/IPT/Instituto Butantan III. Título. 
Candidato(a):

Título da Dissertação:

Orientador(a):
Claudia Iwashita.

Novas estratégias de purificação dos fatores de coagulação Fator VIII e Proteína C a partir de plasma humano empregando cromatografia líquida.

Elizabeth Cheng.

A Comissão Julgadora dos trabalhos de Defesa da Dissertação de Mestrado, em sessão pública realizada a .... ...........
( ) Aprovado(a)
( ) Reprovado(a)

Examinador(a): Assinatura:

Nome:

Instituição:

Examinador(a): Assinatura:

Nome:

Instituição:

Presidente: Assinatura:

Nome:

Instituição: 
À minha mãe Maria Kato e ao meu namorado Michel de Abreu Verinaud por todo amor, carinho, apoio e incentivo.

À todos aqueles que um dia se beneficiarão das pesquisas realizadas com Hemoderivados. 


\section{AGRADECIMENTOS}

Agradeço primeiramente a Deus por direcionar-me à procura da felicidade e da sabedoria e por guiar meu caminho a todo momento.

Ao programa de Pós-graduação Interunidades em Biotecnologia USP/Instituto Butantan/IPT, em nome da coordenadora do curso Dra Ana Clara G. Schenberg, pela oportunidade de desenvolver o mestrado por este programa.

Ao CNPq e à Fundação Butantan pelo suporte financeiro concedido.

À minha orientadora Dra Elisabeth Cheng (Beth Cheng), a quem devo muito pela confiança depositada, pelos ensinamentos práticos e teóricos diariamente no laboratório e, acima de tudo, pelo exemplo de pessoa correta. Beth, gostaria que soubesse que eu a admiro muito por toda sua dedicação ao trabalho, nunca deixando a família de lado. Obrigada por ter me convidado e me incentivado a desenvolver o mestrado após o aprimoramento, por estar sempre disposta a conversar, seja discutindo resultados e futuros experimentos, ou me aconselhando na vida pessoal e profissional.

À Dra Elizabeth Angelica Martins Leme (Beth Martins), pela companhia e risadas no laboratório e pelos inúmeros aprendizados. Beth, obrigada pela oportunidade de aprender a trabalhar em processos em escala piloto, tanto na área de Hemoderivados, quanto na área de desenvolvimento de vacinas. Também agradeço pelas valiosas sugestões na apresentação da qualificação.

Ao Dr Alexandre Yague Lopes (Alê), pela companhia no laboratório. Alê, obrigada por todas as sugestões valiosas na apresentação da qualificação.

À Dra Anita Mítico Tanaka-Azevedo (Anita), por ter me ajudado além da qualificação. Anita, obrigada por ser tão amiga, por ter se disposto a conversar detalhadamente sobre meu trabalho e por todo carinho. 
À Dra Mickie Takagi (Mickie), pelas sugestões após a qualificação. Mickie, obrigada pela gentileza em se dispor a sugerir mudanças no meu trabalho, mesmo não participando formalmente da minha banca de qualificação. Obrigada por todo apoio emocional e por todo carinho.

À todos os pesquisadores do Centro de Biotecnologia do Instituto Butantan por disponibilizarem o espaço físico e os equipamentos, pelos ensinamentos em aulas e seminários.

Aos membros da banca de qualificação: Dra Anita Mítico Tanaka-Azevedo, Dra Ana Marisa Chudzinski Tavassi e Dra Saartje Hernalsteens pela participação e pelas sugestões na qualificação.

À minha família, em especial à minha mãe Maria Kato, que sempre me incentivou a procurar o melhor para minha carreira, mesmo com as dificuldades e a quem eu devo muito pelos ensinamentos sobre a vida e valores morais. Mãe, você é uma mulher batalhadora e guerreira e espero um dia ser um pouco do que você é.

Ao meu namorado Michel de Abreu Verinaud (Morzão), por tanto amor, carinho, paciência e incentivo. Morzão, obrigada por estar comigo em todos os momentos, sejam eles bons ou ruins e me proporcionar tanta alegria. Obrigada por sempre me incentivar a continuar os estudos e a buscar uma vida melhor e por entender os meus feriados e finais de semana de trabalho. Sem todo o seu apoio eu não teria concluído este trabalho. Obrigada por me fazer tão feliz e me fazer sentir a pessoa mais especial do mundo!

À minha dentista Dra Emiko Clarice Okamoto (Dra Emiko), que é mais do que uma dentista, é uma amiga e conselheira. Obrigada por sempre estar pronta para dizer belas palavras confortantes em momentos difíceis e por sempre me fazer acreditar na realização dos meus objetivos com pensamentos positivos.

À Roberta Rodrigues de Carvalho (Rô), por ter sido a primeira a me ajudar no laboratório e a me ensinar a dar os primeiros passos para fazer uma cromatografia. Rô, obrigada pela amizade, pelas caronas e companhia na volta para casa, pelas 
conversas e inúmeras risadas. Obrigada por continuar sempre por perto mesmo em outro laboratório e por tornar os dias mais engraçados e divertidos. Obrigada por tanto carinho sempre! Também gostaria de agradecer à sua filha Danna, que fez parte do meu dia-a-dia, tornando a volta para casa mais divertida.

À Erika Nakajima (Erikita), por tantas ajudas no laboratório, por sempre estar disposta a me ajudar em tudo, independente do que fosse. Erikita, obrigada por tantas conversas e desabafos e pelas mil e uma ajudas, por sempre me levar na secretaria da Biotec e nos outros lugares que precisei ir durante esses 3 anos, inclusive para comer hot dog. Obrigada por toda ajuda na qualificação, desde a paciência em me ouvir reclamando, até arrumar a sala e os equipamentos para apresentação e anotar tudo durante a argüição. Obrigada por todo apoio emocional neste final de trabalho e pelo carinho nestes anos!

À Daniela Jinzenji (Dani), por ser tão paciente, prestativa e atenciosa. Dani, obrigada pelos conselhos e discussões sobre os meus experimentos, pelas ajudas nas revelações dos western, pelos ensinamentos e pelas conversas diariamente. Obrigada também pelos ensinamentos na planta piloto.

À Patrícia Placoná Diniz (Patota), por ser tão alto astral e me fazer rir sempre. Patota, obrigada por alegrar o laboratório e tornar o trabalho mais leve, por cantar músicas que ninguém gosta, mas que mesmo assim todos se divertem. Você faz falta no laboratório!

À Beatriz Isva Gonçalves (Bia), pela amizade desde o primeiro dia do programa de aprimoramento. Bia, obrigada por todas as conversas, por sempre me ouvir, pelas caminhadas, pela companhia no almoço e por ser tão dedicada nos trabalhos que tivemos que fazer nestes anos. Obrigada pela ajuda na qualificação e por todo carinho nestes 3 anos!

Ao Juliano Ventura (Jú), pela companhia, conversas e risadas no laboratório e no almoço. Jú, obrigada por trazer toda sua calma ao laboratório e obrigada por me ensinar a usar o AKTA Pilot. 
Ao Bruno Vitório Marthos (Bruno), pela amizade, companhia e risadas nas aulas e no almoço.

Ao Paulo Vinícius Sanches Daltro de Carvalho (Vinícius), pelas discussões sobre diluições, pela companhia, conversas e risadas no laboratório e no SBBq.

A Laís de Lara Capurro Guimarães (Laís), pela companhia no laboratório e por ser tão alto astral e engraçada. Laís obrigada por cada momento de alegria que você trouxe ao laboratório nos últimos meses.

À todos que estiveram juntos no processo da Sm TSP-2 na planta piloto de produtos recombinantes e que muito contribuíram para meu crescimento pessoal e profissional: Beth Martins, Beth Cheng, Mickie, Erika, Dani, Jú, Juliano Buba, Felipe Cintra, Fernando, Ivana, Celso, Nelson, Marilene, Raimunda, Paulo Lee Ho, Enéas, Léa, Adriano e aos funcionários da área de lavagem e esterilização de materiais da planta da Influenza.

À todos aqueles que passaram pelo laboratório neste período, seja para trabalhar ou para conversar: Cris, Hebert, Aline, Léa, Paulo, Lud, Henrique, Vivian, Fernanda, Naty, Camila e Mariana (Vet), Mariana (Rocilda) e Rafa.

À Sueli, por sempre estar disposta a ajudar com as coisas do laboratório e por ser tão alto astral. Ao Joselino, por sempre estar de bom humor e lavar nosso material com tanta dedicação. Ao segurança André por sempre se preocupar comigo quando ficava até tarde no laboratório. À Marisa, por alegrar meus dias com doces deliciosos. E à todos os outros funcionários do Centro de Biotecnologia que de alguma forma contribuíram para realização deste trabalho.

Aos funcionários da secretaria do Programa Interunidades em Biotecnologia, Marcos, Fábia e Eliane por todo serviço prestado durante o mestrado.

Às bibliotecárias Maria do Socorro e Valéria, da biblioteca do ICB-USP, que fizeram a revisão do trabalho e foram tão atenciosas e prestativas. 
"Uma vida sem desafios não vale a pena ser vivida".

(Rubem Alvez)

"Plante seu jardim e decore sua alma, ao invés de esperar que alguém Ihe traga flores. $E$ você aprende que realmente pode suportar, que realmente é forte, $e$ que pode ir muito mais longe depois de pensar que não se pode mais. E que realmente a vida tem valor e que você tem valor diante da vida."

(William Shakespeare) 


\section{RESUMO}

IWASHITA, C. Novas estratégias de purificação dos fatores de coagulação Fator VIII e Proteína C a partir de plasma humano empregando cromatografia líquida. 2012. 142 f. [Dissertação (Mestrado em Biotecnologia)], Instituto de Ciências Biomédicas, Universidade de São Paulo, São Paulo, 2012.

Neste trabalho estudou-se alguns métodos de purificação de fator VIII de coagulação (FVIII) e da Proteína C (PC) por cromatografia. O concentrado de FVIII é utilizado no tratamento de hemofilia $A$, enquanto que concentrados de PC são usados em pacientes em risco de sofrer trombose venosa profunda. Concentrados de PC ativada podem ser usados no tratamento de septicemias. O emprego da coluna de troca aniônica ANX Sepharose FF como primeira etapa de purificação do plasma permite a eluição do FVIII e da PC com bom fator de purificação. Neste contexto, propomos a separação de FVIII e PC empregando cromatografia de afinidade a metal (IMAC) através de um estudo sistemático empregando colunas IMAC-Cu ${ }^{2+}, \mathrm{Ni}^{2+}, \mathrm{Zn}^{2+}, \mathrm{Co}^{2+}$ e $\mathrm{Fe}^{3+}$ e os métodos de dessorção empregando imidazol, cloreto de amônio e variação de $\mathrm{pH}$. Em colunas com os metais $\mathrm{Fe}^{3+}$ e $\mathrm{Ni}^{2+}$ as proteínas da amostra de entrada praticamente não se ligaram à resina. De um modo geral, a PC ligou-se muito mais fracamente às colunas de IMAC do que o FVIII. Em IMAC-Co ${ }^{2+}$, a PC não é adsorvida pela resina enquanto o FVIII pode ser eluído com imidazol $100 \mathrm{mM}$. Em IMAC-Cu${ }^{2+}$ a PC pode ser eluida com imidazol $10 \mathrm{mM}$ e o FVIII com $200 \mathrm{mM}$. As proteínas ligaram-se muito mais fortemente ao $\mathrm{Cu}^{2+}$ do que aos outros metais estudados. Não foi possível eluir as proteínas da coluna IMAC- $\mathrm{Cu}^{2+}$ nem com $\mathrm{NH}_{4} \mathrm{Cl} 1 \mathrm{M}$ nem quando o pH foi abaixado até 4,0. Em IMAC$\mathrm{Zn}^{2+}$ a $\mathrm{PC}$ não é adsorvida e o FVIII pode ser eluído com imidazol $200 \mathrm{mM}$ ou $\mathrm{NH}_{4} \mathrm{Cl}$ 1M. Diminuindo-se $\mathrm{o} \mathrm{pH}$, as proteínas foram eluidas, mas a recuperação da atividade do FVIII foi baixa, quando partiu-se de $\mathrm{pH} 7,0$, ou nenhuma, quando partiuse de $\mathrm{pH}$ 6,0. Concluímos que as proteínas FVIII e a PC podem ser bem separadas empregando IMAC-Cu ${ }^{2+}$, IMAC- $\mathrm{Zn}^{2+} \mathrm{e}$ IMAC-Co ${ }^{2+}$, sendo esta última coluna apresentou os melhores rendimentos e melhores fatores de purificação para as 2 protéinas.

Palavras-chave: FVIII. Proteína C. IMAC. Cromatografia. Purificação de proteínas. 


\begin{abstract}
IWASHITA, C. New strategies of purification of coagulation Factor VIII and Protein C from human plasma using liquid chromatography. 2012. 142p. [Masters thesis (Biotechnology)], São Paulo: Instituto de Ciências Biomédicas, Universidade de São Paulo, São Paulo, 2012.

In this work purification methods for the coagulation factor VIII (FVIII) and Protein C (PC) by chromatography was studied. Coagulation FVIII concentrate is used for Hemophilia A treatment, while PC concentrates is used in patients at risk of deep vein thrombosis. Activated PC concentrates can be used for the treatment of sepsis. The use of the anion exchange column ANX Sepharose FF as the first purification step allows the elution of FVIII and PC with good purification factors. In this context, we proposed the separation of FVIII and PC using immobilized metal ion affinity chromatography (IMAC). A systematic study was carried out using IMAC-Cu ${ }^{2+}, \mathrm{Ni}^{2+}$, $\mathrm{Zn}^{2+}, \mathrm{Co}^{2+}$ and $\mathrm{Fe}^{3+}$ columns and the desorption methods employing imidazole, ammonium chloride and $\mathrm{pH}$ variation. In the columns containing $\mathrm{Fe}^{3+}$ and $\mathrm{Ni}^{2+}$ metal ions, proteins from the loading samples did not adsorb to the resin. In general, PC interacted much weakly with IMAC columns than FVIII. In IMAC-Co ${ }^{2+}$, PC was not adsorbed to the resin, while FVIII could be eluted with $100 \mathrm{mM}$ imidazole. In IMAC$\mathrm{Cu}^{2+} \mathrm{PC}$ could be eluted with $10 \mathrm{mM}$ imidazole and FVIII with $200 \mathrm{mM}$. Proteins were much more strongly attached to $\mathrm{Cu}^{2+}$ than to the other studied metals. It was not possible to elute the proteins from IMAC-Cu ${ }^{2+}$ column with either $1 \mathrm{M} \mathrm{NH}_{4} \mathrm{Cl}$ or when $\mathrm{pH}$ was descreased to 4,0 . In IMAC- $\mathrm{Zn}^{2+}$, PC was not adsorbed and FVIII could be eluted with $200 \mathrm{mM}$ imidazole or $1 \mathrm{M} \mathrm{NH}_{4} \mathrm{Cl}$. By decreasing the $\mathrm{pH}$, proteins could be eluted, but the recovery of the FVIII was very low, when the decreasing of the $\mathrm{pH}$

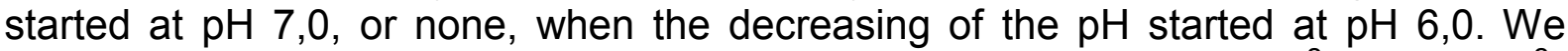
conclude that FVIII and PC could be well separated using IMAC-Cu ${ }^{2+}, \mathrm{IMAC}_{\mathrm{Z}} \mathrm{Zn}^{2+}$ and IMAC- $\mathrm{Co}^{2+}$, and that the $\mathrm{Co}^{2+}$ column gave the best yield and purification factors for the 2 proteins.
\end{abstract}

Keywords: FVIII. Protein C. IMAC. Chromatography. Purification of proteins. 


\section{LISTA DE ILUSTRAÇÕES}

Figura 1 - Fracionamento de plasma pelo método de Cohn-Oncley. ......................26

Figura 2 - Ativação da resina e imobilização do metal. ........................................... 1

Figura 3 - Modelo clássico da cascata de coagulação proposto nos anos $60 . . . . . . . .31$

Figura 4 - Ilustração do modelo celular da cascata de coagulação............................1

Figura 5 - Via da Proteína C no mecanismo de controle da coagulação..................... 1

Figura 6 - Estrutura, função e processamento do FVIII........................................ 34

Figura 7 - Estrutura das proteínas dependentes de vitamina $\mathrm{K}$ presentes no plasma

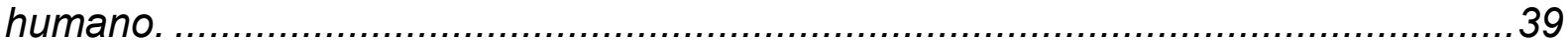

Figura 8 - Reação de y-carboxilação do resíduo glutamil pela enzima $y$-glutamil

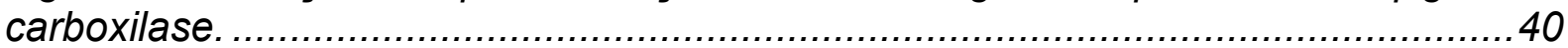

Figura 9 - Pico de acetona usado para determinação da eficiência do

empacotamento a partir de um cromatograma...............................................45

Figura 10 - Fluxograma mostrando a estratégia utilizada para purificação de FVIII e

PC a partir de plasma humano.................................................................50

Figura 11 - Reações do teste cromogênico para determinação da atividade do FVIII

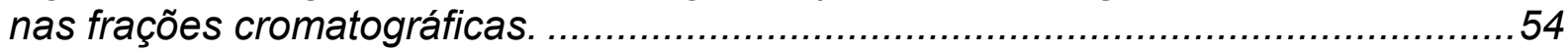

Figura 12. Etapas do teste cromogênico do FVIII. .............................................54

Figura 13 - Reações do teste cromogênico para determinação da atividade da PC

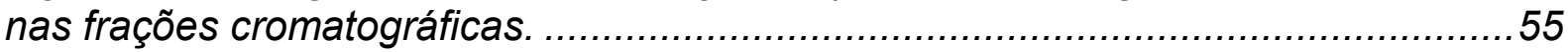

Figura 14 - Etapas do teste cromogênico da Proteína C......................................55

Figura 15 - Avaliação do empacotamento da resina ANX Sepharose FF em coluna

XK 26/40........................................................................................ 58

Figura 16 - Perfil cromatográfico da purificação de plasma em ANX Sepharose FF

(Condição Experimental 1).

Figura 17 - Curva de calibração utilizada no teste cromogênico para determinação de atividade do FVIII nas frações da purificação de plasma em ANX Sepharose FF (Condição Experimental 1).

Figura 18 - Curva de calibração utilizada no teste cromogênico para determinação de atividade da PC nas frações da purificação de plasma em ANX Sepharose FF (Condição Experimental 1)................................................................................61

Figura 19 - Curva de calibração para determinação de concentração de proteínas pelo método de Bradford da purificação de plasma em ANX Sepharose FF (Condição Experimental 1).

Figura 20 - Atividade de FVIII e PC (A) e proteína total $(B)$ nas frações da purificação de plasma em ANX Sepharose FF (Condição Experimental1)...............................62 Figura 21 - Gel de poliacrilamida 7,5\% (em condições redutoras) das frações obtidas na purificação em ANX Sepharose FF (Experimento 1).....................................62 Figura 22 - Atividade de FVIII e PC (A) e proteína total $(B)$ nas frações da purificação em ANX Sepharose FF (Condição Experimental 2).

Figura 23 - Gel de poliacrilamida 7,5\% (em condições redutoras) das frações obtidas na cromatografia de troca iônica com ANX Sepharose FF (Condição Experimental 2).

Figura 24 - Atividade de FVIII e PC (A) e proteína total $(B)$ nas frações da purificação em IMAC-Cu ${ }^{2+}$ empregando coluna HisTrap HP de $5 \mathrm{~mL}$ e dessorção com imidazol. 
Figura 25 - Atividade de FVIII e PC (A) e proteína total (B) nas frações da purificação em IMAC-C L $^{2+}$ empregando coluna Chelating Sepharose FF de $10 \mathrm{mLe}$ dessorção com imidazol.

Figura 26 - Atividade de FVIII e PC (A) e Proteína total $(B)$ da purificação em MAC$\mathrm{Cu}^{2+}$ empregando coluna HiTrap IMAC HP de $1 \mathrm{~mL}$ e variação de $\mathrm{pH}$.

Figura 27 - Atividade de FVIII (A) e Proteína total (B) das frações da purificação em MAC-Cu ${ }^{2+}$ empregando coluna HiTrap IMAC HP de $1 \mathrm{~mL}$ e tampão citrato com concentrações crescentes de $\mathrm{NH}_{4} \mathrm{Cl}$.

Figura 28 - Atividade de FVIII e PC (A) e proteína total $(B)$ nas frações da purificação em IMAC-Ni ${ }^{2+}$....

Figura 29 - Atividade de FVIII e PC (A) e proteína total (B) nas frações obtidas na purificação em IMAC-Zn ${ }^{2+}$ empregando coluna HisTrap HP de $5 \mathrm{~mL}$ e dessorção com imidazol.

Figura 30 - Atividade de FVIII e PC (A) e proteína total (B) nas frações obtidas na purificação em IMAC-Zn ${ }^{2+}$ empregando coluna Chelating Sepharose FF de $10 \mathrm{~mL}$ e dessorção com imidazol.

Figura 31 - Atividade de FVIII e PC (A) e proteína total (B) nas frações obtidas a partir da purificação com IMAC-Zn ${ }^{2+}$ empregando coluna HisTrap HP de $5 \mathrm{~mL}$ e dessorção com imidazol em pH=7,0 .......................................................... 82 Figura 32 - Atividade FVIII e PC (A) e proteína total (B) nas frações obtidas na purificação em IMAC-zinco, utilizando tampões em diferentes $\mathrm{pH}$ para dessorção das proteínas.

Figura 33 - Atividade de FVIII e PC (A) e proteína total $(B)$ nas frações obtidas na purificação em IMAC-Zn ${ }^{2+}$ empregando coluna HisTrap HP de $5 \mathrm{~mL}$ e variação de $\mathrm{pH}$ a partir de $\mathrm{pH} 6,0$. 86

Figura 34 - Atividade de FVIII e PC (A) e proteína total $(B)$ nas frações da purificação em IMAC-Zn ${ }^{2+}$ empregando coluna HiTrap de $1 \mathrm{~mL}$ e dessorção com $\mathrm{NH}_{4} \mathrm{Cl}$..........88 Figura 35 - Atividade de FVIII (A) e proteína total (B) das frações da purificação em IMAC-Co ${ }^{2+}$ empregando coluna HiTrap IMAC HP de $1 \mathrm{~mL}$ e tampões citrato $25 \mathrm{mM}$.

Figura 36 - Atividade de FVIII e PC (A) e proteína total das frações da purificação em IMAC- $\mathrm{Co}^{2+}$ empregando coluna HisTrap HP de $5 \mathrm{~mL}$ e tampões citrato $10 \mathrm{mM}$.....92 Figura 37 - Atividade total de FVIII nas frações obtidas a partir da purificação em IMAC-Co ${ }^{2+}$, utilizando uma coluna Chelating Sepharose Fast Flow de $10 \mathrm{~mL}$ e tampões citrato $10 \mathrm{mM}$......................................................................... 94 Figura 38 - Atividade do FVIII e da PC (A) e proteína total (B) nas frações da purificação em IMAC-Fe ${ }^{3+}$ empregando coluna HiTrap IMAC HP de $1 \mathrm{~mL}$ e tampões citrato $10 \mathrm{mM}$......

Quadro 1 - Comparação dos resultados da purificação de plasma em resinas ANX Sepharose e Q Sepharose. 


\section{LISTA DE TABELAS}

Tabela 1 - Produtos de FVIII derivados de plasma humano avaliados nos EUA. ....36

Tabela 2 - Avaliação do empacotamento da coluna ANX-Sepharose FF. ................58

Tabela 3 - Purificação de FVIII em ANX Sepharose FF (Condição Experimental 1). 63

Tabela 4 - Purificação de PC em ANX Sepharose FF (Condição Experimental 1)...63

Tabela 5 - Resumo dos resultados obtidos para a purificação de FVIII e PC em ANX

Sepharose FF empregando a Condição Experimental 1 .....................................64

Tabela 6 - Purificação de FVIII nas frações da purificação em ANX Sepharose FF

(Condição Experimental 2)..........................................................................67

Tabela 7 - Purificação de PC nas frações da purificação em ANX Sepharose FF

(Condição Experimental 2)........................................................................... 67

Tabela 8 - Purificação de FVIII em IMAC- $\mathrm{Cu}^{2+}$ empregando coluna HisTrap HP de

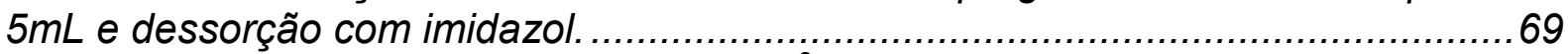

Tabela 9 - Purificação de PC em IMAC- $\mathrm{Cu}^{2+}$ empregando coluna HisTrap HP de $5 \mathrm{ml}$

e dessorção com imidazol. .............................................................................69

Tabela 10 - Purificação de FVIII empregando coluna Chelating Sepharose FF- $\mathrm{Cu}^{2+}$

de $10 \mathrm{mLe}$ dessorção com imidazol. ............................................................. 71

Tabela 11 - Purificação de PC empregando coluna Chelating Sepharose $F F-\mathrm{Cu}^{2+}$ de

$10 \mathrm{~mL}$ e dessorção com imidazol. .................................................................... 71

Tabela 12 - Purificação de FVIII em IMAC- $\mathrm{Cu}^{2+}$ empregando coluna HiTrap IMAC $H P$ de $1 \mathrm{~mL}$ e variação de $\mathrm{pH}$...................................................................... 73

Tabela 13 - Purificação de PC em IMAC- $\mathrm{Cu}^{2+}$ empregando coluna HiTrap IMAC HP de $1 \mathrm{~mL}$ e variação de $\mathrm{pH}$. .......................................................................... 73

Tabela 14 - Purificação de FVIII em IMAC- $\mathrm{Cu}^{2+}$ empregando coluna HiTrap IMAC

$\mathrm{HP}$ de $1 \mathrm{~mL}$ e tampão citrato com concentrações crescentes $\mathrm{NH}_{4} \mathrm{Cl}$.......................75

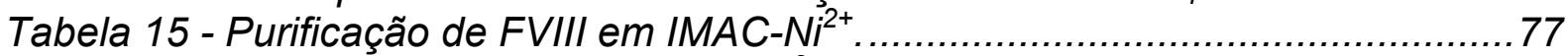

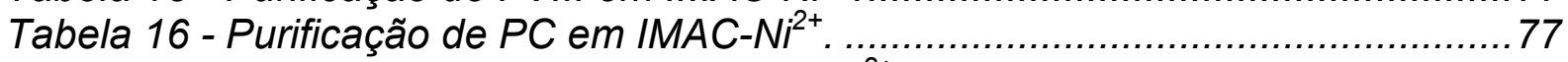

Tabela 17 - Purificação de FVIII em IMAC- $\mathrm{Zn}^{2+}$ empregando coluna HisTrap HP de

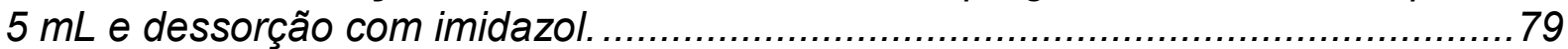

Tabela 18 - Purificação de PC em IMAC- $\mathrm{Zn}^{2+}$ empregando coluna HisTrap HP de 5 $m L$ e dessorção com imidazol. ......................................................................... 79

Tabela 19 - Purificação de FVIII em IMAC-Zn ${ }^{2+}$ empregando coluna Chelating Sepharose FF de $10 \mathrm{~mL}$ e dessorção com imidazol. ............................................81 Tabela 20 - Purificação de PC em IMAC-Zn ${ }^{2+}$ empregando coluna Chelating Sepharose FF de $10 \mathrm{~mL}$ e dessorção com imidazol. ............................................ 81 Tabela 21 - Purificação de FVIII em IMAC-Zn ${ }^{2+}$ empregando coluna HisTrap HP de 5

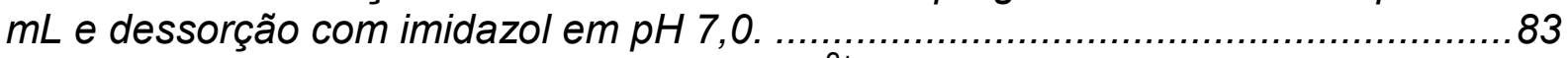
Tabela 22 - Purificação de PC em IMAC-Zn ${ }^{2+}$ empregando coluna HisTrap HP de 5

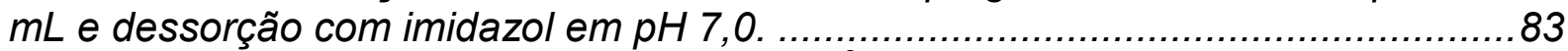
Tabela 23 - Purificação de FVIII em IMAC-Zn ${ }^{2+}$ empregando coluna HisTrap de $5 \mathrm{~mL}$

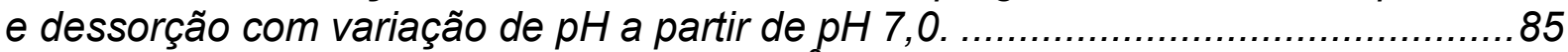
Tabela 24 - Purificação de PC em IMAC-Zn ${ }^{2+}$ empregando coluna HisTrap de $5 \mathrm{~mL}$ e

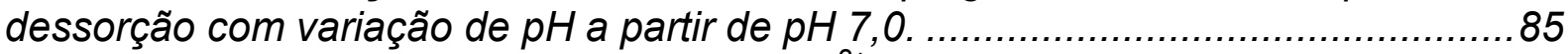
Tabela 25 - Purificação de FVIII em IMAC-Zn ${ }^{2+}$ empregando coluna HisTrap HP de 5

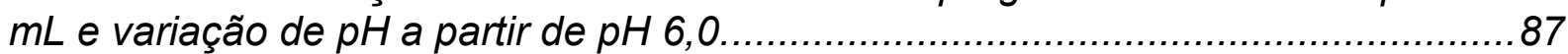
Tabela 26 - Purificação de PC em IMAC-Zn ${ }^{2+}$ empregando coluna HisTrap HP de 5 $m L$ e variação de $p H$ a partir de $p H 6,0$. 
Tabela 27 - Purificação de FVIII em IMAC-Zn ${ }^{2+}$ empregando coluna HiTrap de $1 \mathrm{~mL}$ e dessorção com $\mathrm{NH}_{4} \mathrm{Cl}$.

Tabela 28 - Purificação de PC em IMAC-Zn ${ }^{2+}$ empregando coluna HiTrap de $1 \mathrm{~mL} e$ dessorção com $\mathrm{NH}_{4} \mathrm{Cl}$. 89

Tabela 29 - Purificação de FVIII por IMAC- $\mathrm{Co}^{2+}$ em coluna HiTrap IMAC HP de 1 $m L$ empregando tampões citrato $25 \mathrm{mM}$...................................................91 Tabela 30 - Purificação de FVIII por IMAC- $\mathrm{Co}^{2+}$ empregando coluna HisTrap HP de $5 \mathrm{~mL}$ empregando tampões citrato $10 \mathrm{mM}$. .93 Tabela 31 - Purificação de PC por IMAC- $\mathrm{Co}^{2+}$ empregando coluna HisTrap HP de 5 $\mathrm{mL}$ empregando tampões citrato $10 \mathrm{mM}$.

Tabela 32 - Purificação de FVIII em IMAC-Co ${ }^{2+}$, utilizando coluna Chelating Sepharose Fast Flow de $10 \mathrm{~mL}$ e tampões citrato $10 \mathrm{mM}$.................................94 Tabela 33 - Purificação de FVIII em IMAC-Fe ${ }^{3+}$ empregando coluna HiTrap IMAC HP de $1 \mathrm{~mL}$ e tampões citrato $10 \mathrm{mM}$. .96 Tabela 34 - Purificação de FVIII em IMAC-Fe ${ }^{3+}$ empregando coluna HiTrap IMAC HP de $1 \mathrm{~mL}$ e tampões citrato $10 \mathrm{mM}$. 


\section{LISTA DE ABREVIATURAS E SIGLAS}

- Abs: Absorbância

- ANX: Dietilaminopropil

- APS: Ammonium Persulfate (Persulfato de amônio)

- BSA: Bovine serum albumin (Albumina sérica bovina)

- CPDA-1: Citrato-Fosfato-Dextrose-Adenina

- EDTA: Ethylenediamine tetraacetic acid (ácido etileno-diamino-tetracético)

- HEPES: ácido 4- (2- hidroxietil) - 1- piperazinaetanosulfônico

- HEPT: altura de cada prato teórico

- IDA: Iminodiacetic acid (ácido iminodiacético)

- IMAC: Immobilized metal ion affinity chromatography (Cromatografia de Afinidade a Metal Imobilizado)

- $\quad \mathbf{N} / \mathbf{m}$ : números de pratos teóricos por metro de resina

- NMWL: Nominal molecular weight limit (Limite nominal de peso molecular)

- NTA: Nitrilotriacetic Acid (ácido nitrilotriacético)

- PAGE: PolyAcrylamide Gel Electrophoresis (Eletroforese em gel de poliacrilamida)

- PC: Proteína C

- PFC: plasma fresco congelado

- pNa: p-nitroanilina

- SDS: Sodium Dodecyl Sulfate (Dodecil Sulfato de Sódio)

- TED: tris (carboxymethyl) ethylene-diamine ( $N, N, N$ - tris (carboximetil) etilenodiamina)

- TEMED: N,N,N',N'-Tetramethylethylenediamine (N,N,N',N'Tetrametiletilenodiamina

- TFPI: Tissue factor pathway inhibitor (Inibidor da via de fator tecidual)

- TREN: Tris(2-aminoethyl)amine (Tris (2-aminoetil) amina)

- UI: Unidades Internacionais

- VC: Volume de coluna 


\section{SUMÁRIO}

1 INTRODUÇÃO

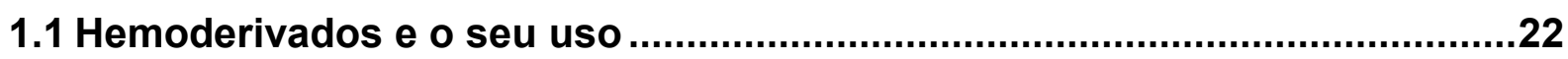

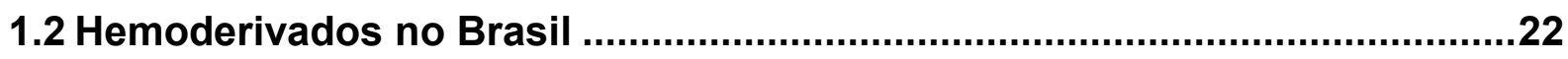

1.3 Hemoderivados no Instituto Butantan.....................................................24

1.4 Purificação de proteínas plasmáticas pelo método de Cohn ........................26

1.5 Purificação de proteínas por Cromatografia...................................................27

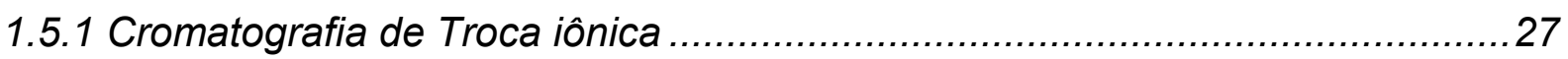

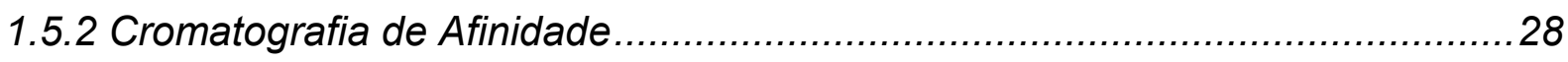

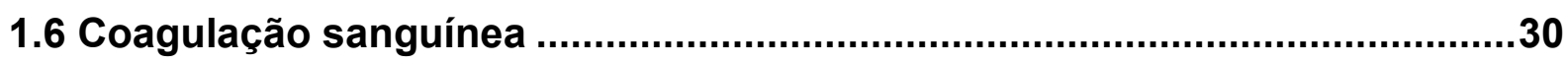

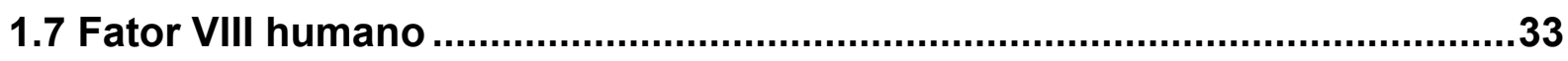

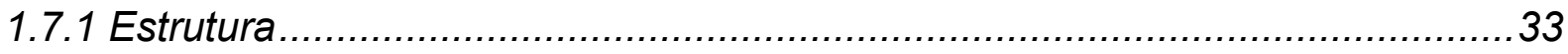

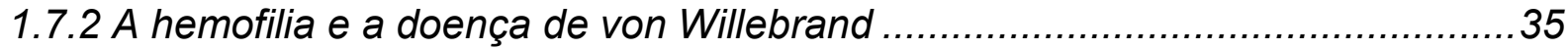

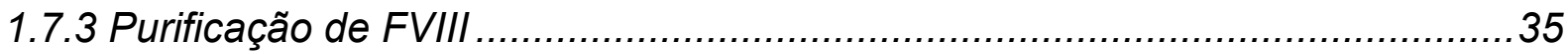

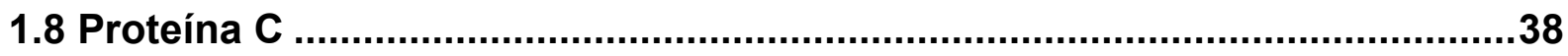

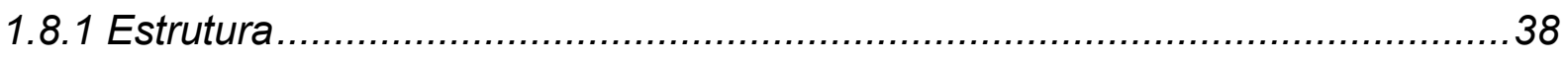

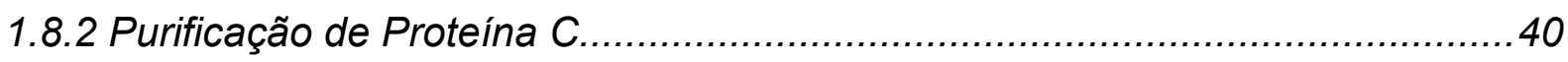

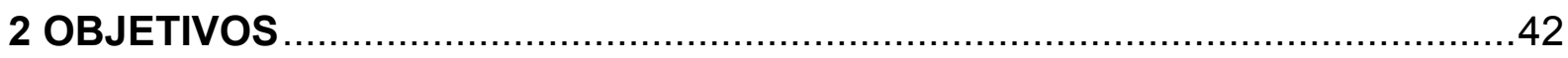

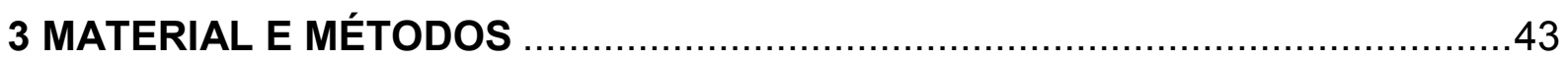

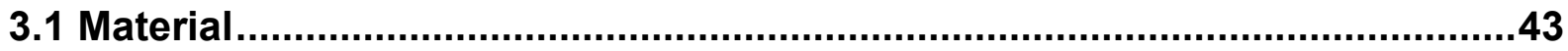

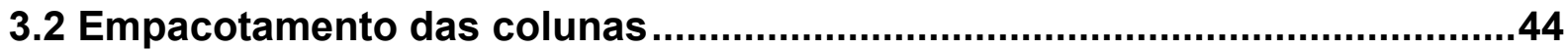

3.3 Avaliação do empacotamento das colunas ..................................................44

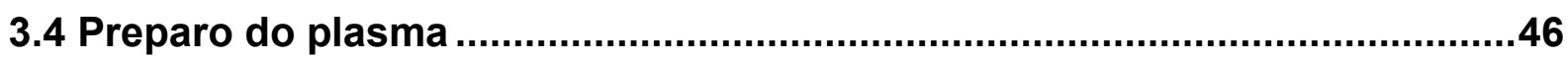

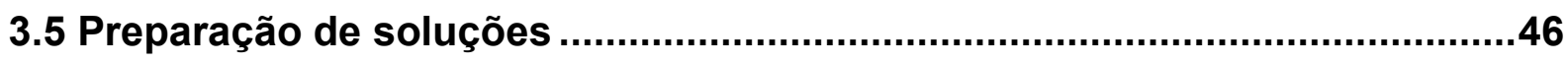

3.6 Purificação de FVIII de coagulação e Proteína C por cromatografia de troca

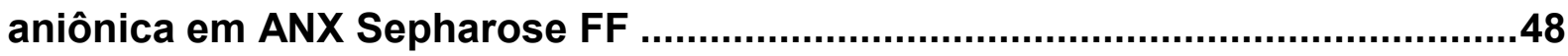

3.6.1 Determinação da concentração de $\mathrm{NaCl}$ para eluição do FVIII e da Proteína $\mathrm{C}$ na purificação de plasma em coluna de troca aniônica ANX Sepharose FF............. 49

3.7 Purificação de FVIII da coagulação e Proteína C empregando cromatografia

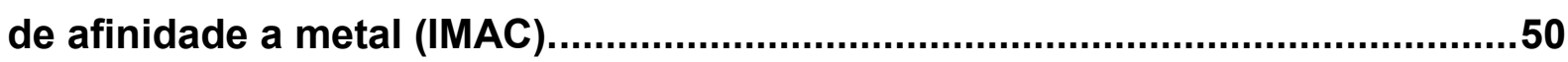

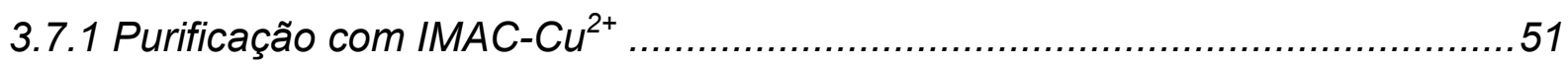

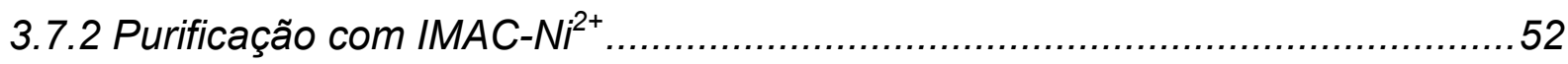

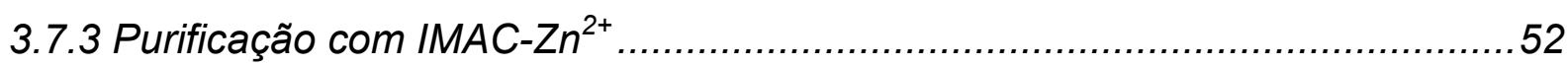


3.7.4 Purificação com IMAC-Co ${ }^{2+}$

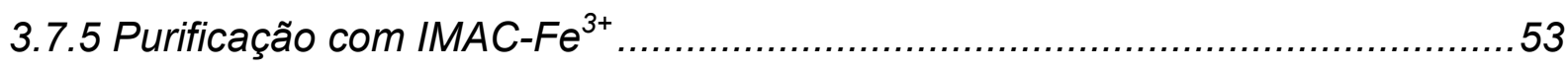

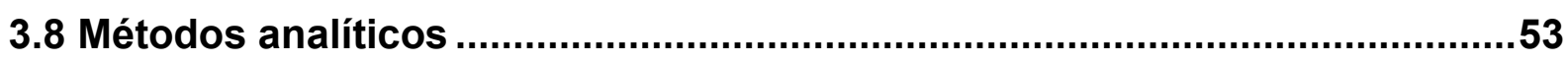

3.8.1 Determinação da atividade de FVIII pelo método cromogênico .......................53

3.8.2 Determinação da atividade da PC pelo método cromogênico..........................55

3.8.3 Determinação da concentração de proteínas pelo método de Bradford ..........56

3.8.4 Eletroforese em gel de poliacrilamida (SDS-PAGE).....................................56

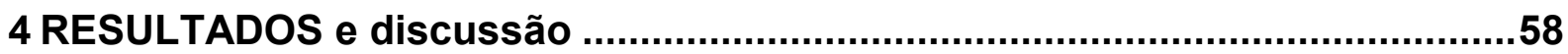

4.1 Purificação de Fator VIII de coagulação e Proteína $C$ por cromatografia de

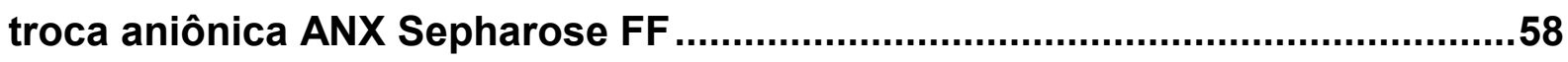

4.1.1 Avaliação do empacotamento da coluna ANX Sepharose FF........................58

4.1.2 Determinação da concentração de $\mathrm{NaCl}$ para a purificação do $\mathrm{FVIII}$ e da proteína $C$ em coluna de troca aniônica ANX Sepharose FF a partir de plasma

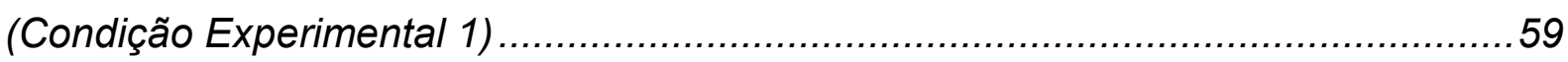

4.1.3 Determinação da concentração de $\mathrm{NaCl}$ para a purificação do $\mathrm{FVIII}$ e da proteína $C$ em coluna de troca aniônica ANX Sepharose FF a partir de plasma

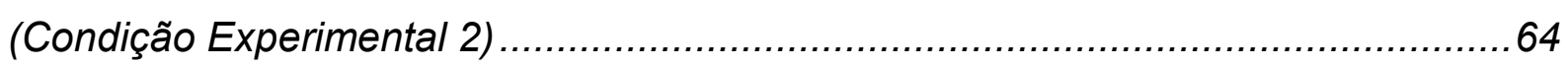

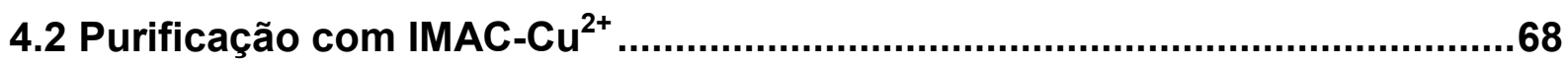

4.2.1 $\mathrm{IMAC} \mathrm{Cu}^{2+}$ empregando coluna HisTrap HP de $5 \mathrm{~mL}$ e dessorção com imidazol 68

4.2.2 IMAC-Cu $\mathrm{Iu}^{2+}$ empregando coluna Chelating Sepharose FF de $10 \mathrm{~mL}$ e dessorção

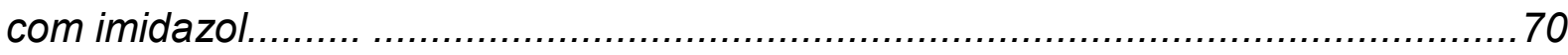

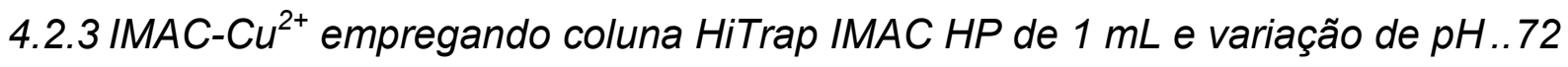

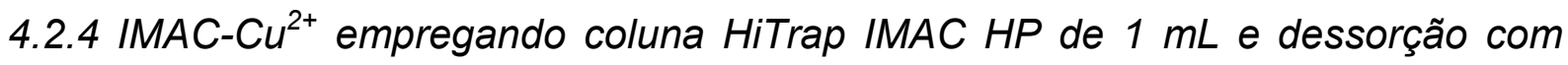

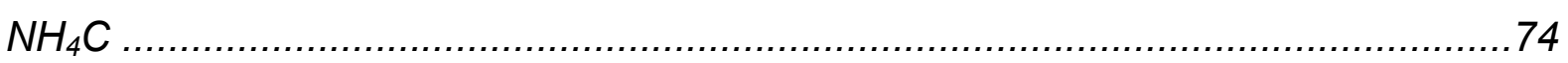

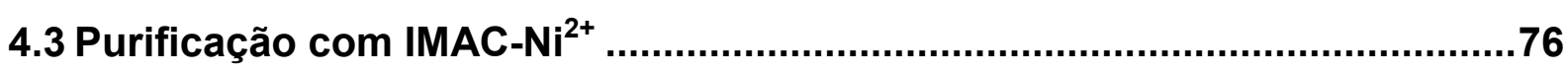

4.4 Purificação com IMAC- $\mathrm{Zn}^{2+}$..................................................................78

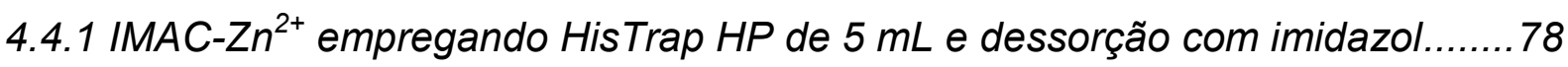

4.4.2 IMAC- $\mathrm{Zn}^{2+}$ empregando Chelating Sepharose FF de $10 \mathrm{~mL}$ e dessorção com imidazol.......

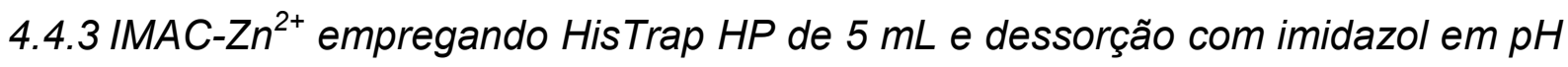
$7,0$.

4.4.4 IMAC- $\mathrm{Zn}^{2+}$ empregando HisTrap HP de $5 \mathrm{~mL}$ e dessorção com variação de $\mathrm{pH}$ a partir de $\mathrm{pH} 7,0$... .84 
4.4.5 IMAC- $Z n^{2+}$ empregando HisTrap HP de $5 \mathrm{~mL}$ e dessorção com variação de $\mathrm{pH}$ a partir de $\mathrm{pH} 6,0$.

4.4.6 IMAC-Zn ${ }^{2+}$ empregando HiTrap IMAC HP de $1 \mathrm{~mL}$ e dessorção com $\mathrm{NH}_{4} \mathrm{Cl}$...88 4.5 Purificação com IMAC-Co ${ }^{2+}$

4.5.1 IMAC-Co ${ }^{2+}$ empregando coluna HiTrap IMAC HP de $1 \mathrm{~mL}$ e tampões citrato 25 $m M$.

4.5.2 IMAC-Co $\mathrm{IO}^{2+}$ empregando coluna HisTrap HP de $5 \mathrm{~mL}$ e tampões citrato $10 \mathrm{~m} .92$ 4.5.3 IMAC-C $\mathrm{Co}^{2+}$ empregando coluna Chelating Sepharose FF de $10 \mathrm{~mL}$ e tampões citrato $10 \mathrm{mM}$.

4.6 Purificação com IMAC-Fe ${ }^{3+}$ .95

5 DISCUSSÃO GERAL .97

5.1 Purificação de FVIII de coagulação e Proteína C por cromatografia de troca aniônica ANX Sepharose FF.

5.2 Purificação de FVIII da coagulação e Proteína C empregando Cromatografia de Afinidade a Metal (IMAC). .98

6 CONCLUSÕES 102

REFERÊNCIAS 103

ANEXOS 109

ANEXO A - Curvas de calibração utilizadas para determinação de atividade de FVIII e PC e para determinação da concentração de proteínas nas frações obtidas na determinação da concentração de $\mathrm{NaCl}$ para eluição de FVIII e da PC na purificação de plasma em coluna de troca aniônica ANX Sepharose FF (Condição Experimental 1). 110

ANEXO B - Curvas de calibração utilizadas para determinação de atividade de FVIII e PC e para determinação da concentração de proteínas nas frações obtidas na determinação da concentração de $\mathrm{NaCl}$ para eluição de FVIII e da PC na purificação de plasma em coluna de troca aniônica ANX Sepharose FF (Condição Experimental 2). 112

ANEXO C - Curvas de calibração utilizadas para determinação de atividade de FVIII e PC e para determinação da concentração de proteínas nas frações da purificação em IMAC-Cu ${ }^{2+}$ empregando coluna HisTrap HP de $5 \mathrm{~mL}$ e dessorção com imidazol. 
ANEXO D - Curvas de calibração utilizadas para determinação de atividade de FVIII e PC e para determinação da concentração de proteínas nas frações da purificação em IMAC-Cu I $^{2+}$ empregando coluna Chelating Sepharose FF de $10 \mathrm{~mL}$ e dessorção com imidazol.

ANEXO E - Curvas de calibração utilizadas para determinação de atividade de FVIII e PC e para determinação da concentração de proteínas nas frações da purificação

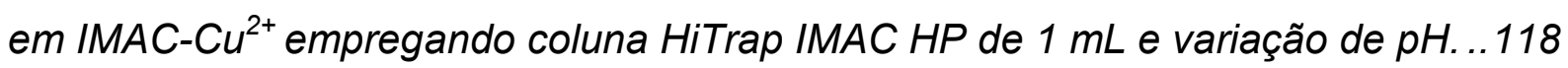
ANEXO F - Curvas de calibração utilizadas para determinação de atividade de FVIII e para determinação da concentração de proteínas nas frações da purificação em IMAC-Cu ${ }^{2+}$ empregando coluna HiTrap IMAC HP de $1 \mathrm{~mL}$ e dessorção com $\mathrm{NH}_{4} \mathrm{Cl}$.

ANEXO G - Curvas de calibração utilizadas para determinação de atividade de FVIII e PC e para determinação da concentração de proteínas nas frações da purificação em IMAC-Ni ${ }^{2+}$.

ANEXO H - Curvas de calibração utilizadas para determinação de atividade de FVIII e PC e para determinação da concentração de proteínas nas frações da purificação em IMAC- $\mathrm{Zn}^{2+}$ empregando coluna HiTrap IMAC HP de $1 \mathrm{~mL}$ e dessorção com imidazol.

ANEXO I - Curvas de calibração utilizadas para determinação de atividade de FVIII e PC e para determinação da concentração de proteínas nas frações da purificação em IMAC-Zn ${ }^{2+}$ empregando coluna Chelating Sepharose FF de $10 \mathrm{~mL}$ e dessorção com imidazol. 126

ANEXO J - Curvas de calibração utilizadas para determinação de atividade de FVIII e PC e para determinação da concentração de proteínas nas frações da purificação em IMAC-Zn ${ }^{2+}$ empregando coluna HisTrap HP de $5 \mathrm{~mL}$ e dessorção com imidazol em $\mathrm{pH} 7,0$. 128

ANEXO K - Curvas de calibração utilizadas para determinação de atividade de FVIII e PC e para determinação da concentração de proteínas nas frações da purificação em IMAC-Zn ${ }^{2+}$ empregando coluna HisTrap HP de $5 \mathrm{~mL}$ e dessorção com variação de $\mathrm{pH}$ a partir de $\mathrm{pH} 7,0$. 130

ANEXO L - Curvas de calibração utilizadas para determinação de atividade de FVIII e PC e para determinação da concentração de proteínas nas frações da purificação em IMAC-Zn ${ }^{2+}$ empregando coluna HisTrap HP de $5 \mathrm{~mL}$ e dessorção com variação de $\mathrm{pH}$ a partir de $\mathrm{pH} 6,0$. 
ANEXO M - Curvas de calibração utilizadas para determinação de atividade de FVIII e PC e para determinação da concentração de proteínas nas frações da purificação em IMAC- $\mathrm{Zn}^{2+}$ empregando coluna HiTrap IMAC HP de $1 \mathrm{~mL}$ e dessorção com $\mathrm{NH}_{4} \mathrm{Cl}$. 134

ANEXO N - Curvas de calibração utilizadas para determinação de atividade de FVIII e PC e para determinação da concentração de proteínas nas frações da purificação em IMAC-Co ${ }^{2+}$ empregando coluna HiTrap IMAC HP de $1 \mathrm{~mL}$ e tampões citrato 25 $m M$. 136

ANEXO O - Curvas de calibração utilizadas para determinação de atividade de FVIII e PC e para determinação da concentração de proteínas nas frações da purificação em IMAC-Co ${ }^{2+}$ empregando coluna HisTrap HP de $5 \mathrm{~mL}$ e tampões citrato $10 \mathrm{mM}$.

ANEXO P - Curvas de calibração utilizadas para determinação de atividade de FVIII e PC e para determinação da concentração de proteínas nas frações da purificação em IMAC-Co ${ }^{2+}$ empregando coluna Chelating Sepharose FF de $10 \mathrm{~mL}$ e tampões citrato $10 \mathrm{mM}$ 140

ANEXO Q - Curvas de calibração utilizadas para determinação de atividade de FVIII e PC e para determinação da concentração de proteínas nas frações da purificação em IMAC-Fe ${ }^{3+}$ 


\section{INTRODUÇÃO}

\subsection{Hemoderivados e o seu uso}

O sangue e seus derivados são de grande importância no âmbito da saúde pública, uma vez que podem ser utilizados na prevenção e tratamento de diversas doenças, traumas, desordens imunológicas, infecções (BURNOUF, 2007) e deficiências congênitas (FARRUGIA et al., 2009).

Após a coleta, o sangue total é submetido a centrifugações que separam as hemácias, leucócitos, plaquetas e o plasma e são denominados hemocomponentes. A partir do fracionamento do plasma, pode-se obter proteínas, denominadas de hemoderivados.

Dados divulgados pelo Ministério da Saúde informam que dos cerca de 11.000 pacientes diagnosticados com coagulopatias congênitas (FARRUGIA et al., 2009) $62,7 \%$ apresentam Hemofilia A, 11,7\% Hemofilia B, 21,2\% Doença de von Willebrand, $2,4 \%$ outras coagulopatias e $2 \%$ outras desordens hemorrágicas não identificadas (REZENDE et al., 2009).

Entre as proteínas do plasma, destacam-se os fatores de coagulação cujos concentrados podem ser utilizados no tratamento de coagulopatias. Concentrados de FVIII são utilizado no tratamento de Hemofilia $A$, podendo ser também usado para o tratamento da doença de von Willebrand. A deficiência de Proteína $C$ também é tratada com concentrados desta proteína. Além disso, a forma ativada desta proteína, a Proteína C ativada, apresenta atividade anticoagulante, antiinflamatória, citoprotetora e antiapoptótica. A terapia de APC reduz a mortalidade em pacientes com sepse severa (GRIFFIN et al., 2006). Além destes produtos podemos citar a comercialização de produtos de FVII, FIX, FXI, FXIII, FvW, fibrinogênio, antitrombina, IgG, a1- Antitripsina, Albumina e Complexo Protrombínico.

\subsection{Hemoderivados no Brasil}

A questão dos hemoderivados é de grande importância, uma vez que engloba questões de saúde pública, econômica e ética.

O fato de a Constituição Federal Brasileira, de 1988, ter proibido o comércio de sangue, seus componentes e derivados, reflete as questões éticas e aumenta a 
responsabilidade do Estado em garantir estes produtos essenciais e de alto custo à saúde pública.

O Brasil arrecada cerca de 4 milhões de bolsas de sangue por ano (FARRUGIA et al., 2009). De cada bolsa de sangue total coletada, separam-se os hemocomponentes do plasma. Estes são armazenados em diferentes temperaturas, para fins transfusionais e têm durabilidade de três a 42 dias, dependendo do tipo de concentrado e do tipo de bolsa plástica usada na coleta do sangue. Os hemocomponentes são transfundidos quase que integralmente. Em geral, os estoques de concentrados de hemácias e de plaquetas estão sempre no limite das necessidades nos serviços de hemoterapia. Muitas bolsas de plasma são inutilizadas e descartadas devido à baixa demanda de uso nos centros de Hemoterapia.

O plasma fresco congelado no período de até oito horas após a coleta do sangue pode ser congelado por um ano à $-20{ }^{\circ} \mathrm{C}$ ou a $-30{ }^{\circ} \mathrm{C}$ por dois anos, e usado em transfusões ou para a produção industrial de fatores da coagulação, sendo chamado de plasma fresco congelado (PFC). Quando congelado após as primeiras oito horas da coleta ou armazenado por tempo superior ao referido, transforma-se em plasma preservado, normal ou comum. Nesse caso, as proteínas lábeis, principalmente o Fator VIII da coagulação, perdem a atividade e o plasma torna-se indicado somente para a produção industrial de albumina e de imunoglobulinas (SOARES, 2002).

Apesar do consumo de PFC brasileiro ser considerado alto, o excedente de PFC ainda é grande e requer a implementação de alternativas que viabilizem o maior aproveitamento possível desta matéria-prima, evitando o seu desperdício.

O Ministério da Saúde compra de empresas estrangeiras os medicamentos derivados de plasma para atender a necessidade da população ao mesmo tempo em que está descartando bolsas de plasma que poderiam ser processadas no país, caso houvesse plantas de Hemoderivados. Dados do Ministério da Saúde indicam que o impacto do custo da importação destes produtos (FVIII, FIX, Albumina e Imunoglobulina intravenosa) para o país é da ordem de US\$282 milhões de dólares por ano, enquanto que para Protrombina parcialmente ativada, Complexo Protrombínico e concentrados de FvW/FVIII, o valor é de US\$ 33 milhões de dólares por ano (FARRUGIA et al., 2009). 
Em relação à disponibilidade dos hemoderivados, observa-se ainda que mesmo com a produção do Fator VIII recombinante, que veio tentar substituir o fator derivado do plasma, também há limite de suprimento. Além do limite de produção, os recombinantes têm como desvantagem o alto custo, sem definição sobre o benefício do seu uso em relação aos fatores da coagulação oriundos do plasma (SOARES, 2002).

Devido aos dados apresentados, o Ministério da Saúde discute a criação de fábricas para o processamento de plasma no país. Estão em construção duas plantas de Hemoderivados no Brasil, uma no Instituto Butantan, em São Paulo, e a outra em Goiana, em Pernambuco, denominada Hemobrás.

\subsection{Hemoderivados no Instituto Butantan}

O Centro de Biotecnologia do Instituto Butantan desde a sua criação em meados da década de 1980 tem projetos voltados para a purificação de hemoderivados. Inicialmente foram desenvolvidos projetos de purificação de proteínas a partir de placentas humanas, uma vez que o plasma humano não era disponível. Proteínas, tais como albumina, catalase, lgG e superóxido dismutase foram obtidas em processos em que um ou mais produtos são purificados concomitantemente com pureza comparável aos produtos comerciais (CABRERACRESPO et al., 2000; GONÇALVES et al.,1999; GRELLET et al., 2001). Mais tarde foram feitos estudos para a purificação de fator VIII suíno (TANAKA et al., $2000 \mathrm{e}$ LORTHIOIS, 2002), usado em tratamento de Hemofilia A com inibidores (GRIBBLE; GARVEY, 2000). Com a disponibilização do plasma humano pelo Hemocentro de Ribeirão Preto, foram iniciados estudos de purificação de fator VIII de coagulação humana (LORTHIOIS, 2002). Em abril de 2008, foi assinado um acordo com o então governador de São Paulo, José Serra, no qual seriam investidos 57 milhões de reais pelo governo estadual para a implantação de uma fábrica de Hemoderivados no Instituto Butantan. Além da fábrica, que está em construção, há uma Planta Piloto, onde está sendo testada, em menor escala, a obtenção dos produtos a serem purificados na fábrica, e o Laboratório de Desenvolvimento de Processos, onde estão sendo estudadas novas estratégias para a purificação das proteínas da fábrica de Hemoderivados e o desenvolvimento de processos de purificação de novas de proteínas de interesse biotecnológico. 
Em vista das perspectivas da construção da fábrica para a produção de hemoderivados no Instituto Butantan, foram surgindo projetos desenhados, em princípio, para serem compatíveis com o processo da fábrica. $O$ processo de fracionamento de plasma humano a ser implantado no Instituto Butantan consiste da purificação sequencial de quatro proteínas: fator VIII de coagulação, fator IX de coagulação, albumina e lgG apenas por cromatografia.

Neste contexto, foi realizado um estudo para verificar a introdução de uma troca aniônica antes da gel filtração, que, no processo da fábrica, seria a primeira etapa de purificação do fator VIII (CHENG et al., 2010; JINZENJI, 2008). A coluna de troca aniônica teria como função principal a concentração do fator VIII e, assim, seria possível utilizar um coluna de gel filtração menor. O acréscimo de uma etapa de purificação seria compensada pela economia de tempo e de custos. Foi observado por Jinzenji (2008) e Carvalho (2008) que a concentração de $\mathrm{NaCl}$ nos tampões empregados na troca aniônica, utilizando a resina Q-Sepharose, tem influência sobre o tamanho do complexo $\mathrm{FVIII/FvW,} \mathrm{o} \mathrm{que,} \mathrm{consequentemente,} \mathrm{interfere} \mathrm{no}$ perfil de separação na coluna de gel filtração. Portanto, um estudo mais detalhado para verificar o efeito da variação da concentração de sais presentes no tampão sobre o tamanho do complexo é necessário para o sucesso da gel filtração.

A purificação da Proteína $C$ foi iniciada em um projeto de iniciação científica de Rodriguez (2007) empregando coluna de afinidade a metal (IMAC) para purificação de FVIII e PC a partir de plasma. Existe um processo muito elegante descrito na literatura para a purificação do fator IX de coagulação humano em que várias proteínas dependentes de vitamina $\mathrm{K}$ são purificadas a partir do complexo protrombínico (MATEJTSCHUK, 1997). Neste processo, em que o fator IX foi obtido em escala de $\mathrm{kg}$, o complexo protrombínico de partida foi obtido a partir de coluna de troca aniônica usada na primeira etapa do processo de purificação de fator IX da fábrica de hemoderivados e em apenas uma etapa, a Proteína $C$ foi separada dos fatores II, VII, IX, mas não do fator X. Seria necessário ainda mais uma etapa de cromatografia para a separação destas 2 proteínas. Rodriguez (2007) verificou que era possível separar o FVIII de coagulação e o complexo protrombínico em IMAC$\mathrm{Cu}^{2+}$. 


\subsection{Purificação de proteínas plasmáticas pelo método de Cohn}

O principal método para purificação de proteínas do plasma humano baseiase no método desenvolvido por Cohn na década de 1940 e modificado posteriormente (BURNOUF, 2007; OFOSU; FREEDMAN; SEMPLE, 2008). Baseiase na precipitação fracionada de proteínas do plasma com etanol em baixas temperaturas, com variação de $\mathrm{pH}$. Os precipitados são separados por centrifugação e as proteínas de interesse seguem sendo fracionadas na linha de purificação (Figura 1).

No método de Cohn, o sangue usualmente é coletado em solução citratada (anticoagulante) e o plasma separado da fração celular por centrifugação é imediatamente congelado. O passo inicial da purificação é a separação do crioprecipitado. O plasma é descongelado a $2-4^{\circ} \mathrm{C}$. A esta temperatura, algumas proteínas, entre as quais o fator VIII de coagulação, continuam insolúveis e são separadas por centrifugação. A etapa de separação desta fração enriquecida de fator VIII por crioprecipitação tem alto custo, uma vez que exige manipulação do plasma em ambiente refrigerado, centrifugação contínua de grande volume, além de implicar em grande perda de proteína e de atividade.

Figura 1 - Fracionamento de plasma pelo método de Cohn-Oncley.

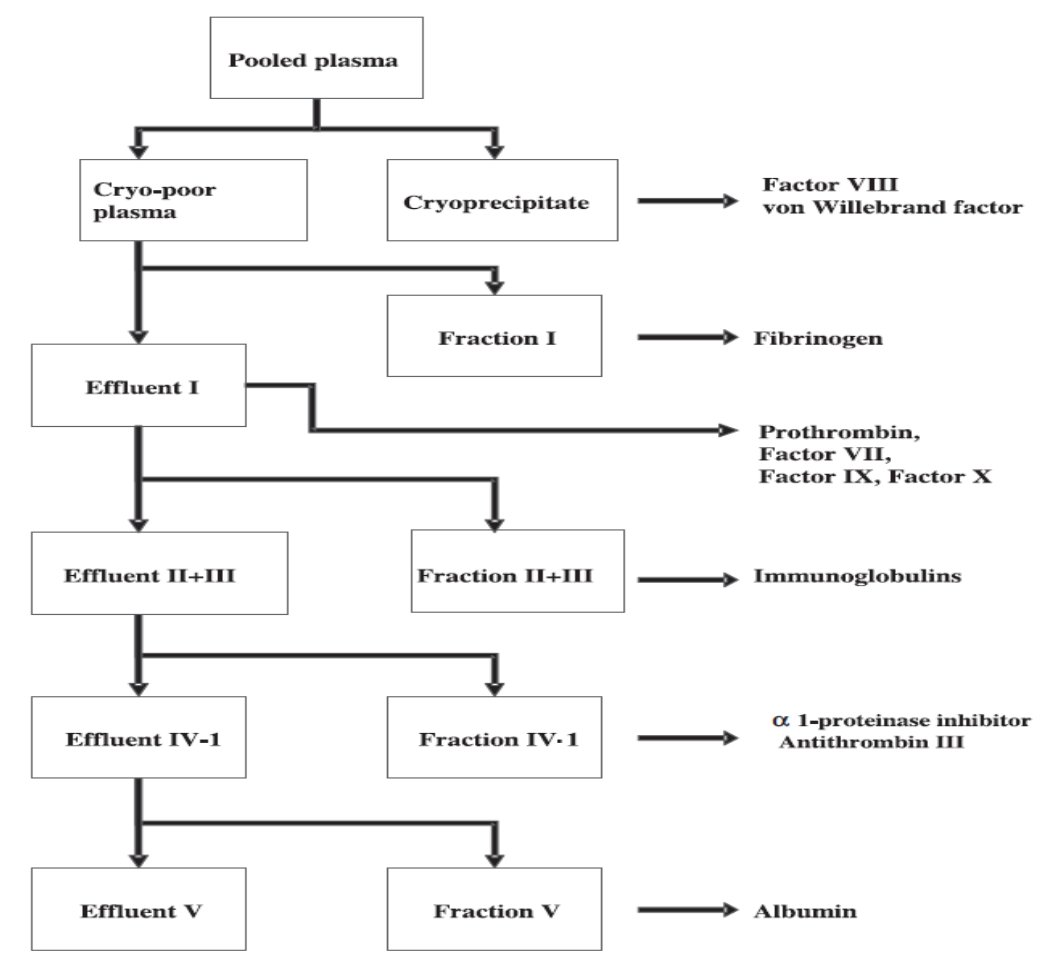

FONTE: (OFOSU et al., 2008) 


\subsection{Purificação de proteínas por Cromatografia}

Atualmente, a maioria das plantas de Hemoderivados utiliza um processo misto de purificação por precipitação pelo método de Cohn e cromatografia. A proposta do Instituto Butantan é produzir os hemoderivados utilizando apenas métodos cromatográficos.

A cromatografia é um método físico-químico de separação dos componentes de uma mistura, realizada por meio da distribuição desses componentes em duas fases, que estão em contato íntimo. Uma das fases permanece estacionária, enquanto a outra se move através dela. Durante a passagem da fase móvel sobre a fase estacionária, os componentes da mistura são distribuídos pelas duas fases de tal forma que cada um deles seja seletivamente retido pela fase estacionária, o que resulta em migrações diferenciais desses componentes (COLLINS; BRAGA; BONATO, 2006).

\subsubsection{Cromatografia de Troca iônica}

Na cromatografia por troca iônica, a fase estacionária é altamente carregada, e solutos com cargas de sinais contrários a esta são seletivamente adsorvidos da fase móvel. Os solutos adsorvidos podem ser subseqüentemente eluídos, por deslocamentos com outros íons, com o mesmo tipo de carga, porém com maior força de interação com a fase estacionária ou por variação de pH (COLLINS; BRAGA; BONATO, 2006).

As resinas de troca aniônica são trocadoras de cargas negativas, ou seja, a resina é carregada positivamente. Por outro lado, as resinas de troca catiônica são trocadoras de cargas positivas, sendo assim carregada negativamente.

Os termos forte e fraca se referem à extensão na qual o estado de ionização dos grupos funcionais variam com o pH. Trocadores iônicos fortes não apresentam variação da capacidade com variações de $\mathrm{pH}$, não ganhando e nem perdendo prótons. Já os trocadores iônicos fracos podem ganhar ou perder prótons com alteração do $\mathrm{pH}$, variando a sua capacidade. Esses termos não se referem a intensidade com que os grupos funcionais se ligam às proteínas (GE HEALTHCARE, 2004). 
A resina ANX Sepharose 4FF apresenta grupos aminos terciários (grupos dietilaminopropil) ligados a uma matriz de agarose com 'cross-linking' de 4\%. A distribuição de poros desta resina foi otimizada para a separação de proteínas de tamanho grande, que aumenta a capacidade de ligação enquanto separa moléculas maiores. O fluxo linear de trabalho recomendado é de $\geq 200 \mathrm{~cm} / \mathrm{h}$.

\subsubsection{Cromatografia de Afinidade}

A metodologia da cromatografia por afinidade envolve a preparação de uma fase estacionária seletiva, por imobilização covalente de ligantes específicos à matriz ou suporte sólido. A amostra é aplicada à coluna contendo o ligante imobilizado ao suporte sólido. As moléculas que não possuem nenhuma afinidade com o ligante passam pela coluna sem serem retidas, enquanto as macromoléculas capazes de se unirem a ele são diferencialmente retidas, em função da intensidade da afinidade (COLLINS; BRAGA; BONATO, 2006).

A cromatografia de afinidade a íons metálicos imobilizados, também conhecida pela sigla IMAC (Immobilized Metal Affinity Chromatography) é uma modalidade da cromatografia de afinidade, em que moléculas ligam-se reversivelmente a metais, imobilizados nas resinas, formando complexos. Essa técnica foi proposta por Everson e Parker e popularizou-se com o trabalho publicado por Porath $\mathrm{e}$ colaboradores em 1975 (BRESSOLIN;
Figura 2 - Ativação da resina e imobilização do metal.
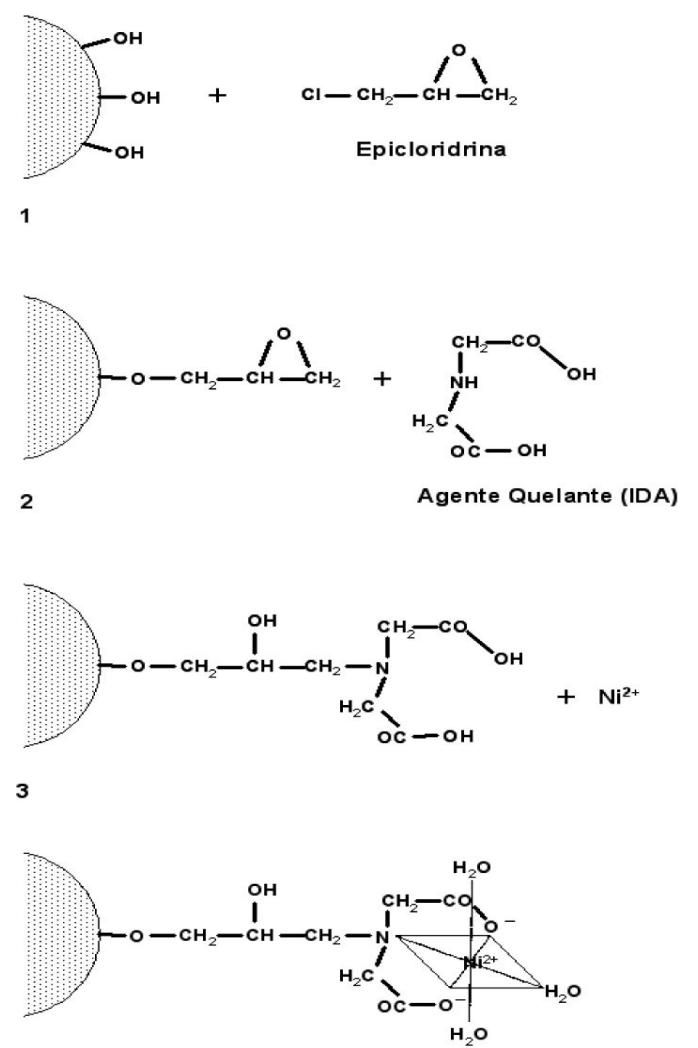

4

Se necessário, pode-se acoplar um braço espaçador. por exemplo, aminohexil, entre as etapas 2 e 3 .

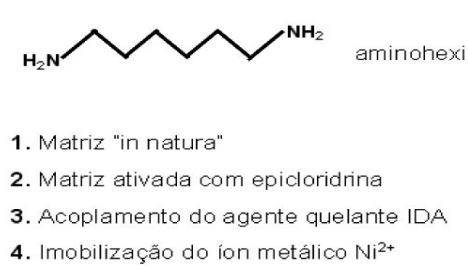

FONTE: (BRESSOLIN; MIRANDA;

BUENO, 2009) 
MIRANDA; BUENO, 2009).

Esta técnica permite a separação de proteínas que possuam histidina, triptofano ou cisteína em sua superfície, os quais formam complexos com íons $\mathrm{Cu}^{2+}$, $\mathrm{Ni}^{+2}, \mathrm{Zn}^{+2}$ e Co ${ }^{+2}$ (BRESSOLIN; MIRANDA; BUENO, 2009; CHARCOSSET, 1998). Estes íons metálicos interagem com o nitrogênio aromático dos grupamentos imidazol, indol e com enxofre do grupamento tiol, respectivamente de cada aminoácido. Os íons metálicos $\mathrm{Fe}^{3+}$ e $\mathrm{Al}^{3+}$ ligam-se a fosfato e fosfoésteres primários, podendo ser utilizado para fosfoproteínas, e o íon $\mathrm{Ca}^{2+}$ coordena de maneira estável o átomo de oxigênio presente em grupos carboxílicos dos resíduos doa aminoácidos ácidos aspártico e glutâmico, podendo ser utilizado para purificação de proteínas ricas em grupamentos carboxílicos, tais como fibrinogênio e calmodulina (BRESSOLIN; MIRANDA; BUENO, 2009).

Íons metálicos como $\mathrm{Cu}^{2+}, \mathrm{Ni}^{+2}, \mathrm{Zn}^{+2}$ e $\mathrm{Co}^{+2}$ podem ser facilmente imobilizados em resinas cromatográficas contendo agentes quelantes, tais como ácido iminodiacético (IDA), N,N,N-tris(carboximetil)etilenodiamina (TED), tris(2aminoetil)amina (TREN) e ácido nitrilotriacético (NTA) (BRESSOLIN; MIRANDA; BUENO, 2009).

De acordo com Porath et al. (1975), a estabilidade dos quelatos formados entre IDA com alguns íons metálicos decresce na seguinte ordem: $\mathrm{Cu}^{2+}>\mathrm{Ni}^{+2}>\mathrm{Zn}^{+2}$ $>\mathrm{Co}^{+2}>>\mathrm{Ca}^{2}=\mathrm{Mg}^{2}$.O agente quelante é acoplado a uma matriz sólida por meio de ligações covalentes. O íon metálico, por sua vez, é imobilizado ao agente quelante por ligações de coordenação formadas entre o íon metálico e átomos de nitrogênio, oxigênio ou enxofre presentes na estrutura do agente quelante (Figura 2).

De modo geral, quanto mais polidentado for o agente quelante, mais estáveis são os complexos formados com os íons metálicos, porém, menor quantidade de sítios permanece disponível para ligação com a biomolécula e, conseqüentemente, a mesma é mais fracamente absorvida (BRESSOLIN; MIRANDA; BUENO, 2009).

O IDA, o agente quelante presente na resina Chelating Sepharose FF usada neste trabalho, é tridentado (possui um átomo de nitrogênio e dois átomos de oxigênio para a coordenação), isto é, quela o íon metálico ocupando três sítios de coordenação (BRESSOLIN; MIRANDA; BUENO, 2009).

IMAC explora a interação entre espécies doadoras de elétrons presentes na superfície de biomoléculas em solução e íons metálicos imobilizados em um suporte sólido (BRESSOLIN; MIRANDA; BUENO, 2009). Uma outra aplicação muito 
conhecida para IMAC é a purificação de proteínas recombinantes que possuem calda de poli(histidina).

As moléculas adsorvidas podem ser eluídas por competição com outras espécies doadoras de elétrons (por exemplo, com imidazol ou com um agente quelante solúvel, como EDTA) ou por protonação de grupos doadores de elétrons presentes na proteína adsorvida (redução de $\mathrm{pH}$ ). De forma geral, íons metálicos imobilizados em uma matriz podem ser removidos pela adição de EDTA (ácido etileno-diamino-tetraacético), sem que haja perda de capacidade da matriz, ou seja, ela pode ser carregada novamente com o diferentes metais (BRESSOLIN; MIRANDA; BUENO, 2009).

As colunas HiTrap IMAC High Performance (HP) e HisTrap HP são préempacotadas, com volume de 1 ou $5 \mathrm{ml}$. Possuem uma matriz de agarose com 'cross-linking' de 6\% ligado covalentemente com um grupo quelante que é confidencial. O tamanho pequeno do 'bead' confere uma alta resolução.

A resina Chelating Sepharose Fast Flow apresenta grupos ácidos iminodiacético (IDA) ligados a Sepharose 6 Fast Flow por ligações éter, com braços longos. A matrix base Sepharose Fast Flow é à base de agarose com 'cross-linking' de $6 \%$. O tamanho da partícula é de 90 um e o fluxo linear de trabalho recomendado para esta resina é de 300 a $400 \mathrm{~cm} / \mathrm{h}$.

\subsection{Coagulação sanguínea}

A cascata de coagulação do sangue é um fenômeno complexo que envolve vários fatores, desde a sinalização por um dano vascular, a aglutinação de plaquetas até a formação do coágulo (DAHLBÄCK, 2000; FURIE; FURIE, 1988).

Nos anos 60 dois grupos de pesquisadores propuseram um modelo de cascata de coagulação compostos por uma série de etapas em que a ativação de um fator levava a ativação de outro, resultando na geração de trombina (HOFFMAN; MONROE, 2007). Segundo este modelo duas vias levam à formação da trombina, as vias intrínseca (ou via de contato) e extrínseca (ou via do fator tissular), como ilustrado na Figura 3. 
Figura 3 - Modelo clássico da cascata de coagulação proposto nos anos 60.

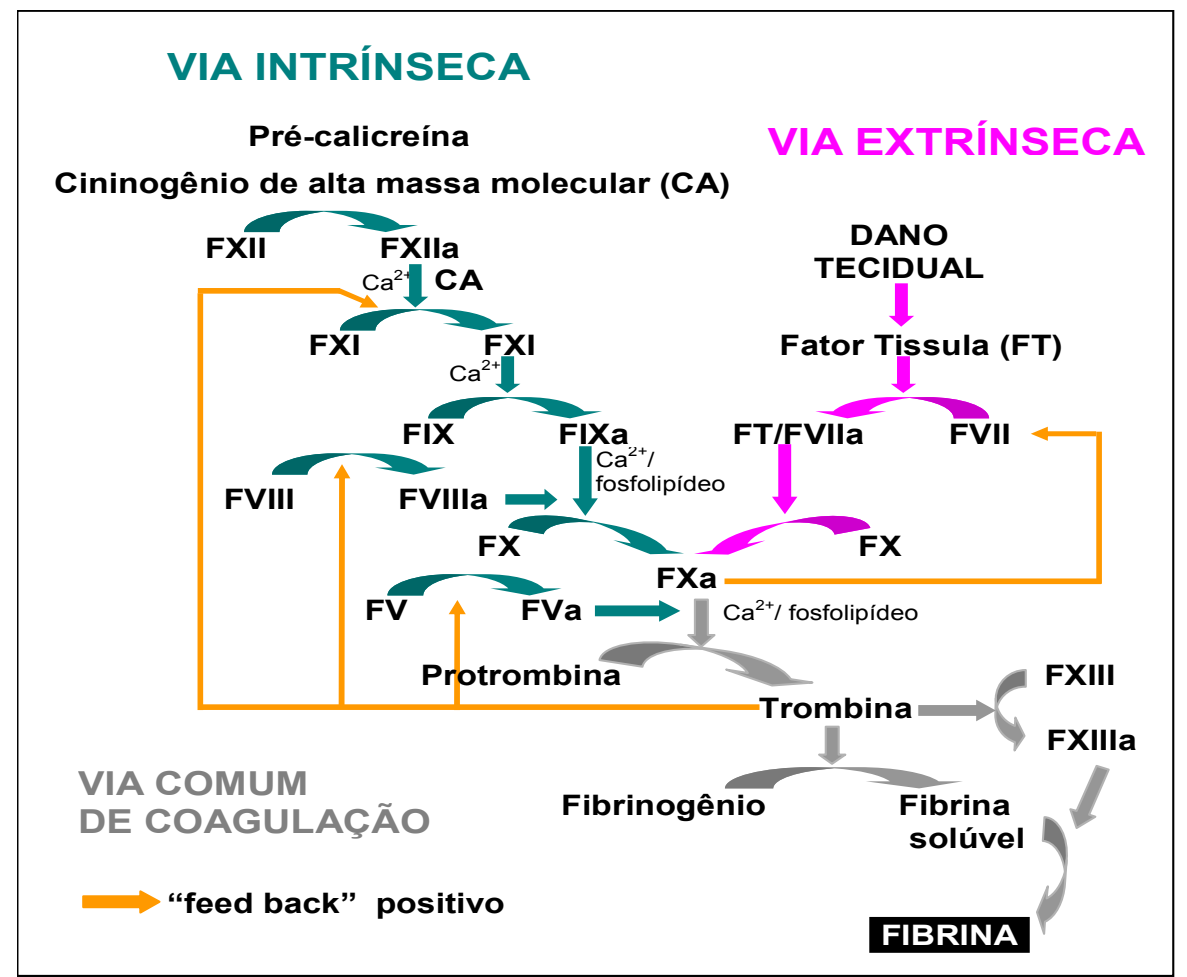

Neste modelo a coagulação possui 2 vias, a via intrínseca e a via extrínseca, que convergem para a via comum para formação de um coágulo de fibrina.

FONTE: (CHENG, 2009)

$\mathrm{Na}$ década de 90 foi proposto um modelo mais completo, o modelo celular, (Figura 4), no qual as reações ocorrem em três estágios: iniciação, amplificação e propagação (HOFFMAN; MONROE, 2007).

Após uma lesão vascular, o objetivo principal da hemostasia é produzir uma rede de fibrin ${ }^{1} a$ insolúvel capaz de interromper a perda sanguínea. A Iniciação (Figura 4A) ocorre nas células capazes de expressar fator tecidual, uma proteína transmembrana presente nas células da matriz subendotelial (fibroblastos) e nos monócitos e células endoteliais em estados inflamatórios. O fator tecidual é o grande iniciador fisiológico da coagulação. Exposto ao plasma pela lesão vascular, liga-se ao fator VIla e dá início a geração de uma pequena quantidade de trombina a partir da ativação dos fatores Xa e Va. A pouca quantidade de trombina produzida nessa etapa é incapaz de iniciar a formação de fibrina, já que a formação do fator Xa é rapidamente interrompida quando o inibidor da via do fator tecidual (TFPI - Tissue

\footnotetext{
* CHENG. São Paulo, 2009.
} 
Factor Pathway Inhibitor) liga-se ao fator Xa e inativa o complexo fator VIla/Fator tecidual (MONROE; HOFFMAN, 2006).

A Amplificação (Figura 4B) ocorre com a mudança do processo do fibroblasto para a superfície plaquetária. O estímulo é amplificado à medida que a plaqueta adere, se ativa e acumula cofatores ativados em sua superfície. A trombina gerada na fase de iniciação é um potente ativador plaquetário. Neste momento, a plaqueta, através da ativação dos cofatores $\mathrm{V}$ e VIII e subseqüente ligação aos seus respectivos receptores, tem parcialmente montados em sua superfície os dois complexos que irão dar origem a propagação da geração de trombina subseqüente (MONROE; HOFFMAN, 2006).

A Propagação (Figura 4C) ocorre pela combinação das proteases ativas com seus cofatores e formação dos complexos "tenase" e "protrombinase" na superfície da plaqueta, fisiologicamente o local melhor adaptado para a geração de quantidades hemostáticas de trombina. A trombina gerada em grandes quantidades cliva então o fibrinogênio em monômeros de fibrina e se responsabiliza também pelo "crosslinking" destes monômeros através da ativação do fator XIII, dando assim firmeza ao coágulo (MONROE; HOFFMAN, 2006).
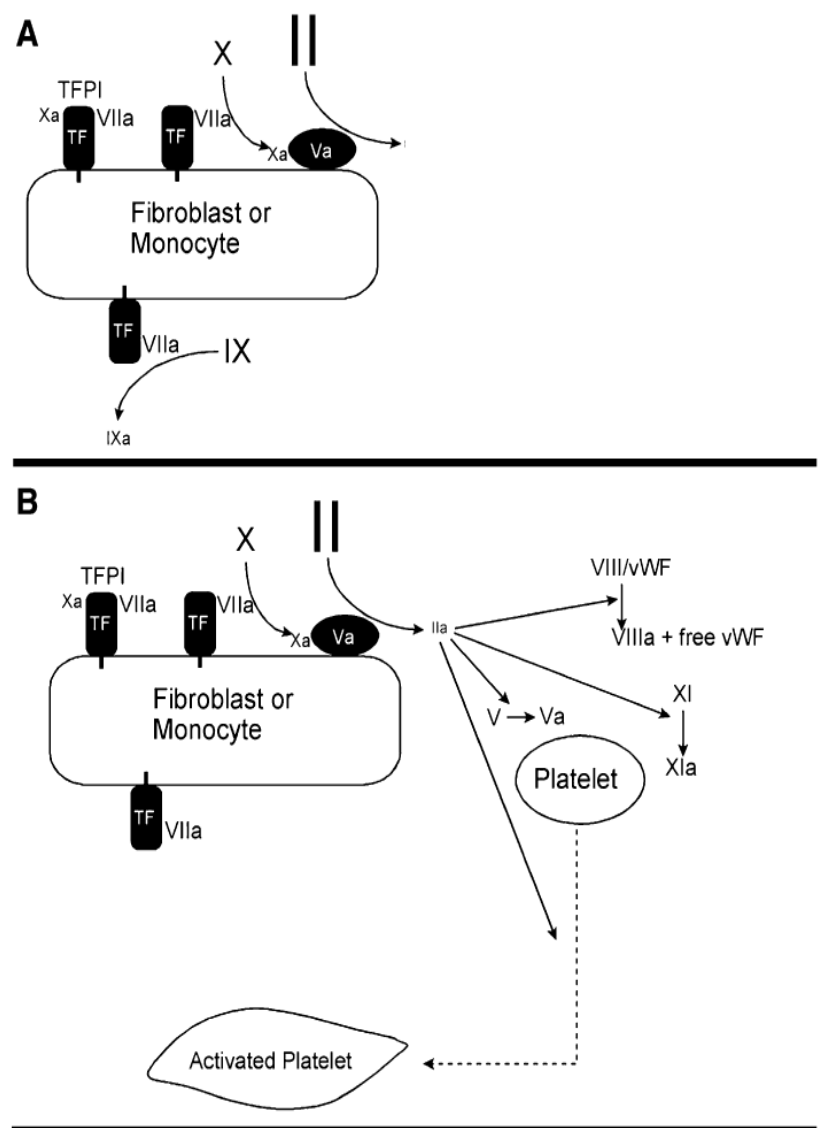

C

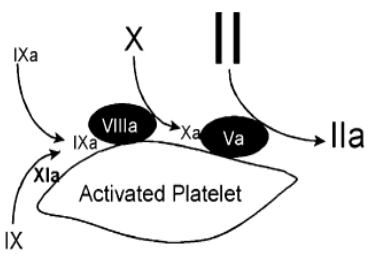

(A) Iniciação, (B) Amplificação,

(C) Propagação.

FONTE: (HOFFMAN; MONROE, 2007) 
A via da Proteína $C$ é considerada por alguns autores como a principal via de controle da coagulação (Figura 5). Após a lesão vascular ou inflamação, o fator tecidual é expresso na superfície endotelial e inicia uma série de reações proteolíticas que resulta na geração de trombina e formação de coágulo de fibrina. A ligação da trombina com a trombomodulina acelera a ativação da PC. A Proteína C ativada (APC) proteolicamente inativa os cofatores Va e VIIla, prevenindo desta forma, a

\section{A Blood coagulation}

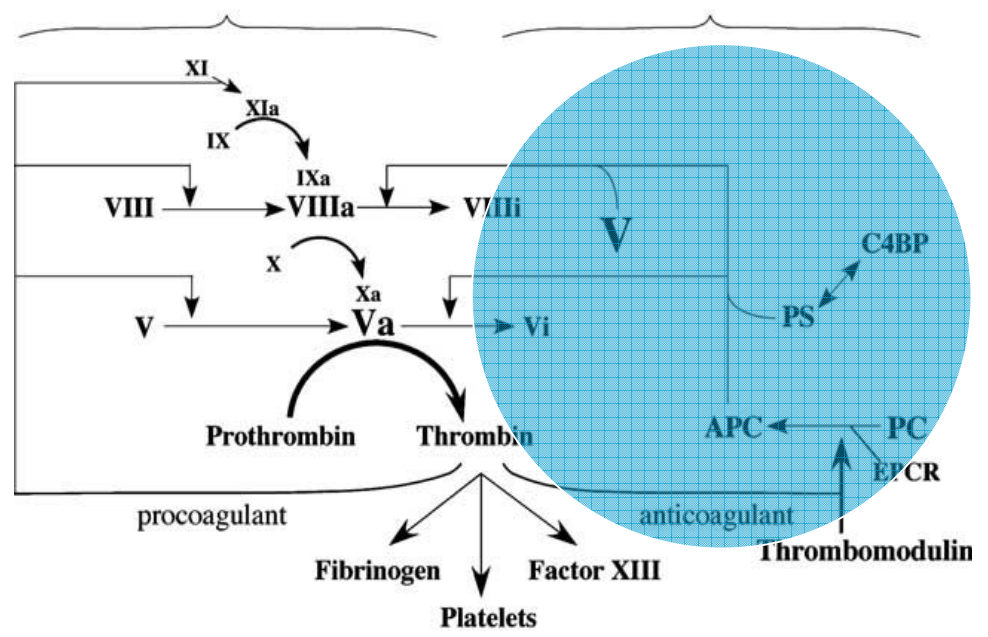

Figura 5 - Via da Proteína C no mecanismo de controle da coagulação (círculo azul).

propagação da cascata de coagulação e inibindo a formação de trombina (LUST; VULCANO; DANESE, 2008).

\subsection{Fator VIII humano}

\subsubsection{Estrutura}

O gene do fator VIII humano é um dos maiores conhecidos, com cerca de 180 Kb e com 25 introns (FURIE; FURIE, 1988). O FVIII é sintetizado nos hepatócitos como multidomínio, uma molécula de cadeia simples com 2332 aminoácidos, com massa molecular de aproximadamente 300 kDa (TAKEYAMA et al., 2009). O plasma humano contém cerca de $150 \mathrm{ng} / \mathrm{ml}$ de fator VIII (FURIE; FURIE, 1988).

O fator VIII possui domínios A1-A2-B-A3-C1-C2. Entre os domínios A existem espaçadores (a1, a2 e a3), que contém regiões ricas em resíduos de Asp e Glu. Após sua síntese, a molécula passa por mudanças pós-traducionais, incluindo glicosilações e sulfatações nos resíduos de Tyr nos espaçadores dos domínios A. Após a liberação na circulação sanguínea, a molécula sofre uma clivagem entre os 
domínios B e A3 originando duas cadeias, a pesada (A1-a1-A2-a2-B) e a leve (a3A3-C1-C2), ligadas não covalentemente pelo metal divalente $\mathrm{Ca}^{2+}$, através dos domínios A1 e A3 (Figura 6). O domínio B, que representa aproximadamente 40\% da massa do FVIII, não tem função conhecida (D' AMICl et al., 2011).

O FVIII é estabilizado no sangue pelo fator de von Willebrand (FvW), que forma um complexo com o FVIII através da interação com o domínio A3. Outras moléculas de von Willebrand ligam-se ao complexo FVIII-vW formando um multímero que pode atingir até 20MDa (KAUFMAN; PIPE 1999). A associação do FVIII com o FvW faz com que o FvW proteja o FVIII de proteólise por diversas serina-proteases, incluindo a proteína $C$ ativada e o FXa (TAKEYAMA et al., 2009). A primeira etapa da ativação do FVIII consiste da dissociação do complexo FVIII/FvW pela trombina.

Figura 6 - Estrutura, função e processamento do FVIII.

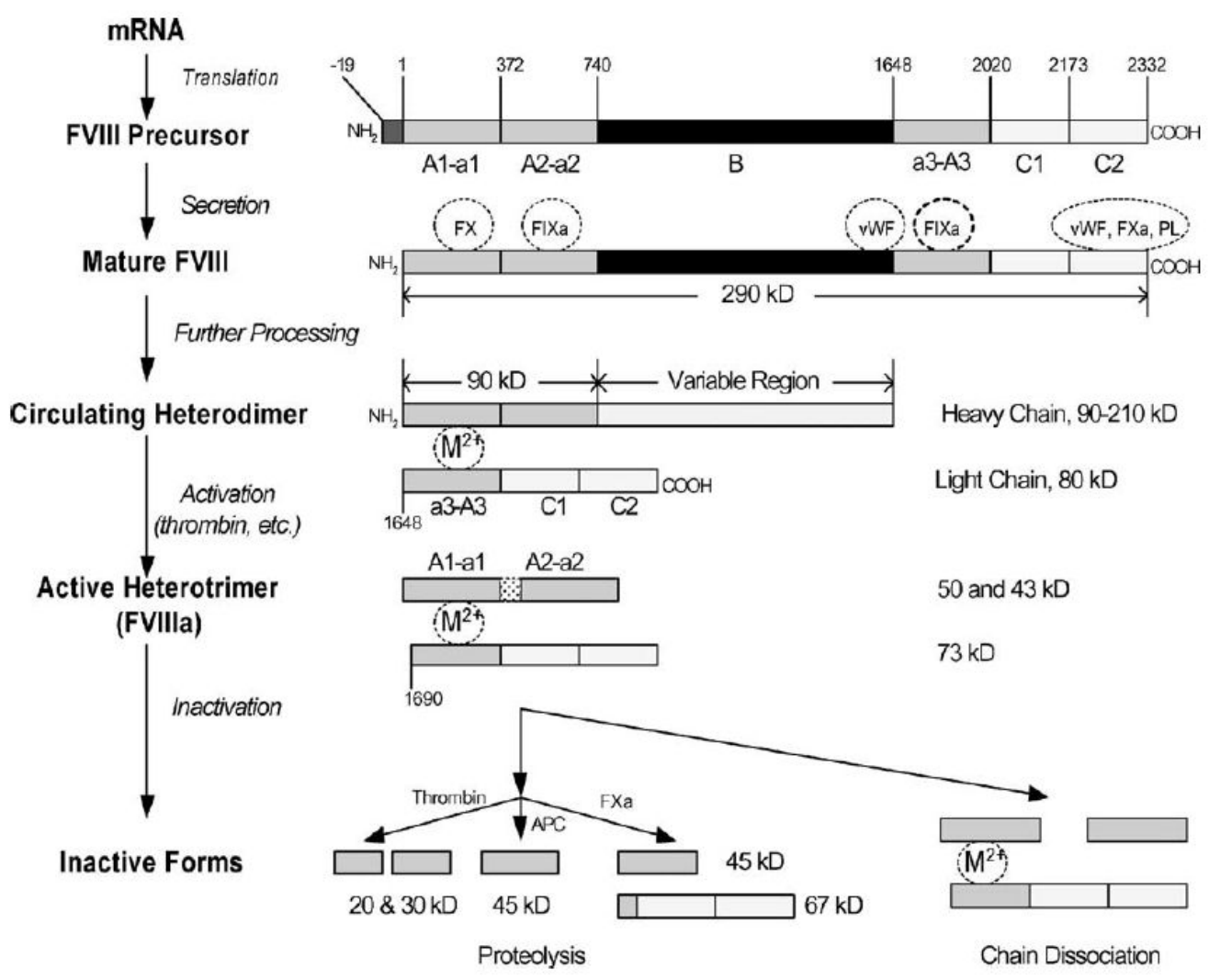

O FVIII é produzido nos hepatócitos e é secretado na sua forma madura com $290 \mathrm{kDa}$, contendo 3 domínios, A, B e C. Na forma circulante é encontrado na forma de heterodímero, com uma cadeia pesada de 90 a $210 \mathrm{kDa}$ e uma cadeia leve com $80 \mathrm{kDa}$. Os locais de interação com outros fatores de coagulação, FvW, fosfolipídeos (PL), e íons metálicos $\left(\mathrm{Me}^{2+}\right)$ estão ilustrados nos círculos tracejados.

FONTE: (WANG et al., 2003) 


\subsubsection{A hemofilia e a doença de von Willebrand}

A Hemofilia A é uma doença genético-hereditária que se caracteriza pela desordem no mecanismo de coagulação do sangue, ocorrendo predominantemente em homens. Existem três tipos de hemofilia: A, B e C. Nestas doenças há deficiência de Fator VIII, IX e XI, respectivamente (FRANCHINI; MANNUCCI, 2011). Além da desordem da hemostasia, a hemofilia é caracterizada por sangramento espontâneo ou provocado nas articulações, músculos, estômago, intestino e sistema nervoso central (WONG; RECHT, 2011).

Antes dos anos 40, o tratamento da hemofilia $A$ se limitava à prática de transfusão sanguínea total ou de plasma fresco. Na década de 70 iniciou-se o uso de crioprecipitado (WONG; RECHT, 2011). Atualmente, o tratamento da hemofilia $A$ consiste principalmente na reposição empregando concentrados de Fator VIII, provenientes do plasma ou recombinante (MAMMEN, 2002; MANNUCCI, 2003).

O principal obstáculo no uso de concentrado de FVIII consiste no desenvolvimento de anticorpos pelo sistema imunológico dos pacientes. Aproximadamente 20 a $30 \%$ dos pacientes com Hemofilia A severa desenvolvem anticorpos utilizando tanto FVIII proveniente de plasma, quanto FVIII recombinante (D' AMICl et al., 2011). Estes pacientes são chamados hemofílicos com inibidores (KEMPTON; WHITE, 2009).

A doença de von Willebrand caracteriza-se por aumento do tempo de sangramento e sintomas decorrentes da desestabilização do fator VIII. O fator de von Willebrand (FvW ) forma um complexo com o FVIII e tem a função de protegê-lo de hidrólises e transportá-lo. Também é necessário para a adesão de plaquetas no endotélio, assim como para a agregação de plaquetas sob condições de estresse. A doença é geralmente tratada com uma droga sintética denominada desmopressina (DDAVP) ou com terapia de reposição utilizando concentrados desta proteína (MORI et al., 2008).

\subsubsection{Purificação de FVIII}

A purificação do complexo $\mathrm{FVIII/FvW} \mathrm{é} \mathrm{particularmente} \mathrm{difícil,} \mathrm{uma} \mathrm{vez} \mathrm{que} \mathrm{o}$ FVIII circula em pequenas concentrações no sangue (100 a $200 \mathrm{ng} / \mathrm{ml}$ ) e é 
extremamente lábil. É, portanto, difícil de obter um produto com alta atividade específica e alto rendimento (MORI et al., 2008).

Concentrados de FVIII derivados de plasma disponíveis comercialmente podem ou não conter o FvW, como mostrado na Tabela 1.

Tabela 1 - Produtos de FVIII derivados de plasma humano avaliados nos EUA.

\begin{tabular}{|c|c|c|}
\hline Product name & Manufacturer & vWf: FVIII ratio \\
\hline \multicolumn{3}{|c|}{ Immunoaffinity purified FVIII products } \\
\hline Hemofil $M^{T M}$ & Baxter & NA \\
\hline Monarc-M $\mathrm{M}^{\mathrm{TM}}$ & $\begin{array}{l}\text { Baxter (from American Red } \\
\text { Cross-collected plasma) }\end{array}$ & NA \\
\hline Monoclate-P $\mathrm{P}^{\oplus}$ & CSL Behring & NA \\
\hline \multicolumn{3}{|c|}{ FVIII products containing vWF } \\
\hline Alphanate ${ }^{\oplus}$ & Grifols & $1: 1$ \\
\hline Humate-P & CSL Behring & $2: 1$ \\
\hline Koate ${ }^{\oplus}$-DVI & Talecris & Unknown \\
\hline
\end{tabular}

NA = não aplicável; vWf = Fator de von Willebrand.

FONTE: (WONG; RECHT, 2011)

Segundo Josic et al. (1994), nos produtos de FVIII que não contém FvW, é necessário adicionar, por exemplo, a albumina para evitar a degradação proteolítica e perda de atividade biológica do FVIII.

A purificação com aplicação direta de plasma em cromatografia de gel filtração foi utilizada por Kaersgaard e Barington (1998) para purificação do complexo FVIII-FvW. Neste estudo foram testadas várias resinas de gel filtração e os melhores resultados foram obtidos com a resina Sepharose 4FF, em que houve cerca de $90 \%$ de rendimento. Estes mesmos pesquisadores descreveram um processo para produção de FvW contendo FVIII a partir de plasma que inicia-se por cromatografia de gel filtração em Sepharose 4FF e prossegue em Q Sepharose HP, SP Sepharose HP e Superose 12 (BARINGTON; KAERSGAARD, 1999). Neste processo, após o processamento de $700 \mathrm{Kg}$ de plasma, o FvW é obtido com $95 \%$ de pureza. A purificação do complexo FVIII/FvW por gel filtração é uma estratégia eficiente, uma vez que o complexo apresenta massa molecular muito maior que a grande maioria das proteínas presentes no plasma. No entanto, do ponto de vista industrial, utilizar essa técnica como primeira etapa de purificação tem a desvantagem de apresentar baixa capacidade em comparação com outras técnicas 
cromatográficas, mesmo levando-se em consideração que a resina Sepharose 4FF é uma resina de aplicação industrial e que permite a aplicação de amostras de até $20 \%$ do volume de coluna.

A purificação de FVIII por cromatografia de afinidade foi utilizada por Te Booy et al. (1989) que estudaram 6 ligantes (2 aminoalquil e 4 aminoalquil-carbamilalquil) acoplados à resina Sepharose CL-4B. Os resultados mostram que em 3 resinas Sepharose acopladas a aminoalquil-carbamilalquil, o FVIII foi recuperado com atividades entre 50 e $65 \%$. A matriz dimetilaminopropilcarbamilpentil- Sepharose CL4B apresentou os melhores resultados e em seguida um processo otimizado e em maior escala foi descrito empregando esta resina para a produção de FVIII (TE BOOY et al. 1990.). O FVIII foi recuperado com $46 \%$ de atividade, que é maior que os $40 \%$ normalmente recuperados quando se utiliza crioprecipitado. Zhou, BurnoufRadosevich e Burfouf (1994) utilizou lentil lectina imobilizada e recuparou cerca de $45 \%$ de atividade de FVIII. Kelley et al. (2004) e Knor et al. (2008) desenvolveram métodos de purificação de FVIII recombinante e FVIII derivado de plasma, respectivamente, utilizando um peptídeo anti-FVIII. Thim et al. (2010) relataram um processo de purificação de FVIII recombinante utilizando cromatografia de imunoafinidade com anticorpo monoclonal recombinante, troca iônica e gel filtração. A técnica de cromatografia por imunoafinidade, apesar de bastante eficiente por apresentar uma ligação específica entre a proteína e o ligante, apresenta alto custo. Em colunas de afinidade a $\mathrm{Ca}^{2+}$, Mantovaara, Pertoft e Porath (1991) purificaram FVIII recombinante em apenas uma etapa, obtendo fator de purificação de 85 vezes.

A cromatografia de troca iônica é uma técnica bastante utilizada, explorando as cargas das proteínas para adsorção à coluna. Essa técnica permite a concentração do eluato, além de purificar proteínas baseadas nas características de força iônica e pH. Esse tipo de cromatografia foi utilizado por Burnouf et al. (1991) para purificação de FVIII a partir de crioprecipitado utilizando a resina DEAE Fractogel TSK 650 M. A recuperação de FVIII foi de cerca de 80 a 90\%. Josic et al. (1994) também partiram do crioprecipitado e utilizaram a resina de troca iônica Fractogel EMD TMAE ou DEAE G 650(S) para separação do complexo FVIII/ FvW. Essa separação foi feita na presença de $50 \mathrm{mM}$ de cálcio no tampão. Mori et al. (2008) partiram do crioprecipitado e testaram várias resinas de troca iônica para purificação do complexo FVIII/FvW, mostrando que a resina Fractogel EMD TMAE apresentou melhores resultados, com recuperação de $86 \%$ de atividade de atividade 
específica de $140 \mathrm{U} / \mathrm{mg}$. Além disso, determinaram que para os trocadores fortes é necessário $450 \mathrm{mM}$ a $600 \mathrm{mM}$ de $\mathrm{NaCl}$ para eluir o FVIII, enquanto que para os trocadores fracos, $250 \mathrm{mM}$. Cheng et al. (2010) descreveram um estudo comparativo entre as resinas $Q$ Sepharose aplicando o plasma diretamente à coluna, visando a concentração da amostra para posterior purificação em uma gel filtração. $A$ resina $Q$ Sepharose FF foi a que apresentou melhores resultados com recuperação de atividade de FVIII em cerca de $50 \%$ e fator de purificação de 55 vezes.

Foi descrito em 2010 um processo de purificação do Complexo Protrombínico, Complexo FVIII/ FvW, IgG, Alfa 1 antitripsina, Albumina e Transferrina pelo método de cromatografia por adsorção em leito expandido, em que $40 \%$ do complexo FVIII/FvW foi recuperado em relação ao plasma (LIHME et al., 2010).

\subsection{Proteína C}

\subsubsection{Estrutura}

A proteína C é uma glicoproteína dependente de vitamina $\mathrm{K}$, de massa molecular $62 \mathrm{kDa}$, formada de duas cadeias, denominadas cadeia leve e cadeia pesada, ligadas através de ponte dissulfeto. A cadeia leve contém o domínio de ácidos $\gamma$-glutâmicos carboxiglutâmicos, responsáveis pela interação com $\mathrm{Ca}^{2+}$, com as membranas fofoslipídicas (importante para a atividade anticoagulante da proteína C ativada) e pela interação com o receptor endotelial da proteína C. Encontram-se na cadeia leve também os dois domínios do fator de crescimento epitelial, cuja função pode estar relacionada à interação com a proteína $S$, fator $V$ ativado e fator VIII ativado. A cadeia pesada contém o domínio da serina protease. A ativação da proteína $C$ consiste na remoção de um peptídeo $\mathrm{N}$-terminal da cadeia pesada catalisada pela trombina (DAHLBÄCK; VILLOUTREIX, 2005).

A proteína $\mathrm{C}$, juntamente com os fatores de coagulação II, VII, IX, X, proteína S e a proteína $Z$, cuja função ainda não é conhecida, pertencem ao grupo das proteínas dependentes de vitamina $\mathrm{K}$. Em conjunto, essas proteínas são denominadas de complexo pró-trombínico. Essas proteínas apresentam em comum um domínio amino-terminal chamado de domínio GLA (Figura 7). Esses domínios contêm múltiplos resíduos de ácido $\gamma$-carboxiglutâmico (GLA) que são fomados a 
partir da carboxilação do ácido glutâmico pela carboxilase dependente de vitamina $\mathrm{K}$ (YAN, 1996) - (Figura 8).

Figura 7 - Estrutura das proteínas dependentes de vitamina $\mathrm{K}$ presentes no plasma humano.

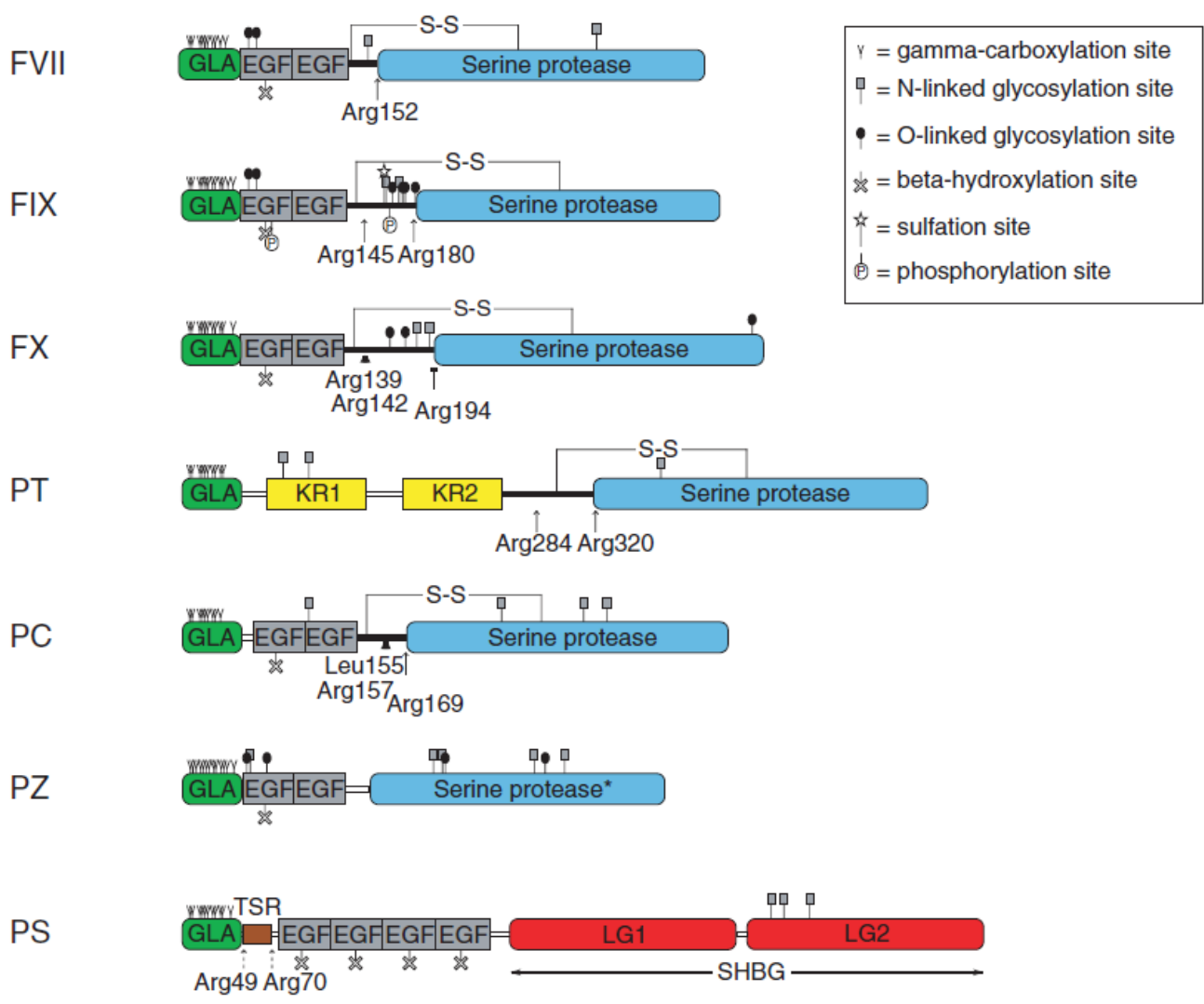

Essas proteínas em conjunto são denominadas de Complexo Protrombínico. Exceto a PS, todas são serina proteases. Todas apresentam o domínio GLA na porção aminoterminal, que contêm múltiplos resíduos GLA que são resultados da modificação póstraducional do ácido glutâmico das proteínas pela enzima $\gamma$-glutamil carboxilase dependente de vitamina K.

FONTE: (HANSSON; STENFLO, 2005)

A deficiência homozigótica da PC está associada ao alto risco de trombose venosa e a heterozigótica causa uma doença conhecida como púrpura fuminans, que pode ser tratada com terapia de reposição com a Proteína $C$ (BAE; YANG; REZAIE, 2007). Até a disponibilização de concentrados de PC, a reposição era realizada utilizando plasma fresco congelado em homozigotos, enquanto que para os heterozigotos, o tratamento era feito a base de anticoagulante oral ou terapia de heparina (Radosevich et al., 2003). Quando ativada, possui atividades antiinflamatória e citoprotetora, sendo usada no tratamento da sepse (BAE; YANG; REZAIE, 2007; O’BRIEN et al., 2007). 
Figura 8 - Reação de y-carboxilação do resíduo glutamil pela enzima y-glutamil carboxilase.

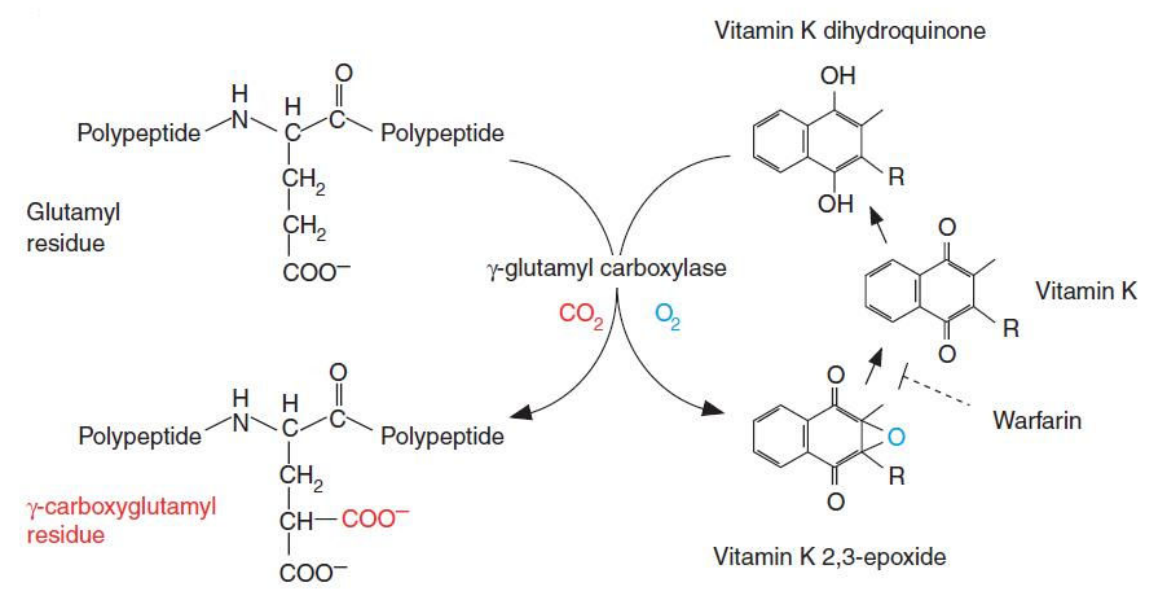

Reação de $Y$-carboxilação do resíduo glutamil pela enzima $\gamma$-glutamil carboxilase, na presença de $\mathrm{CO}_{2}, \mathrm{O}_{2}$ e vitamina $\mathrm{K}$. Sem a presença de vitamina $\mathrm{K}$, essa reação não ocorre, podendo prejudicar na atividade biológica destas proteínas .

FONTE: (HANSSON; STENFLO, 2005)

\subsubsection{Purificação de Proteína C}

Cromatografia de troca iônica na purificação de Proteína $C$ foi utilizada por Radosevich et al. (2003) que partiram do plasma pobre, utilizando colunas de troca iônica e chegando a uma concentração de PC de $58 \mathrm{U} / \mathrm{mL}$, com atividade específica de 215 U/ mg de proteína, e fator de purificação de 12000 vezes em relação ao plasma. Yan (1996) estudou a separação das vitamina K dependentes, entre elas a PC, utilizando pseudoafinidade em coluna de troca iônica, variando a concentração de cloreto de cálcio. Orthner et al. (1995) produziram PC ativada em larga escala utilizando uma coluna de troca iônica, seguida de uma coluna de imunoafinidade e outra de troca iônica para ativação da PC. Na etapa de purificação por imunoafinidade, obteve-se a PC com fator de purificação de 13600 vezes e atividade específica de $231 \mathrm{U} / \mathrm{mg}$.

A proteína $C$ foi parcialmente purificada a partir de coluna de afinidade por metal em um processo de purificação de FIX em que o plasma criopobre é utilizado como matéria prima (MATEJTSCHUK et al., 1997). Wu; Bruley (2002) utilizaram esta técnica para separar PC de algumas proteínas do leite. Lee; Bruley e Kang (2007) verificaram o efeito do $\mathrm{pH}$ na adsorção das proteínas e dessorção utilizando imidazol, na tentativa de separar a PC do FII a partir da fração IV de Cohn por IMAC. 
Este estudo concluiu que entre pH 6,0 e 8,0 não há diferença de adsorção destas duas proteínas, o que resulta na não separação delas.

Nos métodos descritos na literatura para a purificação de FVIII derivado de plasma, o material de partida é sempre o crioprecipitado e esta fração não é a fração que contém as proteínas dependentes de vitamina K. Nos processos de fracionamento de plasma, as proteínas dependentes de vitamina $K$ encontram-se na fração criopobre. Em purificações de plasma em resinas de troca aniônica o FVIII e as proteínas dependentes de vitamina $\mathrm{K}$ coeluem. Embora o fator de purificação do FVIII seja muito bom, porque nas condições empregadas grande parte das proteínas plasmáticas não são adsorvidas na coluna, 2 proteínas dependentes de vitamina $\mathrm{K}$, o Fll e o FX, quando ativadas, são enzimas que primeiramente ativam e em seguida inativam o FVIII. Portanto, ao se iniciar a purificação de plasma em coluna de troca aniônica, a segunda etapa deve separar o FVIII dos fatores de coagulação dependentes de vitamina K. Neste trabalho, estudamos a separação de FVIII das proteínas dependentes de vitamina $\mathrm{K}$, família a que a $\mathrm{PC}$ pertence, empregando cromatografia de afinidade a metal. 


\section{OBJETIVO}

Estudar novas estratégias de purificação de proteínas plasmáticas com aplicação biotecnológica, em especial, os fatores de coagulação FVIII e proteína C, empregando cromatografia de troca aniônica e cromatografia de afinidade a metal. 


\section{MATERIAL E MÉTODOS}

\subsection{Material}

As bolsas de plasma humano utilizadas foram cedidas gentilmente pelo Hemocentro de Ribeirão Preto. O plasma foi coletado em bolsas com volume de aproximadamente $200 \mathrm{~mL}$, contendo tampão CPDA-1 (Citrato - Fosfato - Dextrose - Adenina), com pH aproximadamente 7,4. Todas as bolsas recebidas foram aprovadas por uma triagem sorológica e armazenadas em freezer $-80^{\circ} \mathrm{C}$.

Os equipamentos utilizados foram: Cromatógrafos Akta Explorer $^{\circledR}$ e o Biopilot $^{\circledR}$, ambos da GE Healthcare (GE Healthcare, Uppsala, Suécia) controladas pelo programa UNICORN ${ }^{\circledR}$ versão 3.1; Bomba Peristáltica P-1, da GE Healthcare; Leitor de microplacas Multiskan EX da Thermo (Thermo, Shangai, China); Espectrofotômetro Ultraspec 2000 da Pharmacia Biotech (Pharmacia, Uppsala, Suécia); Fonte para eletroforese - Eletrophoresis Power Supply EP5600 Pharmacia Biotec.

As resinas da GE Healthcare utilizadas foram: $Q$ Sepharose Fast Flow (FF), ANX Sepharose 4 Fast Flow (FF), HiTrap IMAC High Performance (HP) de $1 \mathrm{~mL}$, HisTrap HP de 1 e $5 \mathrm{~mL}$ e Chelating Sepharose Fast Flow.

Todas as soluções foram preparadas utilizando água deionizada do sistema MilliRiOs e para os testes analíticos foi utilizado o sistema MilliQ, ambos da Millipore ${ }^{\circledR}$ (Millipore, Billerica, EUA).

Os reagentes utilizados para o preparo de tampões foram: ácido cítrico [Synth(Synth, Diadema, Brasil)], cloreto de sódio [Merck (Merck, Darmstadti, Alemanha)], cloreto de cálcio (Merck), HEPES [Amresco (Amresco, Ohio, EUA)], cloreto de amônio (Merck), Imidazol [USB (USB, Alemanha)], EDTA Dissódico [VETEC (VETEC, Rio de Janeiro, Brasil)], NaOH [F. Maia (F. Maia, Cotia, Brasil)], $\mathrm{HCl}$ (Merck).

As colunas de afinidade a metal foram carregadas com os metais utilizando soluções de concentração 0,1 M com os seguintes reagentes: $\mathrm{CuSO}_{4}$ [Neon (Neon, São Paulo, Brasil)], $\mathrm{NiSO}_{4}$ [Sigma (Sigma, St Louis, EUA)], $\mathrm{ZnSO}_{4}$ [The Coleman \& Bell Co (The Coleman \& Bell Co, Ohio, EUA)], $\mathrm{CoCl}_{2}$ [Spectrum (Spectrum, New Brunswick)], $\mathrm{FeCl}_{3}$ (Synth). 
Para os métodos analíticos foram utilizados: Ácido acético glacial (Synth), Etanol (Synth), Metanol (Synth), Coomassie Blue R250 (Sigma), Reagente de Bradford [Fermentas (Fermentas, EU)], Acrilamida [Amersham Biosciences (Amersham Biosciences, Uppsala, Suécia)], Tris (Sigma), Persulfato de amônio (Amersham Biosciences), TEMED (Sigma), azul de bromofenol (Synth), Glicerol (Merck), SDS (Amresco), $\beta$-mercaptoetanol (Merck), Glicina (Merck), padrão de massa molecular Unstained Protein Molecular Weight Marker (Fermentas), kit $\mathrm{COATEST}^{\circledR} \mathrm{SP}_{4}$ FVIII [Chromogenix (Chromogenix, EUA)], kit COAMATIC ${ }^{\circledR}$ Protein C (Chromogenix) e kit SilverXpress, da Invitrogen (Invitrogen, Carlsbad, EUA).

\subsection{Empacotamento das colunas}

A resina ANX Sepharose Fast Flow (aproximadamente $70 \mathrm{~mL}$ ) foi empacotada em uma coluna XK 26/40 (GE Healthcare) com um fluxo de $50 \mathrm{ml} / \mathrm{min}$.

A resina Chelating Sepharose Fast Flow (aproximadamente $10 \mathrm{~mL}$ ) foi empacotada utilizando uma coluna C16/20 (GE Healthcare) com um fluxo de 13 $\mathrm{mL} / \mathrm{min}$.

\subsection{Avaliação do empacotamento das colunas}

A altura de cada prato teórico (HEPT), o número de pratos teóricos por metro de resina $(\mathrm{N} / \mathrm{m})$ e o fator de assimetria do pico (As) foram calculados por meio das seguintes equações:

$$
\text { HEPT = altura de um prato teórico }=\mathrm{L} / \mathrm{N}
$$

- em que $L=$ altura da coluna

$\mathrm{N}=$ Número de pratos teóricos

O número de pratos teóricos $(\mathrm{N})$ é calculado através da fórmula:

$$
\mathrm{N}=\text { número de pratos teóricos }=5,54(\mathrm{Vr} / \mathrm{Wr})^{2}
$$

- em que $\mathrm{Vr}=$ volume de eluição da amostra medido a partir da aplicação da amostra $\mathrm{Wr}=$ largura do pico na metade da altura 
O número de pratos teóricos por metro de resina $(\mathrm{N} / \mathrm{m})$ é calculado dividindose o número de pratos teóricos pela altura da coluna, em metros:

$\mathrm{N} / \mathrm{m}=$ número de pratos teóricos por metro de resina $=\mathrm{N} / \mathrm{L}$

O fator de assimetria da coluna é calculada dividindo-se a largura da segunda metade do pico (b) pela largura da primeira metade do pico medidos a $10 \%$ da altura do pico (a) (Figura 8).

$$
\text { As }=\mathrm{b} / \mathrm{a} \quad \text { (4) }
$$

O teste é realizado aplicando-se $1 \%$ de uma solução de acetona $1 \%(\mathrm{v} / \mathrm{v})$ à coluna previamente equilibrada com água ou $\mathrm{NaCl} 0,9 \%(\mathrm{~m} / \mathrm{v})$.

Figura 9 - Pico de acetona usado para determinação da eficiência do empacotamento a partir de um cromatograma.

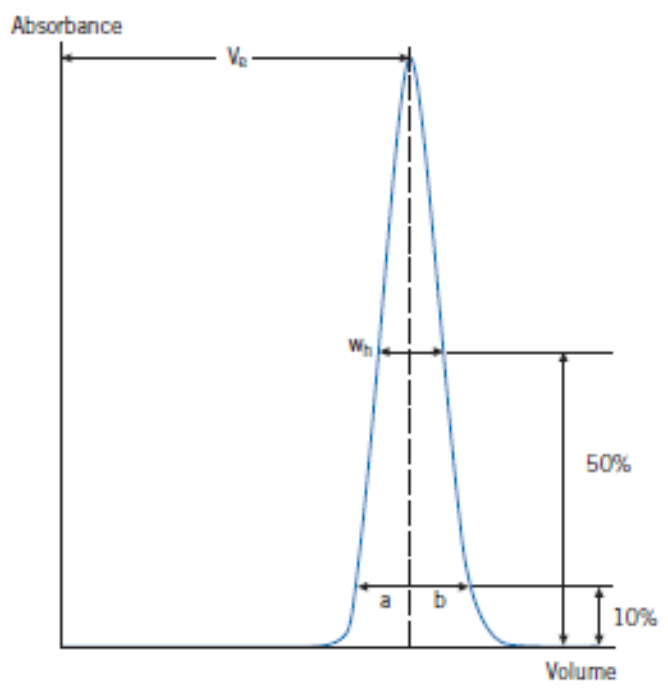

\footnotetext{
$\mathrm{L}=$ altura da coluna

$\mathrm{Wr}=$ largura na metade da altura do pico

$V_{R}=$ distância de eluição do pico

$\mathrm{h}=$ altura do pico

$a=$ largura da primeira metade do pico a $10 \%$ da altura

$b=$ largura da segunda metade do pico a $10 \%$ da altura

HEPT $=$ L/N

$\mathrm{N}=$ número de pratos teóricos calculados $=5,54(\mathrm{Vr} / \mathrm{Wr})^{2}$

$\mathrm{N} / \mathrm{m}=\mathrm{N} / \mathrm{L}$

As $=b / a$
}

FONTE: (AMERSHAM PHARMACIA BIOTECH, 1999) 


\subsection{Preparo do plasma}

As bolsas de plasma que estavam armazenadas em freezer $-80{ }^{\circ} \mathrm{C}$ foram descongeladas em banho-maria a $37^{\circ} \mathrm{C}$. Foi feito um "pool" com 3 a 5 bolsas, o volume foi mensurado e o $\mathrm{pH}$ ajustado para 6,0 ou 7,0 (o plasma tem $\mathrm{pH}$ aproximadamente igual a 7,4), utilizando uma solução de ácido cítrico 0,25 M.

\subsection{Preparação de soluções}

As soluções utilizadas nos experimentos foram:

a) tampão A: tampão citrato $25 \mathrm{mM}$, contendo $\mathrm{CaCl}_{2} 5 \mathrm{mM}$ e NaCl $85 \mathrm{mM}$, pH 6,0;

b) tampão B: tampão citrato $25 \mathrm{mM}$, contendo $\mathrm{CaCl}_{2} 5 \mathrm{mM}$ e $\mathrm{NaCl} 200 \mathrm{mM}$, pH 6,0;

c) tampão C: tampão citrato $25 \mathrm{mM}$, contendo $\mathrm{CaCl}_{2} 5 \mathrm{mM}$ e NaCl 500 mM, pH 6,0;

- tampão C1: tampão C com imidazol 10 mM, pH 6,0,

- tampão C2: tampão C com imidazol 30 mM, pH 6,0,

- tampão C3: tampão C com imidazol 50 mM, pH 6,0,

- tampão C4: tampão C com imidazol 100 mM, pH 6,0,

- tampão C5: tampão C com imidazol 200 mM, pH 6,0,

- tampão C6: tampão C com imidazol 500 mM, pH 6,0,

- tampão C7: tampão C com EDTA 50 mM, pH 6,0,

d) tampão D: tampão citrato $25 \mathrm{mM}$, contendo $\mathrm{CaCl}_{2} 5 \mathrm{mM}$ e $\mathrm{NaCl} 500 \mathrm{mM}$, pH 5,0;

e) tampão E: tampão citrato $25 \mathrm{mM}$, contendo $\mathrm{CaCl}_{2} 5 \mathrm{mM}$ e $\mathrm{NaCl} 500$ mM, pH 4,0;

- tampão E1: tampão E com EDTA 50 mM, pH 4,0,

f) tampão F: tampão citrato $10 \mathrm{mM}$, contendo $\mathrm{CaCl}_{2} 1 \mathrm{mM}$ e $\mathrm{NaCl} 85 \mathrm{mM}, \mathrm{pH}$ 6,0;

g) tampão G: tampão citrato $10 \mathrm{mM}$, contendo $\mathrm{CaCl}_{2} 1 \mathrm{mM}$ e $\mathrm{NaCl} 150 \mathrm{mM}$, pH 6,0;

h) tampão $\mathrm{H}$ : tampão citrato $10 \mathrm{mM}$, contendo $\mathrm{CaCl}_{2} 1 \mathrm{mM}$ e $\mathrm{NaCl} 250 \mathrm{mM}, \mathrm{pH}$ 6,0;

i) tampão I: tampão citrato $10 \mathrm{mM}$, contendo $\mathrm{CaCl}_{2} 1 \mathrm{mM}$ e $\mathrm{NaCl} 500$ mM, pH 6,0;

j) Tampão J: tampão citrato 10 mM, contendo $\mathrm{CaCl}_{2} 5 \mathrm{mM}$ e NaCl 500 mM, pH 6,0;

- tampão J1: tampão J com imidazol 100 mM, pH 6,0,

- tampão J2: tampão J com imidazol 500 mM, pH 6,0,

k) tampão K: tampão HEPES $25 \mathrm{mM}$ e citrato $25 \mathrm{mM}$, contendo $\mathrm{CaCl}_{2} 5 \mathrm{mM}$ e $\mathrm{NaCl}$ $85 \mathrm{mM}, \mathrm{pH} 7,0$;

I) tampão L: tampão HEPES $25 \mathrm{mM}$ e citrato $25 \mathrm{mM}$, contendo $\mathrm{CaCl}_{2} 5 \mathrm{mM}$ e $\mathrm{NaCl}$ $200 \mathrm{mM}, \mathrm{pH} 7,0$; 
m) tampão M1: tampão HEPES $25 \mathrm{mM}$ e tampão citrato $25 \mathrm{mM}$, contendo $\mathrm{CaCl}_{2}$ $5 \mathrm{mM}$ e NaCl $500 \mathrm{mM}$, pH 7,0;

- tampão M2: tampão HEPES $25 \mathrm{mM}$ e tampão citrato $25 \mathrm{mM}$, contendo $\mathrm{CaCl}_{2} 5$ $\mathrm{mM}, \mathrm{NaCl} 500 \mathrm{mM}$ e imidazol $10 \mathrm{mM}, \mathrm{pH}$ 7,0,

- tampão M3: tampão HEPES $25 \mathrm{mM}$ e tampão citrato $25 \mathrm{mM}$, contendo $\mathrm{CaCl}_{2} 5$ $\mathrm{mM}, \mathrm{NaCl} 500 \mathrm{mM}$ e imidazol $30 \mathrm{mM}, \mathrm{pH}$ 7,0,

- tampão M4: tampão HEPES $25 \mathrm{mM}$ e tampão citrato $25 \mathrm{mM}$, contendo $\mathrm{CaCl}_{2} 5$ $\mathrm{mM}, \mathrm{NaCl} 500 \mathrm{mM}$ e imidazol $50 \mathrm{mM}, \mathrm{pH}$ 7,0,

- tampão M5: tampão HEPES $25 \mathrm{mM}$ e tampão citrato $25 \mathrm{mM}$, contendo $\mathrm{CaCl}_{2} 5$ $\mathrm{mM}, \mathrm{NaCl} 500 \mathrm{mM}$ e imidazol $100 \mathrm{mM}, \mathrm{pH}$ 7,0,

- tampão M6: tampão HEPES $25 \mathrm{mM}$ e tampão citrato $25 \mathrm{mM}$, contendo $\mathrm{CaCl}_{2} 5$ $\mathrm{mM}, \mathrm{NaCl} 500 \mathrm{mM}$ e imidazol $200 \mathrm{mM}, \mathrm{pH}$ 7,0,

- tampão M7: tampão HEPES $25 \mathrm{mM}$ e tampão citrato $25 \mathrm{mM}$, contendo $\mathrm{CaCl}_{2} 5$ $\mathrm{mM}, \mathrm{NaCl} 500 \mathrm{mM}$ e imidazol $500 \mathrm{mM}, \mathrm{pH} 7,0$,

- tampão M8: tampão HEPES $25 \mathrm{mM}$ e citrato $25 \mathrm{mM}$, contendo $\mathrm{CaCl}_{2} 5 \mathrm{mM}$, $\mathrm{NaCl} 500 \mathrm{mM}, \mathrm{pH}$ 6,0,

- tampão M9: tampão HEPES $25 \mathrm{mM}$ e citrato $25 \mathrm{mM}$, contendo $\mathrm{CaCl}_{2} 5 \mathrm{mM}$, $\mathrm{NaCl} 500 \mathrm{mM}, \mathrm{pH}$ 5,0,

- tampão M10: tampão HEPES $25 \mathrm{mM}$ e citrato $25 \mathrm{mM}$, contendo $\mathrm{CaCl}_{2} 5 \mathrm{mM}$, $\mathrm{NaCl} 500 \mathrm{mM}, \mathrm{pH}$ 4,0,

- tampão M11: tampão HEPES $25 \mathrm{mM}$ e citrato $25 \mathrm{mM}$, contendo $\mathrm{CaCl}_{2} 5 \mathrm{mM}$, $\mathrm{NaCl} 500 \mathrm{mM}$ e EDTA 50 mM, pH 4,0,

n) tampão $\mathrm{N} 1$ : tampão citrato $25 \mathrm{mM}$, contendo $\mathrm{NH}_{4} \mathrm{Cl} 250 \mathrm{mM}$, pH 6,0;

- tampão N2: tampão citrato $25 \mathrm{mM}$, contendo $\mathrm{NH}_{4} \mathrm{Cl} 500 \mathrm{mM}, \mathrm{pH}$ 6,0,

- tampão N3: tampão citrato $25 \mathrm{mM}$, contendo $\mathrm{NH}_{4} \mathrm{Cl} 750 \mathrm{mM}$, pH 6,0,

- tampão N4: tampão citrato $25 \mathrm{mM}$, contendo $\mathrm{NH}_{4} \mathrm{Cl} 1 \mathrm{M}, \mathrm{pH}$ 6,0,

- tampão N5: tampão citrato $25 \mathrm{mM}$, contendo $\mathrm{NH}_{4} \mathrm{Cl} 1 \mathrm{M}$ e EDTA $50 \mathrm{mM}, \mathrm{pH}$ 6,0;

o) Ácido cítrico 0,25 M para ajustar o pH do plasma;

p) Soluções $0,1 \mathrm{M}$ de $\mathrm{CuSO}_{4}, \mathrm{NiSO}_{4}, \mathrm{ZnSO}_{4}, \mathrm{CoCl}_{2}, \mathrm{FeCl}_{3}$ para cromatografia de afinidade a metal;

q) $\mathrm{NaOH}$ 0,2 M, 0,5 M, $1 \mathrm{M}$ e $6 \mathrm{M}$;

r) $\mathrm{HCl}$ 1:1 e 1:2 (v/v);

s) $\mathrm{NaCl} 0,9 \%(\mathrm{~m} / \mathrm{v})$;

t) $\mathrm{NaCl} 500 \mathrm{mM}, 1 \mathrm{M}$ e $2 \mathrm{M}$; 
u) solução de acrilamida 30\% (acrilamida 29\% (m/v), N,N'-metilenobisacrilamida 1\% $(\mathrm{m} / \mathrm{v}))$;

v) tampão do gel de empilhamento Tris- $\mathrm{HCl}$ 1,5 M, pH 6,8 e SDS 0,1\% (m/v);

x) tampão do gel de separação Tris-HCl 1,5 M, pH 8,8 e SDS 0,1\% (m/v);

w) tampão de corrida: tampão Tris-HCl 25 mM, glicina 192 mM e SDS 0,1\%, pH 8,3

y) APS (persulfato de amônio) $10 \%(\mathrm{~m} / \mathrm{v})$;

z) TEMED (N,N,N',N'-Tetramethylethylenediamine);

aa) tampão de amostra Tris- $\mathrm{HCl} 50 \mathrm{mM}, \mathrm{pH}$ 6,8, azul de bromofenol 0,1\% (m/v), glicerol 10\% (v/v), SDS 2\% (m/v), $\beta$-mercaptoetanol $100 \mathrm{mM}$;

bb) corante Coomassie Blue (ácido acético glacial 10\% (v/v), etanol 45\% (v/v), azul Coomassie R250 0,25\% (m/v));

cc) descorante (Etanol 30\% (v/v), Ácido acético 10\% (v/v), água).

Os tampões foram preparados dissolvendo-se os sais em água, sob agitação. Após ajuste dos pHs com soluções de $\mathrm{NaOH}$ ou $\mathrm{HCl}$, o volume final dos tampões foi completado em provetas.

As soluções contendo EDTA utilizadas na lavagem das colunas foram preparadas dissolvendo-se o EDTA dissódico $50 \mathrm{mM}$ com solução de $\mathrm{NaOH} 1 \mathrm{M}$ em tampão previamente preparado, sob agitação.

\subsection{Purificação de FVIII de coagulação e Proteína C por cromatografia de troca aniônica em ANX Sepharose FF}

O equilíbrio da coluna foi feito com tampão citrato $25 \mathrm{mM}$, contendo $\mathrm{CaCl}_{2} 5$ mM e NaCl 85 mM, pH 6,0 (Tampão A) e em seguida foi aplicado plasma, preparado conforme item 3.4. A fração coletada foi denominada "flowthrough" (FT). A lavagem das proteínas não adsorvidas na coluna após aplicação do plasma foi feita com o tampão de equilíbrio. A fração coletada foi denominda "reequilíbrio" (Reeq.). Foram feitas lavagens sucessivas com concentrações crescentes de $\mathrm{NaCl}$ até a eluição das proteínas de interesse. Após cada purificação foi realizada a limpeza da coluna com $\mathrm{NaOH} 1 \mathrm{M}, \mathrm{NaCl} 2 \mathrm{M}$ e água. A coluna foi armazenada com $\mathrm{NaOH}$ 0,2 M.

As frações coletadas foram submetidas ao teste cromogênico para determinação de atividade do FVIII e da PC, assim como dosagem de proteínas pelo método de Bradford e análise do perfil de proteínas por SDS-PAGE. 
A partir dos dados de atividade $(U)$ e concentração de proteína $(\mathrm{mg})$ foram calculados os valores de atividade específica e o fator de purificação de FVIII e PC:

a) atividade especifica $=$ Atividade total $(\mathrm{U}) /$ Proteína total $(\mathrm{mg})$;

b) fator de purificação= Atividade específica da fração / Atividade específica do plasma.

\subsubsection{Determinação da concentração de $\mathrm{NaCl}$ para eluição do $\mathrm{FVIII}$ e da Proteína C na purificação de plasma em coluna de troca aniônica ANX Sepharose FF}

Para a determinação da concentração de $\mathrm{NaCl}$ para a eluição do FVIII e da Proteína C foram realizados experimentos com a coluna ANX Sepharose FF (com aproximadamente $70 \mathrm{~mL}$ ) seguindo os procedimento descritos no item anterior, empregando as seguintes condições experimentais:

a) condição Experimental 1:O equilíbrio da coluna foi feito com $10 \mathrm{VC}$ de tampão citrato $25 \mathrm{mM}$, contendo $\mathrm{CaCl}_{2} 5 \mathrm{mM}$ e NaCl $85 \mathrm{mM}$, pH 6,0 (Tampão A) e em seguida foi aplicado $10 \mathrm{VC}$ de plasma em pH 6,0. A primeira lavagem após aplicação do plasma (Reequilíbrio) foi feita com $10 \mathrm{VC}$ do tampão de equilíbrio. Foram eluídos $10 \mathrm{VC}$ de tampão citrato $25 \mathrm{mM}$, contendo $\mathrm{CaCl}_{2} 5 \mathrm{mM}$ e NaCl 200 mM, pH 6,0 (Tampão B) e 6,5 VC de tampão citrato $25 \mathrm{mM}$, contendo $\mathrm{CaCl}_{2} 5 \mathrm{mM} \mathrm{e}$ $\mathrm{NaCl} 500$ mM, pH 6,0 (Tampão C). A última fração foi coletada em 2 etapas, a primeira até a eluição de 4,5 VC de tampão, denominada A500A e a segunda com o restante da fração, denominada A500B.

b) condição Experimental 2: O equilíbrio da coluna foi feito com $10 \mathrm{VC}$ de tampão citrato $10 \mathrm{mM}$, contendo $\mathrm{CaCl}_{2} 1 \mathrm{mM}$ e $\mathrm{NaCl} 85 \mathrm{mM}, \mathrm{pH}$ 6,0 (Tampão F) e em seguida foi aplicado $10 \mathrm{VC}$ de plasma em pH 6,0. A primeira lavagem após aplicação do plasma (Reequilíbrio) foi feita com $10 \mathrm{VC}$ do tampão de equilíbrio. Foram eluídos $10 \mathrm{VC}$ de tampão citrato $10 \mathrm{mM}$, contendo $\mathrm{CaCl}_{2} 1 \mathrm{mM}$ e NaCl 150 mM, pH 6,0 (Tampão G) e 7 VC de tampão citrato $10 \mathrm{mM}$, contendo $\mathrm{CaCl}_{2} 1 \mathrm{mM} \mathrm{e}$ $\mathrm{NaCl} 250$ mM, pH 6,0 (Tampão H) e $7 \mathrm{VC}$ de tampão citrato $10 \mathrm{mM}$, contendo $\mathrm{CaCl}_{2}$ 1 mM e NaCl 500 mM, pH 6,0 (Tampão I). A última fração foi coletada em 2 etapas, 
a primeira até a eluição de 4,5 VC de tampão, denominada A500A e a segunda com o restante da fração, denominada A500B.

Após a definição da melhor condição experimental, foram realizados vários experimentos para obtenção da fração A500A para os estudos em IMAC. Essa estratégia de purificação pode ser observada na Figura . Alguns experimentos em ANX Sepharose FF foram realizados em pH 7,0.

Figura 10 - Fluxograma mostrando a estratégia utilizada para purificação de FVIII e PC a partir de plasma humano.

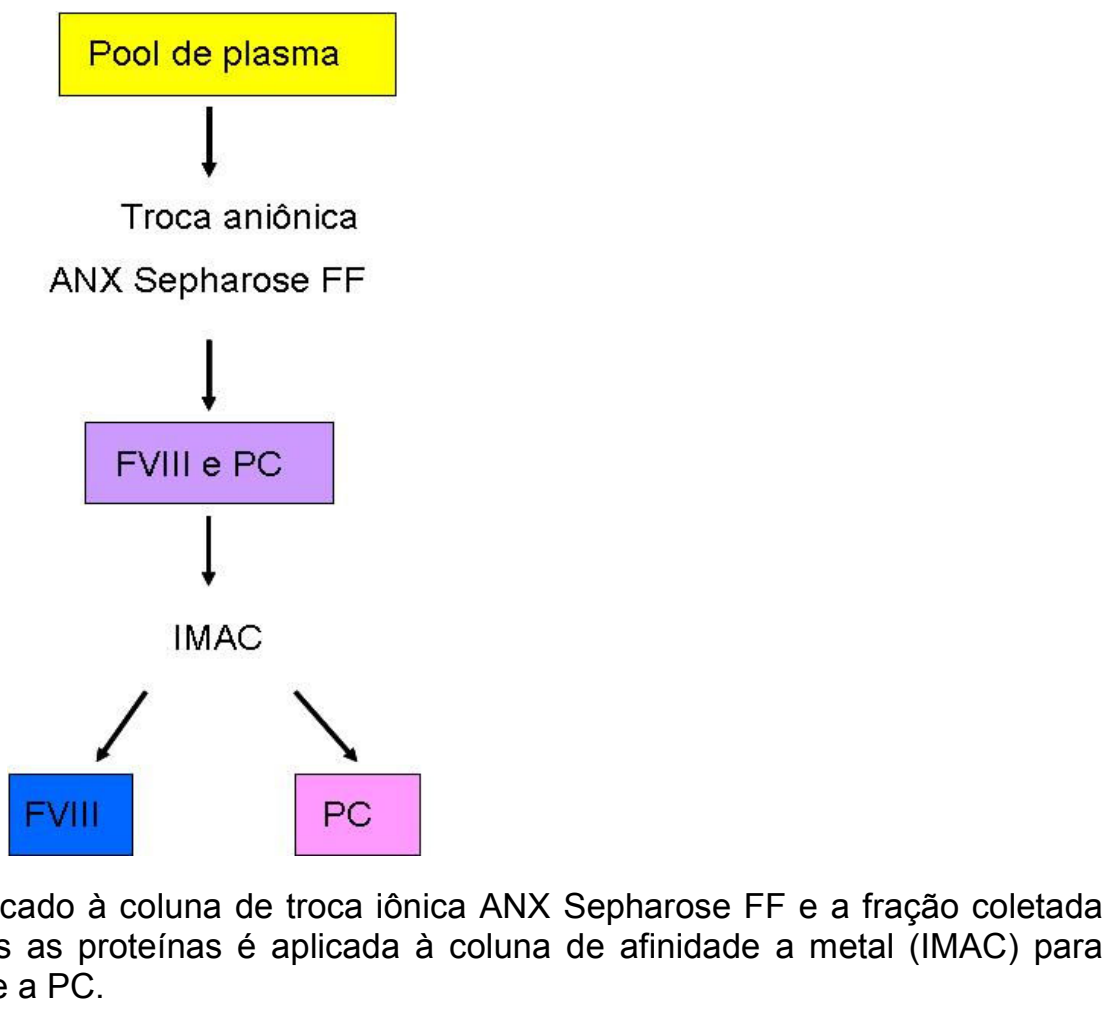

FONTE: (IWASHITA, 2012)

O plasma é aplicado à coluna de troca iônica ANX Sepharose FF e a fração coletada contendo ambas as proteínas é aplicada à coluna de afinidade a metal (IMAC) para separar o FVIII e a PC.

\subsection{Purificação de FVIII da coagulação e Proteína C empregando cromatografia de afinidade a metal (IMAC).}

Estudo sistemático foi realizado com os metais cobre, níquel, zinco, cobalto e ferro. Foram estudados 3 métodos de dessorção das proteínas, utilizando concentraçãoes crescentes de imidazol e $\mathrm{NH}_{4} \mathrm{Cl}$ e variação de $\mathrm{pH}$. Foram utilizadas 3 colunas: HiTrap IMAC HP, HisTrap HP e Chelating Sepharose FF.

As colunas foram carregadas com soluções de $\mathrm{CuSO}_{4}, \mathrm{NiSO}_{4}, \mathrm{ZnSO}_{4}, \mathrm{CoCl}_{2}$, ou $\mathrm{FeCl}_{3}$ na concentração de $0,1 \mathrm{M}$, por pelo menos 24 horas. 
Inicialmente, o excesso da solução do metal foi lavado com água e, em seguida, a coluna foi equilibrada com tampão citrato e a amostra A500A aplicada. A fração recolhida foi denominada "flow through" $(F T)$. As proteínas não adsorvidas foram eluídas com o tampão de equilíbrio. A fração recolhida foi denominada "reequilíbrio" (Reeq.).

Os tampões utilizados para a dessorção das proteínas foram eluídos sequencialmente. Para os experimentos com imidazol foram utilizados tampões citrato com concentrações crescentes de imidazol até $500 \mathrm{mM}$. Para os experimentos com $\mathrm{NH}_{4} \mathrm{Cl}$ foram utilizados tampões citrato com concentrações crescentes deste sal até $1 \mathrm{M}$. Para os experimentos com variação de $\mathrm{pH}$, foram realizados experimentos variando o $\mathrm{pH}$ de 6 a pH 4 .

Após cada experimento a coluna foi lavada seguindo o seguinte procedimento: $\mathrm{NaCl}$ 0,9\% (m/v), Tampão citrato com EDTA $50 \mathrm{mM}, \mathrm{NaCl}$ 0,9\% (m/v), $\mathrm{NaOH} 1 \mathrm{M}$, água, $\mathrm{NaCl} 1 \mathrm{M}$, água. $\mathrm{O}$ armazenamento da coluna foi feito com solução $0,1 \mathrm{M}$ do metal a ser utilizado no próximo experimento.

Foram realizados os testes cromogênicos para determinação de atividade do FVIII e da PC, assim como dosagem de proteínas totais pelo método de Bradford e análise do perfil de proteínas por SDS-PAGE com as amostras das purificações.

\subsubsection{Purificação com IMAC-Cu+}

Foram utilizadas as colunas HiTrap IMAC HP de $1 \mathrm{~mL}$, HisTrap HP de $5 \mathrm{~mL}$ e Chelating Sepharose FF de $10 \mathrm{~mL}$.

Os tampões utilizados nos experimentos com imidazol foram os tampões citrato $25 \mathrm{mM}$, contendo $\mathrm{CaCl}_{2} 5 \mathrm{mM}, \mathrm{NaCl} 500 \mathrm{mM}$ e imidazol em concentrações crescentes (tampões da série $\mathrm{C}$ ).

No estudo em que se verificou $\mathrm{opH}$ de dessorção da proteínas foram empregados os tampões citrato $25 \mathrm{mM}$, contendo $\mathrm{CaCl}_{2} 5 \mathrm{mM}, \mathrm{NaCl} 500 \mathrm{mM}$ em pH 7, 6, 5 e 4 (tampões M7 a M11).

No experimento de dessorção das proteínas utilizando $\mathrm{NH}_{4} \mathrm{Cl}$ foram utilizados os tampões citrato $25 \mathrm{mM}$, contendo concentrações crescentes de $\mathrm{NH}_{4} \mathrm{Cl}$ (tampões N1 a N5). 


\subsubsection{Purificação com IMAC-Ni ${ }^{2+}$}

Os experimentos com IMAC- $\mathrm{Ni}^{2+}$ foram realizados utilizando a coluna de $1 \mathrm{~mL}$ HisTrap HP.

O estudo para verificar a concentração de imidazol necessária para a dessorção das proteínas foi realizado empregando-se os tampões citrato $25 \mathrm{mM}$, contendo $\mathrm{CaCl}_{2} 5 \mathrm{mM}, \mathrm{NaCl} 500 \mathrm{mM}$ e concentrações crescentes de imidazol (tampões da série $\mathrm{C}$ ).

\subsubsection{Purificação com IMAC- $-\mathrm{Zn}^{2+}$}

Foram utilizadas as colunas HiTrap IMAC HP de $1 \mathrm{~mL}$, HisTrap HP de $5 \mathrm{~mL}$ e Chelating Sepharose FF de $10 \mathrm{~mL}$.

Os tampões utilizados nos experimentos com imidazol foram os tampões citrato $25 \mathrm{mM}$, contendo $\mathrm{CaCl}_{2} 5 \mathrm{mM}, \mathrm{NaCl} 500 \mathrm{mM}$ e concentrações crescentes de imidazol (tampões da série $\mathrm{C}(\mathrm{pH}$ 6,0) e M1 a M7 (pH 7,0)).

No estudo em que se verificou $\mathrm{opH}$ de dessorção de proteínas foram empregados os tampões citrato $25 \mathrm{mM}$, contendo $\mathrm{CaCl}_{2} 5 \mathrm{mM}$ e $\mathrm{NaCl} 500 \mathrm{mM}$ (tampões C, D, E para pH 6,0 e tampões M1, M8 a M10 para pH 7,0).

No experimento de dessorção das proteínas utilizando $\mathrm{NH}_{4} \mathrm{Cl}$ foi utilizado o tampão citrato $25 \mathrm{mM}$, contendo $\mathrm{NH}_{4} \mathrm{Cl} 1 \mathrm{M}$ (tampão $\mathrm{N} 4$ ).

\subsubsection{Purificação com IMAC-Co ${ }^{2+}$}

Os experimentos com cobalto foram realizados com as colunas HiTrap IMAC HP de $1 \mathrm{~mL}$, HisTrap HP de $5 \mathrm{~mL}$ e Chelating Sepharose FF de $10 \mathrm{~mL}$.

O estudo para verificar a concentração de imidazol necessária para a dessorção das proteínas foi realizado empregando-se o tampão citrato $10 \mathrm{mM}$ e 25 $\mathrm{mM}$. Nos experimentos com citrato $10 \mathrm{mM}$ os tampões empregados foram os tampões citrato $10 \mathrm{mM}$, contendo $\mathrm{CaCl}_{2} 5 \mathrm{mM}, \mathrm{NaCl} 500 \mathrm{mM}$ e imidazol $100 \mathrm{mM} \mathrm{e}$ $500 \mathrm{mM}$ (tampões da série J) e nos experimentos com citrato $25 \mathrm{mM}$ os tampões empregados foram os tampões citrato $25 \mathrm{mM}$, contendo $\mathrm{CaCl}_{2} 5 \mathrm{mM}, \mathrm{NaCl} 500 \mathrm{mM}$ (tampões da série C). 
A amostra A500A empregada no experimento com citrato $10 \mathrm{mM}$ foi diluída 2,5 vezes com solução de $\mathrm{NaCl} 500 \mathrm{mM}$.

\subsubsection{Purificação com IMAC-Fe ${ }^{3+}$}

Para os experimentos com IMAC-Fe ${ }^{3+}$ foi utilizada a coluna HiTrap IMAC HP de $1 \mathrm{~mL}$.

O estudo para verificar a concentração de imidazol necessária para a dessorção das proteínas foi realizado empregando-se o tampão citrato $10 \mathrm{mM}$ e 25 $\mathrm{mM}$. Nos experimentos com citrato $10 \mathrm{mM}$ os tampões empregados foram os tampões citrato $10 \mathrm{mM}$, contendo $\mathrm{CaCl}_{2} 5 \mathrm{mM}, \mathrm{NaCl} 500 \mathrm{mM}$ e imidazol $100 \mathrm{mM} \mathrm{e}$ $500 \mathrm{mM}$ (tampões da série $\mathrm{J}$ ) e nos experimentos com citrato $25 \mathrm{mM}$ os tampões empregados foram os tampões citrato $25 \mathrm{mM}$, contendo $\mathrm{CaCl}_{2} 5 \mathrm{mM}, \mathrm{NaCl} 500 \mathrm{mM}$ (tampões da série $C$ ).

A amostra A500A empregada no experimento com citrato $10 \mathrm{mM}$ foi aplicada à coluna sem diluição.

\subsection{Métodos analíticos}

\subsubsection{Determinação da atividade de FVIII pelo método cromogênico}

A atividade de FVIII nas frações obtidas nas cromatografias foi determinada pelo método cromogênico, com uso do kit COATEST ${ }^{\circledR} \mathrm{SP}_{4} \mathrm{FVIII} \mathrm{(Chromogenix).} \mathrm{Este}$ kit é utilizado em análises clínicas, no diagnóstico ou monitoramento de pacientes com deficiência de FVIII.

Neste teste, o FX é ativado em FX ativado pelo fator IXa, na presença de cálcio e fosfolipídio e o FXa ativa o FVIII, que atua como cofator da reação. Utilizando quantidades ótimas de $\mathrm{Ca}^{2+}$ e fosfolipídio não reveladas pelo fabricantes, além de um excesso de fator IXa e fator $X$, a taxa de ativação de fator $X$ depende exclusivamente da quantidade de FVIII. $\mathrm{O}$ fator Xa promove a hidrólise do substrato cromogênico S-2765, liberando o grupo cromofórico p-nitroanilina (pNa) (Figura ). A intensidade da cor é mensurada por espectrofotômetro a 405nm. A geração de Fator Xa e a intensidade de cor é proporcional à atividade de FVIII na amostra, uma vez 
que o FVIII é um cofator da reação. A hidrólise do substrato cromogênico S-2765 pela trombina é prevenido pela adição de inibidor de trombina (I-2581) ao substrato.

Figura 11 - Reações do teste cromogênico para determinação da atividade do FVIII nas frações cromatográficas.

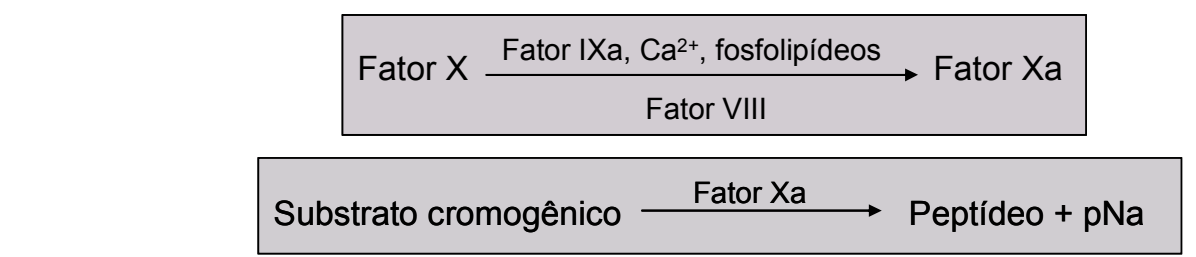

FONTE: (CHROMOGENIX, 2006)

Este teste foi realizado em microplacas, seguindo a seqüência mostrada na Figura 16. Após a adição de cada reagente, a microplaca foi incubada a $37^{\circ} \mathrm{C}$, por 5 minutos. O ácido acético $20 \%$ foi utilizado para parar a reação. A leitura da microplaca foi feita utilizando Leitor de microplacas Multiskan EX da Thermo.

A curva de calibração foi construída a partir do "pool" de plasma e para cada "pool" de plasma foi construída uma curva de calibração. Considerou-se 1 unidade de FVIII (U) a quantidade de FVIII em $1 \mathrm{~mL}$ de plasma humano normal.

A leitura da absorbância em 492nm serviu como "branco da microplaca". Deste modo, aplicando os valores de absorbância $\left(A^{405}-A^{492}\right)$ na equação da reta da curva de calibração, pode-se obter a atividade do FVIII em cada fração.

Figura 12. Etapas do teste cromogênico do FVIII.

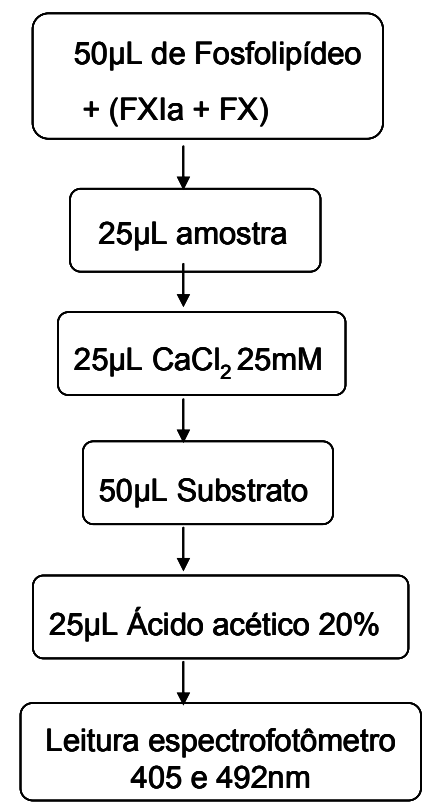

FONTE: (IWASHITA, 2012) 


\subsubsection{Determinação da atividade da PC pelo método cromogênico}

Para análise da atividade de PC nas frações obtidas nas cromatografias foi utilizado o método cromogênico, com uso do kit COAMATIC $^{\circledR}$ Protein C (Chromogenix).

A Proteína $C$ no plasma é ativada por uma enzima específica do veneno da cobra Cabeça de cobre (Agkistrodon Contortrix Contortrix). A quantidade de proteína $C$ ativada é determinada pela taxa de hidrólise do substrato cromogênico S-2366. A intensidade da cor devido à liberação do grupo cromofórico p-nitroanilina $(\mathrm{pNa})$ é mensurada por espectrofotômetro, utilizando um comprimento de onda de $405 \mathrm{~nm}$, sendo proporcional ao nível de Proteína C no plasma.

Figura 13 - Reações do teste cromogênico para determinação da atividade da PC nas frações cromatográficas.

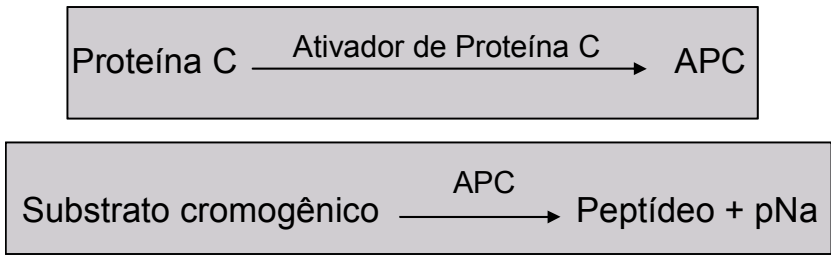

FONTE: (CHROMOGENIX, 2006)

Este teste foi realizado em microplacas, seguindo sequência mostrada na Figura 18. Após a adição de cada reagente, a microplaca foi incubada a $37^{\circ} \mathrm{C}$, por 10 minutos. O ácido acético $20 \%$ (v/v) foi utilizado para parar a reação.

Figura 14 - Etapas do teste cromogênico da Proteína C.

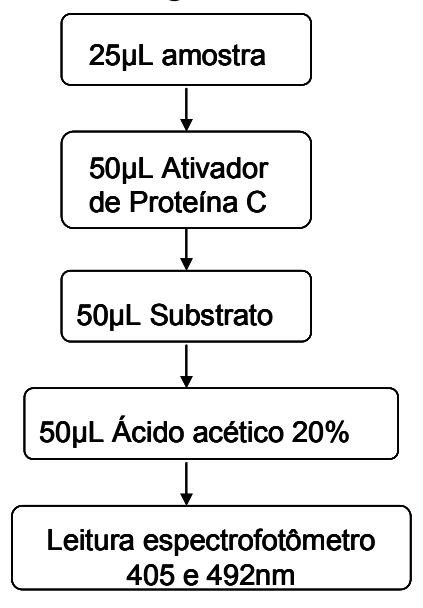

FONTE: (IWASHITA, 2012) 
Para curva de calibração utilizamos o pool de plasma utilizado no dia de cada experimento correspondente. A amostra não diluída foi considerada como $100 \%$ de atividade da PC. Para todas as amostras foi feita a seguinte diluição: $50 \mu \mathrm{L}$ de amostra $+150 \mu \mathrm{L}$ de água. Considerou-se 1 unidade de $\mathrm{PC}(\mathrm{U})$ a quantidade de $\mathrm{PC}$ em $1 \mathrm{~mL}$ de plasma humano normal.

A leitura da absorbância em 492 nm serviu como "branco da microplaca". Deste modo, aplicando os valores de absorbância $\left(A^{405}-A^{492}\right)$ na equação da reta da curva de calibração, pode-se obter a \% de atividade de PC nas frações.

\subsubsection{Determinação da concentração de proteínas pelo método de Bradford}

A determinação da concentração protéica total das frações obtidas nos experimentos foi realizada pelo método de Bradford (1976), utilizando BSA (2 $\mathrm{mg} / \mathrm{mL}$ ) como padrão. Para curva de calibração a concentração de BSA variou de 0 a $2,5 \mu \mathrm{g}$ em um volume total de $200 \mu \mathrm{L}$ ao qual foram adicionados $800 \mu \mathrm{L}$ do reagente de Bradford.

As amostras foram diluídas, quando necessárias, em $\mathrm{NaCl} 0,9 \%(\mathrm{~m} / \mathrm{v})$, para um volume total de $200 \mu \mathrm{L}$. Foi adicionado o volume de $800 \mu \mathrm{L}$ do reagente de Bradford.

A leitura foi realizada em espectrofotômetro, a um comprimento de onda de $595 \mathrm{~nm}$.

A equação da reta da curva de calibração permitiu o cálculo da quantidade de massa de proteína nas frações das purificações. A massa de proteína em cada fração é calculada considerando a diluição usada na dosagem e o volume total da fração.

\subsubsection{Eletroforese em gel de poliacrilamida (SDS-PAGE)}

A eletroforese em gel de poliacrilamida foi realizada seguindo o protocolo descrito por Laemmli (1970). O gel de separação foi feito a uma concentração de $7,5 \%(\mathrm{v} / \mathrm{v})$, com $1 \mathrm{~mm}$ de espessura. Após polimerização deste gel, foi aplicado sobre este, o gel de empilhamento $5 \%(\mathrm{v} / \mathrm{v})$.

As amostras foram preparadas utilizando tampão de amostra 5 vezes concentrado. O tampão de amostra utilizado foi: Tris- $\mathrm{HCl} 50 \mathrm{mM}, \mathrm{pH} 6,8$, azul de 
bromofenol 0,1\% (m/v), glicerol 10\% (v/v), SDS 2\% (m/v), $\beta$-mercaptoetanol $100 \mathrm{mM}$. Após essa mistura, as amostras foram aquecidas a $96{ }^{\circ} \mathrm{C}$, por aproximadamente 5 minutos.

As amostras foram aplicadas ao gel e a corrida foi realizada a uma tensão de 120V, utilizando como tampão de corrida Tris-Glicina, contendo SDS. As corridas tiveram um tempo médio de duração de 1 hora e 40 minutos. O padrão de massa molecular utilizado foi Unstained Protein Molecular Weight Marker (Fermentas), tanto para os géis corados com Coomassie como os corados com Prata.

Os géis foram corados sob agitação com o corante Coomassie Blue (ácido acético glacial 10\% (v/v), etanol 45\% (v/v), azul Coomassie R250 0,25\% (m/v)) por aproximadamente 1 hora, sendo depois descorados até as bandas de proteínas ficarem evidentes.

Para as amostras com quantidade menor que $30 \mu \mathrm{g}$ de proteínas totais, previamente determinado pelo método de Bradford, os géis foram corados com Prata, utilizando o kit SilverXpress, Invitrogen. O volume de cada solução determinado pelo fabricante do kit foi diminuído para uso, no entanto, mantendo a proporção estabelecida. $\mathrm{O}$ tempo de cada etapa foi o estabelecido pelo fabricante do kit. 


\section{RESULTADOS E DISCUSSÃO}

\subsection{Purificação de Fator VIII de coagulação e Proteína C por cromatografia de troca aniônica ANX Sepharose FF}

\subsubsection{Avaliação do empacotamento da coluna ANX Sepharose FF}

O empacotamento da resina ANX Sepharose FF em coluna XK 26/40 foi avaliado de acordo método descrito no item 3.3.

O cromatograma obtido está mostrado na Figura 15. As constantes medidas e os demais parâmetros usados para o cálculo estão mostrados na Tabela 2.

Figura 15 - Avaliação do empacotamento da resina ANX Sepharose FF em coluna XK 26/40.

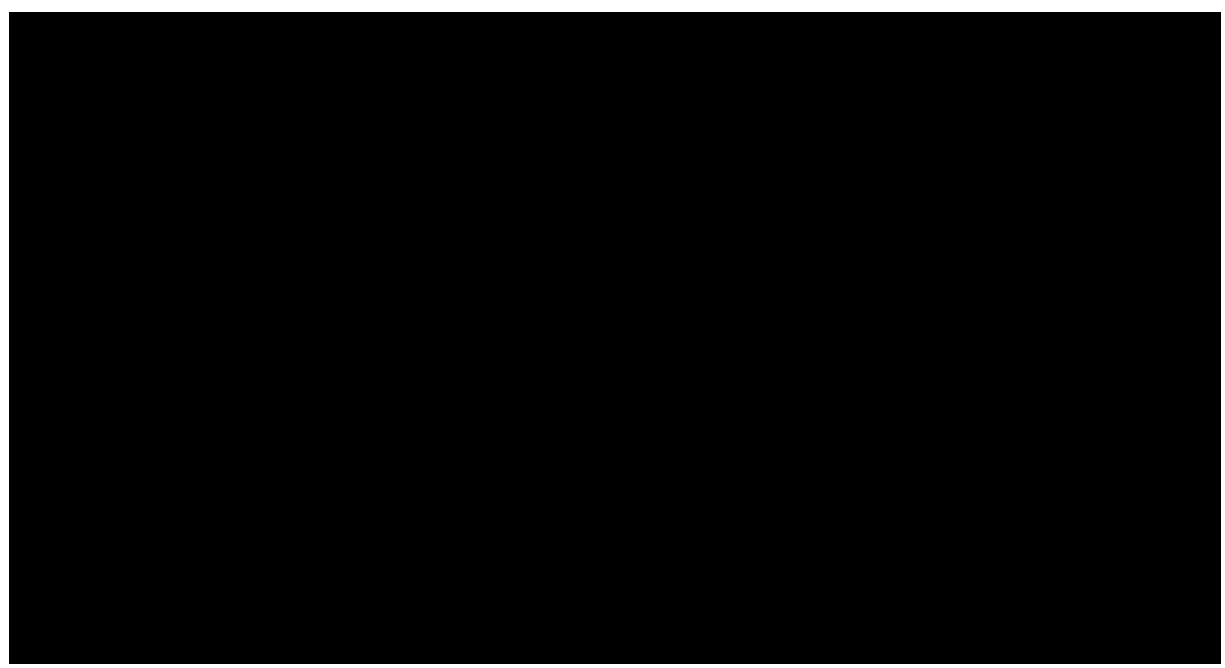

Foi injetado o volume de $1 \%$ de VC de uma solução de acetona $1 \%$ (v/v). A detecção foi feita em UV $280 \mathrm{~nm}$. As constantes (a) e (b) são os valores das larguras na primeira e na FONTE:(IWASHITA, 2012)

segunda metade do pico, respectivamente, medidos a $10 \%$ da altura do pico.

Tabela 2 - Avaliação do empacotamento da coluna ANX-Sepharose FF.

\begin{tabular}{cccccccccc}
\hline $\mathbf{L}(\mathbf{c m})$ & $\mathbf{H}(\mathbf{c m})$ & $\mathbf{W r}(\mathbf{c m})$ & $\mathbf{V r}(\mathbf{c m})$ & $\mathbf{N}$ & $\mathbf{H E T P}(\mu \mathrm{m})$ & $\mathbf{N} / \mathbf{m}$ & $\mathbf{a}(\mathbf{c m})$ & $\mathbf{b}(\mathbf{c m})$ & As \\
15,5 & 6,8 & 1,4 & 9,7 & 265,94 & 0,058 & 17,15 & 1 & 1,4 & 1,4 \\
\hline
\end{tabular}

FONTE:(IWASHITA, 2012) 
O número de pratos teóricos por metro calculado $(\mathrm{N} / \mathrm{m})$ a partir do cromatograma, empregando as equações descritas no item 1.3, foi de 17,15 e a assimetria (As) 1,4 .

O valor de assimetria (As) é um parâmetro importante, pelo qual pode-se verificar a qualidade do empacotamento. $O$ valor ideal de As é 1,0 . O valor obtido para a coluna ANX Sepharose 4FF, As=1,4, é aceitável para colunas de troca iônica. A altura média de pratos teóricos (HETP) é outro parâmetro importante, sendo o valor ideal igual a 3 vezes o diâmetro dos "beads" da resina utilizada. Uma vez que o diâmetro desta resina varia de 45 a $165 \mu \mathrm{m}$, o valor de HETP ideal é de 0,013 a 0,049. O valor obtido de HETP de 0,058 ainda foi considerado aceitável para nossos estudos com coluna de troca iônica. Este valor é usado como referência, pois a coluna pode perder a eficiência após algum tempo de uso e um dos parâmetros que pode ser usado para verificar as condições da coluna é o valor de HEPT.

Essa avaliação foi feita para todas as colunas empacotadas no laboratório.

\subsubsection{Determinação da concentração de $\mathrm{NaCl}$ para a purificação do $\mathrm{FVIII}$ e da proteína $C$ em coluna de troca aniônica ANX Sepharose FF a partir de plasma (Condição Experimental 1)}

A determinação das condições experimentais de lavagem e de eluição de proteínas em cromatografia de troca iônica são importantes para se obter produtos com maior pureza.

Neste trabalho foi utilizada a resina de troca aniônica ANX Sepharose FF. Foram testadas 2 condições experimentais para lavagem intermedária e eluição de FVIII e PC.

$\mathrm{Na}$ Condição Experimental 1 foram empregadas condições usadas para purificações em Q Sepharose FF no laboratório. Em estudo sistemático com a coluna de $Q$ Sepharose FF foi verificado que com uma lavagem intermediária com $200 \mathrm{mM}$ de $\mathrm{NaCl}$ seria possível eluir proteínas contaminantes, com perda mínima de FVIII. Também foi verificado que o FVIII elui com $500 \mathrm{mM}$ de $\mathrm{NaCl}$ e que os fatores de coagulação IX e X também são recuperados nesta fração (CHENG et al., 2010).

O perfil cromatográfico da purificação de plasma em coluna ANX Sepharose FF nestas condições pode ser observado na Figura 16.

As frações coletadas foram submetidas ao teste cromogênico para a determinação das atividades do FVIII e da PC. As curvas de calibração estão 
mostradas nas Figuras 17 e 18, respectivamente. As tabelas detalhadas com os resultados obtidos e os valores calculados a partir da curva de calibração de atividade e proteína encontram-se no ANEXO A.

Figura 16 - Perfil cromatográfico da purificação de plasma em ANX Sepharose FF (Condição Experimental 1).

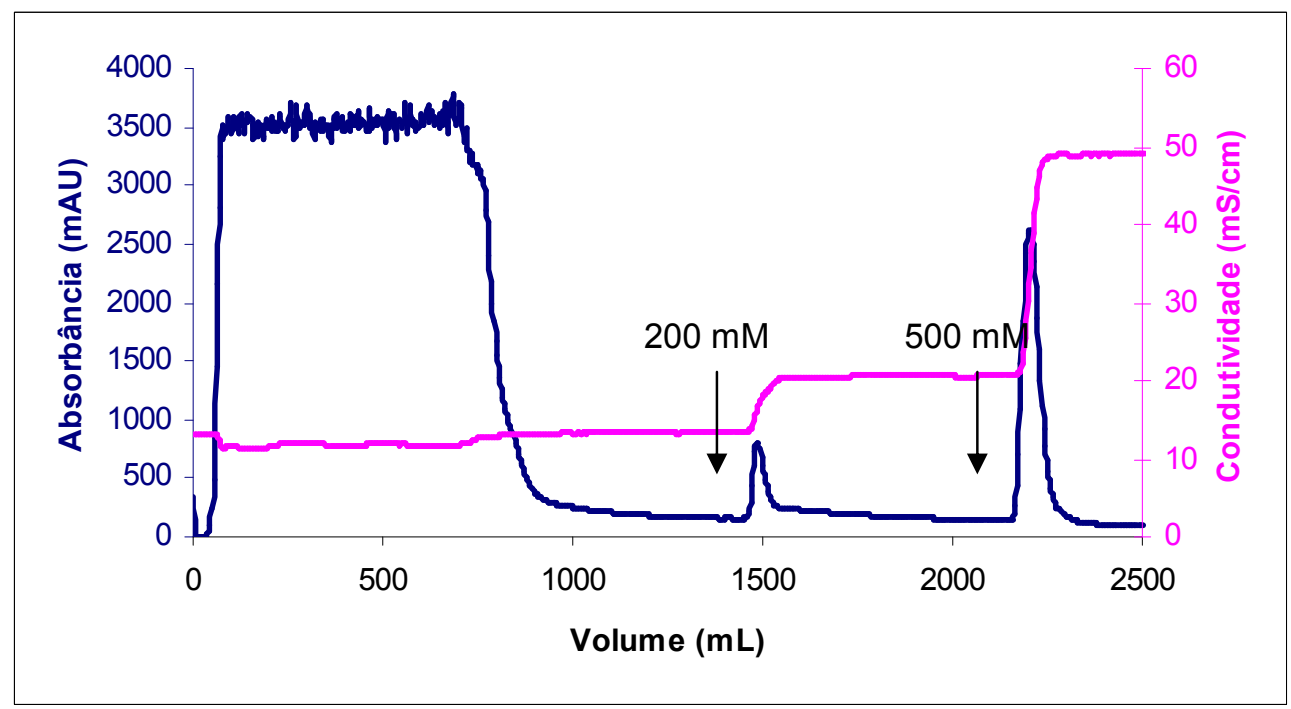

A detecção foi feita em UV $280 \mathrm{~nm}$. O plasma foi aplicado à coluna e as proteínas que não se ligaram à ela foram recolhidas no $\mathrm{FT}$, que corresponde ao primeiro pico na figura. Foram realizadas 2 lavagens usando tampão citrato contendo $\mathrm{NaCl} 200 \mathrm{mM}$ e $500 \mathrm{mM}$ de $\mathrm{NaCl}$, respectivamente.

FONTE:(IWASHITA, 2012)

Figura 17 - Curva de calibração utilizada no teste cromogênico para determinação de atividade do FVIII nas frações da purificação de plasma em ANX Sepharose FF (Condição Experimental 1).

\begin{tabular}{|c|c|c|c|}
\hline $\begin{array}{c}\text { \% } \\
\text { Atividade }\end{array}$ & $\begin{array}{c}\text { Abs 405 } \\
\mathbf{n m}\end{array}$ & $\begin{array}{c}\text { Abs 492 } \\
\mathbf{n m}\end{array}$ & $\begin{array}{c}\text { Abs 405- } \\
\mathbf{4 9 2} \mathbf{~ n m}\end{array}$ \\
\hline $\mathbf{0}$ & 0 & 0 & 0 \\
\hline $\mathbf{5 0}$ & 0,143 & $-0,015$ & 0,158 \\
\hline $\mathbf{1 0 0}$ & 0,271 & $-0,015$ & 0,286 \\
\hline
\end{tabular}

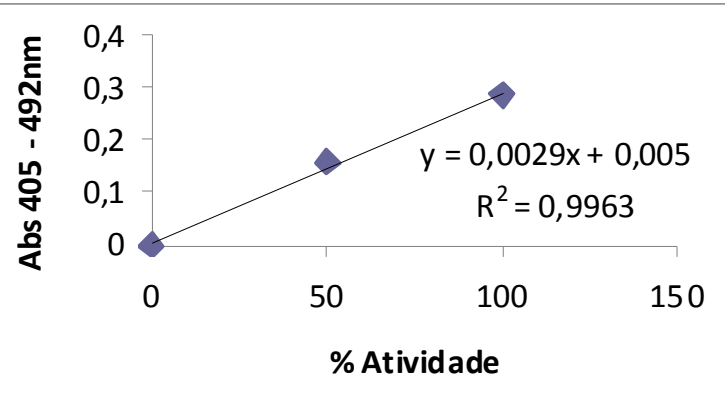

FONTE:(IWASHITA, 2012) 
Figura 18 - Curva de calibração utilizada no teste cromogênico para determinação de atividade da PC nas frações da purificação de plasma em ANX Sepharose FF (Condição Experimental 1).

\begin{tabular}{|c|c|c|c|}
\hline $\begin{array}{c}\mathbf{\%} \\
\text { Atividade }\end{array}$ & $\begin{array}{c}\text { Abs 405 } \\
\mathbf{n m}\end{array}$ & $\begin{array}{c}\text { Abs 492 } \\
\mathbf{n m}\end{array}$ & $\begin{array}{c}\text { Abs } \mathbf{4 0 5} \\
\mathbf{4 9 2} \mathbf{~ n m}\end{array}$ \\
\hline $\mathbf{0}$ & 0 & 0 & 0 \\
\hline $\mathbf{1 0}$ & 0,103 & 0,017 & 0,086 \\
\hline $\mathbf{2 0}$ & 0,156 & 0,006 & 0,15 \\
\hline $\mathbf{5 0}$ & 0,328 & 0,012 & 0,316 \\
\hline $\mathbf{7 5}$ & 0,501 & 0,015 & 0,486 \\
\hline $\mathbf{1 0 0}$ & 0,541 & 0,018 & 0,523 \\
\hline
\end{tabular}

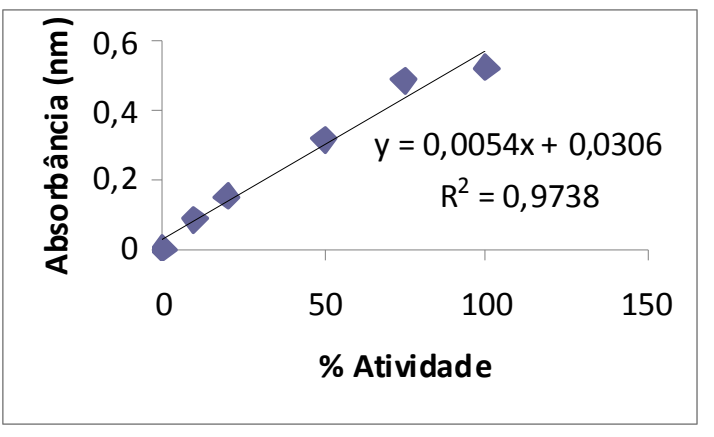

FONTE:(IWASHITA, 2012)

A dosagem de proteínas foi realizada pelo método de Bradford. A figura 19 mostra a curva da calibração obtida e a equação gerada para obtenção dos valores de massas de cada fração.

Figura 19 - Curva de calibração para determinação de concentração de proteínas pelo método de Bradford da purificação de plasma em ANX Sepharose FF (Condição Experimental 1).

\begin{tabular}{|c|c|c|c|c|}
\hline $\begin{array}{c}\text { BSA } \\
(\mathbf{u g})\end{array}$ & $\begin{array}{c}\text { BSA } \\
(\mathbf{u L})\end{array}$ & $\begin{array}{c}\mathbf{N a C l} \\
\mathbf{0 , 9 \%}(\boldsymbol{\mu L})\end{array}$ & $\begin{array}{c}\text { Reagente de } \\
\text { Bradford } \\
(\boldsymbol{\mu L})\end{array}$ & $\begin{array}{c}\text { Abs } \\
\mathbf{5 9 5} \mathbf{n m}\end{array}$ \\
\hline $\mathbf{0}$ & 0 & 200 & 800 & 0,784 \\
\hline $\mathbf{5}$ & 2,5 & 197,5 & 800 & 1,271 \\
\hline $\mathbf{1 0}$ & 5 & 195 & 800 & 1,497 \\
\hline $\mathbf{1 5}$ & 7,5 & 192,5 & 800 & 1,706 \\
\hline $\mathbf{2 0}$ & 10 & 190 & 800 & 1,922 \\
\hline $\mathbf{2 5}$ & 12,5 & 187,5 & 800 & 2,113 \\
\hline
\end{tabular}

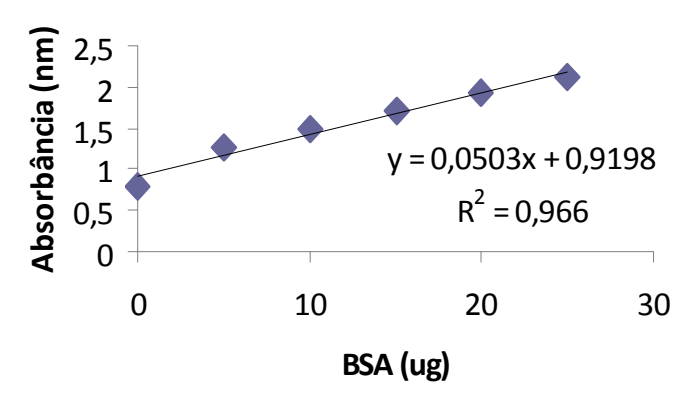

FONTE:(IWASHITA, 2012)

Os resultados obtidos neste experimento estão mostrados nas Tabelas 3 e 4 e a representação gráfica dos resultados está mostrado na Figura 20. As atividades do FVIII e da PC encontram-se na fração A500A. Não houve perda de atividade na fração de lavagem com $200 \mathrm{mM}$ de $\mathrm{NaCl}$ (FIGURA 20A). A maior porcentagem de proteínas foi encontrada no "flowthrough" (FT) (Figura 20B ).

O perfil protéico da purificação em gel de poliacrilamida das frações coletadas está mostrado na Figura 21. 
Figura 20 - Atividade de FVIII e PC (A) e proteína total (B) nas frações da purificação de plasma0 em ANX Sepharose FF (Condição Experimental1).

(A)

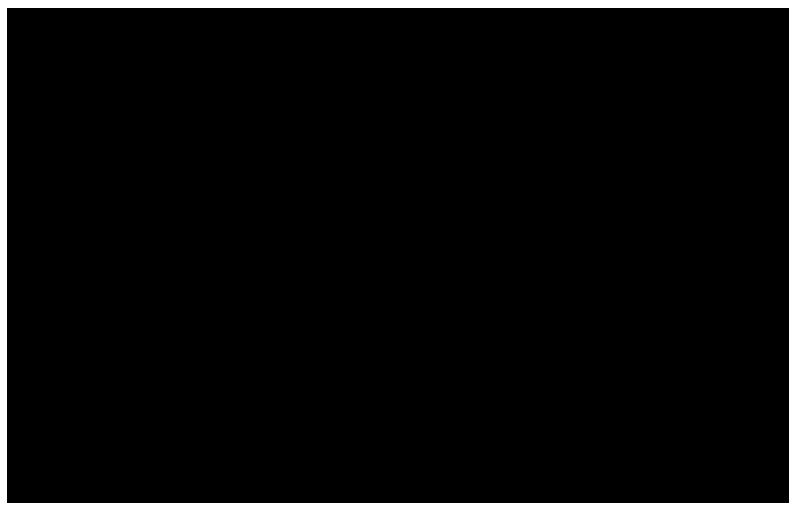

(B)

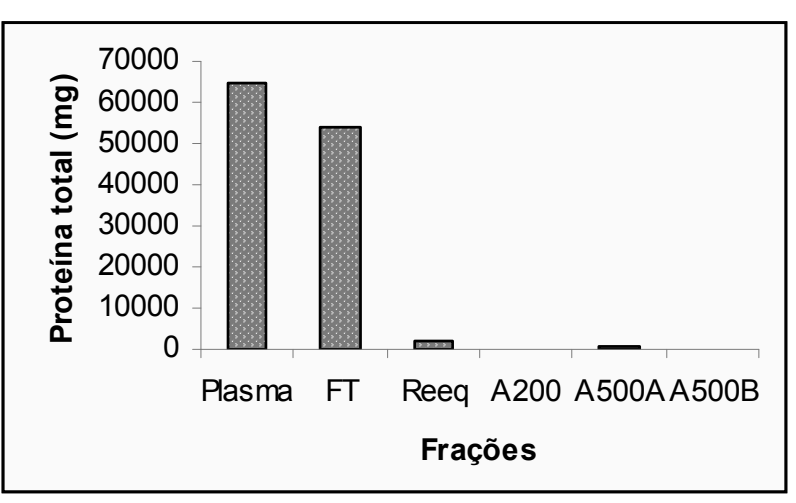

As frações recolhidas foram: FT (proteínas que não se ligam à coluna), Reeq. (lavagem das proteínas que não se ligam à coluna), A200 (lavagem com tampão contendo $\mathrm{NaCl}$ $200 \mathrm{mM}$ ) e $A 500$ (lavagem com tampão contendo $\mathrm{NaCl} 500 \mathrm{mM}$ ). A fração $\mathrm{A} 500$ foi recolhida em 2 etapas, a fração A500A corresponde ao pico e a A500B ao restante da lavagem.

FONTE:(IWASHITA, 2012)

Figura 21 - Gel de poliacrilamida 7,5\% (em condições redutoras) das frações obtidas na purificação em ANX Sepharose FF (Experimento 1).

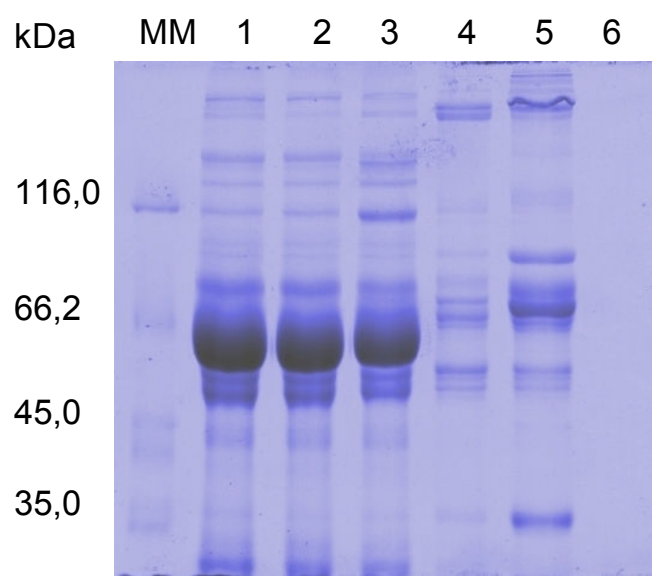

Canaletas: 1. Plasma $(36 \mu \mathrm{g})$; 2. FT $(35,8 \mu \mathrm{g})$; 3. Reeq $(28,8 \mu \mathrm{g}) ; 4$. A200 $(5,6 \mu \mathrm{g}) ; 5$. A500A $(11,2 \mu \mathrm{g}) ; 6$. A500B (Pelo método de Bradford não foi detectada a presença de proteínas nesta fração). As amostras de plasma, FT e Reeq foram diluídas 25 vezes para que o perfil proteico pudesse ser visto. As demais amostras não foram diluídas.

FONTE:(IWASHITA, 2012) 
Tabela 3 - Purificação de FVIII em ANX Sepharose FF (Condição Experimental 1).

\begin{tabular}{ccccccc}
\hline Amostra & $\begin{array}{c}\text { Volume da } \\
\text { fração (mL) }\end{array}$ & $\begin{array}{c}\text { Concentração de } \\
\text { proteínas (mg/mL) }\end{array}$ & $\begin{array}{c}\text { Proteína } \\
\text { total (mg) }\end{array}$ & $\begin{array}{c}\text { Atividade } \\
\text { total (U) }\end{array}$ & $\begin{array}{c}\text { \% de atividade } \\
\text { recuperada }\end{array}$ & $\begin{array}{c}\text { Atividade } \\
\text { Específica } \\
\text { (U/mg) }\end{array}$ \\
\hline Plasma & 716,7 & 90,6 & 64933 & 100696 & 100 & $\begin{array}{c}\text { Fator de } \\
\text { Purificação }\end{array}$ \\
\hline FT & 716,7 & 75,1 & 53824 & 717 & 1 & $-1,5$ \\
\hline Reeq. & 684,7 & 2,5 & 1712 & -1712 & - & - \\
\hline A200 & 716,7 & 0,3 & 208 & 0 & - & - \\
\hline A500A & 358,3 & 1,4 & 490 & 79733 & - & - \\
\hline A500B & 143,3 & 0,0 & - & -287 & - & - \\
\hline
\end{tabular}

FONTE:(IWASHITA, 2012)

Tabela 4 - Purificação de PC em ANX Sepharose FF (Condição Experimental 1).

\begin{tabular}{|c|c|c|c|c|c|c|c|}
\hline Amostra & $\begin{array}{l}\text { Volume da } \\
\text { fração }(m L)\end{array}$ & $\begin{array}{l}\text { Concentração } \\
\text { de proteínas } \\
\text { (mg/mL) }\end{array}$ & $\begin{array}{c}\text { Proteína } \\
\text { total (mg) }\end{array}$ & $\begin{array}{c}\text { Atividade } \\
\text { total (U) }\end{array}$ & $\begin{array}{l}\% \text { de atividade } \\
\text { recuperada }\end{array}$ & $\begin{array}{c}\text { Atividade } \\
\text { Específica } \\
\text { (U/mg) }\end{array}$ & $\begin{array}{c}\text { Fator de } \\
\text { Purificação }\end{array}$ \\
\hline Plasma & 716,7 & 90,6 & 64933 & 70667 & 100 & 1,1 & 1,0 \\
\hline FT & 716,7 & 75,1 & 53824 & 14191 & 20 & 0,3 & 0,2 \\
\hline Reeq. & 684,7 & 2,5 & 1712 & -959 & - & - & - \\
\hline A200 & 716,7 & 0,3 & 208 & -1720 & - & - & - \\
\hline A500A & 358,3 & 1,4 & 490 & 64216 & 91 & 131 & 121,3 \\
\hline A500B & 143,3 & 0,0 & - & -631 & - & - & - \\
\hline
\end{tabular}

FONTE:(IWASHITA, 2012) 
Dados calculados a partir de vários experimentos utilizando essa condição experimental possibilitaram a determinação da média e desvio padrão para os resultados da purificação de FVIII e PC (Tabela 5).

Tabela 5 - Resumo dos resultados obtidos para a purificação de FVIII e PC em ANX Sepharose FF empregando a Condição Experimental 1.

\begin{tabular}{ccc}
\hline & FVIII (5)* $^{*}$ & PC (4)* \\
\hline Atividade específica do plasma (U/mg) & $1,3 \pm 0,2$ & $1,1 \pm 0,1$ \\
\hline \% de recuperação de atividade & $69 \pm 18$ & $67 \pm 22$ \\
\hline Atividade específica na fração A500A (U/mg) & $139 \pm 15$ & $119 \pm 18$ \\
Fator de purificação & $110 \pm 11$ & $107 \pm 19$ \\
\hline
\end{tabular}

* Número de experimentos

FONTE:(IWASHITA, 2012)

Observa-se que há uma variação muito grande de recuperação de atividade, que pode ser explicada pela variabilidade da amostra inicial, mesmo partindo-se de "pools" de plasma para minimizar este problema. O fator de purificação para o FVIII foi de 110 vezes. Este valor é 2 vezes maior que o observado para a purificação de plasma em Q Sepharose FF (CHENG et al. 2010), indicando que a resina ANX Sepharose FF é mais eficiente para a purificação de FVIII. Entretanto, semelhantemente à resina $Q$ Sepharose FF, o FVIII coelui com a $P C$, e provavelmente as demais proteínas dependentes de vitamina $K$, na fração de eluição contendo $500 \mathrm{mM}$ de $\mathrm{NaCl}$.

\subsubsection{Determinação da concentração de $\mathrm{NaCl}$ para a purificação do $\mathrm{FVIII}$ e da proteína $C$ em coluna de troca aniônica ANX Sepharose FF a partir de plasma (Condição Experimental 2)}

Nesta purificação foram empregadas as condições experimentais descritas por Mori et al. (2008) para a purificação de FVIII em diversas resinas de troca aniônica. Empregando resinas de troca aniônica fraca, o crioprecipitado era adsorvido na resina com tampão citrato contendo $\mathrm{NaCl} 120 \mathrm{mM}$ e o fator de coagulação eluído com o mesmo tampão contendo $250 \mathrm{mM}$ de sal. Para as resinas de troca aniônica forte, o FVIII foi eluído com 450 mM a 600 mM de sal. Sendo ANX Sepharose FF uma resina de troca aniônica fraca, nosso objetivo era verificar se seria possível eluir o FVIII com 250 mM de sal. 
As curvas de calibração para determinação das atividades de FVIII e PC e para determinação da concentração de proteínas encontram-se no ANEXO B.

Os resultados obtidos neste experimento mostram que a atividade de FVIII e PC não foram observadas nas frações de lavagem com tampões contendo $150 \mathrm{mM}$ e $250 \mathrm{mM}$ de $\mathrm{NaCl}$ (Tabelas 6 e 7), ambas as proteínas eluíram na fração contendo $500 \mathrm{mM}$ de $\mathrm{NaCl}$ (Figura 22A). Portanto, não foi possível eluir o FVIII e a PC da resina ANX Sepharose FF nas condições experimentais descritas por Mori et al. (2008).

Figura 22 - Atividade de FVIII e PC (A) e proteína total (B) nas frações da purificação em ANX Sepharose FF (Condição Experimental 2).

(A)

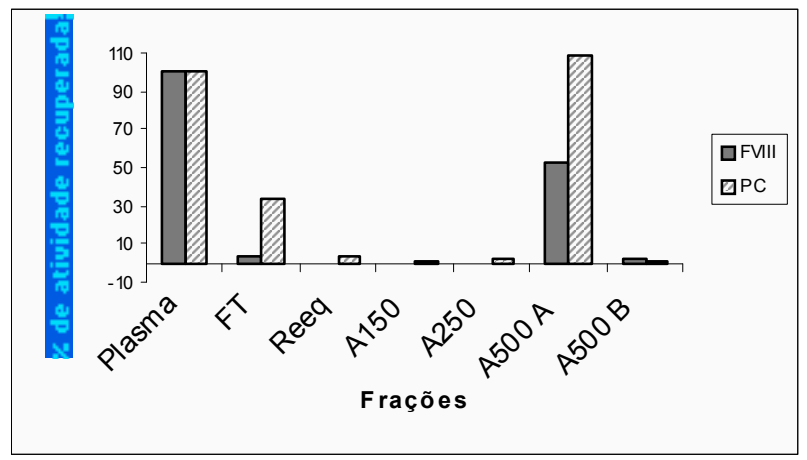

(B)

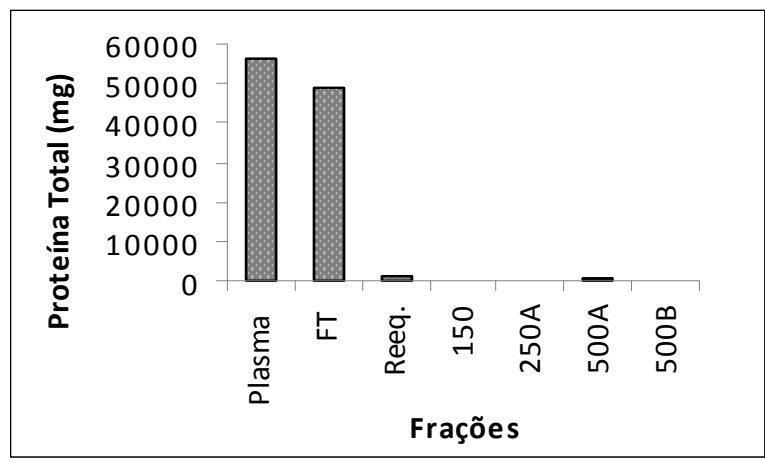

As frações recolhidas foram: FT (proteínas que não se ligam à coluna), Reeq. (lavagem das proteínas que não se ligam à coluna), A150 (lavagem com tampão contendo $\mathrm{NaCl} 150 \mathrm{mM}$ ), A250 (lavagem com tampão contendo $\mathrm{NaCl} 250 \mathrm{mM}$ ) e A500 (lavagem com tampão contendo $\mathrm{NaCl} 500 \mathrm{mM}$ ). A fração A500 foi recolhida em 2 etapas, a fração A500A corresponde ao pico e a A500B ao restante da lavagem.

FONTE:(IWASHITA, 2012)

A partir da determinação da quantidade de proteínas totais nas frações pelo método de Bradford, pode-se observar que a maior porcentagem de proteínas recuperadas encontra-se no FT (Figura 22B), o que demonstra que o FVIII e a PC encontram-se bem separados da maioria das outras proteínas presentes no plasma.

Neste experimento o fator de purificação do FVIII foi de 84 vezes, enquanto para a PC foi de 167 vezes.

A concentração de $\mathrm{NaCl}$ presente no tampão de eluição tem influência sobre o tamanho do complexo FVIII/FvW. Quanto maior a concentração de sal, maior a 
razão entre o FVIII e o FVW (MORI et al., 2008). Somente os concentrados de FVIII que contém complexos FVIII/FvW de alta massa molecular, isto é, aqueles em que a razão FVIII/FvW é pequena, podem também ser utilizados no tratamento da doença de von Willebrand. O perfil protéico das frações da purificação pode ser observado no gel de poliacrilamida mostrado na Figura 23. O perfil protéico da fração de eluição do FVIII e da PC das purificações é bastante semelhante nas duas condições experimentais estudadas (canaleta 5 da Figura 21 e canaleta 6 da Figura 23).

Figura 23 - Gel de poliacrilamida 7,5\% (em condições redutoras) das frações obtidas na cromatografia de troca iônica com ANX Sepharose FF (Condição Experimental 2).

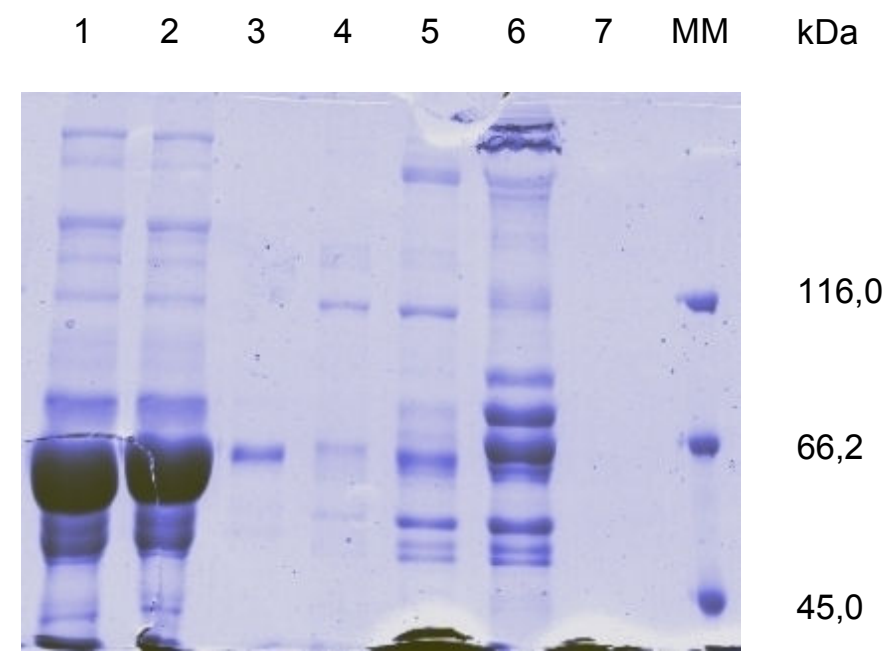

Canaletas: 1. Plasma $(78,40 \mu \mathrm{g})$; 2. FT $(67,92 \mu \mathrm{g})$; 3. Reeq $(1,52 \mu \mathrm{g}) ; 4$. A150 $(3,6 \mu \mathrm{g})$; 5. A250 $(10,4 \mu \mathrm{g}) ; 6$. A500A $(22 \mu \mathrm{g}) ; 7$. A500B $(0,4 \mu \mathrm{g})$. As amostras de plasma, FT e Reeq foram diluídas 25 vezes para que o perfil protéico pudesse ser visto. As demais amostras não foram diluídas.

FONTE:(IWASHITA, 2012)

Uma vez que não foi possível eluir as proteínas de interesse no tampão citrato com menor concentração de sal e também que o fator de purificação obtido do FVIII foi menor nesta Condição Experimental 2, as purificações com IMAC foram, então, realizadas usando-se a fração A500A obtida da purificação de plasma em coluna de ANX Sepharose FF empregando-se a Condição Experimental 1. 
Tabela 6 - Purificação de FVIII nas frações da purificação em ANX Sepharose FF (Condição Experimental 2).

\begin{tabular}{cccccccc}
\hline Amostra & $\begin{array}{c}\text { Volume da } \\
\text { fração }(\mathbf{m L})\end{array}$ & $\begin{array}{c}\text { Concentração } \\
\text { de proteínas } \\
(\mathbf{m g} / \mathbf{m L})\end{array}$ & $\begin{array}{c}\text { Proteína } \\
\text { Total } \\
(\mathbf{m g})\end{array}$ & $\begin{array}{c}\text { Atividade } \\
\text { total }(\mathbf{U})\end{array}$ & $\begin{array}{c}\text { \% de atividade } \\
\text { recuperada }\end{array}$ & $\begin{array}{c}\text { Atividade } \\
\text { Específica } \\
(\text { U/mg) }\end{array}$ & $\begin{array}{c}\text { Fator de } \\
\text { Purificação }\end{array}$ \\
\hline Plasma & 716,7 & 78,40 & 56186,6 & 74688 & 100 & 1,3 \\
\hline FT & 716,7 & 67,92 & 48681,5 & 2880 & 3,9 & - \\
\hline Reeq. & 716,7 & 1,52 & 1087,2 & -836 & - & - \\
\hline A150 & 716,7 & 0,18 & 128,5 & -571 & - & - \\
\hline A250 & 322,5 & 0,52 & 167,0 & -450 & - & - \\
\hline A500A & 322,5 & 1,10 & 355,4 & 39762 & 53,2 & 111,9 \\
\hline A500B & 83,0 & 0,02 & 2,0 & 1302 & 1,7 & 65,1 \\
\hline
\end{tabular}

FONTE:(IWASHITA, 2012)

Tabela 7 - Purificação de PC nas frações da purificação em ANX Sepharose FF (Condição Experimental 2).

\begin{tabular}{|c|c|c|c|c|c|c|c|}
\hline Amostra & $\begin{array}{l}\text { Volume da } \\
\text { Fração (mL) }\end{array}$ & $\begin{array}{l}\text { Concentração } \\
\text { de proteínas } \\
\text { (mg/mL) }\end{array}$ & $\begin{array}{l}\text { Proteína } \\
\text { Total (MG) }\end{array}$ & $\begin{array}{l}\text { Atividade } \\
\text { total (U) }\end{array}$ & $\begin{array}{l}\% \text { de atividade } \\
\text { recuperada }\end{array}$ & $\begin{array}{c}\text { Atividade } \\
\text { Específica } \\
\text { (U/mg) }\end{array}$ & $\begin{array}{c}\text { Fator de } \\
\text { Purificação }\end{array}$ \\
\hline Plasma & 716,7 & 78,4 & 56186,6 & 70734 & 100 & 1,2 & 1,0 \\
\hline $\mathbf{F T}$ & 716,7 & 67,92 & 48681,5 & 23783 & 34 & 0,5 & 0,4 \\
\hline Reeq. & 716,7 & 1,52 & 1087,2 & 2574 & 4 & 2,4 & 2,0 \\
\hline A150 & 716,7 & 0,18 & 128,5 & 380 & 1 & 3,0 & 2,5 \\
\hline$A 250$ & 322,5 & 0,52 & 167 & 1422 & 2 & 8,5 & 7,1 \\
\hline A500A & 322,5 & 1,1 & 355,4 & 77113 & 109 & 217 & 180,8 \\
\hline A500B & 83,0 & 0,02 & 2,0 & 180 & 0,25 & 90 & 75 \\
\hline
\end{tabular}

FONTE:(IWASHITA, 2012) 


\subsection{Purificação com IMAC-Cu ${ }^{2+}$}

Inicialmente foram realizados estudos utilizando imidazol para dessorver as proteínas. Somente com os metais em que os resultados foram considerados bons foram estudadas a dessorção com variação de $\mathrm{pH}$ e diferentes concentrações de $\mathrm{NH}_{4} \mathrm{Cl}$. Além disso, para estes metais testou-se utilizar a coluna Chelating Sepharose FF de $10 \mathrm{~mL}$.

\subsubsection{IMAC-Cu${ }^{2+}$ empregando coluna HisTrap HP de $5 \mathrm{~mL}$ e dessorção com imidazol}

Os resultados obtidos neste experimento estão mostrados nas tabelas 8 e 9 e na Figura 24. As curvas de calibração para determinação das atividades de FVIII e PC e para determinação da concentração de proteínas encontram-se no ANEXO C. A PC foi eluída com tampão citrato contendo $10 \mathrm{mM}$ de imidazol, enquanto que o FVIII, com $200 \mathrm{mM}$ de imidazol. Boa parte das proteínas contaminantes foram eliminadas nas frações contendo 30 e $50 \mathrm{mM}$ de imidazol, o que possibilitou o aumento da pureza das 2 proteínas. O fator de purificação do FVIII foi de 7,9 e da PC 3,2 vezes.

Figura 24 - Atividade de FVIII e PC (A) e proteína total (B) nas frações da purificação em IMAC-Cu ${ }^{2+}$ empregando coluna HisTrap HP de $5 \mathrm{~mL}$ e dessorção com imidazol.

(A)

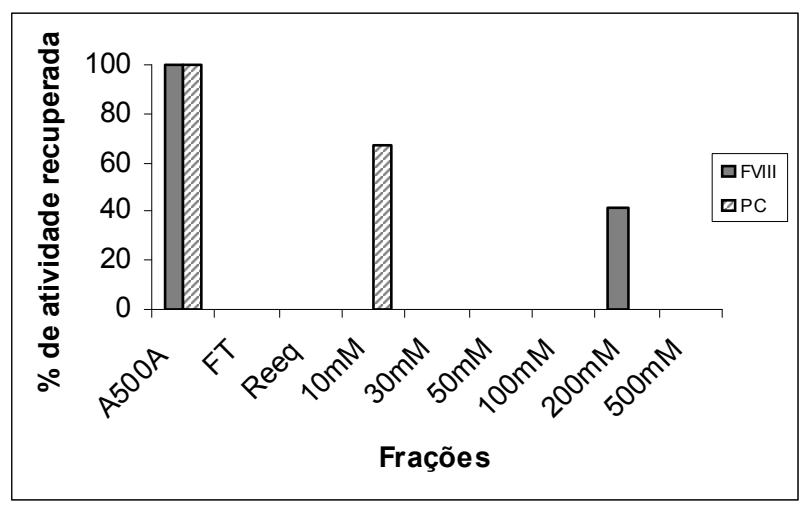

(B)

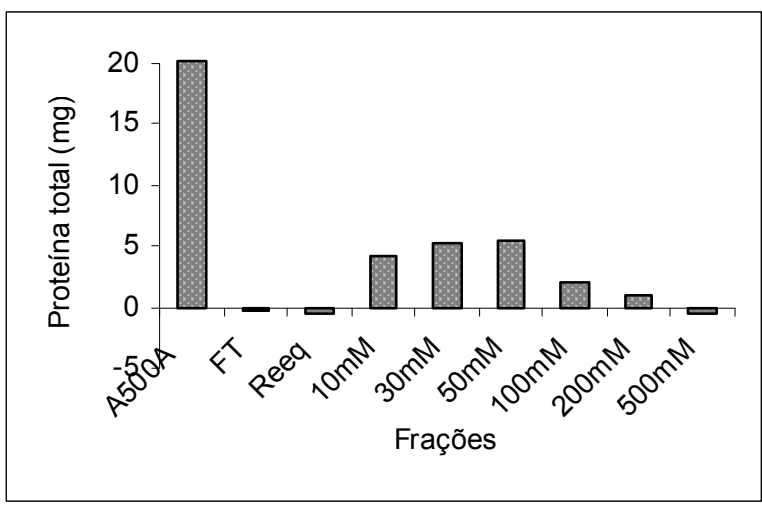

As frações recolhidas foram: FT (proteínas que não se ligam à coluna), Reeq. (lavagem das proteínas que não se ligam à coluna), $10 \mathrm{mM}, 30 \mathrm{mM}, 50 \mathrm{mM}, 100$ $\mathrm{mM}, 200 \mathrm{mM}$ e $500 \mathrm{mM}$, que correspondem às concentrações de imidazol no tampão citrato $25 \mathrm{mM}$ contendo $\mathrm{NaCl} 500 \mathrm{mM}$, pH 6,0 utilizadas na lavagem e eluição das proteínas de interesse.

FONTE:(IWASHITA, 2012) 
Tabela 8 - Purificação de FVIII em IMAC- $\mathrm{Cu}^{2+}$ empregando coluna HisTrap HP de $5 \mathrm{~mL}$ e dessorção com imidazol.

\begin{tabular}{cccccccc}
\hline & $\begin{array}{c}\text { Volume da } \\
\text { Amostra }\end{array}$ & $\begin{array}{c}\text { Concentração } \\
\text { de proteínas } \\
(\mathbf{m g} / \mathbf{m L})\end{array}$ & $\begin{array}{c}\text { Proteína } \\
\text { total }(\mathbf{m g})\end{array}$ & $\begin{array}{c}\text { Atividade } \\
\text { total (U) }\end{array}$ & $\begin{array}{c}\text { \% de } \\
\text { Recuperação }\end{array}$ & $\begin{array}{c}\text { Atividade } \\
\text { Específica } \\
(\mathbf{U} / \mathbf{m g})\end{array}$ & $\begin{array}{c}\text { Fator de } \\
\text { Purificação }\end{array}$ \\
\hline $\mathbf{A 5 0 0 A}$ & 25 & 0,81 & 20,24 & 1915,7 & 100,0 & 94,6 & 1,0 \\
\hline $\mathbf{F T}$ & 25 & $-0,01$ & $-0,24$ & $-148,6$ & - & - & - \\
\hline Reeq & 75 & $-0,01$ & $-0,62$ & $-424,3$ & - & - & - \\
\hline $\mathbf{1 0 m M}$ & 75 & 0,06 & 4,19 & $-424,3$ & - & - & - \\
\hline $\mathbf{3 0 m M}$ & 75 & 0,07 & 5,32 & $-424,3$ & - & - & - \\
\hline $\mathbf{5 0 m M}$ & 75 & 0,07 & 5,50 & $-424,3$ & - & - & - \\
\hline $\mathbf{1 0 0 m M}$ & 75 & 0,03 & 2,12 & $-210,0$ & - & - & - \\
\hline $\mathbf{2 0 0 m M}$ & 75 & $-0,01$ & 1,06 & 797,1 & 41,6 & 752 & 7,9 \\
\hline $\mathbf{5 0 0 m M}$ & 75 & $-0,01$ & $-0,52$ & $-488,6$ & - & - & - \\
\hline FONTE:(IWASHITA, 2012) & & & & & &
\end{tabular}

Tabela 9 - Purificação de PC em IMAC- $\mathrm{Cu}^{2+}$ empregando coluna HisTrap HP de $5 \mathrm{ml}$ e dessorção com imidazol.

\begin{tabular}{cccccccc}
\hline Amostra & $\begin{array}{c}\text { Volume da } \\
\text { fração }(\mathbf{m L})\end{array}$ & $\begin{array}{c}\text { Concentração } \\
\text { de proteínas } \\
(\mathbf{m g} / \mathbf{m L})\end{array}$ & $\begin{array}{c}\text { Proteína } \\
\text { total }(\mathbf{m g})\end{array}$ & $\begin{array}{c}\text { Atividade } \\
\text { total (U) }\end{array}$ & $\begin{array}{c}\text { \% de } \\
\text { Recuperação }\end{array}$ & $\begin{array}{c}\text { Atividade } \\
\text { Específica } \\
(\text { U/mg) }\end{array}$ & $\begin{array}{c}\text { Fator de } \\
\text { Purificação }\end{array}$ \\
\hline $\mathbf{A 5 0 0 A}$ & 25 & 0,81 & 20,24 & 2332,6 & 100,0 & 115,2 & 1,0 \\
\hline $\mathbf{F T}$ & 25 & $-0,01$ & $-0,24$ & $-18,8$ & - & - & - \\
\hline $\mathbf{R e e q}$ & 75 & $-0,01$ & $-0,62$ & $-67,4$ & - & - & - \\
\hline $\mathbf{1 0 m M}$ & 75 & 0,06 & 4,19 & 1552,2 & 66,5 & 370,4 & 3,2 \\
\hline $\mathbf{3 0 m M}$ & 75 & 0,07 & 5,32 & $-2,2$ & - & - & - \\
\hline $\mathbf{5 0 m M}$ & 75 & 0,07 & 5,50 & $-56,5$ & - & - & - \\
\hline $\mathbf{1 0 0 m M}$ & 75 & 0,03 & 2,12 & $-67,4$ & - & - & - \\
\hline $\mathbf{2 0 0 m M}$ & 75 & $-0,01$ & 1,06 & $-78,3$ & - & - & - \\
\hline $\mathbf{5 0 0 m M}$ & 75 & $-0,01$ & $-0,52$ & $-67,4$ & - & - & - \\
\hline
\end{tabular}

FONTE:(IWASHITA, 2012) 


\subsubsection{IMAC-Cu${ }^{2+}$ empregando coluna Chelating Sepharose FF de $10 \mathrm{~mL}$ e dessorção com imidazol}

Uma coluna Chelating Sepharose FF de $10 \mathrm{~mL}$ foi testada. Esta é uma resina também usada para cromatografia de afinidade a metal, mas seu grupo ligante (acido imidodiacético) é diferente ao grupo ligante das colunas HiTrap IMAC, cujo ligante, segundo o fabricante das 2 colunas (GE Healthcare), tem afinidade muito maior aos metais e sua estrutura é segredo industrial.

Os resultados obtidos neste experimento estão mostrados nas tabelas $10 \mathrm{e}$ 11 e na Figura 25. As curvas de calibração para determinação das atividades de FVIII e PC e para determinação da concentração de proteínas encontram-se no ANEXO D. Em todas as frações recolhidas havia atividade de FVIII, sendo em maior porcentagem na fração eluída com 200 mM de imidazol. A PC por sua vez se liga fracamente à coluna e eluiu com imidazol $10 \mathrm{mM}$. A maior parte das proteínas são encontradas na fração eluída com imidazol $10 \mathrm{mM}$.

$\mathrm{Na}$ coluna HisTrap HP a fração contendo imidazol 30 mM e 50 mM eram as frações com maior concentração de proteína. Na coluna Chelating Sepharose FF a maior parte das proteínas ligaram-se mais fracamente e eluiam na mesma fração da PC (imidazol $10 \mathrm{mM}$ ), diminuindo a atividade específica desta proteína. A diferença de afinidade das proteínas pelo metal pode ser explicada pela diferença da estrutura dos grupos ligantes das 2 resinas.

Figura 25 - Atividade de FVIII e PC (A) e proteína total (B) nas frações da purificação em IMAC-Cu ${ }^{2+}$ empregando coluna Chelating Sepharose FF de 10 mLe dessorção com imidazol.

(A)

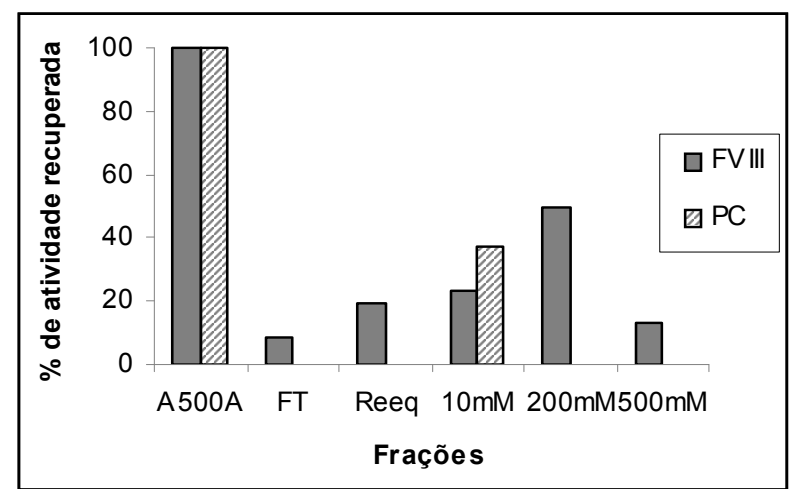

(B)

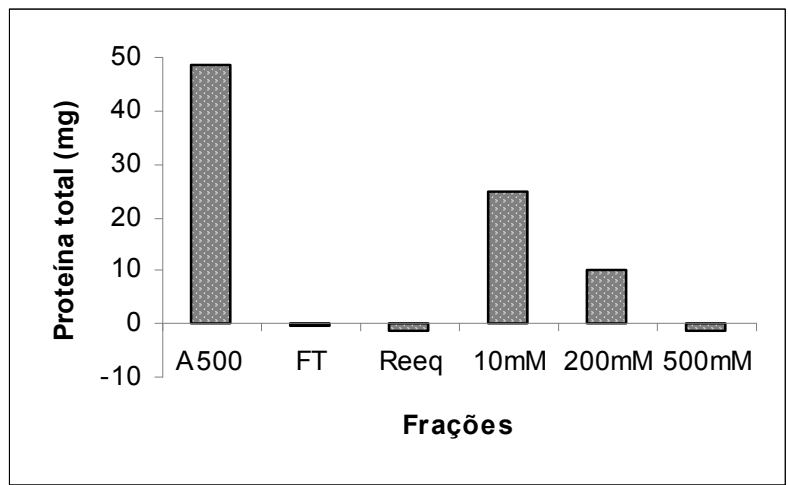

As frações recolhidas foram: FT (proteínas que não se ligam à coluna), Reeq. (lavagem das proteínas que não se ligam à coluna), $10 \mathrm{mM}, 200 \mathrm{mM}$ e $500 \mathrm{mM}$, que correspondem às concentrações de imidazol no tampão citrato $25 \mathrm{mM}$ contendo $\mathrm{NaCl} 500 \mathrm{mM}, \mathrm{pH} 6,0$ utilizados na lavagem e eluição das proteínas de interesse.

FONTE: (IWASHITA, 2012) 
Tabela 10 - Purificação de FVIII empregando coluna Chelating Sepharose FF- $\mathrm{Cu}^{2+}$ de $10 \mathrm{mLe}$ dessorção com imidazol.

\begin{tabular}{cccccccc}
\hline & $\begin{array}{c}\text { Volume } \\
\text { da fração } \\
(\mathbf{m L})\end{array}$ & $\begin{array}{c}\text { Concentração } \\
\text { de proteinas } \\
\mathbf{( m g / m L}\end{array}$ & $\begin{array}{c}\text { Proteína } \\
\text { total } \\
\mathbf{( m g )}\end{array}$ & $\begin{array}{c}\text { Atividade } \\
\text { total (U) }\end{array}$ & $\begin{array}{c}\text { \% de } \\
\text { Recuperação }\end{array}$ & $\begin{array}{c}\text { Atividade } \\
\text { Específica } \\
\text { (U/mg) }\end{array}$ & $\begin{array}{c}\text { Fator de } \\
\text { Purificação }\end{array}$ \\
\hline $\mathbf{A 5 0 0}$ & 50,0 & 0,97 & 48,5 & 6593,1 & 100,0 & 136 & 1,0 \\
\hline $\mathbf{F T}$ & 50,0 & $-0,01$ & $-0,3$ & 551,4 & 8,4 & - & - \\
\hline Reeq & 150 & $-0,01$ & $-1,4$ & 1279,2 & 19,4 & - & - \\
\hline $\mathbf{1 0 m M}$ & 150 & 0,17 & 24,8 & 1529,2 & 23,2 & 62 & 0,4 \\
\hline $\mathbf{2 0 0} \mathbf{m M}$ & 150 & 0,07 & 10,1 & 3279,2 & 49,7 & 324 & 2,3 \\
\hline $\mathbf{5 0 0 m M}$ & 150 & $-0,01$ & $-1,25$ & 862,5 & 13,1 & - & - \\
\hline
\end{tabular}

FONTE: (IWASHITA, 2012)

Tabela 11 - Purificação de PC empregando coluna Chelating Sepharose FF- $\mathrm{Cu}^{2+}$ de $10 \mathrm{~mL}$ e dessorção com imidazol.

\begin{tabular}{cccccccc}
\hline & $\begin{array}{c}\text { Volume da } \\
\text { fração }(\mathbf{m L})\end{array}$ & $\begin{array}{c}\text { Concentração } \\
\text { de proteínas } \\
(\mathbf{m g} / \mathbf{m L})\end{array}$ & $\begin{array}{c}\text { Proteína } \\
\text { total } \\
(\mathbf{m g})\end{array}$ & $\begin{array}{c}\text { Atividade } \\
\text { total (U) }\end{array}$ & $\begin{array}{c}\text { \% de } \\
\text { Recuperação }\end{array}$ & $\begin{array}{c}\text { Atividade } \\
\text { Específica } \\
(\mathbf{U} / \mathbf{m g})\end{array}$ & $\begin{array}{c}\text { Fator de } \\
\text { Purificação }\end{array}$ \\
\hline $\mathbf{A 5 0 0}$ & 50,0 & 0,97 & 48,5 & 2194,8 & 100,0 & 45 & 1,0 \\
\hline $\mathbf{F T}$ & 50,0 & $-0,01$ & $-0,3$ & $-366,6$ & - & - & - \\
\hline Reeq & 150 & $-0,01$ & $-1,4$ & $-1090,5$ & - & - & - \\
\hline $\mathbf{1 0 M m}$ & 150 & 0,17 & 24,8 & 814,4 & 37,1 & 33 & 0,7 \\
\hline $\mathbf{2 0 0 m M}$ & 150 & 0,07 & 10,125 & $-1099,7$ & - & - & - \\
\hline $\mathbf{5 0 0 m M}$ & 150 & $-0,01$ & $-1,25$ & $-1108,9$ & - & - & - \\
\hline
\end{tabular}

FONTE: (IWASHITA, 2012) 


\subsubsection{IMAC-Cu ${ }^{2+}$ empregando coluna HiTrap IMAC HP de $1 \mathrm{~mL}$ e variação de $\mathrm{pH}$}

Como os estudos de IMAC-Cu ${ }^{2+}$ empregando imidazol para dessorção das proteínas apresentaram bons resultados, decidiu-se prosseguir os estudos utilizando variação de $\mathrm{pH}$ e diferentes concentrações de $\mathrm{NH}_{4} \mathrm{Cl}$ para dessorção das proteínas.

Os resultados estão mostrados nas tabelas 1213 e na Figura 26. As curvas de calibração para determinação das atividades de FVIII e PC e para determinação da concentração de proteínas encontram-se no ANEXO E. Foi observada uma pequena atividade de $\mathrm{FVIII}$ no $\mathrm{FT}$, mas não houve recuperação da atividade em nenhuma fração de lavagem. A PC somente foi recuperada quando se adicionou EDTA ao tampão. A figura 12B mostra que somente $50 \%$ das proteínas foram recuperadas e na presença de EDTA.

Figura 26 - Atividade de FVIII e PC (A) e Proteína total (B) da purificação em MAC$\mathrm{Cu}^{2+}$ empregando coluna HiTrap IMAC HP de $1 \mathrm{~mL}$ e variação de $\mathrm{pH}$.

(A)

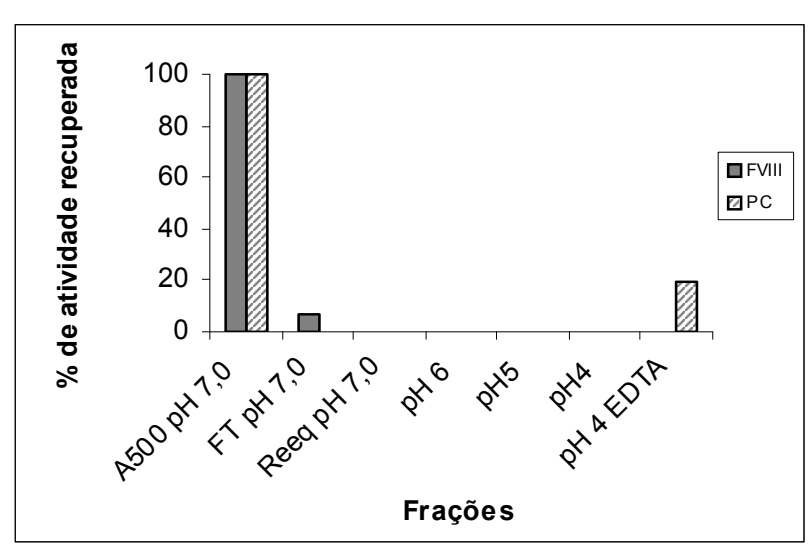

(B)

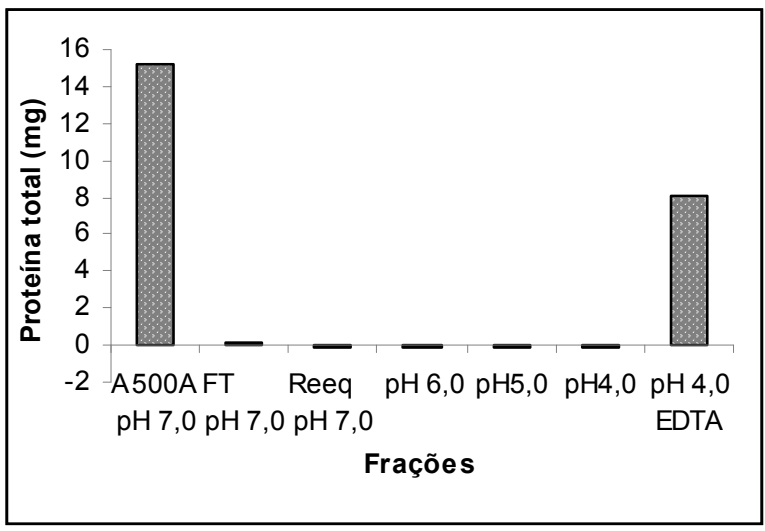

As frações foram recolhidas utilizando variação decrescente de $\mathrm{pH}$, de $\mathrm{pH} 7,0$ a pH 4,0. Também foi feita uma lavagem com tampão em pH 4,0 contendo EDTA.

FONTE: (IWASHITA, 2012)

A ausência de atividade de FVIII nas frações pode ser explicada pelo fato de a proteína não ser estável no $\mathrm{pH}$ de dessorção, pois este fator de coagulação liga-se muito fortemente ao $\mathrm{Cu}^{2+}$. Resultado semelhante ao da PC foi observado por Vançan et al. (2002) durante a purificação de $\operatorname{lgG}$ em colunas de afinidade a metal. Em coluna de afinidade a $\mathrm{Cu}^{2+}$ esta proteína somente foi recuperada na presença de EDTA. Portanto, este método não foi eficiente para a separação de FVIII e PC. 
Tabela 12 - Purificação de FVIII em IMAC- $\mathrm{Cu}^{2+}$ empregando coluna HiTrap IMAC HP de 1 mL e variação de pH.

\begin{tabular}{ccccccc} 
Volume da & $\begin{array}{c}\text { Concentração } \\
\text { de proteínas } \\
\text { Amostra }\end{array}$ & $\begin{array}{c}\text { Proteína } \\
\text { fração }(\mathbf{m L})\end{array}$ & $\begin{array}{c}\text { Atividade } \\
\text { total (U) }\end{array}$ & $\begin{array}{c}\text { \% de } \\
\text { Recuperação }\end{array}$ & $\begin{array}{c}\text { Atividade } \\
\text { Específica } \\
\text { (U/mg) }\end{array}$ & $\begin{array}{c}\text { Fator de } \\
\text { Purificação }\end{array}$ \\
\hline A500 pH 7,0 & 9,6 & 1,59 & 15,25 & 1274 & 100,0 & 83,5 \\
\hline FT pH 7,0 & 9,6 & 0,02 & 0,18 & 86 & 6,8 & 477 \\
\hline Reeq pH 7,0 & 24,0 & 0,00 & $-0,09$ & - & - & - \\
\hline pH 6 & 24,0 & $-0,01$ & $-0,16$ & - & - & - \\
\hline pH5 & 24,0 & $-0,01$ & $-0,13$ & - & - & - \\
\hline pH4 & 24,0 & $-0,01$ & $-0,17$ & - & - & - \\
\hline pH 4 EDTA & 24,0 & 0,34 & 8,09 & - & - & - \\
\hline
\end{tabular}

FONTE: (IWASHITA, 2012)

Tabela 13 - Purificação de PC em IMAC- $\mathrm{Cu}^{2+}$ empregando coluna HiTrap IMAC HP de 1 mL e variação de pH.

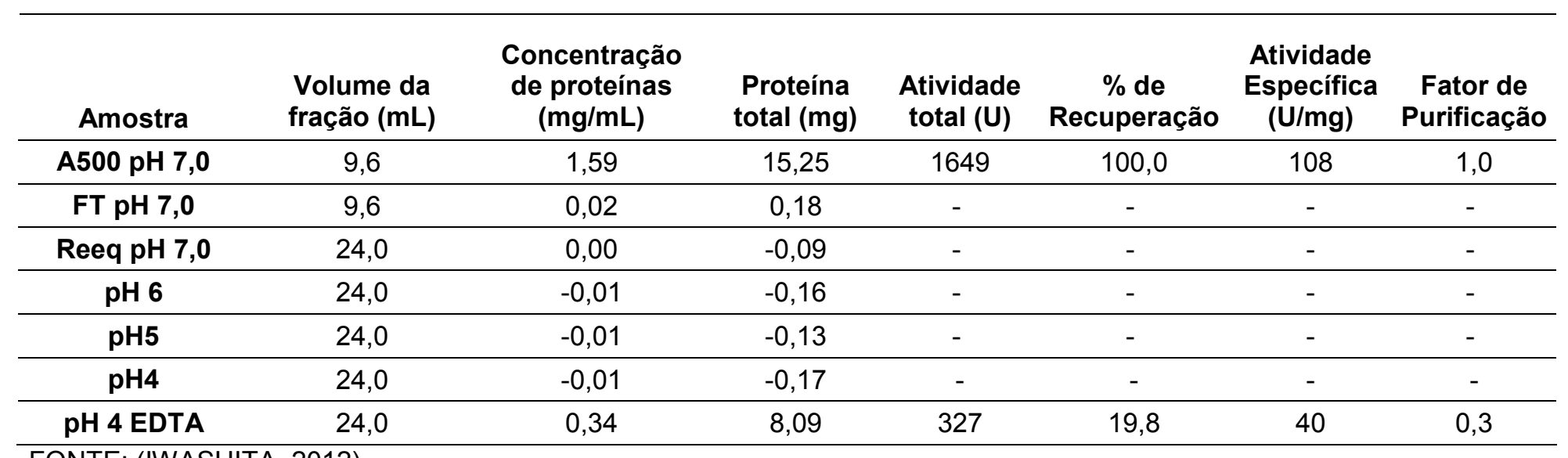

FONTE: (IWASHITA, 2012) 


\subsubsection{IMAC-Cu ${ }^{2+}$ empregando coluna HiTrap IMAC HP de $1 \mathrm{~mL}$ e dessorção $\operatorname{com~} \mathrm{NH}_{4} \mathrm{Cl}$}

Neste estudo de IMAC-Cu${ }^{2+}$ empregando $\mathrm{NH}_{4} \mathrm{Cl}$ para a dessorção de FVIII, também não houve recuperação de atividade de FVIII. Não foi observada atividade de FVIII (Tabela 14 e Figura 27A) e presença de proteínas nas frações lavadas com concentrações crescentes de $\mathrm{NH}_{4} \mathrm{Cl}$, as proteínas adsorvidas na coluna foram eluídas somente na presença de EDTA (Figura 27B).

As curvas de calibração para determinação das atividades de FVIII e PC e para determinação da concentração de proteínas encontram-se no ANEXO F.

Desta forma, $\mathrm{NH}_{4} \mathrm{Cl}$ não foi eficiente para recuperar o $\mathrm{FVIII} \mathrm{da} \mathrm{coluna} \mathrm{até} \mathrm{a}$ concentração de $1 \mathrm{M}$. Aumentar ainda mais a concentração de sal poderia resultar na precipitação das proteínas.

Figura 27 - Atividade de FVIII (A) e Proteína total (B) das frações da purificação em MAC- $\mathrm{Cu}^{2+}$ empregando coluna HiTrap IMAC HP de $1 \mathrm{~mL}$ e tampão citrato com concentrações crescentes de $\mathrm{NH}_{4} \mathrm{Cl}$.

(A)

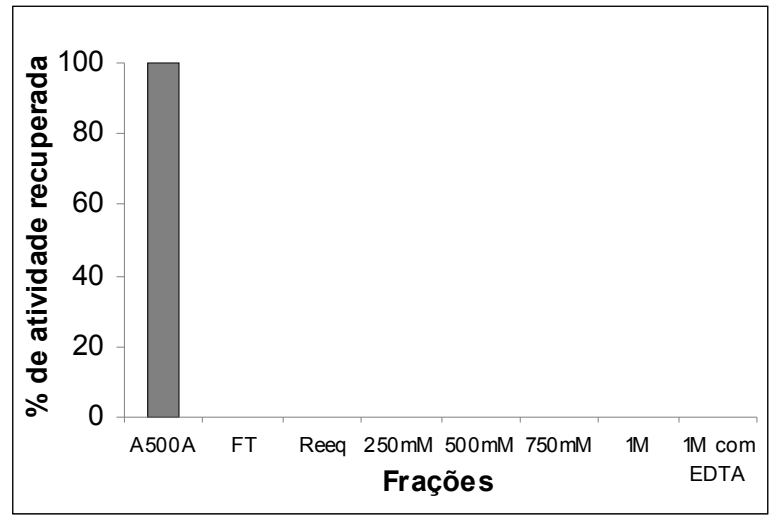

(B)

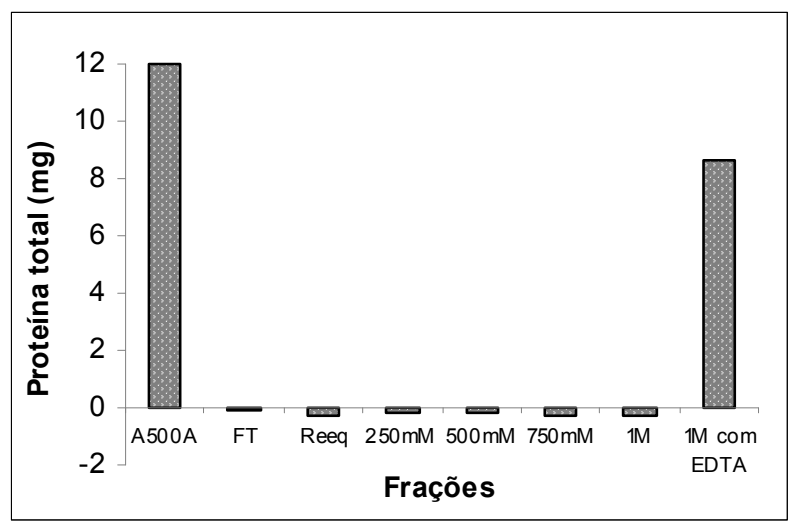

As frações recolhidas foram: FT (proteínas que não se ligam à coluna), Reeq. (lavagem das proteínas que não se ligam à coluna), $250 \mathrm{mM}, 500 \mathrm{mM}, 750 \mathrm{mM}$ e $1 \mathrm{M}$ que correspondem às concentrações de $\mathrm{NH}_{4} \mathrm{Cl}$ no tampão citrato $25 \mathrm{mM}$ contendo $\mathrm{NaCl} 500$ mM, pH 6,0 utilizadas para lavagem e eluição das proteínas. Também foi feita uma lavagem com tampão citrato $25 \mathrm{mM}$ contendo $\mathrm{NaCl} 500 \mathrm{mM}, \mathrm{NH}_{4} \mathrm{Cl} 1 \mathrm{M}$ e EDTA 50mM, pH 6,0.

FONTE: (IWASHITA, 2012) 
Tabela 14 - Purificação de FVIII em IMAC- $\mathrm{Cu}^{2+}$ empregando coluna HiTrap IMAC HP de 1 mL e tampão citrato com concentrações crescentes $\mathrm{NH}_{4} \mathrm{Cl}$.

\begin{tabular}{cccccccc}
\hline Amostra & $\begin{array}{c}\text { Volume da } \\
\text { fração }(\mathbf{m L})\end{array}$ & $\begin{array}{c}\text { Concentração } \\
\text { de proteínas } \\
(\mathbf{m g} / \mathbf{m L})\end{array}$ & $\begin{array}{c}\text { Proteína } \\
\text { total }(\mathbf{m g})\end{array}$ & $\begin{array}{c}\text { Atividade } \\
\text { total (U) }\end{array}$ & $\begin{array}{c}\text { \% de } \\
\text { Recuperação }\end{array}$ & $\begin{array}{c}\text { Atividade } \\
\text { Específica } \\
(\mathbf{U} / \mathbf{m g})\end{array}$ & $\begin{array}{c}\text { Fator de } \\
\text { Purificação }\end{array}$ \\
\hline A500A & 12,5 & 0,96 & 12,0 & 1047 & 100 & 87 & 1,0 \\
\hline FT & 12,5 & $-0,01$ & $-0,1$ & - & - & - & - \\
\hline Reeq & 25 & $-0,01$ & $-0,2$ & - & - & - & - \\
\hline $\mathbf{2 5 0 m M}$ & 24 & $-0,01$ & $-0,2$ & - & - & - & - \\
\hline $\mathbf{5 0 0 m M}$ & 26 & $-0,01$ & $-0,2$ & - & - & - & - \\
\hline $\mathbf{7 5 0 m M}$ & 27 & $-0,01$ & $-0,3$ & - & - & - & - \\
\hline $\mathbf{1 M}$ & 25 & $-0,01$ & $-0,3$ & - & - & - & - \\
\hline $\mathbf{1 M}$ com EDTA & 20 & 0,43 & 8,6 & - & - & - & - \\
\hline
\end{tabular}

FONTE: (IWASHITA, 2012) 


\subsection{Purificação com IMAC-Ni ${ }^{2+}$}

A presença de um número grande de resíduos de histidina na seqüência do FVIII e o fato da coluna HisTrap HP ser a mais comumente utilizada para a purificação de proteínas recombinantes indicavam que esta coluna poderia ser eficiente para a separação desejada.

Os resultados deste experimento estão mostrados na Figura 28 e nas tabelas 15 e 16. As curvas de calibração para determinação das atividades de FVIII e PC e para determinação da concentração de proteínas encontram-se no ANEXO G. Podese observar que a maior porcentagem das proteínas aplicadas à coluna HisTrap HP são encontradas no reequilíbrio, isto é, não são adsorvidas na coluna. Nas frações "Reeq" e "10mM" são encontradas as maiores porcentagens de atividade do FVIII e a sua atividade específica nestas frações é menor do que a da amostra inicial A500A. A atividade da PC encontra-se somente na fração "Reeq.".

Portanto, nas condições experimentais empregadas, a ligação de ambas as proteínas com o níquel foi muito fraca e não foi possível obter uma boa separação. É possível que para que haja uma boa interação com $\mathrm{Ni}^{2+}$ seja necessário a presença de várias histidinas alinhadas ou espacialmente muito próximas entre si, requisito preenchido por proteínas recombinantes, mas não pelo FVIII ou PC.

Figura 28 - Atividade de FVIII e PC (A) e proteína total (B) nas frações da purificação em IMAC-Ni ${ }^{2+}$.

(A)

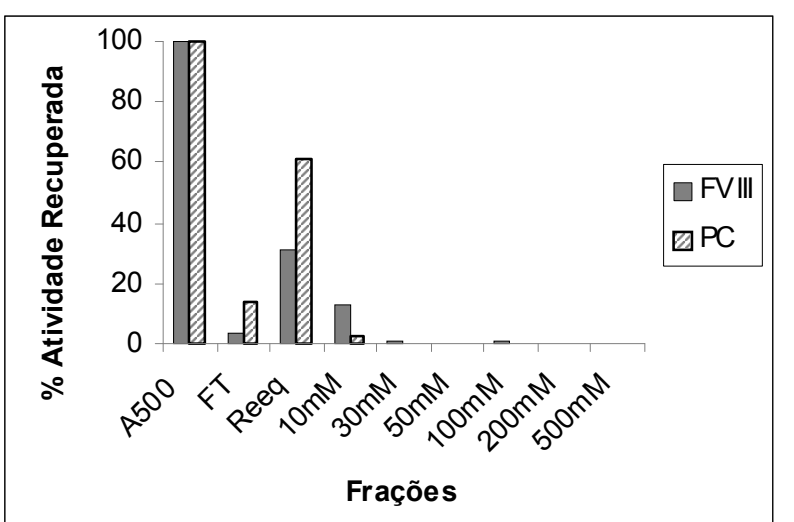

(B)

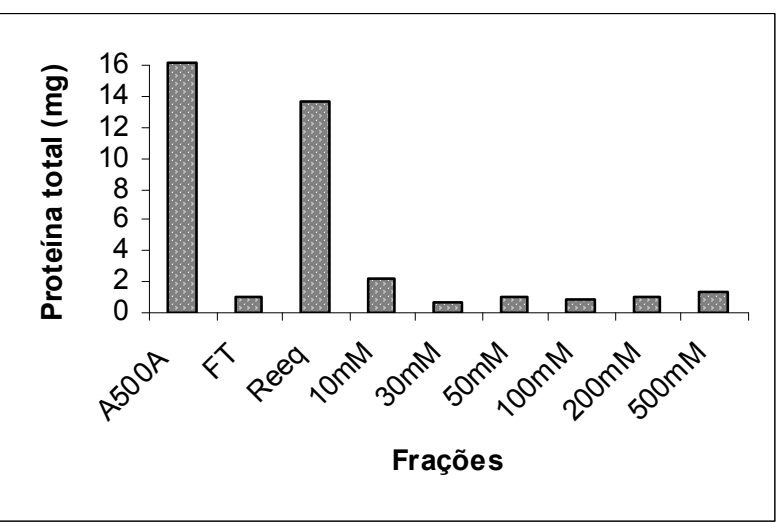

As frações recolhidas foram: FT (proteínas que não se ligam à coluna), Reeq. (lavagem das proteínas que não se ligam à coluna), $10 \mathrm{mM}, 30 \mathrm{mM}, 50 \mathrm{mM}, 100$ $\mathrm{mM}, 200 \mathrm{mM}$ e $500 \mathrm{mM}$, que correspondem às concentrações de imidazol no tampão citrato $25 \mathrm{mM}$ contendo $\mathrm{NaCl} 500 \mathrm{mM}$, pH 6,0 utilizadas na lavagem e FONTE: (IWASHITA, 2012) 
Tabela 15 - Purificação de FVIII em IMAC-Ni ${ }^{2+}$.

\begin{tabular}{cccccccc}
\hline Amostras & $\begin{array}{c}\text { Volume da } \\
\text { fração }(\mathbf{m L})\end{array}$ & $\begin{array}{c}\text { Concentração } \\
\text { de proteínas } \\
(\mathbf{m g} / \mathbf{m L})\end{array}$ & $\begin{array}{c}\text { Proteína } \\
\text { total } \\
(\mathbf{m g})\end{array}$ & $\begin{array}{c}\text { Atividade } \\
\text { total (U) }\end{array}$ & $\begin{array}{c}\text { \% de } \\
\text { Recuperação }\end{array}$ & $\begin{array}{c}\text { Atividade } \\
\text { Específica } \\
(\mathbf{U} / \mathbf{m g})\end{array}$ & $\begin{array}{c}\text { Fator de } \\
\text { Purificação }\end{array}$ \\
\hline $\mathbf{A 5 0 0}$ & 9,6 & 1,7 & 16,2 & 820 & 100 & 50,6 & \\
\hline $\mathbf{F T}$ & 9,6 & 0,1 & 1,0 & 27 & 3,29 & 27 & 0,53 \\
\hline $\mathbf{R e e q}$ & 24 & 0,6 & 13,7 & 253 & 30,88 & 18,4 & 0,36 \\
\hline $\mathbf{1 0} \mathbf{m M}$ & 10 & 0,2 & 2,3 & 105 & 12,87 & 45,6 & 0,90 \\
\hline $\mathbf{3 0 m M}$ & 10 & 0,1 & 0,7 & 9 & 1,06 & 12,8 & 0,25 \\
\hline $\mathbf{5 0 m M}$ & 10 & 0,1 & 1,0 & 2 & 0,28 & 2,4 & 0,05 \\
\hline $\mathbf{1 0 0 m M}$ & 10 & 0,1 & 0,8 & 5 & 0,67 & 6,5 & 0,12 \\
\hline $\mathbf{2 0 0 m M}$ & 10 & 0,1 & 1,0 & 2 & 0,28 & 2,0 & 0,03 \\
\hline $\mathbf{5 0 0 m M}$ & 10 & 0,1 & 1,3 & -4 & - & - & - \\
\hline
\end{tabular}

FONTE: (IWASHITA, 2012)

Tabela 16 - Purificação de PC em IMAC-Ni ${ }^{2+}$.

\begin{tabular}{|c|c|c|c|c|c|c|c|}
\hline Amostras & $\begin{array}{l}\text { Volume da } \\
\text { fração (mL) }\end{array}$ & $\begin{array}{c}\text { Concentração } \\
\text { de proteínas } \\
(\mathrm{mg} / \mathrm{mL})\end{array}$ & $\begin{array}{l}\text { Proteína } \\
\text { total (mg) }\end{array}$ & $\begin{array}{c}\text { Atividade } \\
\text { total (U) }\end{array}$ & $\begin{array}{c}\% \text { de } \\
\text { Recuperação }\end{array}$ & $\begin{array}{c}\text { Atividade } \\
\text { Específica } \\
\text { (U/mg) }\end{array}$ & $\begin{array}{c}\text { Fator de } \\
\text { Purificação }\end{array}$ \\
\hline A500 & 9,6 & 1,7 & 16,2 & 1281,3 & 100,0 & 79,0 & 1,0 \\
\hline FT & 9,6 & 0,1 & 1,0 & 177,9 & 13,9 & 177,9 & 2,25 \\
\hline Reeq & 24 & 0,6 & 13,7 & 778,8 & 60,8 & 56,8 & 0,71 \\
\hline $10 \mathrm{mM}$ & 10 & 0,2 & 2,3 & 33,2 & 2,6 & 14,4 & 0,18 \\
\hline $30 \mathrm{mM}$ & 10 & 0,1 & 0,7 & $-24,8$ & - & - & - \\
\hline $50 \mathrm{mM}$ & 10 & 0,1 & 1,0 & $-33,5$ & - & - & - \\
\hline $100 \mathrm{mM}$ & 10 & 0,1 & 0,8 & $-33,5$ & - & - & - \\
\hline $200 \mathrm{mM}$ & 10 & 0,1 & 1,0 & $-32,0$ & - & - & - \\
\hline $500 \mathrm{mM}$ & 10 & 0,1 & 1,3 & $-32,0$ & - & - & - \\
\hline
\end{tabular}

FONTE: (IWASHITA, 2012) 


\subsection{Purificação com IMAC- $\mathrm{Zn}^{2+}$}

\subsubsection{IMAC- $\mathrm{Zn}^{2+}$ empregando HisTrap HP de $5 \mathrm{~mL}$ e dessorção com imidazol}

Iniciamos os estudos com IMAC- $\mathrm{Zn}^{2+}$ utilizando imidazol para dessorção das proteínas. Os resultados deste experimento estão mostrado nas tabelas 17 e 18 e na Figura 29. As curvas de calibração para determinação das atividades de FVIII e PC e para determinação da concentração de proteínas encontram-se no ANEXO H. O FVIII é eluído utilizando imidazol $200 \mathrm{mM}$ e sua recuperação foi de $55 \%$. Nesta etapa o fator de purificação d FVIII foi de 5,8 vezes. A PC não se liga à matriz da coluna e sua recuperação foi de $65 \%$ no FT. A PC coeluiu com a maioria das proteínas no FT. Na fração "10 mM" também há recuperação de uma parte de proteínas, o que permite uma lavagem intermediária para que o FVIII e a PC possam ser bem separados.

Em experimentos anteriores em que várias lavagens intermediárias foram testadas, foi observado que o FVIII elui em várias frações e que a fração contendo maior atividade foi a da lavagem com imidazol $100 \mathrm{mM}$. Entretanto, a recuperação de FVIII atinge o valor de pouco mais que $50 \%$ somente se a lavagem for realizada com imidazol $200 \mathrm{mM}$.

Figura 29 - Atividade de FVIII e PC (A) e proteína total (B) nas frações obtidas na purificação em IMAC-Zn ${ }^{2+}$ empregando coluna HisTrap HP de $5 \mathrm{~mL}$ e dessorção com imidazol.

(A)

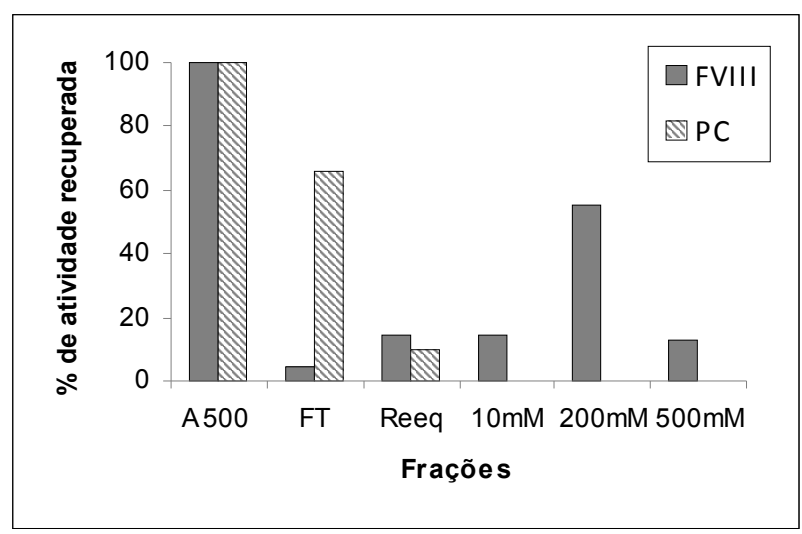

As frações recolhidas foram: FT (proteínas que não se ligam à coluna), Reeq. (lavagem das proteínas que não se ligam à coluna), 10 mM, $200 \mathrm{mM}$ e $500 \mathrm{mM}$, que correspondem às concentrações de imidazol no tampão citrato $25 \mathrm{mM}$ contendo $\mathrm{NaCl}$ $500 \mathrm{mM}, \mathrm{pH}$ 6,0 utilizadas para lavagem e eluição das proteínas.
(B)

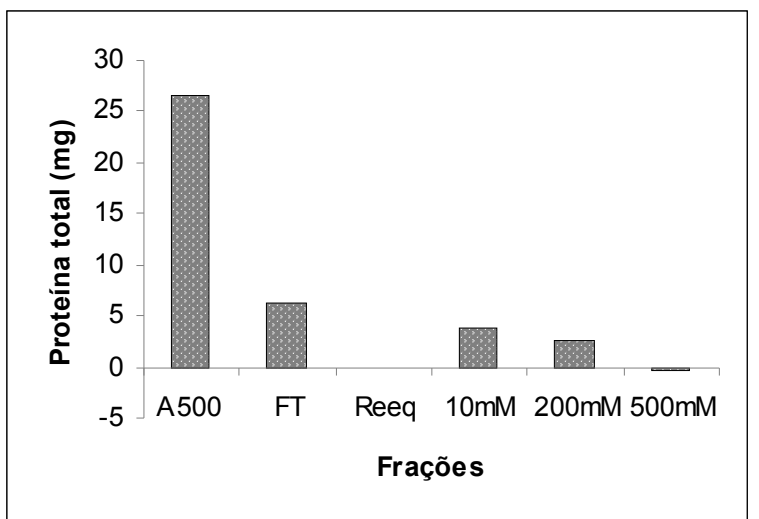

FONTE: (IWASHITA, 2012) 
Tabela 17 - Purificação de FVIII em IMAC- $\mathrm{Zn}^{2+}$ empregando coluna HisTrap HP de 5 mL e dessorção com imidazol.

\begin{tabular}{cccccccc}
\hline Amostra & $\begin{array}{c}\text { Volume da } \\
\text { fração }(\mathbf{m L})\end{array}$ & $\begin{array}{c}\text { Concentração } \\
\text { de proteínas } \\
(\mathbf{m g} / \mathbf{m L})\end{array}$ & $\begin{array}{c}\text { Proteína } \\
\text { total }(\mathbf{m g})\end{array}$ & $\begin{array}{c}\text { Atividade } \\
\text { total }(\mathbf{U})\end{array}$ & $\begin{array}{c}\text { \% de atividade } \\
\text { recuperada }\end{array}$ & $\begin{array}{c}\text { Atividade } \\
\text { Específica } \\
(\mathbf{U} / \mathbf{m g})\end{array}$ & $\begin{array}{c}\text { Fator de } \\
\text { Purificação }\end{array}$ \\
\hline $\mathbf{A 5 0 0}$ & 25,0 & 1,06 & 26,57 & 2541,7 & 100,0 & 95,6 & 1,0 \\
\hline $\mathbf{F T}$ & 25,0 & 0,25 & 6,33 & 116,7 & 4,6 & 18,4 & 0,2 \\
\hline $\mathbf{R e e q}$ & 75 & 0,00 & 0,00 & 375,0 & 14,8 & - & - \\
\hline $\mathbf{1 0} \mathbf{m M}$ & 75 & 0,05 & 3,80 & 375,0 & 14,8 & 98,6 & 1,0 \\
\hline $\mathbf{2 0 0} \mathbf{m M}$ & 75 & 0,03 & 2,51 & 1400,0 & 55,1 & 557,7 & 5,8 \\
\hline $\mathbf{5 0 0 m M}$ & 75 & $-0,01$ & $-0,43$ & 325,0 & 12,8 & - & - \\
\hline FONTE: (IWASHITA, 2012) & & & & & & &
\end{tabular}

FONTE: (IWASHITA, 2012)

Tabela 18 - Purificação de PC em IMAC- $\mathrm{Zn}^{2+}$ empregando coluna HisTrap HP de 5 mL e dessorção com imidazol.

\begin{tabular}{cccccccc}
\hline & $\begin{array}{c}\text { Volume da } \\
\text { Amostra }\end{array}$ & $\begin{array}{c}\text { Concentração } \\
\text { de proteínas } \\
(\mathbf{m g} / \mathbf{m L})\end{array}$ & $\begin{array}{c}\text { Proteína } \\
\text { total }(\mathbf{m g})\end{array}$ & $\begin{array}{c}\text { Atividade } \\
\text { total (U) }\end{array}$ & $\begin{array}{c}\text { \% de atividade } \\
\text { recuperada }\end{array}$ & $\begin{array}{c}\text { Atividade } \\
\text { Específica (U/mg) }\end{array}$ & $\begin{array}{c}\text { Fator de } \\
\text { Purificação }\end{array}$ \\
\hline $\mathbf{A 5 0 0}$ & 25,0 & 1,06 & 26,57 & 4290,9 & 100,0 & 161,5 & 1,0 \\
\hline $\mathbf{F T}$ & 25,0 & 0,25 & 6,33 & 2825,4 & 65,8 & 446,3 & 2,7 \\
\hline $\mathbf{R e e q}$ & 75 & 0,00 & 0,00 & 420,3 & 9,8 & - & - \\
\hline $\mathbf{1 0} \mathbf{m M}$ & 75 & 0,05 & 3,80 & $-187,5$ & $-4,4$ & - & - \\
\hline $\mathbf{2 0 0} \mathbf{m M}$ & 75 & 0,03 & 2,51 & $-213,4$ & $-5,0$ & - & - \\
\hline $\mathbf{5 0 0 m M}$ & 75 & $-0,01$ & $-0,43$ & $-213,4$ & $-5,0$ & - & - \\
\hline FONTE: (IWHASHITA, 2012) & & & & & & & -
\end{tabular}




\subsubsection{IMAC-Zn ${ }^{2+}$ empregando Chelating Sepharose FF de $10 \mathrm{~mL}$ e dessorção com imidazol}

Os resultados deste experimento estão mostrados nas tabelas 19 e 20 e na Figura 30. As curvas de calibração para determinação das atividades de FVIII e PC e para determinação da concentração de proteínas encontram-se no ANEXO I. A atividade de FVIII foi encontrada predominantemente nas frações FT e Reeq e a atividade de PC somente nestas duas frações. As proteínas carregadas na coluna também foram recuperadas somente no FT e no Reeq. Desta maneira, não há uma separação eficiente do FVIII e da PC.

Os resultados obtidos com $\mathrm{Zn}^{2+}$ são semelhantes aos encontrado com $\mathrm{Cu}^{2+}$, as proteínas também se ligam mais fracamente ao metal na coluna Chelating Sepharose FF em comparação com a coluna His Trap HP.

Figura 30 - Atividade de FVIII e PC (A) e proteína total $(B)$ nas frações obtidas na purificação em IMAC-Zn ${ }^{2+}$ empregando coluna Chelating Sepharose FF de $10 \mathrm{~mL}$ e dessorção com imidazol.

(A)

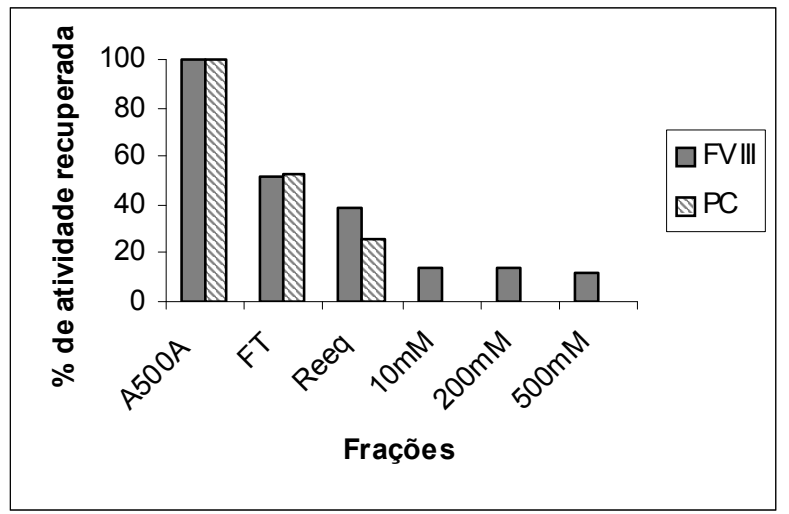

(B)

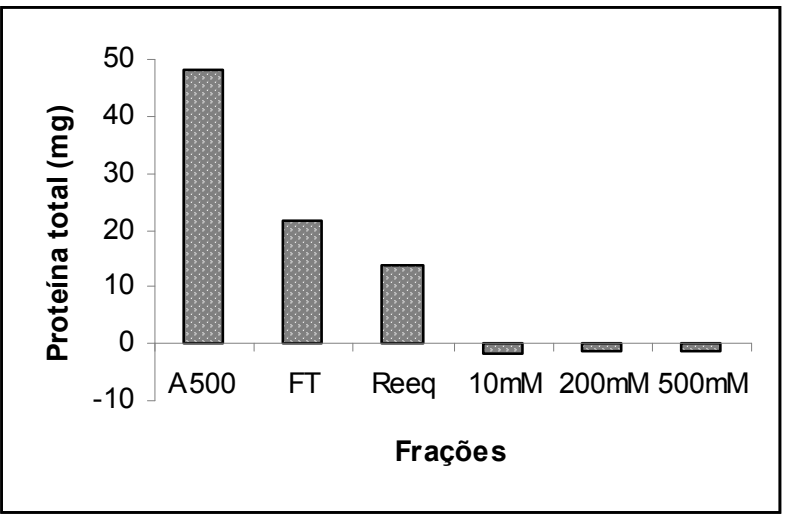

As frações recolhidas foram: FT (proteínas que não se ligam à coluna), Reeq. (lavagem das proteínas que não se ligam à coluna), $10 \mathrm{mM}, 200 \mathrm{mM}$ e $500 \mathrm{mM}$, que correspondem às concentrações de imidazol no tampão citrato $25 \mathrm{mM}$ contendo $\mathrm{NaCl}$ $500 \mathrm{mM}, \mathrm{pH}$ 6,0 utilizadas para lavagem e eluição das proteínas.

FONTE: (IWASHITA, 2012) 
Tabela 19 - Purificação de FVIII em IMAC-Zn ${ }^{2+}$ empregando coluna Chelating Sepharose FF de 10 mL e dessorção com imidazol.

\begin{tabular}{cccccccc}
\hline Amostra & $\begin{array}{c}\text { Volume da } \\
\text { fração }(\mathbf{m L})\end{array}$ & $\begin{array}{c}\text { Concentração } \\
\text { de proteínas } \\
(\mathbf{m g} / \mathbf{m L})\end{array}$ & $\begin{array}{c}\text { Proteína } \\
\text { total }(\mathbf{m g})\end{array}$ & $\begin{array}{c}\text { Atividade } \\
\text { total }(\mathbf{U})\end{array}$ & $\begin{array}{c}\text { \% de } \\
\text { Recuperação }\end{array}$ & $\begin{array}{c}\text { Atividade } \\
\text { Específica } \\
(\mathbf{U} / \mathbf{m g})\end{array}$ & $\begin{array}{c}\text { Fator de } \\
\text { Purificação }\end{array}$ \\
\hline A500A & 50 & 0,97 & 48,3 & 5454,2 & 100 & 113 & 1,0 \\
\hline FT & 50 & 0,43 & 21,6 & 2829,2 & 51,9 & 131 & 1,1 \\
\hline Reeq & 150 & 0,09 & 14,0 & 2112,5 & 38,7 & 151 & 1,3 \\
\hline $\mathbf{1 0 m M}$ & 150 & $-0,01$ & $-1,6$ & 737,5 & 13,5 & - & - \\
\hline $\mathbf{2 0 0 m M}$ & 150 & $-0,01$ & $-1,4$ & 737,5 & 13,5 & - & - \\
\hline $\mathbf{5 0 0 m M}$ & 150 & $-0,01$ & $-1,4$ & 654,2 & 12,0 & - & - \\
\hline FONTE: (IWASHITA 2012) & & & & & &
\end{tabular}

Tabela 20 - Purificação de PC em IMAC-Zn ${ }^{2+}$ empregando coluna Chelating Sepharose FF de 10 mL e dessorção com imidazol.

\begin{tabular}{|c|c|c|c|c|c|c|c|}
\hline Amostra & $\begin{array}{l}\text { Volume da } \\
\text { fração (mL) }\end{array}$ & $\begin{array}{l}\text { Concentração } \\
\text { de proteínas } \\
\text { (mg/mL) }\end{array}$ & $\begin{array}{l}\text { Proteína } \\
\text { total (mg) }\end{array}$ & $\begin{array}{l}\text { Atividade } \\
\text { total (U) }\end{array}$ & $\begin{array}{c}\% \text { de } \\
\text { Recuperação }\end{array}$ & $\begin{array}{l}\text { Atividade } \\
\text { Específica } \\
\text { (U/mg) }\end{array}$ & $\begin{array}{c}\text { Fator de } \\
\text { Purificação }\end{array}$ \\
\hline A500A & 50 & 0,97 & 48,3 & 7280 & 100 & 151 & 1,0 \\
\hline FT & 50 & 0,43 & 21,6 & 3806 & 52,28 & 176 & 1,1 \\
\hline Reeq & 150 & 0,09 & 14,0 & 1901 & 26,11 & 136 & 0,9 \\
\hline $10 \mathrm{mM}$ & 150 & $-0,01$ & $-1,6$ & -401 & - & - & - \\
\hline $200 \mathrm{mM}$ & 150 & $-0,01$ & $-1,4$ & -427 & - & - & - \\
\hline $500 \mathrm{mM}$ & 150 & $-0,01$ & $-1,4$ & -401 & - & - & - \\
\hline
\end{tabular}




\subsubsection{IMAC- $\mathrm{Zn}^{2+}$ empregando HisTrap HP de $5 \mathrm{~mL}$ e dessorção com imidazol em $\mathrm{pH} 7,0$}

Visando realizar experimentos de dessorção através da variação de pH para dessorver as proteínas, realizamos um teste inicial com imidazol, em pH 7,0 para verificar se as proteínas seriam adsorvidas. Os resultados deste experimento são mostrados nas Tabelas 21 e 22 e na Figura 31. As curvas de calibração para determinação das atividades de FVIII e PC e para determinação da concentração de proteínas encontram-se no ANEXO J. A atividade de FVIII foi encontrada em maior porcentagem na fração "50 mM" de imidazol. A atividade de PC foi encontrada nas frações Reeq. e na fração eluída com imidazol $10 \mathrm{mM}$. A maioria das proteínas foram encontradas nas frações eluídas com tampão citrato contendo imidazol,10 e $30 \mathrm{mM}$ havendo uma boa separação das duas proteínas. Este perfil é semelhante ao obtido em pH 6,0, se analisarmos em conjunto as frações "30 mM", "50mM" e "100 mM" da Tabela 20. A soma das atividades de FVIII nas 3 frações foi de 2044U, a soma das massas das proteínas $10,45 \mathrm{mg}$ resultando numa atividade específica de 195,5 e fator de purificação de 1,76 vezes.

Figura 31 - Atividade de FVIII e PC (A) e proteína total (B) nas frações obtidas a partir da purificação com IMAC-Zn ${ }^{2+}$ empregando coluna HisTrap HP de $5 \mathrm{~mL}$ e dessorção com imidazol em pH=7,0.

(A)

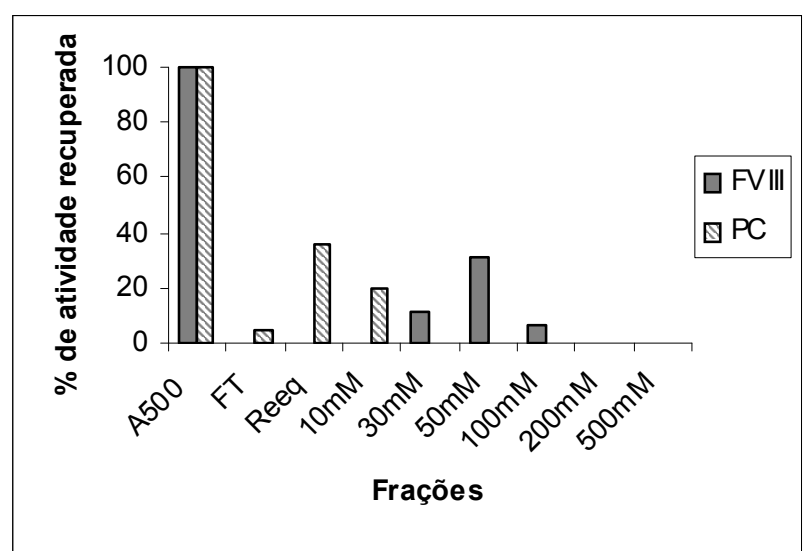

(B)

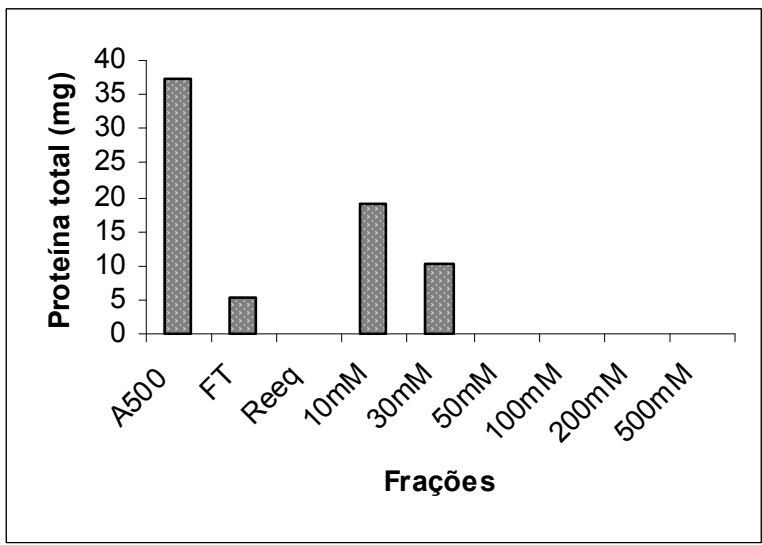

As frações recolhidas foram: FT (proteínas que não se ligam à coluna), Reeq. (lavagem das proteínas que não se ligam à coluna), $10 \mathrm{mM}, 30 \mathrm{mM}, 50 \mathrm{mM}, 100 \mathrm{mM}$, $200 \mathrm{mM}$ e $500 \mathrm{mM}$, que correspondem às concentrações de imidazol no tampão citrato $25 \mathrm{mM}$ contendo $\mathrm{NaCl} 500$ mM, pH 6,0 utilizadas na lavagem e eluição das proteínas.

FONTE: (IWASHITA, 2012) 
Tabela 21 - Purificação de FVIII em IMAC-Zn ${ }^{2+}$ empregando coluna HisTrap HP de $5 \mathrm{~mL}$ e dessorção com imidazol em pH 7,0.

\begin{tabular}{|c|c|c|c|c|c|c|c|}
\hline Amostra & $\begin{array}{c}\text { Volume } \\
\text { da fração } \\
\text { (mL) }\end{array}$ & $\begin{array}{c}\text { Concentração } \\
\text { de proteínas } \\
\text { (mg/mL) }\end{array}$ & $\begin{array}{c}\text { Proteína } \\
\text { total (mg) }\end{array}$ & $\begin{array}{c}\text { Atividade } \\
\text { total (U) }\end{array}$ & $\begin{array}{c}\% \text { de } \\
\text { Recuperação }\end{array}$ & $\begin{array}{c}\text { Atividade } \\
\text { Específica } \\
\text { (U/mg) }\end{array}$ & $\begin{array}{c}\text { Fator de } \\
\text { Purificação }\end{array}$ \\
\hline A500 & 25 & 1,5 & 37,4 & 4150 & 100 & 111 & 1,0 \\
\hline $\mathbf{F T}$ & 25 & 0,2 & 5,2 & -50 & - & - & - \\
\hline Reeq & 75 & $-0,1$ & $-9,3$ & -150 & - & - & - \\
\hline $10 \mathrm{mM}$ & 75 & 0,3 & 19,2 & -56 & - & - & - \\
\hline $30 \mathrm{mM}$ & 75 & 0,1 & 10,4 & 469 & 11 & 45,0 & 0,4 \\
\hline $50 \mathrm{mM}$ & 75 & 0,0 & 0,05 & 1294 & 31 & 25880 & 233,1 \\
\hline $100 \mathrm{mM}$ & 75 & 0,0 & $-0,4$ & 281 & 7 & - & - \\
\hline $200 \mathrm{mM}$ & 75 & 0,0 & $-0,2$ & -131 & - & - & - \\
\hline $500 \mathrm{mM}$ & 75 & 0,0 & 0,1 & -206 & - & - & - \\
\hline
\end{tabular}

Tabela 22 - Purificação de PC em IMAC-Zn ${ }^{2+}$ empregando coluna HisTrap HP de 5 mL e dessorção com imidazol em pH 7,0.

\begin{tabular}{|c|c|c|c|c|c|c|c|}
\hline Amostra & $\begin{array}{l}\text { Volume da } \\
\text { fração (mL) }\end{array}$ & $\begin{array}{c}\text { Concentração } \\
\text { de proteínas } \\
\text { (mg/mL) }\end{array}$ & $\begin{array}{l}\text { Proteína } \\
\text { total (mg) }\end{array}$ & $\begin{array}{c}\text { Atividade } \\
\text { total (U) }\end{array}$ & $\begin{array}{c}\% \text { de } \\
\text { Recuperação }\end{array}$ & $\begin{array}{c}\text { Atividade } \\
\text { Específica } \\
\text { (U/mg) }\end{array}$ & $\begin{array}{c}\text { Fator de } \\
\text { Purificação }\end{array}$ \\
\hline A500 & 25 & 1,5 & 37,4 & 4971 & 100 & 133 & 1,0 \\
\hline FT & 25 & 0,2 & 5,2 & 213 & 4 & 40,9 & 0,30 \\
\hline Reeq & 75 & $-0,1$ & $-9,3$ & 1788 & 36 & & \\
\hline $10 \mathrm{mM}$ & 75 & 0,3 & 19,2 & 963 & 19 & 50,1 & 0,37 \\
\hline $30 \mathrm{mM}$ & 75 & 0,1 & 10,4 & -613 & - & - & - \\
\hline $50 \mathrm{mM}$ & 75 & 0,0 & 0,0 & -638 & - & - & - \\
\hline $100 \mathrm{mM}$ & 75 & 0,0 & $-0,4$ & -663 & - & - & - \\
\hline $200 \mathrm{mM}$ & 75 & 0,0 & $-0,2$ & -650 & - & - & - \\
\hline $500 \mathrm{mM}$ & 75 & 0,0 & 0,1 & -675 & - & - & - \\
\hline
\end{tabular}

FONTE: (IWASHITA, 2012) 


\subsubsection{IMAC- $\mathrm{Zn}^{2+}$ empregando HisTrap HP de $5 \mathrm{~mL}$ e dessorção com variação de $\mathrm{pH}$ a partir de $\mathrm{pH} 7,0$}

Após verificar que o FVIII liga-se à coluna em $\mathrm{pH} 7,0$, foi estudada a dessorção das proteínas com variação de $\mathrm{pH}$ em IMAC- $\mathrm{Zn}^{2+}$. Os resultados deste experimento são mostrados nas Tabelas 23 e 24 e na Figura 32. As curvas de calibração para determinação das atividades de FVIII e PC e para determinação da concentração de proteínas encontram-se no ANEXO K. A atividade de FVIII foi observada apenas na fração eluída com pH 5,0, enquanto que a atividade de PC, nas frações eluídas com pH 7,0 e 6,0. A dosagem de proteína das frações mostrou que a maioria das proteínas coeluiu com o FVIII na fração em pH 5,0.

Portanto, o FVIII pode ser separado da PC variando-se o pH de eluição, embora a recuperação da atividade de FVIII tenha sido baixa, provavelmente porque esta proteína seja menos estável neste $\mathrm{pH}$ do que em $\mathrm{pHs}$ mais próximos do $\mathrm{pH}$ neutro. É interessante notar que a fração que apresenta o maior conteúdo proteico é a fração pH 5,0, razão pela qual a atividade específica do FVIII nesta fração é menor do que na fração A500A. A diminuição da atividade específica e da atividade de FVIII indicam que este método de purificação não é apropriado para a purificação desta proteína. Por outro lado, se as 3 primeiras frações fossem coletadas juntas a recuperação de atividade de PC seria de $73 \%$ e o fator de purificação de 1,7 vezes. Isto indica que este método foi mais adequado para a purificação de PC.

Figura 32 - Atividade FVIII e PC (A) e proteína total (B) nas frações obtidas na purificação em IMAC-zinco, utilizando tampões em diferentes $\mathrm{pH}$ para dessorção das proteínas.

(A)

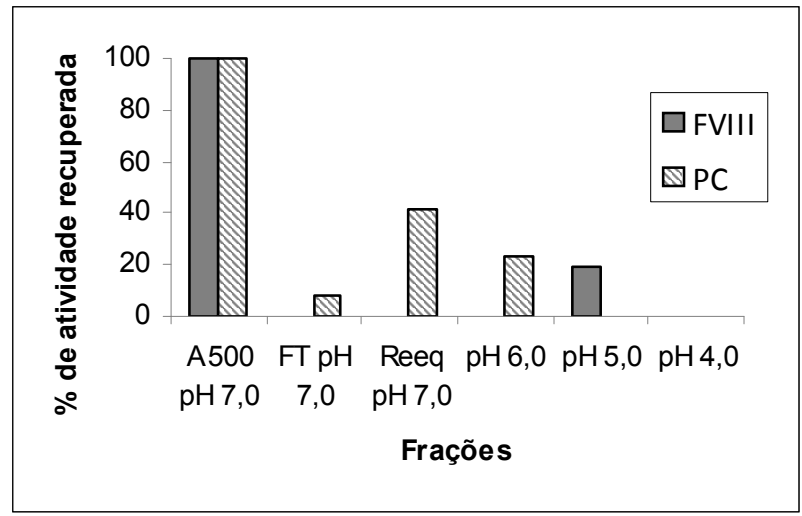

(B)

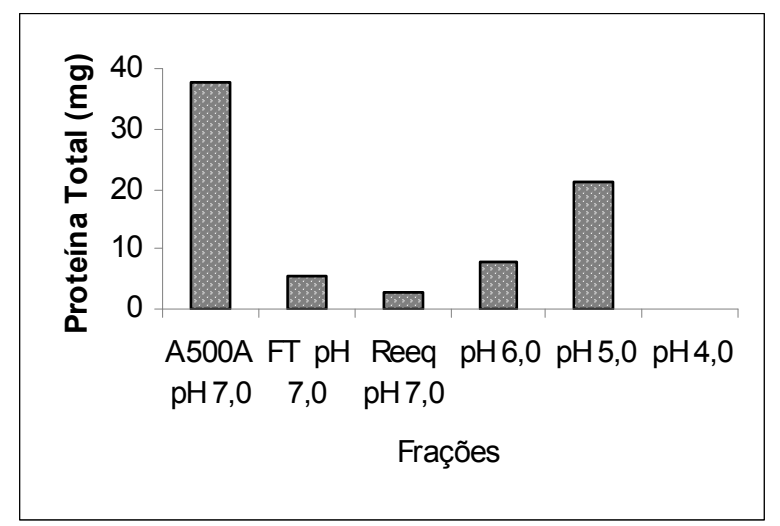

As frações foram recolhidas de acordo com a variação decrescente de $\mathrm{pH}$, de $\mathrm{pH}$ 7,0 a pH 4,0 no tampão citrato $25 \mathrm{mM}$, contendo $\mathrm{CaCl}_{2} 5 \mathrm{mM}$ e NaCl $500 \mathrm{mM}$.

FONTE: (IWASHITA, 2012) 
Tabela 23 - Purificação de FVIII em IMAC-Zn ${ }^{2+}$ empregando coluna HisTrap de $5 \mathrm{~mL}$ e dessorção com variação de pH a partir de $\mathrm{pH} 7,0$.

\begin{tabular}{cccccccc} 
Amostra & $\begin{array}{c}\text { Volume } \\
\text { da fração } \\
(\mathbf{m L})\end{array}$ & $\begin{array}{c}\text { Concentração } \\
\text { de proteínas } \\
(\mathbf{m g} / \mathbf{m L})\end{array}$ & $\begin{array}{c}\text { Proteína } \\
\text { total }(\mathbf{m g})\end{array}$ & $\begin{array}{c}\text { Atividade } \\
\text { total (U) }\end{array}$ & $\begin{array}{c}\text { \% de } \\
\text { Recuperação }\end{array}$ & $\begin{array}{c}\text { Atividade } \\
\text { Específica } \\
\mathbf{( U / m g )}\end{array}$ & $\begin{array}{c}\text { Fator de } \\
\text { Purificação }\end{array}$ \\
\hline A500A & 25 & 1,51 & 37,76 & 3981,3 & 100 & 105,4 & 1,0 \\
\hline FT & 25 & 0,22 & 5,57 & $-43,8$ & - & - & - \\
\hline pH7 & 75 & 0,04 & 2,81 & $-93,8$ & - & - & - \\
\hline pH 6 & 75 & 0,10 & 7,86 & $-56,3$ & - & - & - \\
\hline pH5 & 75 & 0,28 & 20,95 & 768,8 & 19,3 & 36,7 & 0,34 \\
\hline pH4 & 75 & 0,00 & 0,09 & $-168,8$ & - & - & - \\
\hline
\end{tabular}

FONTE: (IWASHITA, 2012)

Tabela 24 - Purificação de PC em IMAC-Zn ${ }^{2+}$ empregando coluna HisTrap de $5 \mathrm{~mL}$ e dessorção com variação de pH a partir de pH 7,0 .

\begin{tabular}{cccccccc}
\hline Amostra & $\begin{array}{c}\text { Volume } \\
\text { da fração } \\
(\mathbf{m L})\end{array}$ & $\begin{array}{c}\text { Concentração } \\
\text { de proteínas } \\
(\mathbf{m g} / \mathbf{m L})\end{array}$ & $\begin{array}{c}\text { Proteína } \\
\text { total } \\
(\mathbf{m g})\end{array}$ & $\begin{array}{c}\text { Atividade } \\
\text { total (U) }\end{array}$ & $\begin{array}{c}\text { \% de } \\
\text { Recuperação }\end{array}$ & $\begin{array}{c}\text { Atividade } \\
\text { Específica } \\
(\mathbf{U} / \mathbf{m g})\end{array}$ & $\begin{array}{c}\text { Fator de } \\
\text { Purificação }\end{array}$ \\
\hline A500A & 25 & 1,51 & 37,76 & 5116,7 & 100,0 & 135,5 & 1,0 \\
\hline FT & 25 & 0,22 & 5,57 & 420,8 & 8,2 & 75,5 & 0,55 \\
\hline pH7 & 75 & 0,04 & 2,81 & 2125,0 & 41,5 & 756,2 & 5,58 \\
\hline pH6 & 75 & 0,10 & 7,86 & 1212,5 & 23,7 & 154,2 & 1,13 \\
\hline pH5 & 75 & 0,28 & 20,95 & $-37,5$ & - & - & - \\
\hline pH4 & 75 & 0,00 & 0,09 & $-87,5$ & - & - & - \\
\hline
\end{tabular}

FONTE: (IWASHITA, 2012) 


\subsubsection{IMAC- $\mathrm{Zn}^{2+}$ empregando HisTrap HP de $5 \mathrm{~mL}$ e dessorção com variação de $\mathrm{pH}$ a partir de $\mathrm{pH} 6,0$}

Os resultados deste experimento estão mostrados nas Tabelas 25 e 26 e Figura 33. As curvas de calibração para determinação das atividades de FVIII e PC e para determinação da concentração de proteínas encontram-se no ANEXO L. Nas condições empregadas, não foi observada atividade de FVIII, a atividade de PC foi encontrada no FT e as proteínas foram recuperadas nas frações FT, Reeq. e pH 5,0.

Novamente perdeu-se a atividade de FVIII em experimento de variação de $\mathrm{pH}$, indicando que esta proteína é muito sensível à variação de $\mathrm{pH}$. A diferença no perfil da Figura 33B em comparação à Figura 32B, indica que as proteínas aplicadas à coluna ligaram-se mais fortemente ao metal em pH 7,0, ainda assim considerandose os valores das frações FT e Reeq. da Tabela 26 juntas, a PC seria recuperada sem diminuição da atividade específica.

Desta forma, em IMAC- $\mathrm{Zn}^{2+}$, partindo-se de $\mathrm{pH} 6,0$, os resultados indicam que este método não é adequado para purificar nem a PC nem para o FVIII.

Figura 33 - Atividade de FVIII e PC (A) e proteína total (B) nas frações obtidas na purificação em IMAC-Zn ${ }^{2+}$ empregando coluna HisTrap HP de $5 \mathrm{~mL}$ e variação de $\mathrm{pH}$ a partir de $\mathrm{pH} 6,0$.

(A)

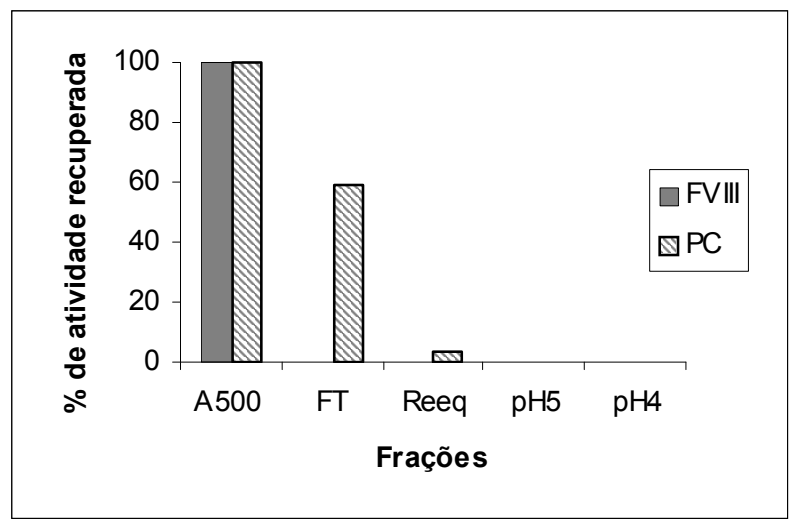

(B)

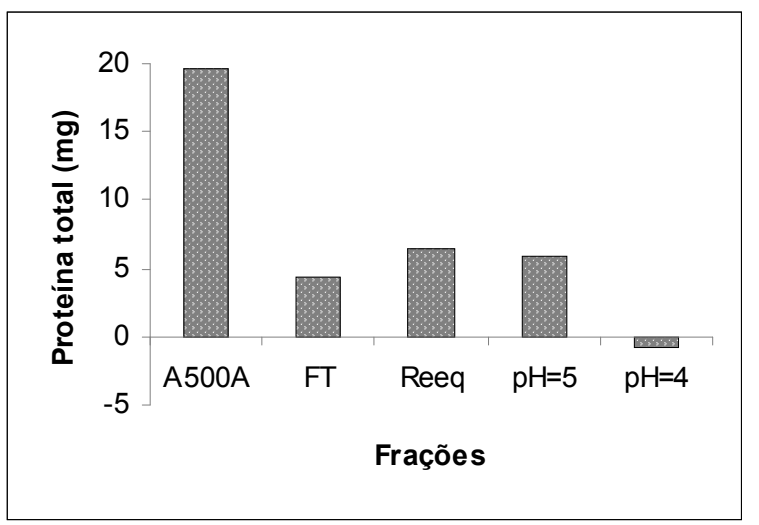

As frações foram recolhidas de acordo com a variação de $\mathrm{pH}$ no tampão citrato $25 \mathrm{mM}$, contendo $\mathrm{CaCl}_{2} 5 \mathrm{mM}$ e $\mathrm{NaCl} 500 \mathrm{mM}$, de $\mathrm{pH}$ 6,0 a pH 4,0.

FONTE: (IWASHITA, 2012) 
Tabela 25 - Purificação de FVIII em IMAC-Zn ${ }^{2+}$ empregando coluna HisTrap HP de 5 mL e variação de pH a partir de pH 6,0.

\begin{tabular}{cccccccc}
\hline & $\begin{array}{c}\text { Volume da } \\
\text { fração } \\
\text { Amostra }\end{array}$ & $\begin{array}{c}\text { Concentração } \\
\text { de proteínas } \\
(\mathbf{m g} / \mathbf{m L})\end{array}$ & $\begin{array}{c}\text { Proteína } \\
\text { total }(\mathbf{m g})\end{array}$ & $\begin{array}{c}\text { Atividade } \\
\text { total (U) }\end{array}$ & $\begin{array}{c}\text { \% de } \\
\text { Recuperação }\end{array}$ & $\begin{array}{c}\text { Atividade } \\
\text { Específica } \\
(\text { U/mg) }\end{array}$ & $\begin{array}{c}\text { Fator de } \\
\text { Purificação }\end{array}$ \\
\hline A500 pH 6,0 & 25 & 0,78 & 19,54 & 1101 & 100 & 56 & 1,0 \\
\hline FT pH 6,0 & 25 & 0,18 & 4,38 & $-134,3$ & - & - & - \\
\hline Reeq pH 6,0 & 75 & 0,09 & 6,40 & $-488,6$ & - & - & - \\
\hline pH 5,0 & 75 & 0,08 & 5,89 & $-338,6$ & - & - & - \\
\hline pH 4,0 & 75 & $-0,01$ & $-0,72$ & $-445,7$ & - & - & - \\
\hline FONTE: (IWASHITA, 2012) & & & & &
\end{tabular}

FONTE: (IWASHITA, 2012)

Tabela 26 - Purificação de PC em IMAC-Zn ${ }^{2+}$ empregando coluna HisTrap HP de 5 mL e variação de pH a partir de pH 6,0.

\begin{tabular}{cccccccc}
\hline Amostra & $\begin{array}{c}\text { Volume da } \\
\text { fração }(\mathbf{m L})\end{array}$ & $\begin{array}{c}\text { Concentração } \\
\text { de proteínas } \\
(\mathbf{m g} / \mathbf{m L})\end{array}$ & $\begin{array}{c}\text { Proteína } \\
\text { total } \\
(\mathbf{m g})\end{array}$ & $\begin{array}{c}\text { Atividade } \\
\text { total (U) }\end{array}$ & $\begin{array}{c}\text { \% de } \\
\text { Recuperação }\end{array}$ & $\begin{array}{c}\text { Atividade } \\
\text { Específica } \\
(\mathbf{U} / \mathbf{m g})\end{array}$ & $\begin{array}{c}\text { Fator de } \\
\text { Purificação }\end{array}$ \\
\hline A500A pH 6,0 & 25 & 0,78 & 19,54 & 2568 & 100 & 131 & 1 \\
\hline FT pH 6,0 & 25 & 0,18 & 4,38 & 1517 & 59,09 & 346 & 2,64 \\
\hline Reeq pH 6,0 & 75 & 0,09 & 6,40 & 95,7 & 3,72 & 15 & 0,11 \\
\hline pH 5,0 & 75 & 0,08 & 5,89 & $-360,9$ & - & - & - \\
\hline pH 4,0 & 75 & $-0,01$ & $-0,72$ & $-360,9$ & - & - & - \\
\hline
\end{tabular}

FONTE: (IWASHITA, 2012) 


\subsubsection{IMAC- $\mathrm{Zn}^{2+}$ empregando HiTrap IMAC HP de $1 \mathrm{~mL}$ e dessorção com $\mathrm{NH}_{4} \mathrm{Cl}$}

Prosseguindo os experimentos com IMAC- $\mathrm{Zn}^{2+}$, estudou-se a dessorção das proteínas variando-se a concentração de $\mathrm{NH}_{4} \mathrm{Cl}$ nos tampões de eluição. Os resultados deste experimento estão mostrados nas Tabelas 27 e 28 e Figura 34 . As curvas de calibração para determinação das atividades de FVIII e PC e para determinação da concentração de proteínas encontram-se no ANEXO M. O FVIII foi eluído com $100 \%$ de $\mathrm{NH}_{4} \mathrm{Cl}$, que corresponde a uma solução $1 \mathrm{M}$ de $\mathrm{NH}_{4} \mathrm{Cl}$, enquanto a PC não se ligou à coluna. O fator de purificação do FVIII foi 8,3 vezes. Cerca de $83 \%$ das proteínas foram recuperadas no FT.

O FVIII e a PC puderam ser bem separados por IMAC- $\mathrm{Zn}^{2+}$ utilizando $\mathrm{NH}_{4} \mathrm{Cl}$, que é uma alternativa de custo mais baixo para substituir o imidazol.

Figura 34 - Atividade de FVIII e $P C_{(A)}$ e proteína total (B) nas frações da purificação em IMAC- $\mathrm{Zn}^{2+}$ empregando coluna HiTrap de $1 \mathrm{~mL}$ e dessorção com $\mathrm{NH}_{4} \mathrm{Cl}$.

(A)

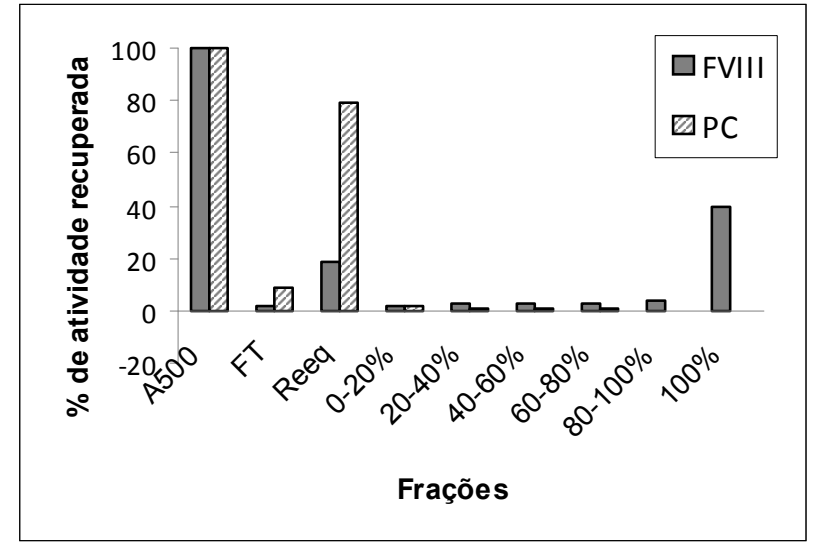

(B)

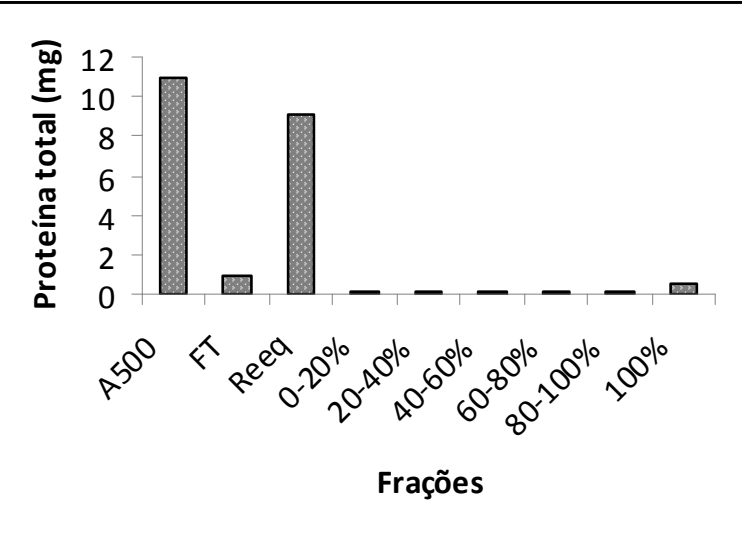

Foi feito um gradiente linear, aumentando a concentração de $\mathrm{NH}_{4} \mathrm{Cl} 1 \mathrm{M}$. As frações recolhidas foram: FT (proteínas que não se ligam à coluna), Reeq. (lavagem das proteínas que não se ligam à coluna), 0-20\%, 20-40\%, 40-60\%, 60-80\%, 80-100\% e $100 \%$. $100 \%$ corresponde a $\mathrm{NH}_{4} \mathrm{Cl} 1 \mathrm{M}$ em tampão citrato $25 \mathrm{mM}$, contendo $\mathrm{NaCl}$ $500 \mathrm{mM}$.

FONTE: (IWASHITA, 2012) 
Tabela 27 - Purificação de FVIII em IMAC-Zn ${ }^{2+}$ empregando coluna HiTrap de 1 mL e dessorção com $\mathrm{NH}_{4} \mathrm{Cl}$.

\begin{tabular}{|c|c|c|c|c|c|c|c|}
\hline Amostra & $\begin{array}{l}\text { Volume da } \\
\text { fração }(m L)\end{array}$ & $\begin{array}{l}\text { Concentração de } \\
\text { proteínas (mg/mL) }\end{array}$ & $\begin{array}{l}\text { Proteína } \\
\text { Total (mg) }\end{array}$ & $\begin{array}{l}\text { Atividade } \\
\text { total (U) }\end{array}$ & $\begin{array}{l}\% \text { de atividade } \\
\text { recuperada }\end{array}$ & $\begin{array}{c}\text { Atividade } \\
\text { Específica } \\
\text { (U/mg) }\end{array}$ & $\begin{array}{c}\text { Fator de } \\
\text { Purificação }\end{array}$ \\
\hline A500A & 9,6 & 1,13 & 10,89 & 1056,0 & 100 & 97,0 & 1,0 \\
\hline FT & 9,6 & 0,10 & 0,98 & 22,4 & 2,1 & 22,8 & 0,2 \\
\hline Reeq & 28,8 & 0,32 & 9,08 & 192,0 & 18,2 & 21,1 & 0,2 \\
\hline $0-20 \%$ & 2 & 0,10 & 0,20 & 22,7 & 2,1 & 113,5 & 1,1 \\
\hline $20-40 \%$ & 2 & 0,09 & 0,19 & 24,7 & 2,3 & 130 & 1,3 \\
\hline $40-60 \%$ & 2 & 0,06 & 0,13 & 24,7 & 2,3 & 190 & 2,0 \\
\hline $60-80 \%$ & 2 & 0,06 & 0,12 & 30,7 & 2,9 & 255,8 & 2,6 \\
\hline $80-100 \%$ & 2 & 0,06 & 0,12 & 45,3 & 4,3 & 377,5 & 3,8 \\
\hline $100 \%$ & 18 & 0,03 & 0,52 & 414,0 & 39,2 & 796,1 & 8,2 \\
\hline
\end{tabular}

FONTE: (IWASHITA, 2012)

Tabela 28 - Purificação de PC em IMAC-Zn ${ }^{2+}$ empregando coluna HiTrap de $1 \mathrm{~mL}$ e dessorção com $\mathrm{NH}_{4} \mathrm{Cl}$.

\begin{tabular}{|c|c|c|c|c|c|c|c|}
\hline Amostra & $\begin{array}{l}\text { Volume da } \\
\text { fração (mL) }\end{array}$ & $\begin{array}{c}\text { Concentração } \\
\text { de proteínas } \\
\text { (mg/mL) }\end{array}$ & $\begin{array}{l}\text { Proteína } \\
\text { Total (mg) }\end{array}$ & $\begin{array}{l}\text { Atividade } \\
\text { total (U) }\end{array}$ & $\begin{array}{l}\% \text { de atividade } \\
\text { recuperada }\end{array}$ & $\begin{array}{c}\text { Atividade } \\
\text { Específica } \\
\text { (U/mg) }\end{array}$ & $\begin{array}{c}\text { Fator de } \\
\text { Purificação }\end{array}$ \\
\hline A500A & 9,6 & 1,13 & 10,89 & 1694,4 & 100 & 155,6 & 1,0 \\
\hline FT & 9,6 & 0,10 & 0,98 & 142,4 & 8,4 & 145,3 & 0,9 \\
\hline Reeq & 28,8 & 0,32 & 9,08 & 1339,2 & 79,0 & 147,5 & 0,9 \\
\hline $0-20 \%$ & 2 & 0,10 & 0,20 & 22,7 & 1,3 & 113,5 & 0,7 \\
\hline $40-60 \%$ & 2 & 0,06 & 0,13 & 7,7 & 0,5 & 59,2 & 0,4 \\
\hline $60-80 \%$ & 2 & 0,06 & 0,12 & 9,3 & 0,6 & 77,5 & 0,5 \\
\hline $80-100 \%$ & 2 & 0,06 & 0,12 & 4,7 & 0,3 & 39,1 & 0,2 \\
\hline $100 \%$ & 18 & 0,03 & 0,52 & $-3,0$ & $-0,2$ & - & - \\
\hline
\end{tabular}




\subsection{Purificação com IMAC-Co ${ }^{2+}$}

\subsubsection{IMAC-Co ${ }^{2+}$ empregando coluna HiTrap IMAC HP de $1 \mathrm{~mL}$ e tampões citrato $25 \mathrm{mM}$}

Os resultados deste experimento estão mostrados na Tabela 29 e na Figura 35. As curvas de calibração para determinação das atividades de FVIII e para determinação da concentração de proteínas encontram-se no ANEXO N.

Neste experimento foi observado que a cor vermelho claro da coluna carregada com o metal foi gradativamente diminuindo de intensidade, indicando que o $\mathrm{Co}^{2+}$ foi arrastado, provavelmente pelo tampão citrato. A presença de proteínas e de atividade de FVIII somente nas frações FT e Reeq estão de acordo com esta observação. Segundo Porath (1988) e Ueda; Gout e Morganti (2003) a estabilidade do complexo formado entre o ligante IDA e o metal decresce na ordem $\mathrm{Cu}^{2+}>\mathrm{Ni}^{2+}>$ $\mathrm{Zn}^{2+}>\mathrm{Co}^{2+}$. Os resultados deste experimento indicam que esta sequência é válida também para a nossa coluna, embora o ligante não seja IDA. O $\mathrm{Co}^{2+}$ foi arrancado da coluna, mesmo utilizando uma concentração de citrato 2,4 vezes mais diluída que a concentração máxima recomendada pelo fabricante da resina (GE Healthcare), enquanto $\circ \mathrm{Cu}^{2+}, \circ \mathrm{Ni}^{2+}$ e $\circ \mathrm{Zn}^{2+}$ formaram complexos estáveis com o ligante. Embora seja um agente quelante, o citrato também tem atividade anticoagulante, razão principal pela qual é utilizado como tampão nestes experimentos.

Figura 35 - Atividade de FVIII (A) e proteína total (B) das frações da purificação em IMAC-Co ${ }^{2+}$ empregando coluna HiTrap IMAC HP de $1 \mathrm{~mL}$ e tampões citrato $25 \mathrm{mM}$.

(A)

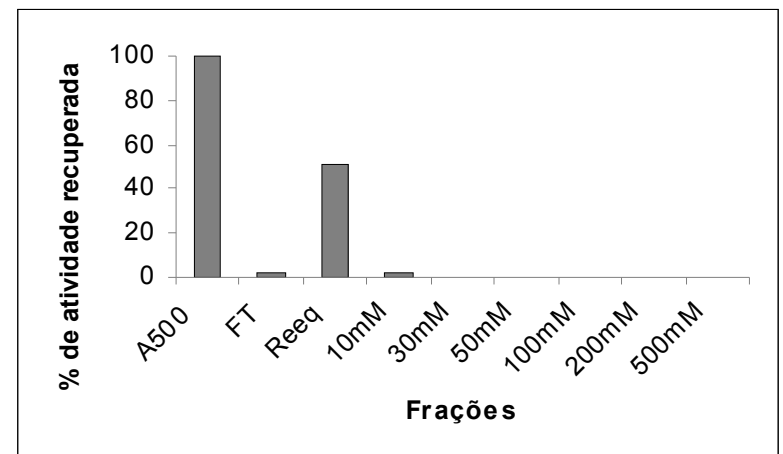

As frações recolhidas foram: FT (proteínas que não se ligam à coluna), Reeq. (lavagem das proteínas que não se ligam à coluna), $10 \mathrm{mM}, 30 \mathrm{mM}, 50 \mathrm{mM}, 100 \mathrm{mM}$, $200 \mathrm{mM}$ e $500 \mathrm{mM}$, que correspondem às concentrações de imidazol utilizadas no tampão citrato para lavagem e eluição das proteínas.
(B)

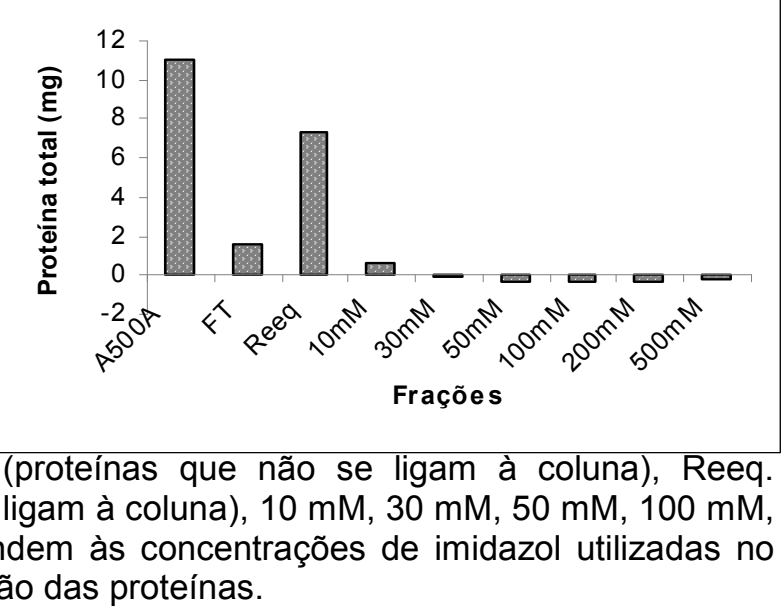

FONTE: (IWASHITA, 2012) 
Tabela 29 - Purificação de FVIII por IMAC- $\mathrm{Co}^{2+}$ em coluna HiTrap IMAC HP de $1 \mathrm{~mL}$ empregando tampões citrato 25 mM.

\begin{tabular}{cccccccc}
\hline Amostra & $\begin{array}{c}\text { Volume da } \\
\text { fração }(\mathbf{m L})\end{array}$ & $\begin{array}{c}\text { Concentração } \\
\text { de proteínas } \\
(\mathbf{m g} / \mathbf{m L})\end{array}$ & $\begin{array}{c}\text { Proteína } \\
\text { total }(\mathbf{m g})\end{array}$ & $\begin{array}{c}\text { Atividade } \\
\text { total (U) }\end{array}$ & $\begin{array}{c}\text { \% de atividade } \\
\text { recuperada }\end{array}$ & $\begin{array}{c}\text { Atividade } \\
\text { Específica } \\
\mathbf{( U / m g )}\end{array}$ & $\begin{array}{c}\text { Fator de } \\
\text { Purificação }\end{array}$ \\
\hline A500A & 9,6 & 1,15 & 11,01 & 1061 & 100 & 96,3 & 1,0 \\
\hline $\mathbf{F T}$ & 9,6 & 0,17 & 1,61 & 24 & 2,2 & 14,9 & 0,1 \\
\hline $\mathbf{R e e q}$ & 24 & 0,30 & 7,29 & 540 & 50,9 & 74,0 & 0,7 \\
\hline $\mathbf{1 0} \mathbf{m M}$ & 24 & 0,03 & 0,69 & 24 & 2,2 & 34,7 & 0,3 \\
\hline $\mathbf{3 0} \mathbf{m M}$ & 24 & 0,00 & $-0,04$ & -36 & - & - & - \\
\hline $\mathbf{5 0} \mathbf{m M}$ & 24 & $-0,01$ & $-0,31$ & -36 & - & - & - \\
\hline $\mathbf{1 0 0} \mathbf{m M}$ & 24 & $-0,01$ & $-0,29$ & -48 & - & - & - \\
\hline $\mathbf{2 0 0} \mathbf{m M}$ & 24 & $-0,01$ & $-0,27$ & -24 & - & - & - \\
\hline $\mathbf{5 0 0} \mathbf{m M}$ & 24 & $-0,01$ & $-0,25$ & -60 & - & - & - \\
\hline
\end{tabular}

FONTE: (IWASHITA, 2012) 


\subsubsection{IMAC-Co ${ }^{2+}$ empregando coluna HisTrap HP de $5 \mathrm{~mL}$ e tampões citrato 10 $m M$}

Os resultados desse experimento estão mostrados nas Tabelas 30 e 31 e Figura 36. As curvas de calibração para determinação das atividades de FVIII e PC e para determinação da concentração de proteínas encontram-se no ANEXO O. Empregando tampão citrato $10 \mathrm{mM}$ ao invés de $25 \mathrm{mM}$, não foi observado escape de metal durante a purificação. O FVIII se liga ao metal nestas condições e pode ser eluído com tampão citrato $10 \mathrm{mM}$, contendo $500 \mathrm{~mm} \mathrm{NaCl}, 5 \mathrm{mM} \mathrm{CaCl} 2$ e imidazol 100mM, pH 6,0 (Tampão J4). A Proteína C coelui com a maioria das proteínas e não se liga a coluna, saindo no FT e Reeq. o que resulta em uma boa separação do FVIII e da PC.

Em experimento realizado com lavagens empregando tampões citrato contendo concentrações intermediárias de imidazol, foi observada atividade de FVIII em todas as frações até $100 \mathrm{mM}$, enquanto que a PC foi encontrada apenas no FT e Reeq., o que levou à escolha deste tampão para eluir o FVIII.

Figura 36 - Atividade de FVIII e PC (A) e proteína total das frações da purificação em IMAC- $\mathrm{Co}^{2+}$ empregando coluna HisTrap HP de $5 \mathrm{~mL}$ e tampões citrato $10 \mathrm{mM}$.

(A)

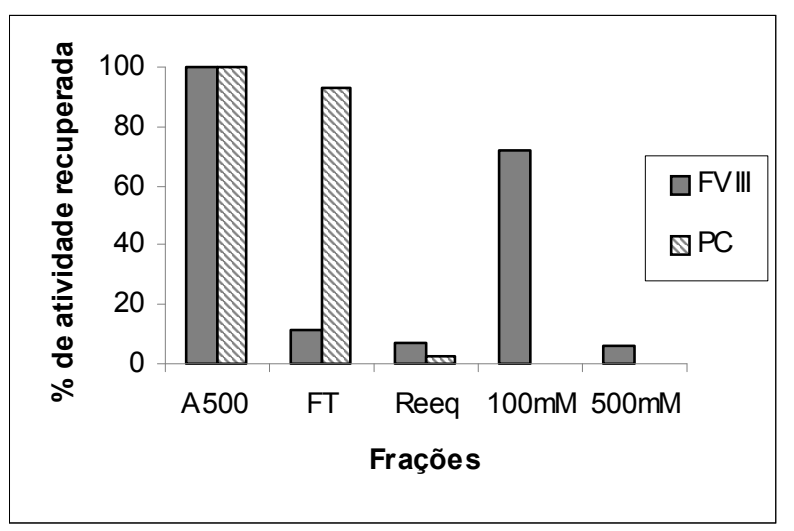

As frações recolhidas foram: FT (proteínas que não se ligam à coluna), Reeq. (lavagem das proteínas que não se ligam à coluna), $100 \mathrm{mM}$ e $500 \mathrm{mM}$, que correspondem às concentrações de imidazol utilizadas no tampão citrato para lavagem e eluição das proteínas.
(B)

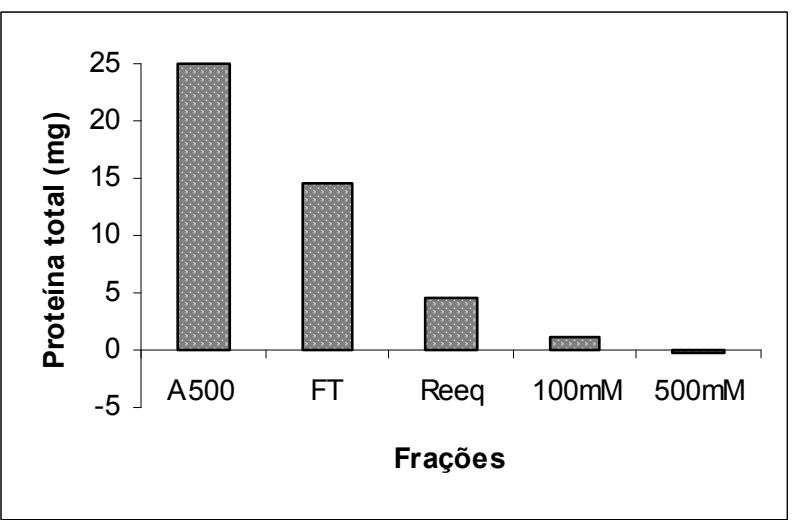

FONTE: (IWASHITA, 2012) 
Tabela 30 - Purificação de FVIII por IMAC- $\mathrm{Co}^{2+}$ empregando coluna HisTrap HP de 5 mL empregando tampões citrato 10 mM.

\begin{tabular}{cccccccc}
\hline Amostra & $\begin{array}{c}\text { Volume da } \\
\text { fração }(\mathbf{m L})\end{array}$ & $\begin{array}{c}\text { Concentração } \\
\text { de proteinas } \\
(\mathbf{m g} / \mathbf{m L})\end{array}$ & $\begin{array}{c}\text { Proteína } \\
\text { total }(\mathbf{m g})\end{array}$ & $\begin{array}{c}\text { Atividade } \\
\text { total }(\mathbf{U})\end{array}$ & $\begin{array}{c}\% \text { de } \\
\text { atividade } \\
\text { recuperada }\end{array}$ & $\begin{array}{c}\text { Atividade } \\
\text { Específica } \\
(\mathbf{U} / \mathbf{m g})\end{array}$ & $\begin{array}{c}\text { Fator de } \\
\text { Purificação }\end{array}$ \\
\hline A500A & 62,0 & 0,40 & 24,95 & 3803 & 100 & 152,4 & 1,0 \\
\hline $\mathbf{F T}$ & 62,0 & 0,23 & 14,47 & 434 & 11,41 & 30,0 & 0,20 \\
\hline Reeq & 74 & 0,06 & 4,59 & 271 & 7,14 & 59,0 & 0,38 \\
\hline $\mathbf{1 0 0 M m}$ & 73 & 0,02 & 1,20 & 2750 & 72,31 & 2291,6 & 15 \\
\hline $\mathbf{5 0 0} \mathbf{m M}$ & 75 & 0,00 & $-0,22$ & 250 & 6,57 & - & - \\
\hline
\end{tabular}

FONTE: (IWASHITA, 2012)

Tabela 31 - Purificação de PC por IMAC- $\mathrm{Co}^{2+}$ empregando coluna HisTrap HP de 5 mL empregando tampões citrato 10 mM.

\begin{tabular}{cccccccc}
\hline Amostra & $\begin{array}{c}\text { Volume da } \\
\text { fração }(\mathbf{m L})\end{array}$ & $\begin{array}{c}\text { Concentração } \\
\text { de proteínas } \\
(\mathbf{m g} / \mathbf{m L})\end{array}$ & $\begin{array}{c}\text { Proteína } \\
\text { total }(\mathbf{m g})\end{array}$ & $\begin{array}{c}\text { Atividade } \\
\text { total }(\mathbf{U})\end{array}$ & $\begin{array}{c}\text { \% de atividade } \\
\text { recuperada }\end{array}$ & $\begin{array}{c}\text { Atividade } \\
\text { Específica } \\
(\text { U/mg) }\end{array}$ & $\begin{array}{c}\text { Fator de } \\
\text { Purificação }\end{array}$ \\
\hline A500A & 62,0 & 0,40 & 24,95 & 4352 & 100 & 174,4 & 1,0 \\
\hline FT & 62,0 & 0,23 & 14,47 & 4055 & 93,16 & 280,2 & 1,6 \\
\hline Reeq & 74 & 0,06 & 4,59 & 133 & 3,06 & $-129,0$ & - \\
\hline $\mathbf{1 0 0 M m}$ & 73 & 0,02 & 1,20 & -175 & - & - & - \\
\hline $\mathbf{5 0 0} \mathbf{m M}$ & 75 & 0,00 & $-0,22$ & -180 & - & - & - \\
\hline
\end{tabular}

FONTE: (IWASHITA, 2012) 


\subsubsection{IMAC- $\mathrm{Co}^{2+}$ empregando coluna Chelating Sepharose FF de $10 \mathrm{~mL}$ e tampões citrato $10 \mathrm{mM}$}

Os resultados deste experimento estão mostrados na Tabela 32 e na Figura 37. As curvas de calibração para determinação das atividades de FVIII e PC e para determinação da concentração de proteínas encontram-se no ANEXO P. Nesta purificação não se observou escape de metal. Entretanto atividade de FVIII foi principalmente na fração $\mathrm{FT}$, o que indica que a proteína não se liga muito bem à essa coluna.

Como já foi discutido em experimento com $\mathrm{Cu}^{2+}$ e $\mathrm{Zn}^{2+}$, essa coluna apresenta o quelante IDA, enquanto que as colunas HiTrap IMAC HP e HisTrap HP apresentam um quelante que não é divulgado. Esta diferença do quelante pode explicar a diferença dos resultados.

Tabela 32 - Purificação de FVIII em IMAC- $\mathrm{Co}^{2+}$, utilizando coluna Chelating Sepharose Fast Flow de $10 \mathrm{~mL}$ e tampões citrato $10 \mathrm{mM}$.

\begin{tabular}{cccc}
\hline Amostra & $\begin{array}{c}\text { Volume da } \\
\text { fração }(\mathbf{m L})\end{array}$ & $\begin{array}{c}\text { Atividade } \\
\text { total (U) }\end{array}$ & $\begin{array}{c}\text { \% de } \\
\text { Recuperação }\end{array}$ \\
\hline A500A & 120 & 7015,7 & 100 \\
\hline FT & 120 & 6072,9 & 86,6 \\
\hline Reeq & 120 & 1430,4 & 20,4 \\
\hline 100Mm & 150 & 734 & 10,5 \\
\hline 500Mm & 150 & 698 & 9,9 \\
\hline FONTE: (IWASHITA, 2012) & &
\end{tabular}

Figura 37 - Atividade total de FVIII nas frações obtidas a partir da purificação em IMAC-Co ${ }^{2+}$, utilizando uma coluna Chelating Sepharose Fast Flow de $10 \mathrm{~mL}$ e tampões citrato $10 \mathrm{mM}$.

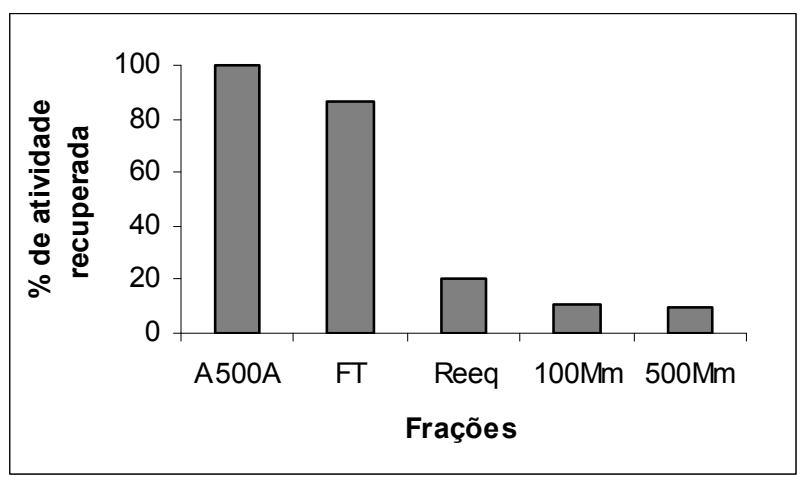

As frações recolhidas foram: FT (proteínas que não se ligam à coluna), Reeq. (lavagem das proteínas que não se ligam à coluna), $100 \mathrm{mM}$ e $500 \mathrm{mM}$, que correspondem às concentrações de imidazol utilizadas no tampão citrato para lavagem e eluição das proteínas.

FONTE: (IWASHITA, 2012) 


\subsection{Purificação com IMAC-Fe ${ }^{3+}$}

Utilizando ferro como metal imobilizado em IMAC, foram realizados experimentos empregando o tampão citrato $10 \mathrm{mM}$ e $25 \mathrm{mM}$. No experimento com citrato $25 \mathrm{mM}$ foi observado que o metal era arrancado da coluna pelo tampão de equilíbrio. A da coluna carregada com o metal apresenta esta coloração alaranjada. Após a eluição do tampão de equilíbrio a coluna ficou praticamente incolor.

As curvas de calibração para determinação das atividades de FVIII e PC e para determinação da concentração de proteínas encontram-se no ANEXO Q.

Empregando o tampão citrato $10 \mathrm{mM}$, a coluna continuou apresentando coloração característica após a realização do experimento, indicando que o metal continuava ligado à coluna. Os resultados mostrados nas Tabelas 33 e 34 e na Figura 38 indicam que o FVIII e a PC não se ligam à coluna, assim como as demais proteínas, sugerindo que, nas condições experimentais empregada, o $\mathrm{Fe}^{3+}$ não é adequado para purificação destas proteínas.

Figura 38 - Atividade do FVIII e da PC (A) e proteína total (B) nas frações da purificação em IMAC-Fe ${ }^{3+}$ empregando coluna HiTrap IMAC HP de 1 $\mathrm{mL}$ e tampões citrato $10 \mathrm{mM}$.

(A)

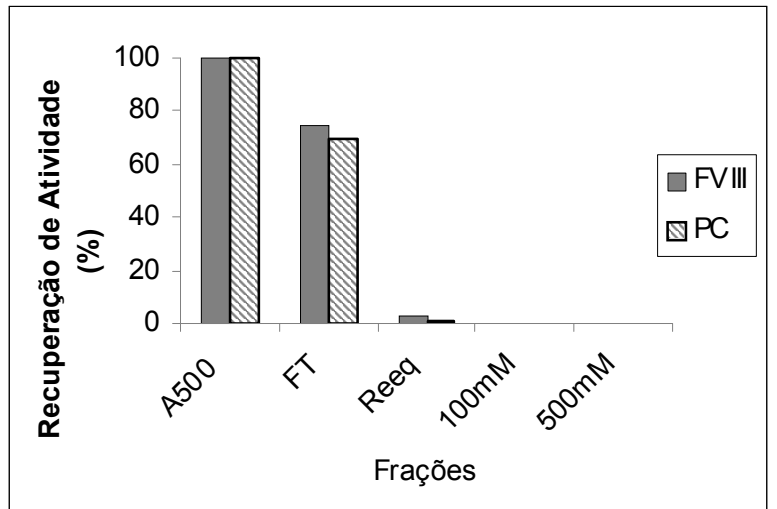

As frações recolhidas foram: FT (proteínas que não se ligam à coluna), Reeq. (lavagem das proteínas que não se ligam à coluna), $100 \mathrm{mM}$ e $500 \mathrm{mM}$, que

correspondem às concentrações de imidazol utilizadas no tampão citrato para lavagem e eluição das proteínas.

(B)

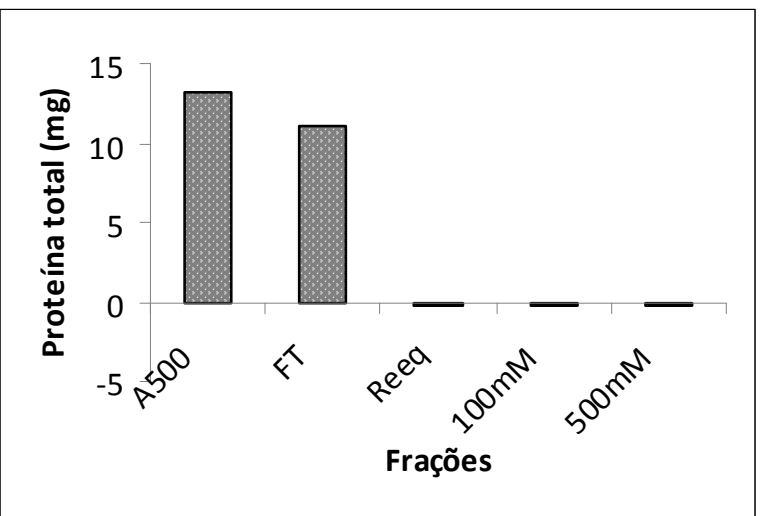
FONTE: (IWASHITA, 2012) 
Tabela 33 - Purificação de FVIII em IMAC-Fe ${ }^{3+}$ empregando coluna HiTrap IMAC HP de 1 mL e tampões citrato 10 mM.

\begin{tabular}{|c|c|c|c|c|c|c|c|}
\hline Amostra & $\begin{array}{l}\text { Volume da } \\
\text { fração (mL) }\end{array}$ & $\begin{array}{l}\text { Concentração de } \\
\text { proteínas } \\
\text { (mg/mL) }\end{array}$ & $\begin{array}{l}\text { Proteína } \\
\text { total (mg) }\end{array}$ & $\begin{array}{l}\text { Atividade } \\
\text { total (U) }\end{array}$ & $\begin{array}{l}\% \text { de atividade } \\
\text { recuperada }\end{array}$ & $\begin{array}{c}\text { Atividade } \\
\text { Específica } \\
\text { (U/mg) }\end{array}$ & $\begin{array}{c}\text { Fator de } \\
\text { Purificação }\end{array}$ \\
\hline A500 & 9,6 & 1,4 & 13,2 & 1586 & 100 & 120 & 1,0 \\
\hline FT & 9,6 & 1,1 & 11,0 & 1176 & 74 & 107 & 0,9 \\
\hline Reeq & 24 & 0,0 & $-0,2$ & 49 & 3 & - & - \\
\hline $100 \mathrm{mM}$ & 24 & 0,0 & $-0,2$ & -49 & - & - & - \\
\hline $500 \mathrm{mM}$ & 24 & 0,0 & $-0,2$ & -49 & - & - & - \\
\hline
\end{tabular}

FONTE: (IWASHITA, 2012)

Tabela 34 - Purificação de FVIII em IMAC-Fe ${ }^{3+}$ empregando coluna HiTrap IMAC HP de 1 mL e tampões citrato 10 mM.

\begin{tabular}{|c|c|c|c|c|c|c|c|}
\hline Amostra & $\begin{array}{l}\text { Volume da } \\
\text { fração (mL) }\end{array}$ & $\begin{array}{l}\text { Concentração } \\
\text { de proteínas } \\
\text { (mg/mL) }\end{array}$ & $\begin{array}{l}\text { Proteína } \\
\text { Total (mg) }\end{array}$ & $\begin{array}{c}\text { Atividade } \\
\text { total (U) }\end{array}$ & $\begin{array}{c}\% \text { de } \\
\text { Recuperação }\end{array}$ & $\begin{array}{c}\text { Atividade } \\
\text { Específica } \\
\text { (U/mg) }\end{array}$ & $\begin{array}{c}\text { Fator de } \\
\text { Purificação }\end{array}$ \\
\hline A500A & 9,6 & 1,4 & 13,2 & 1297 & 100 & 98,2 & 1,0 \\
\hline $\mathbf{F T}$ & 9,6 & 1,1 & 11,0 & 907 & 70 & 82,4 & 0,8 \\
\hline Reeq & 24 & 0,0 & $-0,2$ & 19 & 1 & - & - \\
\hline $100 \mathrm{mM}$ & 24 & 0,0 & $-0,2$ & -119 & - & - & - \\
\hline $500 \mathrm{mM}$ & 24 & 0,0 & $-0,2$ & -133 & - & - & - \\
\hline
\end{tabular}

FONTE: (IWASHITA, 2012) 


\section{DISCUSSÃO GERAL}

\subsection{Purificação de FVIII de coagulação e Proteína C por cromatografia de troca aniônica ANX Sepharose FF}

Em estudos anteriores do laboratório utilizou-se tampão citrato contendo 500 $\mathrm{mM}$ de $\mathrm{NaCl}$ para eluição do FVIII humano e suíno em cromatografias de troca aniônica em resina de Q Sepharose FF (CHENG et al., 2010; LORTHIOIS, 2002; TANAKA, 2000).

Neste trabalho foram testadas 2 condições experimentais para determinar as concentrações de $\mathrm{NaCl}$ no tampão citrato para eluição de FVIII e PC.

$\mathrm{Na}$ condição experimental 1 foram empregadas condições experimentais anteriormente usadas para purificações em Q Sepharose FF. Em estudo sistemático, foi verificado que com uma lavagem intermediária com $\mathrm{NaCl} 200 \mathrm{mM}$ seria possível eluir proteínas contaminantes, com perda mínima de FVIII. Também foi verificado que os fatores de coagulação IX e X coeluem com o FVIII na fração de eluição com $500 \mathrm{mM}$ de $\mathrm{NaCl}$ (CHENG et al., 2010). Empregando a resina ANX Sepharose FF, os resultados foram semelhantes em relação ao perfil de atividade das frações coletadas, o FVIII eluiu com $\mathrm{NaCl} 500 \mathrm{mM}$, não houve perda de atividade na lavagem com $\mathrm{NaCl} 200$ mM e a PC, que, como os fatores de coagulação FIX e FX, pertence à família dos fatores dependentes de vitamina $\mathrm{K}$, coeluiu com o FVIII. O rendimento e o fator de purificação obtidos com a ANX Sepharose FF, no entanto, foram superiores aos obtidos com a $Q$ Sepharose FF.

Quadro 1 - Comparação dos resultados da purificação de plasma em resinas ANX Sepharose e Q Sepharose.

\begin{tabular}{|c|c|c|}
\hline & ANX(5) & $Q(3)^{*}$ \\
\hline $\begin{array}{c}\text { \% de recuperação } \\
\text { de atividade }\end{array}$ & $69 \pm 18$ & $48 \pm 19$ \\
\hline Fator de purificação & $110 \pm 11$ & 55 \\
\hline
\end{tabular}

FONTE: (IWASHITA, 2012) 
$\mathrm{Na}$ condição experimental 2 foram testadas as condições experimentais empregadas por Mori et al. (2008) para purificação de FVIII em colunas de troca aniônica fraca. O objetivo foi verificar se o FVIII poderia ser eluído com $\mathrm{NaCl} 250 \mathrm{mM}$ empregando a resina ANX Sepharose FF, condição experimental em que estes pesquisadores eluiram o FVIII, empregando diversas resinas de troca aniônica fraca. Nossos resultados demonstraram que não é possível eluir o FVIII e a PC com apenas $250 \mathrm{mM}$ de $\mathrm{NaCl}$.

As purificações de plasma em coluna de troca aniônica ANX Sepharose FF realizadas neste trabalho para os estudos em IMAC foram realizadas nas condições experimentais 1.

\subsection{Purificação de FVIII da coagulação e Proteína C empregando Cromatografia de Afinidade a Metal (IMAC)}

Resinas de afinidade têm sido cada vez mais utilizadas em processos de purificação devido, principalmente, à possibilidade de obtenção de produtos com alto grau de pureza. IMAC tem sido uma técnica muito utilizada devido ao seu baixo custo (quando comparadas à técnicas de Imunoafinidade), à especificidade e alta capacidade de adsorção. Além disso, diferentes íons metálicos podem ser imobilizados usando o mesmo adsorvente, podendo ser utilizados em mais de 100 ciclos (BRESOLIN; MIRANDA; BUENO, 2009). É importante observar que não é de nosso conhecimento que a purificação de FVIII por cromatografia de afinidade a metal já tenha sido descrita na literatura.

Uma das desvantagens é o desprendimento ou escape do metal. Caso a proteína alvo purificada seja utilizada para fins terapêuticos, a presença de íon metálico pode ocasionar problemas, pois muitos metais são cancerígenos (BRESOLIN; MIRANDA; BUENO, 2009; UEDA; GOUT; MORGANTI, 2003). Isso pode ser resolvido utilizando colunas de gel filtração, que em muitos processos são usadas como última etapa de purificação, seja para troca de tampão ou para a separação de multímeros.

O FVIII possui 75 resíduos de histidinas na seqüência primária e a Proteína $C$, de 12 (BURNOUF; RADOSEVICH, 2001) a 15 resíduos (LEE; BRULEY; KANG, 2007) na superfície. A presença de resíduos de histidina indicam que o uso de IMAC pode ser eficiente para a separação destas proteínas. 
Neste estudo foram testados os íons cobre, níquel, zinco, cobalto e ferro para purificação de FVIII e PC.

De acordo com Porath (1988) e Ueda, Gout e Morganti (2003), a estabilidade dos quelatos formados entre IDA e alguns íons metálicos decresce na seguinte ordem: $\mathrm{Cu}^{2+}>\mathrm{Ni}^{+2}>\mathrm{Zn}^{+2}>\mathrm{Co}^{+2}>\mathrm{Ca}^{2}=\mathrm{Mg}^{2+}$. Observamos que o ligante das colunas utilizadas também formam complexos de estabilidades diferentes com os metais utilizados, alguns metais ligam-se mais fortemente à resina que outros. Nas

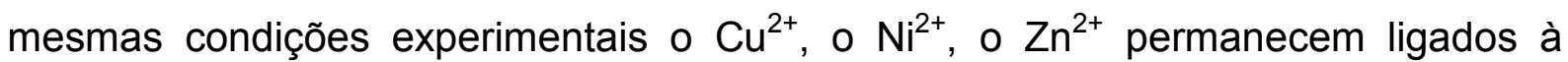
coluna, enquanto o $\mathrm{Co}^{2+}$ e o $\mathrm{Fe}^{3+}$ não. Experimentos com estes 2 últimos somente foram possíveis após a diluição do tampão citrato de $25 \mathrm{mM}$ para $10 \mathrm{mM}$, embora a concentração usada seja 2,4 vezes mais baixa que a concentração máxima recomendada pelo fabricante da resina.

Inicialmente foram realizados experimentos utilizando imidazol para dessorção das proteínas. A amostra aplicada em IMAC foi a fração A500A da coluna ANX Sepharose FF e o tampão de equilíbrio e adsorção das proteínas utilizado foi o tampão de eluição da coluna ANX Sepharose FF (tampão sem imidazol).

Entre as colunas testadas, a força de interação entre proteínas e resina foi decrescente na seguinte seqüência: IMAC-Cu ${ }^{2+}, I_{M A C}-\mathrm{Zn}^{2+} \cong \mathrm{IMAC}^{2} \mathrm{CO}^{2+}, \mathrm{IMAC}^{2} \mathrm{Ni}^{2+}$ $\cong$ IMAC-Fe ${ }^{3+}$.

Não foi observado adsorção de proteínas na coluna de IMAC-Fe ${ }^{3+}$. Embora a descrição do uso deste metal seja escassa na literatura e nem apareça na seqüência descrita por Porath (1988), Wu e Bruley (2002) descreveram a separação de $\mathrm{PC}$ de várias proteínas do leite, utilizando IMAC- $\mathrm{Fe}^{3+}$. A dessorção com imidazol $15 \mathrm{mM}$ indica que a $\mathrm{PC}$ ligou-se fracamente à resina.

Os resultados com níquel, utilizando imidazol para dessorção das proteínas, demonstraram que nas condições empregadas, nem FVIII nem PC ligam-se bem à coluna. A presença de um número grande de resíduos de histidina na seqüência do FVIII e o fato de esta coluna ser a mais comumente utilizada para a purificação de proteínas recombinantes indicavam que esta coluna poderia ser eficiente para a separação desejada. Entretanto, observamos que a ligação do FVIII à coluna é muito fraca. É possível que para uma boa interação com $\mathrm{Ni}^{2+}$ seja necessária a presença de várias histidinas alinhadas ou espacialmente muito próximas entre si, requisito preenchido por proteínas recombinantes, mas não pelo FVIII ou PC. 
Os resultados obtidos com zinco foram melhores que os encontrados para níquel, já que o FVIII ligou-se à coluna e a proteína C não. Grande parte do FVIII pode ser recuperado com tampão citrato contendo $50 \mathrm{mM}$ de imidazol. Houve uma perda de atividade de FVIII nas frações contendo 100 e 200 mM de imidazol, o que justificaria a definição da concentração de imidazol 200 mM para eluição de FVIII.

Purificações com cobalto foram realizadas após a diluição do tampão citrato $25 \mathrm{mM}$ para $10 \mathrm{mM}$. Quando se utiliza várias concentrações de imidazol a partir de 10 mM, verificou-se que o FVIII sai em várias frações de lavagem, enquanto a PC não se liga à coluna. Desta forma, foi definido que a melhor concentração de imidazol para o FVIII é de $100 \mathrm{mM}$.

Em coluna IMAC-Cu ${ }^{2+}$, as 2 proteínas foram adsorvidas pela resina. A PC foi eluída com imidazol 10 mM e FVIII com imidazol 200 mM. Além disso, foi possível realizar uma lavagem intermediária com imidazol 30 e 50 mM.

Em resumo, a concentração de imidazol definida como a mais conveniente para eluir o FVIII das colunas de IMAC-Cu ${ }^{2+}$, IMAC- $\mathrm{Zn}^{2+}$, e foi de $200 \mathrm{mM}$ e $100 \mathrm{mM}$ para colunas de IMAC-CO ${ }^{2+}$. Na coluna IMAC-Cu ${ }^{2+}$, o rendimento de FVIII foi de 42 $\%$ e o fator de purificação de 8 vezes. Na coluna IMAC- $\mathrm{Zn}^{2+}$, o rendimento de FVIII foi de $55 \%$ e o fator de purificação de 6 vezes. Na coluna IMAC-Co ${ }^{2+}$, o rendimento de FVIII foi de $72 \%$ e o fator de purificação de 15 vezes. A PC ligou-se muito mais fracamente que o FVIII e foi recuperado nas 3 colunas ou no FT e Reeq, ou com apenas imidazol $10 \mathrm{mM}$. Portanto, IMAC-Co ${ }^{2+}$ apresentou os melhores resultados nos experimentos de dessorção com imidazol.

$\mathrm{O}$ pH padrão dos experimentos foi o $\mathrm{pH} 6,0$, porque em estudos anteriores do laboratório foi observado que o FVIII é mais estável neste pH. Como seria interessante verificar o perfil de purificação do estudo de dessorção com variação de $\mathrm{pH}$ a partir de $\mathrm{pH} 7,0$, foi realizado um experimento a partir da purificação de plasma em ANX Sepharose FF e dessorção do IMAC- $Z^{2+}$ com imidazol em pH 7,0. Foram realizados experimentos de dessorção a partir de $\mathrm{pH}$ 7,0 e de $\mathrm{pH}$ 6,0. Os resultados obtidos mostraram que as proteínas ligaram-se mais fortemente à resina em $\mathrm{pH} 7,0$. Em IMAC-Cu ${ }^{2+}$ as proteínas ligam-se de uma maneira tão forte à resina que não foi possível dessorvê-las mesmo em pH 4,0, somente na presença de EDTA. Resultado semelhante foi observado por Vançan et al. (2002) durante a purificação de IgG em colunas de afinidade a metal. O $\operatorname{lgG}$ foi adsorvido à coluna em $\mathrm{pH} 7,0$ na coluna afinidade a $\mathrm{Zn}^{2+}$ e eluído em 6,0 , enquanto em coluna de afinidade a $\mathrm{Cu}^{2+}$ esta 
proteína somente foi recuperada na presença de EDTA. Tanto na coluna IMAC- $\mathrm{Zn}^{2+}$ como na coluna IMAC- $\mathrm{Cu}^{2+}$ foi observada perda de atividade de FVIII, provavelmente devido à instabilidade desta proteína em pHs mais baixos que 6,0. A dessorção de proteínas através da diminuição de pH não foi eficiente.

$\mathrm{O}$ último método de dessorção estudado foi realizado empregando o $\mathrm{NH}_{4} \mathrm{Cl}$. Como o cloreto de amônio tem o custo mais baixo do que o imidazol, seria uma alternativa na purificação. O estudo foi realizado com IMAC-Zn ${ }^{2+}$ e IMAC-Cu ${ }^{2+}$. Com IMAC- $-\mathrm{Zn}^{2+}$ pode-se observar que o $\mathrm{NH}_{4} \mathrm{Cl}$ pode ser utilizado no lugar do imidazol para dessorver as proteínas. A PC não se liga à coluna e o FVIII pode ser eluido com $\mathrm{NH}_{4} \mathrm{Cl} 1 \mathrm{M}$. Com IMAC-Cu${ }^{2+}$ não foi possível dessorver as proteínas com $\mathrm{NH}_{4} \mathrm{Cl}$ $1 \mathrm{M}$, somente na presença de EDTA.

Em resumo, foi possível separar o FVIII da PC, e provavelmente de todos os fatores de coagulação dependentes de vitamina $\mathrm{K}$, empregando colunas de afinidade a metal empregando diversos métodos de dessorção. Com imidazol foi possivel a separação de FVIII e PC em colunas de IMAC-Cu ${ }^{2+}, I_{M A C}-\mathrm{Zn}^{2+}$ e IMAC$\mathrm{Co}^{2+}$. Variando-se o $\mathrm{pH}$ na dessorção das proteínas não foi possível recuperar o FVIII e com $\mathrm{NH}_{4} \mathrm{Cl}$, foi possível separar FVIII da PC somente em IMAC- $\mathrm{Zn}^{2+}$.

Três tamanhos de colunas foram utilizadas ao longo do trabalho porque nas colunas de $1 \mathrm{~mL}$ a massa de proteína recuperada era muito pequena ou abaixo da faixa de detecção. Assim, começamos a trabalhar com colunas de $5 \mathrm{~mL}$. Ao mesmo tempo, estava disponível no laboratório a resina Chelating Sepharose FF, que é uma resina usada para estudos de cromatografia de afinidade a metal, cujo ligante IDA é o mais comumente descrito na literatura. Uma coluna de Chelating Sepharose FF de $10 \mathrm{~mL}$ foi empacotada no laboratório.

A principal diferença entre Chelating Sepharose FF e a HiTrap IMAC HP é que as 2 resinas possuem ligantes diferentes. $O$ ligante da Chelating Sepharose FF é o ácido iminodiacético (IDA) enquanto o da HiTrap IMAC HP é segredo industrial. Segundo o fabricante das 2 resinas, a GE Healthcare, na resina de HiTrap IMAC HP o metal liga-se mais fortemente e consequentemente ocorre pouco vazamento do metal. Nossos resultados com as colunas de $\mathrm{Cu}^{2+}, \mathrm{Zn}^{2+}$ e $\mathrm{Co}^{2+}$ indicam que as proteínas também ligam-se mais fortemente à HiTrap IMAC HP do que à Chelating Sepharose $\mathrm{FF}$, somente na coluna de $\mathrm{Cu}^{2+}$ as proteínas ligaram-se à resina, as proteínas não se ligaram nem ao $\mathrm{Zn}^{2+}$, nem ao $\mathrm{Co}^{2+}$. Portanto a coluna HiTrap IMAC HP é mais adequada para a purificação de FVIII e separação de FVIII e PC. 


\section{CONCLUSÕES}

- Em coluna ANX Sepharose FF, o FVIII e a PC são eluídos com 500 mM de $\mathrm{NaCl}$, apresentando perfil de eluição semelhante ao das resinas de troca iônica forte.

- O fator de purificação de FVIII em coluna ANX Sepharose FF é duas vezes maior que em coluna $Q$ Sepharose FF, o que torna a coluna ANX Sepharose FF mais eficiente.

- Em colunas IMAC-Ni ${ }^{2+}$ e IMAC-Fe ${ }^{3+}$ não foi possível realizar as purificações porque, nas condições experimentais empregadas, as proteínas de interesse, FVIII e $\mathrm{PC}$, tiveram pouca ou nenhuma afinidade aos metais.

- Empregando imidazol para a dessorção das protéinas, o FVIII e a PC foram separados em colunas IMAC-Cu ${ }^{2+}$, IMAC- $^{2} \mathrm{n}^{2+}$ e IMAC-Co ${ }^{2+}$.

- O método de dessorção através da variação de pH não é adequado para a purificação dos fatores de coagulação estudados devido à perda de atividade do FVIII em pHs mais baixos que 6,0.

- O $\mathrm{NH}_{4} \mathrm{Cl}$ como agente de dessorção, foi eficiente para separar o FVIII e a PC em colunas IMAC- $-\mathrm{Zn}^{2+}$.

- Experimento em IMAC- $\mathrm{Co}^{2+}$ apresentou os melhores resultados neste estudo, houve boa separação do FVIII e da PC, maior \% de recuperação de atividades e melhores fatores de purificação. 


\section{REFERÊNCIAS*}

AMERSHAM PHARMACIA BIOTECH. Protein Purification: handbook, Uppsala: Amersham Pharmacia Biotech AB, 1999. 97p.

BAE, J. S.; YANG, L.; REZAIE, A. R. Receptors of the protein C activation and activated protein $C$ signaling pathways are colocalized in lipid rafts of endothelial cells. Proc. Natl. Acad. Sci. USA., v. 104, p. 2867-2872, 2007.

BARINGTON, K. A.; KAERSGAARD, P. A very-high-purity von Willebrand factor preparation containing high-molecular-weight multimers. Vox Sang., v. 76, p. 85-89, 1999.

BRADFORD, M. M. A rapid and sensitive method for the quantitation of microgram quantities of protein utilizing the principle of protein-dye binding. Anal. Biochem., v.72, p.248-274, 1976.

BRASIL. Constituição (1988). Constituição da República Federativa do Brasil. Brasília, DF: Senado, 1988.

BRESOLIN, I. T. L.; MIRANDA, E. A.; BUENO, S. M. A. Cromatografia de Afinidade por íons metálicos imobilizados (IMAC) de Biomoléculas: Aspectos Fundamentais e Aplicações Tecnológicas. Quim. Nova, v. 32, p.1288-1296, 2009.

BURNOUF, T.; BURNOUF-RADOSEVICH, M.; HUART, J. J.; GOUDEMAND, M. A high purified Factor VIII:c concentrate prepared from cryoprecipitate by ion-exchange chromatography. Vox Sang., v.60, p. 8-15, 1991.

BURNOUF, T.; RADOSEVICH, M. Affinity chromatography in the industrial purification of plasma proteins for therapeutic use. J. Biochem. Biophys. Methods, v. 49, p. $575-586,2001$.

BURNOUF, T. Modern plasma fractionation. Transfus. Med. Rev., v. 21, p. 101-17, 2007.

CABRERA-CRESPO, J.; GONÇALVES, V. M.; MARTINS, E. A. L.; GRELLET, S.; LOPES, A. Y. \& RAW, I. Albumin Purification from Human Placenta. Biotechnol. Appl. Biochem., v. 31, p. 101-106, 2000.

CARVALHO, R. R. Desenvolvimento de processos para purificação de Fator VIII de coagulação a partir de plasma humano. 2008. 111f. Monografia (Aprimoramento em Biotecnologia) - Centro de Biotecnologia, Instituto Butantan, São Paulo, 2008.

COLLINS, C. H.; BRAGA, G. L.; BONATO, P. S. Fundamentos de Cromatografia. Campinas: Unicamp, 2006, p. 456. 
CHARCOSSET, C. Purification of Proteins by Membrane Chromatography. J. Chem. Technol. Biotechnol., v. 71, p. 95-110, 1998.

CHENG, E.; JINZENJI, D.; LORTHIOIS, A. P. A. A.; CARVALHO, R. R.; TANAKAAZEVEDO, A. M.; RAW, I.; MARTINS, E. A. L. Purification of coagulation factor VIII using chromatographic methods. Direct chromatography of plasma in anion exchange resins. Biotechnol. Lett, v. 32, p.1207-1214, 2010.

D'AMICI, G. M.; BLASI, B.; D’ALESSANDRO, A.; VAGLIO, S.; ZOLLA, L. Plasmaderived clotting factor VIII: Heterogeneity evaluation in the quest for potential inhibitory-antibody stimulating factors. Electrophoresis, v. 32, p. 1-10, 2011.

DAHLBÄCK, B. \& VILLOUTREIX, B. O. The anticoagulant protein C pathway. FEBS Letters, v. 579, p. 3310-3316, 2005.

DAHLBACK B. Blood coagulation. Lancet , v. 355, p. 1627-1632, 2000.

FARRUGIA, A.; EVERS, T.; FALCOU, P. F.; BURNOUF, T.; AMORIM, L.; THOMAS, S. Plasma fractionation issues. Biologicals, v.37, p. 88-93, 2009.

FRANCHINI, M.; MANNUCI, P. M. Inhibitors of propagation of coagulation (factors VIII, IX and XI): a review of current therapeutic practice. Br. J. Clin. Pharmacol., v. 72, n. 4, p. 553-562, 2011.

FURIE, B.; FURIE, B. C. The molecular basis of blood coagulation. Cell, v. 53, p. 505-518, 1988.

GONÇALVES, V. M.; LEITE, L. C. C.; RAW, I. \& CABRERA-CRESPO, J. Purification of catalase from human placenta. Biotechnol. Appl. Biochem., v. 29, Pt 1, p. 73-7, 1999.

GRELLET S.; MARTINS, E. A. L.; GONÇALVEZ, V. M.; LOPES, A. P. Y.; RAW, I.; CABRERA-CRESPO, J. An associated process for the purification of immunglobulin $G$, catalase, superoxide dismutase and albumin from haemolysed human placenta blood. Biotechnol. Appl. Biochem., v. 34, p. 135-142, 2001.

GRIBBLE, J.; GARVEY, M. B. Porcine factor VIII provides clinical benefit to patients with high levels of inhibitors to human and porcine factor VIII. Haemophilia, v.6, n. 5, p. 482-485, 2000.

GRIFFIN, J.; FERNÁNDEZ, J. A.; MOSNIER, L. O.; LIU, D.; CHENG, T.; GUO, H.; ZLOKOVIC, B. V. The promisse of protein C. Blood Cell Mol. Dis., v. 36, p. 211-216, 2006.

HANSSON, K.; STENFLO, J. Post translational modifications in proteins involved in blood coagulation. J. Thromb. Haemost., v.3, p. 2633-2648, 2005.

HOFFMAN, M.; MONROE, D. M. Coagulation 2006: A Modern View of Hemostasis. Hematol. Oncol. Clin. North. AM., v. 21, p. 1-11, 2007. 
JINZENJI, D. Desenvolvimento de processo cromatográfico para purificação de fator VIII humano. Emprego da anticorpos contra fragmentos específicos da proteína na avaliação da pureza e estabilidade durante as etapas de purificação. 2008. 194 f. Dissertação (Mestrado em Biotecnologia) - Instituto de Ciências Biomédicas, Universidade de São Paulo, São Paulo, 2008.

JOSIC, Dj.; SCHWINN, H.; STADLER, M.; STRANCAR, A. Purification os factor VIII and von Willebrand factor from human plasma by anion-exchange chromatography. J. Chromatogr. B, v. 662, p. 181-190, 1994.

KAESGAARD, P.; BARINGTON, K. A. Isolation of the factor VIII-von Willebrand factor complex directly from plasma by gel filtration. J. Chromatogr. B, v. 715, p. 357-367, 1998.

KAUFMAN, R. J.; PIPE, S. W. Regulation of factor VIII expression and activity by von Willebrand factor. Thromb. Haemost., v. 82, p. 201-208, 1999.

KELLEY, B. D.; TANNATT, M.; MAGNUSSON, R.; HAGELBERG, S.; BOOTH, J. Development and validation of an affinity chromatography step usig a peptide ligand for cGMP production of Factor VIII. Biotechnol. Bioeng., v. 87, p. 400-412, 2004.

KEMPTON, C. L.; WHITE, G. C. How we treat a hemophilia A patient with a factor VIII inhibitor. Blood, v. 113, p. 11-17, 2009.

KNOR, S.; KHRENOV, A.; LAUFER, B.; BENHIDA, A.; GRAILLY, S.C.; SCHWAAB, R.; OLDENBURG, J.; BEAUFORT, N.; MAGDOLEN, V.; SAINT-REMY, J.M.R.; SAENKO, E. L.; HAUSER, C. A. E.; KESSLER, H. Efficient factor VIII affinity purification using a small synthetic ligand. J. Thromb. Haemost., v.6, p. 470-477, 2008.

LAEMMLI, U. K. Cleavage of structural proteins during the assembly of the head of bacteriophage T4. Nature, v. 227, p. 680-685, 1970.

LIHME, A.; HANSEN, M. B.; ANDERSEN, I. V.; BURNOUF, T. A novel core fractionation process of human plasma by expanded bed adsorption chromatography. Anal Biochem.,v. 399, n. 1, p. 102-109, 2010.

LEE J. J.; BRULEY D. F.; KANG K. A. Effect of ph and imidazole on protein C purification from Cohn fraction IV-1 by IMAC. Adv. Exp. Med. Biol., v. 599, p. 61-6, 2007.

LORTHIOIS, A. P. A. A. Estudo para purificação de fator VIII humano e suíno. Ensaios de sensibilidade a tratamentos antivirais. 2002. 111 f. Dissertação (Mestrado em Biotecnologia) - Instituto de Ciências Biomédicas, Universidade de São Paulo, São Paulo, 2002.

LUST, M.; VULCANO, M.; DANESE, S. The protein C pathway in inflammatory bowel disease: the missing link between inflammation and coagulation. Trends Mol. Med., v. 14, 2008. 
MAMMEN, E. F. Recombinant Factor VIII Products and Hemophilia A: Efficacy, Safety, and Inhibitor Development. Sem. Thromb. Hemost., v. 28, p. 239-240, 2002.

MANNUCCI, P. M. Hemophilia: treatment options in the twenty-first century. J. Thromb. Haemost., v. 1, p. 1349-55, 2003.

MANTOVAARA, T.; PERTOFT, H.; PORATH, J. Purification of Factor VIII:C coagulant activity from rat liver nonparenchymal cell culture medium by immobilized metal ion affinity chromatography. Biotechnol. Appl. Biochem., v.13, p. 120-126, 1991.

MATEJTSCHUK, P.; FELDMAN, A.; ROTT, J.; MORE, J. Affinity separations of proteins. In: MATEJTSCHUK, P. Affinity separations: a practical approach. New York: IRL PRESS, 1997, p.61-97.

MONROE, D. M.; HOFFMAN, M. What does it take to make the perfect clot? Arteioscler. Thromb. Vasc. Biol., v. 26, p. 41-48, 2006.

MORI, F.; NARDINI, I.; ROSSI, P.; NARDINI, C.; FARINA, C. Progress in large-scale purification of factor $\mathrm{VIII} /$ von Willebrand factor concentrates using ion-exchange Chromatography. Vox Sang., v. 95, p. 298-307, 2008.

O'BRIEN, J. M.; ALI, N. A.; ABEREGG, S. K.; ABRAHAM, E. Sepsis. Am. J. Med., v. 120, p.1012-1022, 2007.

OFOSU, F. A.; FREEDMAN, J.; SEMPLE, J. W. Plasma-derives biological medicines used to promote Haemostasis. Thromb. Haemost., v. 99, p. 851-862, 2008.

ORTHNER, C. L.; RALSTON, A. H.; GEE, D.; KENT, R.; KOLEN, B.; MCGRIFF, J. D.; DROHAN, W. Large-scale production and properties of immunoaffinity-purified human activated protein C concentrate. Vox Sang., v. 69, p. 309-318, 1995.

PORATH, J.; CARLSSON, J.; OLSSON, J.; BELFRAGE, G. Metal Chelate Affinity Chromatography: A New Approach to Protein Fractionation, Nature, v. 258, p. 598599, 1975.

PORATH, J. IMAC-Immobilized metal ion affinity based chromatography. Trends Analyt. Chem., v. 7, p. 254-259, 1988.

RADOSEVICH, M.; ZHOU, F. L.; HUART, J. J.; BURNOUF, T. Chromatographic purification and properties of a therapeutic human protein $\mathrm{C}$ concentrate. $\mathbf{J}$. Chromatogr. B Analyt., v. 790, p. 199-207, 2003.

REZENDE, S. M.; PINHEIRO, K.; CARAM, C.; GENOVEZ, G.; BARCA, D. Registry of inherited coagulopathies in Brazil: first report. Haemophilia, v. 15, p. 142-149, 2009. 
de Conclusão de Curso (Graduação em Biotecnologia) - Faculdade de Ciências e Letras, Universidade Estadual Paulista, Assis, 2007. [Projeto FAPESP 2007/077645].

SOARES, B. M. Política de Hemoderivados no Brasil: Desafios e Perspectivas. 101f. Dissertação (Mestrado em Desenvolvimento Sustentável) - Centro de Desenvolvimento Sustentável, Universidade de Brasília, Brasília, 2002.

TAKEYAMA, M.; NOGAMI, K.; OKUDA, M.; SHIMA, M. Von Willebrand factor protects the $\mathrm{Ca}^{2+}$-dependent structure of the factor VIII light chain. Br. J. Haematol., v.146, p. 531-537, 2009.

TANAKA, A. M.; TANAKA, A. S.; LOPES, A. P. Y.; TAKAGI, M.; CABRERACRESPO, J., RAW, I. Purification of porcine plasma Factor FVIII using chromatographic methods. Biotechnol. Lett., v. 22, p.257-260, 2000.

TE BOOY, M. P.; FABER, A. DE JONGE. E. WOLTERINK, E. P.; RIETHORST, W.; BEUGELING, T.; BANTJES, A.; OVER, J.; KONIG, B. W. Large-scale purification of factor VIII by affinity chromatography: optimization of process parameters. $\mathbf{J}$. Chromatogr., v. 503, p. 103-113, 1990.

TE BOOY, M. P.W.M.; RIETHORST, W.; FABER, A.; OVER, J.; KONIG B. W. Affinity purification of plasma proteins: characterization of six affinity matrices and their application for the isolation of human factor VIII. Thromb. Haemost., v. 61, n. 2, p. 234-237, 1989.

THIM, L.; VANDAHL, B.; KARLSSON, J.; KLAUSEN, N. K.; PEDERSEN, J.; KROGH, T. N.; KJALKE, M.; PETERSEN, J. M.; JOHNSEN, L. B.; BOLT, G.; NORBY, P. L.; STEENSTRUP, T. D. Purification and characterization of a new recombinant factor VIII (N8). Haemophilia, v. 16, p. 349-359, 2010.

UEDA, E. K. M.; GOUT, P. W.; MORGANTI, L. Current and prospective applications of metal ion-protein binding. J. Chromatogr. A., v. 988, p. 1-23, 2003.

VANÇAN, S.; MIRANDA, E. A.; BUENO, S. M. A. IMAC of human IgG: studies with IDA-immobilized copper, nickel, zinc, and cobalt ions and different buffer systems. Proc. Biochem., v. 37, p.573-579, 2002.

WANG, W., WANG, Y. J., KELNER, D. N. Coagulation factor VIII: structure and stability. Int. J. Pharm, v. 259, p. 1-15, 2003.

WONG, T.; RECHT, M. Current options and new developments in the treatment of Haemophilia. Drugs, v. 71, p. 305-320, 2011.

WU, H.; BRULEY, D.F. Chelator, metal ion and buffer studies for Protein C separation. Comp. Biochem. Physiol. Part A, v. 132, p. 213-220, 2002.

YAN, S. B. Review of conformation-specific affinity purification methods for plasma vitamin K-dependent proteins. J. Mol. Recognit., v. 9, p. 211-218, 1996. 
ZHOU, F. L.; BURNOUF-RADOSEVICH, M.; BURNOUF, T. Purification of Factor VIIIr von Willebrand factor from human plasma on immobilized lentil lectin. Protein Expr. Purif., v.5, p.138-143, 1994. 
ANEXOS 
ANEXO A - Curvas de calibração utilizadas para determinação de atividade de FVIII e PC e para determinação da concentração de proteínas nas frações obtidas na determinação da concentração de $\mathrm{NaCl}$ para eluição de FVIII e da PC na purificação de plasma em coluna de troca aniônica ANX Sepharose FF (Condição Experimental 1).

Curva de calibração para determinação de atividade de FVIII.

\begin{tabular}{cccc}
\hline $\begin{array}{c}\text { \% } \\
\text { Atividade }\end{array}$ & $\begin{array}{c}\text { Abs 405 } \\
\mathbf{n m}\end{array}$ & $\begin{array}{c}\text { Abs 492 } \\
\mathbf{n m}\end{array}$ & $\begin{array}{c}\text { Abs 405-492 } \\
\mathbf{n m}\end{array}$ \\
\hline $\mathbf{0}$ & 0 & 0 & 0 \\
\hline $\mathbf{5 0}$ & 0,143 & $-0,015$ & 0,158 \\
\hline $\mathbf{1 0 0}$ & 0,271 & $-0,015$ & 0,286 \\
\hline
\end{tabular}

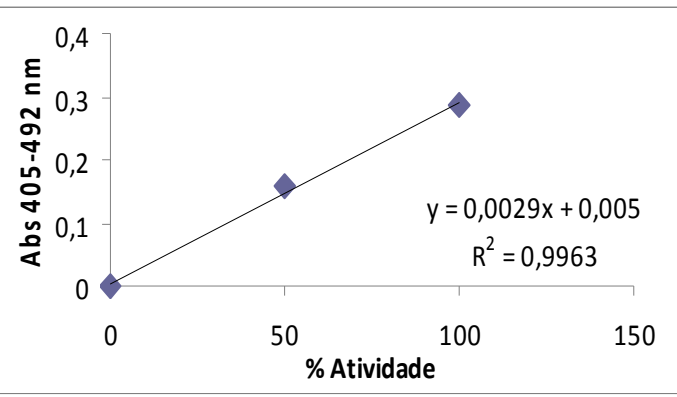

Determinação de atividade de FVIII nas frações da purificação.

\begin{tabular}{cccccc}
\hline Amostras & $\begin{array}{c}\text { Volume da } \\
\text { fração (mL) }\end{array}$ & $\begin{array}{c}\text { Abs 405-492 } \\
\mathbf{n m}\end{array}$ & Atividade & $\begin{array}{c}\text { Atividade } \\
\text { total (U) }\end{array}$ & $\begin{array}{c}\text { \% de atividade } \\
\text { recuperada }\end{array}$ \\
\hline Plasma & 716,7 & 0,286 & 140,5 & 100696,4 & 100 \\
\hline FT & 716,7 & 0,007 & 1,0 & 716,7 & 0,7 \\
\hline Reeq & 684,75 & 0 & $-2,5$ & $-1711,9$ & - \\
\hline A200 & 716,7 & 0,005 & 0,0 & 0,0 & - \\
\hline A500A & 358,35 & 0,45 & 222,5 & 79732,9 & 79,2 \\
\hline A500B & 143,34 & 0,001 & $-2,0$ & $-286,7$ & - \\
\hline
\end{tabular}

Curva de calibração para determinação de atividade de PC.

\begin{tabular}{cccc}
\hline $\begin{array}{c}\text { \% } \\
\text { Atividade }\end{array}$ & $\begin{array}{c}\text { Abs 405 } \\
\mathbf{n m}\end{array}$ & $\begin{array}{c}\text { Abs 492 } \\
\mathbf{n m}\end{array}$ & $\begin{array}{c}\text { Abs } \mathbf{4 0 5 - 4 9 2} \\
\mathbf{n m}\end{array}$ \\
\hline $\mathbf{0}$ & 0 & 0 & 0 \\
\hline $\mathbf{1 0}$ & 0,103 & 0,017 & 0,086 \\
\hline $\mathbf{2 0}$ & 0,156 & 0,006 & 0,15 \\
\hline $\mathbf{5 0}$ & 0,328 & 0,012 & 0,316 \\
\hline $\mathbf{7 5}$ & 0,501 & 0,015 & 0,486 \\
\hline $\mathbf{1 0 0}$ & 0,541 & 0,018 & 0,523 \\
\hline
\end{tabular}

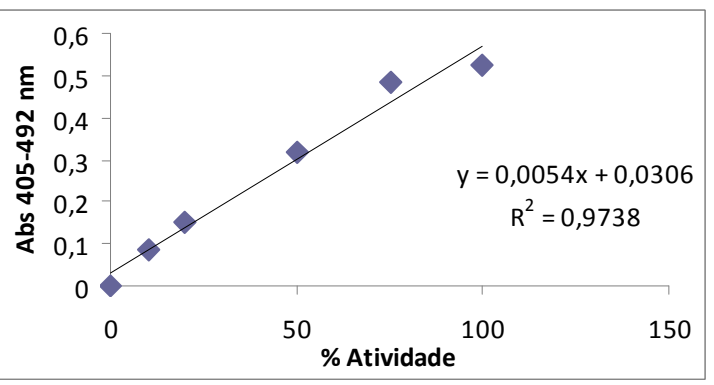

Determinação de atividade de PC nas frações da purificação.

\begin{tabular}{cccccc}
\hline Amostras & $\begin{array}{c}\text { Volume da } \\
\text { fração }(\mathbf{m L})\end{array}$ & $\begin{array}{c}\text { Abs 405-492 } \\
\mathbf{n m}\end{array}$ & Atividade & $\begin{array}{c}\text { Atividade } \\
\text { total (U) }\end{array}$ & $\begin{array}{c}\text { \% de atividade } \\
\text { recuperada }\end{array}$ \\
\hline Plasma & 716,7 & 0,523 & 98,6 & 70666,6 & 100 \\
\hline FT & 716,7 & 0,129 & 19,8 & 14190,7 & 20,1 \\
\hline Reeq & 684,75 & 0,023 & $-1,4$ & $-958,7$ & - \\
\hline A200 & 716,7 & 0,018 & $-2,4$ & $-1720,1$ & - \\
\hline A500A & 358,35 & 0,926 & 179,2 & 64216,3 & 90,9 \\
\hline A500B & 143,34 & 0,008 & $-4,4$ & $-630,7$ & - \\
\hline
\end{tabular}


Curva de calibração para determinação da concentração de proteínas nas frações da purificação.

\begin{tabular}{cc}
\hline BSA $(\boldsymbol{\mu g})$ & Abs 595nm \\
\hline $\mathbf{0}$ & 0,784 \\
\hline $\mathbf{5}$ & 1,271 \\
\hline $\mathbf{1 0}$ & 1,497 \\
\hline $\mathbf{1 5}$ & 1,706 \\
\hline $\mathbf{2 0}$ & 1,922 \\
\hline $\mathbf{2 5}$ & 2,113 \\
\hline
\end{tabular}

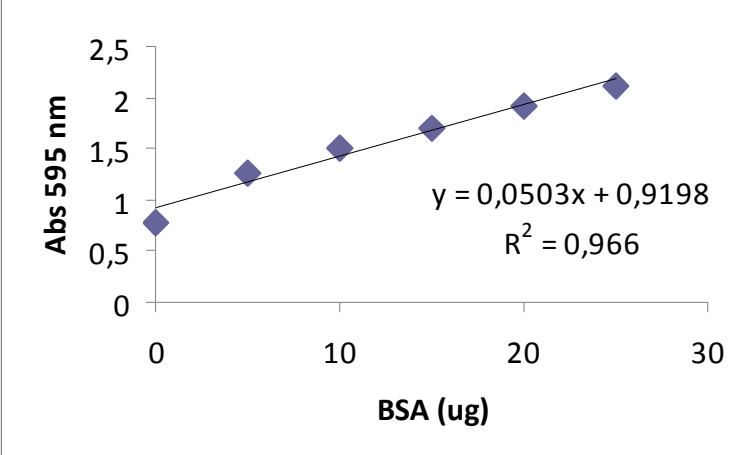

Determinação da concentração de proteínas nas frações da purificação.

\begin{tabular}{cccccccc}
\hline Amostras & $\begin{array}{c}\text { Volume } \\
\mathbf{d a} \text { fração } \\
(\mathbf{m L})\end{array}$ & $\begin{array}{c}\text { Volume de } \\
\text { amostra } \\
(\boldsymbol{\mu L})\end{array}$ & $\begin{array}{c}\text { Fator de } \\
\text { diluição }\end{array}$ & $\begin{array}{c}\text { Abs 595 } \\
\mathbf{n m}\end{array}$ & $\begin{array}{c}\text { Massa de } \\
\text { proteína } \\
(\boldsymbol{\mu g})\end{array}$ & $\begin{array}{c}\text { Concentração Proteína } \\
\text { de proteína } \\
(\mathbf{m g} / \mathbf{m L})\end{array}$ & $\begin{array}{c}\text { Protal } \\
\text { total } \\
(\mathbf{m g})\end{array}$ \\
\hline Plasma & 716,7 & 0,1 & 10.000 & 1,372 & 9,1 & 90,6 & 64933 \\
\hline FT & 716,7 & 0,2 & 1.000 & 1,67 & 15,0 & 75,1 & 53824 \\
\hline Reeq & 684,75 & 0,2 & 10.000 & 0,944 & 0,5 & 2,5 & 1712 \\
\hline A200 & 716,7 & 20 & 10 & 1,209 & 5,8 & 0,29 & 208 \\
\hline A500A & 358,35 & 10 & 20 & 1,603 & 13,7 & 1,368 & 490 \\
\hline A500B & 143,34 & 200 & - & 0,984 & 1,3 & 0,01 & 1 \\
\hline
\end{tabular}


ANEXO B - Curvas de calibração utilizadas para determinação de atividade de FVIII e PC e para determinação da concentração de proteínas nas frações obtidas na determinação da concentração de $\mathrm{NaCl}$ para eluição de $\mathrm{FVIII} \mathrm{e} \mathrm{da} \mathrm{PC} \mathrm{na} \mathrm{purificação} \mathrm{de} \mathrm{plasma}$ em coluna de troca aniônica ANX Sepharose FF (Condição Experimental 2).

Curva de calibração para determinação da atividade de FVIII.

\begin{tabular}{cccc}
\hline $\begin{array}{c}\% \\
\text { Atividade }\end{array}$ & $\begin{array}{c}\text { Abs 405 } \\
\mathbf{n m}\end{array}$ & $\begin{array}{c}\text { Abs 492 } \\
\mathbf{n m}\end{array}$ & $\begin{array}{c}\text { Abs 405- } \\
\mathbf{4 9 2} \mathbf{~ n m}\end{array}$ \\
\hline $\mathbf{0}$ & 0 & 0 & 0 \\
\hline $\mathbf{5 0}$ & 0,286 & 0,002 & 0,284 \\
\hline $\mathbf{1 0 0}$ & 0,545 & 0,003 & 0,542 \\
\hline
\end{tabular}

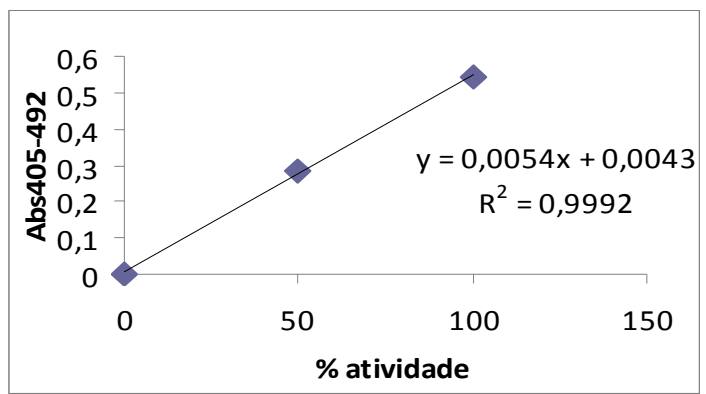

Determinação de atividade de FVIII nas frações da purificação.

\begin{tabular}{cccccc}
\hline Frações & $\begin{array}{c}\text { Volume da } \\
\text { fração }(\mathbf{m L})\end{array}$ & $\begin{array}{c}\text { Abs 405- } \\
\mathbf{4 9 2} \mathbf{~ n m}\end{array}$ & Atividade & $\begin{array}{c}\text { Atividade } \\
\text { total }\end{array}$ & $\begin{array}{c}\text { \% de } \\
\text { atividade } \\
\text { recuperada }\end{array}$ \\
\hline Plasma & 716,75 & 0,567 & 104,20 & 74688 & 100 \\
\hline FT & 716,75 & 0,026 & 4,02 & 2880 & 3,9 \\
\hline Reeq & 716,75 & $-0,002$ & $-1,17$ & -836 & - \\
\hline A150 & 716,75 & 0 & $-0,80$ & -571 & - \\
\hline A250 & 332,53 & $-0,003$ & $-1,35$ & -450 & - \\
\hline A500 A & 332,53 & 0,65 & 119,57 & 39762 & 53,2 \\
\hline A500 B & 83 & 0,089 & 15,69 & 1302 & 1,7 \\
\hline
\end{tabular}

Curva de calibração para determinação da atividade de PC.

\begin{tabular}{cccc}
\hline $\begin{array}{c}\boldsymbol{\%} \\
\text { Atividade }\end{array}$ & $\begin{array}{c}\text { Abs } \\
\mathbf{4 0 5} \mathbf{~ n m}\end{array}$ & $\begin{array}{c}\text { Abs } \\
\mathbf{4 9 2} \mathbf{~ n m}\end{array}$ & $\begin{array}{c}\text { Abs 405- } \\
\mathbf{4 9 2} \mathbf{~ n m}\end{array}$ \\
\hline $\mathbf{0}$ & 0 & 0 & 0 \\
\hline $\mathbf{1 0}$ & 0,04 & $-0,006$ & 0,046 \\
\hline $\mathbf{2 0}$ & 0,113 & $-0,005$ & 0,118 \\
\hline $\mathbf{5 0}$ & 0,253 & 0,002 & 0,251 \\
\hline $\mathbf{7 5}$ & 0,39 & 0,002 & 0,388 \\
\hline $\mathbf{1 0 0}$ & 0,494 & 0,005 & 0,489 \\
\hline
\end{tabular}

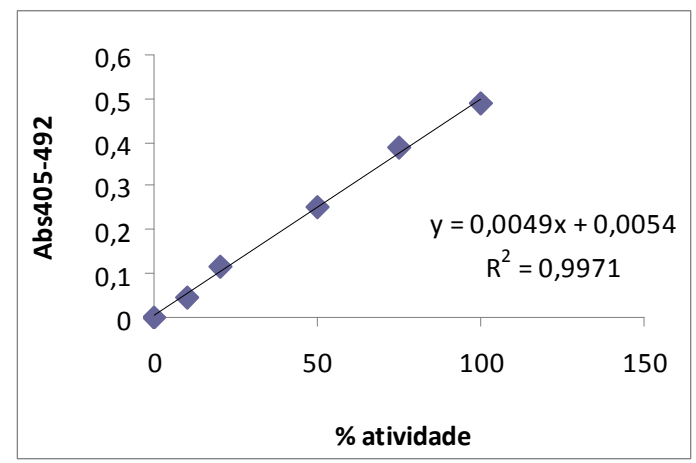

Determinação de atividade de PC nas frações da purificação.

\begin{tabular}{cccccc}
\hline Frações & $\begin{array}{c}\text { Volume da } \\
\text { fração }(\mathbf{m L})\end{array}$ & $\begin{array}{c}\text { Abs 405-492 } \\
\mathbf{n m}\end{array}$ & Atividade & $\begin{array}{c}\text { Atividade } \\
\text { total }\end{array}$ & $\begin{array}{c}\text { \% de } \\
\text { atividade } \\
\text { recuperada }\end{array}$ \\
\hline Plasma & 716,7 & 0,489 & 98,69 & 70734 & 100 \\
\hline FT & 716,7 & 0,168 & 33,18 & 23783 & 33,6 \\
\hline Reeq & 716,7 & 0,023 & 3,59 & 2574 & - \\
\hline A150 & 716,7 & 0,008 & 0,53 & 380 & - \\
\hline A250 & 322,51 & 0,027 & 4,41 & 1422 & - \\
\hline A500 A & 322,51 & 1,177 & 239,10 & 77113 & 109,0 \\
\hline A500 B & 83 & 0,016 & 2,16 & 180 & 0,3 \\
\hline
\end{tabular}


Curva de calibração para determinação da concentração de proteínas nas frações da purificação.

\begin{tabular}{cc}
\hline BSA $(\boldsymbol{\mu g})$ & Abs $595 \mathbf{~ n m}$ \\
\hline $\mathbf{0}$ & 0,772 \\
\hline $\mathbf{5}$ & 0,987 \\
\hline $\mathbf{1 0}$ & 1,17 \\
\hline $\mathbf{1 5}$ & 1,318 \\
\hline $\mathbf{2 0}$ & 1,967 \\
\hline $\mathbf{2 5}$ & 2,009 \\
\hline
\end{tabular}

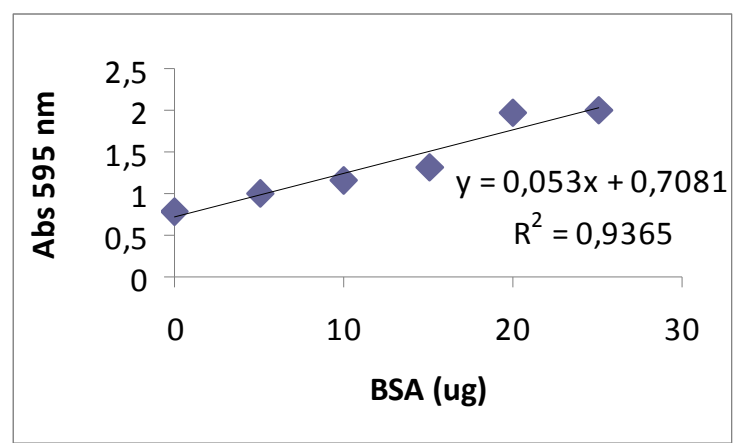

Determinação da concentração de proteínas nas frações da purificação.

\begin{tabular}{cccccccc}
\hline Amostras & $\begin{array}{c}\text { Volume da } \\
\text { fração } \\
(\mathbf{m L})\end{array}$ & $\begin{array}{c}\text { Volume de } \\
\text { amostra } \\
(\boldsymbol{\mu L})\end{array}$ & $\begin{array}{c}\text { Fator de } \\
\text { diluição }\end{array}$ & $\begin{array}{c}\text { Abs 595 } \\
\mathbf{n m}\end{array}$ & $\begin{array}{c}\text { Massa de } \\
\text { proteína } \\
(\boldsymbol{\mu g})\end{array}$ & $\begin{array}{c}\text { Concentração } \\
\text { de proteínas } \\
(\mathbf{m g} / \mathbf{m L})\end{array}$ & $\begin{array}{c}\text { Proteína } \\
\text { total }(\mathbf{m g})\end{array}$ \\
\hline Plasma & 716,7 & 0,2 & 10.000 & 1,539 & 15,68 & 78,40 & 56186,6 \\
\hline FT & 716,7 & 0,2 & 10.000 & 1,428 & 13,58 & 67,92 & 48681,5 \\
\hline Reeq. & 716,7 & 10 & 20 & 1,512 & 15,17 & 1,52 & 1087,2 \\
\hline A150 & 716,7 & 50 & 4 & 1,183 & 8,96 & 0,18 & 128,5 \\
\hline A250A & 322,5 & 20 & 10 & 1,257 & 10,36 & 0,52 & 167,0 \\
\hline A500A & 322,5 & 20 & 10 & 1,876 & 22,04 & 1,10 & 355,4 \\
\hline A500B & 83 & 200 & - & 0,966 & 4,87 & 0,02 & 2,0 \\
\hline
\end{tabular}


ANEXO C - Curvas de calibração utilizadas para determinação de atividade de FVIII e PC e para determinação da concentração de proteínas nas frações da purificação em IMAC$\mathrm{Cu}^{2+}$ empregando coluna HisTrap HP de $5 \mathrm{~mL}$ e dessorção com imidazol.

Curva de calibração para determinação de atividade de FVIII.

\begin{tabular}{cccc}
\hline $\begin{array}{c}\text { \% } \\
\text { Atividade }\end{array}$ & $\begin{array}{c}\text { Abs 405 } \\
\text { nm }\end{array}$ & $\begin{array}{c}\text { Abs 492 } \\
\mathbf{n m}\end{array}$ & $\begin{array}{c}\text { Abs 405-492 } \\
\mathbf{n m}\end{array}$ \\
\hline $\mathbf{0}$ & 0 & 0 & 0 \\
\hline $\mathbf{5 0}$ & 0,178 & $-0,004$ & 0,182 \\
\hline $\mathbf{1 0 0}$ & 0,347 & 0 & 0,347 \\
\hline
\end{tabular}

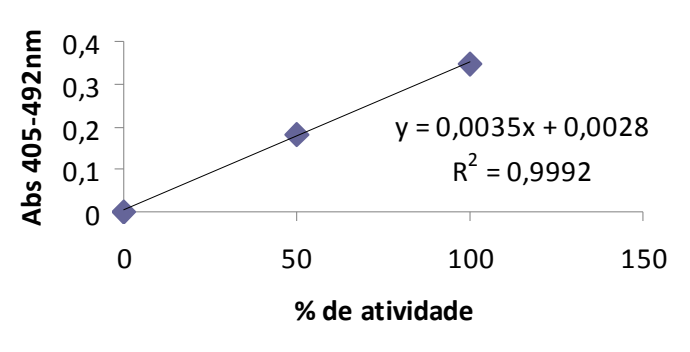

Determinação de atividade de FVIII nas frações da purificação.

\begin{tabular}{|c|c|c|c|c|c|}
\hline Amostras & $\begin{array}{l}\text { Volume da } \\
\text { Fração (mL) }\end{array}$ & $\begin{array}{c}\text { Abs } 405-492 \\
n m\end{array}$ & Atividade & $\begin{array}{c}\text { Atividade } \\
\text { total (U) }\end{array}$ & $\begin{array}{c}\% \text { de atividade } \\
\text { recuperada }\end{array}$ \\
\hline A500A & 25 & 0,271 & 76,6 & 1915,7 & 100 \\
\hline FT & 25 & $-0,018$ & $-5,9$ & $-148,6$ & - \\
\hline Reeq & 75 & $-0,017$ & $-5,7$ & $-424,3$ & - \\
\hline $10 \mathrm{mM}$ & 75 & $-0,017$ & $-5,7$ & $-424,3$ & - \\
\hline $30 \mathrm{mM}$ & 75 & $-0,017$ & $-5,7$ & $-424,3$ & - \\
\hline $50 \mathrm{mM}$ & 75 & $-0,017$ & $-5,7$ & $-424,3$ & - \\
\hline $100 \mathrm{mM}$ & 75 & $-0,007$ & $-2,8$ & $-210,0$ & - \\
\hline $200 \mathrm{mM}$ & 75 & 0,04 & 10,6 & 797,1 & 41,61 \\
\hline $500 \mathrm{mM}$ & 75 & $-0,02$ & $-6,5$ & $-488,6$ & - \\
\hline
\end{tabular}

Curva de calibração para determinação de atividade de PC.

\begin{tabular}{cccc}
$\begin{array}{c}\% \\
\text { Atividade }\end{array}$ & $\begin{array}{c}\text { Abs 405 } \\
\mathbf{n m}\end{array}$ & $\begin{array}{c}\text { Abs 492 } \\
\mathbf{n m}\end{array}$ & $\begin{array}{c}\text { Abs 405-492 } \\
\mathbf{n m}\end{array}$ \\
\hline $\mathbf{0}$ & 0 & 0 & 0 \\
\hline $\mathbf{1 0}$ & 0,077 & 0,001 & 0,076 \\
\hline $\mathbf{2 0}$ & 0,152 & 0,002 & 0,15 \\
\hline $\mathbf{5 0}$ & 0,357 & 0,003 & 0,354 \\
\hline $\mathbf{7 5}$ & 0,507 & 0,009 & 0,498 \\
\hline $\mathbf{1 0 0}$ & 0,715 & 0,011 & 0,704 \\
\hline
\end{tabular}

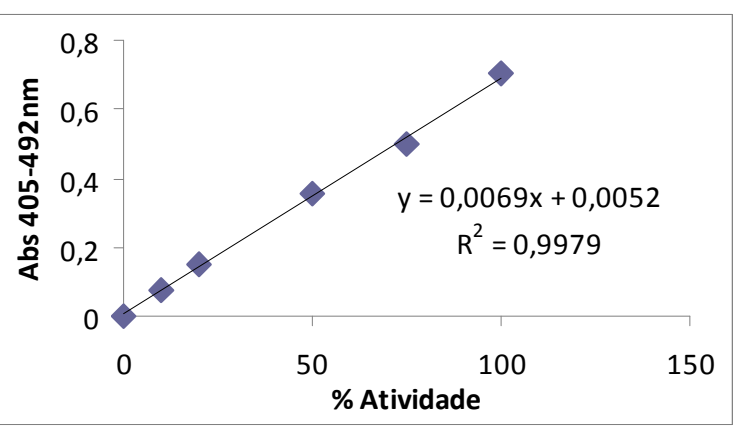

Determinação de atividade de FVIII nas frações da purificação.

\begin{tabular}{cccccc}
\hline Amostras & $\begin{array}{c}\text { Volume da } \\
\text { Fração }(\mathbf{m L})\end{array}$ & $\begin{array}{c}\text { Abs } \mathbf{4 0 5 - 4 9 2} \\
\mathbf{n m}\end{array}$ & Atividade & $\begin{array}{c}\text { Atividade } \\
\text { Total (U) }\end{array}$ & $\begin{array}{c}\text { \% de atividade } \\
\text { Recuperada }\end{array}$ \\
\hline $\mathbf{A 5 0 0 A}$ & 25 & 0,649 & 93,3 & 2332,6 & 100 \\
\hline $\mathbf{F T}$ & 25 & 0 & $-0,8$ & $-18,8$ & - \\
\hline $\mathbf{R e e q}$ & 75 & $-0,001$ & $-0,9$ & $-67,4$ & - \\
\hline $\mathbf{1 0 M m}$ & 75 & 0,148 & 20,7 & 1552,2 & 66,54 \\
\hline $\mathbf{3 0} \mathbf{M m}$ & 75 & 0,005 & 0,0 & $-2,2$ & - \\
\hline $\mathbf{5 0} \mathbf{m M}$ & 75 & 0 & $-0,8$ & $-56,5$ & - \\
\hline $\mathbf{1 0 0 M m}$ & 75 & $-0,001$ & $-0,9$ & $-67,4$ & - \\
\hline $\mathbf{2 0 0} \mathbf{M m}$ & 75 & $-0,002$ & $-1,0$ & $-78,3$ & - \\
\hline $\mathbf{5 0 0} \mathbf{m}$ & 75 & $-0,001$ & $-0,9$ & $-67,4$ & - \\
\hline
\end{tabular}


Curva de calibração para determinação da concentração de proteínas nas frações da purificação.

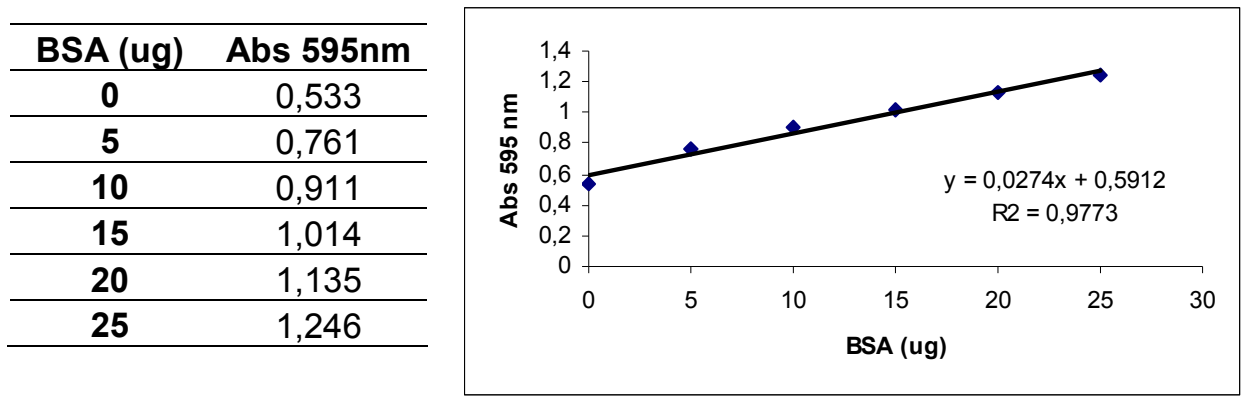

Determinação da concentração de proteínas nas frações da purificação.

\begin{tabular}{ccccccccc}
\hline Amostras & $\begin{array}{c}\text { Volume } \\
\text { da fração } \\
(\mathbf{m L})\end{array}$ & $\begin{array}{c}\text { Volume de } \\
\text { amostra }(\boldsymbol{\mu L})\end{array}$ & $\begin{array}{c}\text { Fator de } \\
\text { Diluição }\end{array}$ & $\begin{array}{c}\text { Abs 595 } \\
\mathbf{n m}\end{array}$ & $\begin{array}{c}\text { Massa de } \\
\text { proteína } \\
(\boldsymbol{\mu g})\end{array}$ & $\begin{array}{c}\text { Volume } \\
\text { amostra } \\
(\boldsymbol{\mu L})\end{array}$ & $\begin{array}{c}\text { Concentração } \\
\text { de proteínas } \\
(\mathbf{m g} / \mathbf{m L})\end{array}$ & $\begin{array}{c}\text { Proteína } \\
\text { total } \\
(\mathbf{m g})\end{array}$ \\
\hline $\mathbf{A 5 0 0 A}$ & 25 & 10 & 20 & 0,813 & 8,09 & 10 & 0,81 & 20,24 \\
\hline $\mathbf{F T}$ & 25 & 200 & - & 0,539 & $-1,91$ & 200 & $-0,01$ & $-0,24$ \\
\hline $\mathbf{R e e q}$ & 75 & 200 & - & 0,546 & $-1,65$ & 200 & $-0,01$ & $-0,62$ \\
\hline $\mathbf{1 0 m M}$ & 75 & 200 & - & 0,897 & 11,16 & 200 & 0,06 & 4,19 \\
\hline $\mathbf{3 0} \mathbf{m M}$ & 75 & 200 & - & 0,98 & 14,19 & 200 & 0,07 & 5,32 \\
\hline $\mathbf{5 0} \mathbf{m M}$ & 75 & 200 & - & 0,993 & 14,66 & 200 & 0,07 & 5,50 \\
\hline $\mathbf{1 0 0} \mathbf{m M}$ & 75 & 200 & - & 0,746 & 5,65 & 200 & 0,03 & 2,12 \\
\hline $\mathbf{2 0 0} \mathbf{m M}$ & 75 & 200 & - & 0,669 & 2,84 & 200 & 0,01 & 1,06 \\
\hline $\mathbf{5 0 0 m M}$ & 75 & 200 & - & 0,553 & $-1,39$ & 200 & $-0,01$ & $-0,52$ \\
\hline
\end{tabular}


ANEXO D - Curvas de calibração utilizadas para determinação de atividade de FVIII e PC e para determinação da concentração de proteínas nas frações da purificação em IMAC$\mathrm{Cu}^{2+}$ empregando coluna Chelating Sepharose FF de $10 \mathrm{~mL}$ e dessorção com imidazol.

Curva de calibração para determinação de atividade de FVIII.

\begin{tabular}{cccc}
\hline \% Atividade & $\begin{array}{c}\text { Abs 405 } \\
\mathbf{n m}\end{array}$ & $\begin{array}{c}\text { Abs } \\
\mathbf{4 9 2} \mathbf{~ n m}\end{array}$ & $\begin{array}{c}\text { Abs } \mathbf{4 0 5 - 4 9 2} \\
\mathbf{n m}\end{array}$ \\
\hline $\mathbf{0}$ & 0 & 0 & 0 \\
\hline $\mathbf{5 0}$ & 0,149 & $-0,004$ & 0,153 \\
\hline $\mathbf{1 0 0}$ & 0,361 & $-0,003$ & 0,364 \\
\hline
\end{tabular}

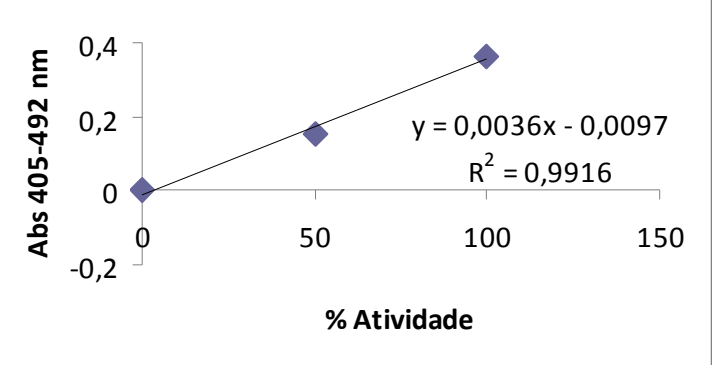

Determinação de atividade de FVIII nas frações da purificação.

\begin{tabular}{cccccc}
\hline Amostras & $\begin{array}{c}\text { Volume da } \\
\text { fração }(\mathbf{m L})\end{array}$ & $\begin{array}{c}\text { Abs } \mathbf{4 0 5}-\mathbf{4 9 2} \\
\mathbf{n m}\end{array}$ & Atividade & $\begin{array}{c}\text { Atividade } \\
\text { Total }(\mathbf{U})\end{array}$ & $\begin{array}{c}\text { \% de atividade } \\
\text { recuperada }\end{array}$ \\
\hline $\mathbf{A 5 0 0 A}$ & 50,0 & $-0,031$ & 131,86 & 6593,1 & 100 \\
\hline $\mathbf{F T}$ & 50,0 & $-0,031$ & 11,03 & 551,4 & 8,36 \\
\hline Reeq & 150 & $-0,031$ & 8,53 & 1279,2 & 19,40 \\
\hline $\mathbf{1 0} \mathbf{m M}$ & 150 & $-0,031$ & 10,19 & 1529,2 & 23,19 \\
\hline $\mathbf{2 0 0} \mathbf{m M}$ & 150 & $-0,031$ & 21,86 & 3279,2 & 49,74 \\
\hline $\mathbf{5 0 0} \mathbf{m M}$ & 150 & $-0,031$ & 5,75 & 862,5 & 13,08 \\
\hline
\end{tabular}

Curva de calibração para determinação de atividade de PC.

\begin{tabular}{cccc}
\hline $\begin{array}{c}\text { \% Atividade } \\
\text { Abs 405 } \\
\mathbf{n m}\end{array}$ & $\begin{array}{c}\text { Abs 492 } \\
\mathbf{n m}\end{array}$ & $\begin{array}{c}\text { Abs 405-492 } \\
\mathbf{n m}\end{array}$ \\
\hline $\mathbf{0}$ & 0 & 0 & 0 \\
\hline $\mathbf{1 0}$ & 0,302 & 0,006 & 0,296 \\
\hline $\mathbf{2 0}$ & 0,56 & 0,013 & 0,547 \\
\hline $\mathbf{5 0}$ & 1,094 & 0,033 & 1,061 \\
\hline $\mathbf{7 5}$ & 1,288 & 0,053 & 1,235 \\
\hline $\mathbf{1 0 0}$ & 1,297 & 0,057 & 1,24 \\
\hline
\end{tabular}

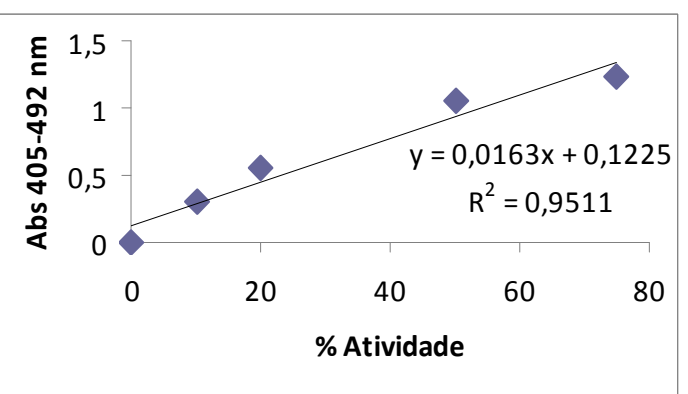

Determinação de atividade de PC nas frações da purificação.

\begin{tabular}{cccccc}
\hline Amostras & $\begin{array}{c}\text { Volume da } \\
\text { fração }(\mathbf{m L})\end{array}$ & $\begin{array}{c}\text { Abs 405-492 } \\
\mathbf{n m}\end{array}$ & Atividade & $\begin{array}{c}\text { Atividade } \\
\text { Total (U) }\end{array}$ & $\begin{array}{c}\text { \% de atividade } \\
\text { recuperada }\end{array}$ \\
\hline A500A & 50,0 & 0,838 & 43,90 & 2194,8 & 100 \\
\hline FT & 50,0 & 0,003 & $-7,33$ & $-366,6$ & - \\
\hline Reeq & 150 & 0,004 & $-7,27$ & $-1090,5$ & - \\
\hline $\mathbf{1 0} \mathbf{m M}$ & 150 & 0,211 & 5,43 & 814,4 & 37,1 \\
\hline $\mathbf{2 0 0} \mathbf{m M}$ & 150 & 0,003 & $-7,33$ & $-1099,7$ & - \\
\hline $\mathbf{5 0 0} \mathbf{m M}$ & 150 & 0,002 & $-7,39$ & $-1108,9$ & - \\
\hline
\end{tabular}


Curva de calibração para determinação da concentração de proteínas nas frações da purificação.

\begin{tabular}{cc}
\hline BSA $(\boldsymbol{\mu g})$ & Abs $595 \mathbf{n m}$ \\
\hline $\mathbf{0}$ & 0,51 \\
\hline $\mathbf{5}$ & 0,758 \\
\hline $\mathbf{1 0}$ & 0,951 \\
\hline $\mathbf{1 5}$ & 1,068 \\
\hline $\mathbf{2 0}$ & 1,203 \\
\hline $\mathbf{2 5}$ & 1,272 \\
\hline
\end{tabular}

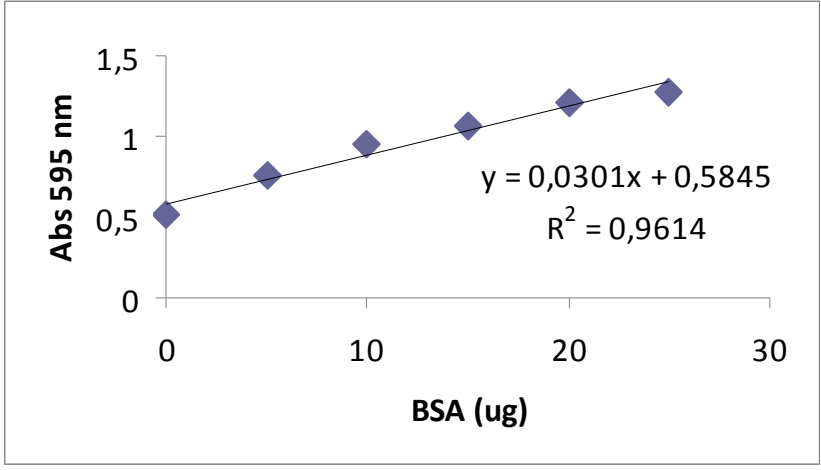

Determinação da concentração de proteínas nas frações da purificação.

\begin{tabular}{cccccccc}
\hline Amostras & $\begin{array}{c}\text { Volume da } \\
\text { fração }(\mathbf{m L})\end{array}$ & $\begin{array}{c}\text { Volume de } \\
\text { amostra }(\boldsymbol{\mu L})\end{array}$ & $\begin{array}{c}\text { Fator de } \\
\text { diluição }\end{array}$ & $\begin{array}{c}\text { Abs 595 } \\
\mathbf{n m}\end{array}$ & $\begin{array}{c}\text { Massa de } \\
\text { proteína } \\
(\boldsymbol{\mu g})\end{array}$ & $\begin{array}{c}\text { Concentração } \\
\text { de proteínas } \\
(\mathbf{m g} / \mathbf{m L})\end{array}$ & $\begin{array}{c}\text { Prot total } \\
(\mathbf{m g})\end{array}$ \\
\hline $\mathbf{A 5 0 0}$ & 50,0 & 10 & 20 & 0,875 & 9,7 & 0,97 & 48,50 \\
\hline $\mathbf{F T}$ & 50,0 & 50 & 4 & 0,575 & $-0,3$ & $-0,01$ & $-0,30$ \\
\hline Reeq & 150 & 50 & 4 & 0,57 & $-0,5$ & $-0,01$ & $-1,40$ \\
\hline $\mathbf{1 0} \mathbf{m M}$ & 150 & 50 & 4 & 0,832 & 8,3 & 0,17 & 24,80 \\
\hline $\mathbf{2 0 0} \mathbf{m M}$ & 150 & 200 & - & 0,989 & 13,5 & 0,07 & 10,13 \\
\hline $\mathbf{5 0 0} \mathbf{m M}$ & 150 & 200 & - & 0,534 & $-1,7$ & $-0,01$ & $-1,25$ \\
\hline
\end{tabular}


ANEXO E - Curvas de calibração utilizadas para determinação de atividade de FVIII e PC e para determinação da concentração de proteínas nas frações da purificação em IMAC$\mathrm{Cu}^{2+}$ empregando coluna HiTrap IMAC HP de $1 \mathrm{~mL}$ e variação de $\mathrm{pH}$.

Curva de calibração para determinação de atividade de FVIII.

\begin{tabular}{cccc}
\hline $\begin{array}{c}\mathbf{\%} \\
\text { atividade }\end{array}$ & $\begin{array}{c}\text { Abs 405 } \\
\mathbf{n m}\end{array}$ & $\begin{array}{c}\text { Abs 492 } \\
\mathbf{n m}\end{array}$ & $\begin{array}{c}\text { Abs 405-492 } \\
\mathbf{n m}\end{array}$ \\
\hline $\mathbf{0}$ & 0 & 0 & 0 \\
\hline $\mathbf{5 0}$ & 0,213 & $-0,001$ & 0,214 \\
\hline $\mathbf{1 0 0}$ & 0,453 & 0 & 0,453 \\
\hline
\end{tabular}

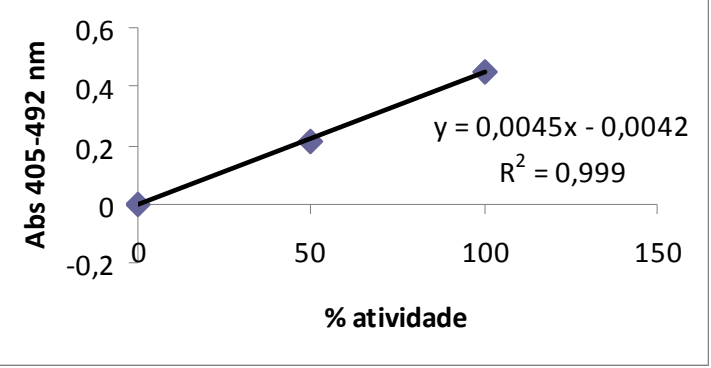

Determinação de atividade de FVIII nas frações da purificação.

\begin{tabular}{cccccc}
\hline Amostras & $\begin{array}{c}\text { Volume da } \\
\text { fração (mL) }\end{array}$ & $\begin{array}{c}\text { Abs 405-492 } \\
\text { nm }\end{array}$ & Atividade & $\begin{array}{c}\text { Atividade } \\
\text { total (U) }\end{array}$ & $\begin{array}{c}\text { \% de atividade } \\
\text { recuperada }\end{array}$ \\
\hline A500 pH 7 & 9,6 & 0,527 & 132,750 & 1274,4 & 100,00 \\
\hline FTpH 7 & 9,6 & 0,032 & 9,000 & 86,4 & 6,78 \\
\hline Reeq pH 7 & 24,0 & $-0,011$ & $-1,750$ & $-42,0$ & - \\
\hline pH 6 & 24,0 & $-0,011$ & $-1,750$ & $-42,0$ & - \\
\hline pH5 & 24,0 & $-0,011$ & $-1,750$ & $-42,0$ & - \\
\hline pH4 & 24,0 & $-0,011$ & $-1,750$ & $-42,0$ & - \\
\hline pH 4 EDTA & 24,0 & $-0,012$ & $-2,000$ & $-48,0$ & - \\
\hline
\end{tabular}

Curva de calibração para determinação de atividade de PC.

\begin{tabular}{cccc}
\hline $\begin{array}{c}\boldsymbol{\%} \\
\text { Atividade }\end{array}$ & $\begin{array}{c}\text { Abs 405 } \\
\mathbf{n m}\end{array}$ & $\begin{array}{c}\text { Abs 492 } \\
\mathbf{n m}\end{array}$ & $\begin{array}{c}\text { Abs } \mathbf{4 0 5 - 4 9 2} \\
\mathbf{n m}\end{array}$ \\
\hline $\mathbf{0}$ & 0 & 0 & 0 \\
\hline $\mathbf{1 0}$ & 0,088 & 0,003 & 0,085 \\
\hline $\mathbf{2 0}$ & 0,16 & 0,001 & 0,159 \\
\hline $\mathbf{5 0}$ & 0,414 & 0,008 & 0,406 \\
\hline $\mathbf{7 5}$ & 0,568 & 0,01 & 0,558 \\
\hline $\mathbf{1 0 0}$ & 0,693 & 0,018 & 0,675 \\
\hline
\end{tabular}

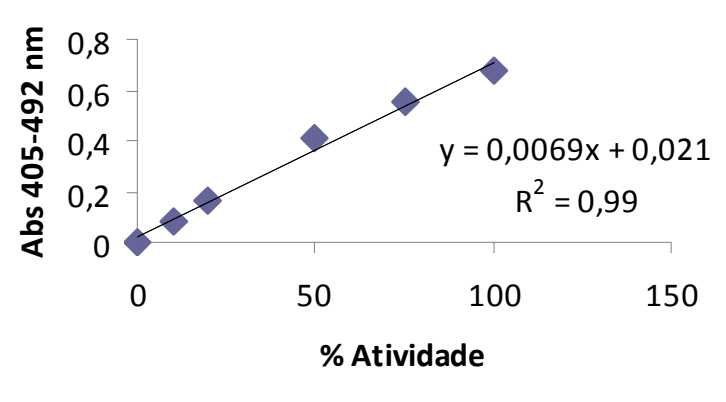

\begin{tabular}{cccccc}
\hline Amostras & $\begin{array}{c}\text { Volume da } \\
\text { fração }(\mathbf{m L})\end{array}$ & $\begin{array}{c}\text { Abs } \mathbf{4 0 5 - 4 9 2} \\
\mathbf{n m}\end{array}$ & Atividade & $\begin{array}{c}\text { Atividade } \\
\text { total (U) }\end{array}$ & $\begin{array}{c}\text { \% de atividade } \\
\text { recuperada }\end{array}$ \\
\hline A500 pH 7 & 9,6 & 1,19 & 171,72 & 1648,56 & 100,00 \\
\hline FT Ph 7 & 9,6 & 0,00 & $-0,16$ & $-1,53$ & - \\
\hline Reeq pH 7 & 24,0 & 0,00 & $-0,30$ & $-7,30$ & - \\
\hline pH 6 & 24,0 & 0,00 & $-0,59$ & $-14,26$ & - \\
\hline pH5 & 24,0 & 0,00 & $-0,59$ & $-14,26$ & - \\
\hline pH4 & 24,0 & 0,00 & $-0,59$ & $-14,26$ & - \\
\hline pH 4 EDTA & 24,0 & 0,10 & 13,61 & 326,61 & 19,81 \\
\hline
\end{tabular}


Curva de calibração para determinação da concentração de proteínas nas frações da purificação.

\begin{tabular}{cc}
\hline BSA $(\boldsymbol{\mu g})$ & Abs $595 \mathbf{n m}$ \\
\hline $\mathbf{0}$ & 0,489 \\
\hline $\mathbf{5}$ & 0,722 \\
\hline $\mathbf{1 0}$ & 0,885 \\
\hline $\mathbf{1 5}$ & 1,011 \\
\hline $\mathbf{2 0}$ & 1,122 \\
\hline $\mathbf{2 5}$ & 1,195 \\
\hline
\end{tabular}

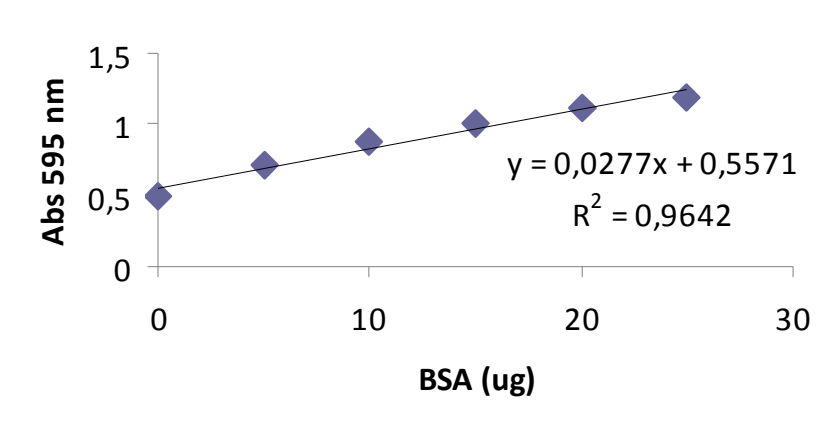

Determinação da concentração de proteínas nas frações da purificação.

\begin{tabular}{|c|c|c|c|c|c|c|c|}
\hline Amostras & $\begin{array}{l}\text { Volume da } \\
\text { fração }(\mathrm{mL})\end{array}$ & $\begin{array}{c}\text { Volume de } \\
\text { amostra }(\mu \mathrm{L})\end{array}$ & $\begin{array}{l}\text { Fator de } \\
\text { Diluição }\end{array}$ & Abs $595 \mathrm{~nm}$ & $\begin{array}{c}\text { Massa de } \\
\text { proteína }(\mu \mathrm{g})\end{array}$ & $\begin{array}{l}\text { Concentração de } \\
\text { proteínas (mg/mL) }\end{array}$ & $\begin{array}{c}\text { Proteína total } \\
(\mathbf{m g})\end{array}$ \\
\hline $\mathrm{A} 500 \mathrm{pH} 7$ & 9,6 & 10 & 20 & 0,99 & 15,89 & 1,59 & 15,25 \\
\hline FT pH 7 & 9,6 & 200 & - & 0,66 & 3,81 & 0,02 & 0,18 \\
\hline Reeq pH 7 & 24,0 & 200 & - & 0,54 & $-0,74$ & 0,00 & $-0,09$ \\
\hline $\mathrm{pH} 6$ & 24,0 & 200 & - & 0,52 & $-1,30$ & $-0,01$ & $-0,16$ \\
\hline pH5 & 24,0 & 200 & - & 0,53 & $-1,07$ & $-0,01$ & $-0,13$ \\
\hline $\mathrm{pH} 4$ & 24,0 & 200 & - & 0,52 & $-1,44$ & $-0,01$ & $-0,17$ \\
\hline pH 4 EDTA & 24,0 & 10 & 20 & 0,65 & 3,37 & 0,34 & 8,09 \\
\hline
\end{tabular}


ANEXO F - Curvas de calibração utilizadas para determinação de atividade de FVIII e para determinação da concentração de proteínas nas frações da purificação em IMAC$\mathrm{Cu}^{2+}$ empregando coluna HiTrap IMAC HP de $1 \mathrm{~mL}$ e dessorção com $\mathrm{NH}_{4} \mathrm{Cl}$.

Curva de calibração para determinação da atividade de FVIII.

\begin{tabular}{cccc}
\hline \% atividade & $\begin{array}{c}\text { Abs 405 } \\
\text { nm }\end{array}$ & $\begin{array}{c}\text { Abs 492 } \\
\text { nm }\end{array}$ & $\begin{array}{c}\text { Abs 405-492 } \\
\text { nm }\end{array}$ \\
\hline $\mathbf{0}$ & 0 & 0 & 0 \\
\hline $\mathbf{5 0}$ & 0,178 & $-0,004$ & 0,182 \\
\hline $\mathbf{1 0 0}$ & 0,347 & 0 & 0,347 \\
\hline
\end{tabular}

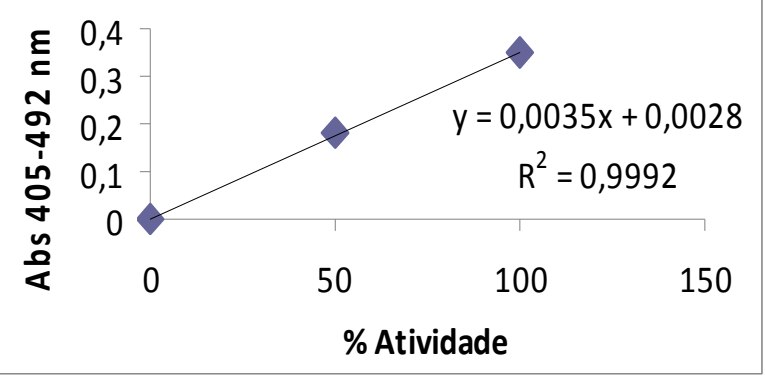

Determinação de atividade de FVIII nas frações da purificação.

\begin{tabular}{cccccc}
\hline Amostras & $\begin{array}{c}\text { Volume da } \\
\text { fração }(\mathbf{m L})\end{array}$ & $\begin{array}{c}\text { Abs } \mathbf{4 0 5 - 4 9 2} \\
\mathbf{n m}\end{array}$ & Atividade & $\begin{array}{c}\text { Atividade } \\
\text { total (U) }\end{array}$ & $\begin{array}{c}\text { \% de atividade } \\
\text { recuperada }\end{array}$ \\
\hline $\mathbf{A 5 0 0 A}$ & 12,5 & 0,296 & 83,8 & 1047,1 & 100,0 \\
\hline $\mathbf{F T}$ & 12,5 & $-0,020$ & $-6,5$ & $-81,4$ & - \\
\hline Reeq & 25 & $-0,021$ & $-6,8$ & $-170,0$ & - \\
\hline $\mathbf{2 5 0} \mathbf{m M}$ & 24 & $-0,020$ & $-6,5$ & $-156,3$ & - \\
\hline $\mathbf{5 0 0 m M}$ & 26 & $-0,017$ & $-5,7$ & $-147,1$ & - \\
\hline $\mathbf{7 5 0} \mathbf{m M}$ & 27 & $-0,020$ & $-6,5$ & $-175,9$ & - \\
\hline $\mathbf{1 M}$ & 25 & $-0,019$ & $-6,2$ & $-155,7$ & - \\
\hline $\mathbf{1 M}$ com EDTA & 20 & $-0,022$ & $-7,1$ & $-141,7$ & - \\
\hline
\end{tabular}


Curva de calibração para determinação da concentração de proteínas nas frações das purificações.

\begin{tabular}{cc}
\hline BSA $(\boldsymbol{\mu g})$ & Abs $\mathbf{5 9 5} \mathbf{~ n m}$ \\
\hline 0 & 0,485 \\
\hline 5 & 0,67 \\
\hline 10 & 0,876 \\
\hline 15 & 0,979 \\
\hline 20 & 1,107 \\
\hline 25 & 1,167 \\
\hline
\end{tabular}

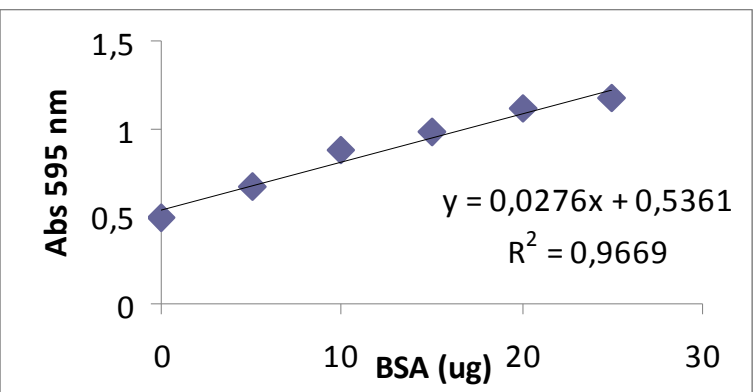

Determinação da concentração de proteínas nas frações da purificação.

\begin{tabular}{cccccccc}
\hline Amostras & $\begin{array}{c}\text { Volume da } \\
\text { fração }(\mathbf{m L})\end{array}$ & $\begin{array}{c}\text { Volume de } \\
\text { Amostra }(\boldsymbol{\mu L})\end{array}$ & $\begin{array}{c}\text { Fator de } \\
\text { diluição }\end{array}$ & $\begin{array}{c}\text { Abs } \\
\mathbf{5 9 5} \mathbf{n m}\end{array}$ & $\begin{array}{c}\text { Massa de } \\
\text { proteína }(\boldsymbol{\mu g})\end{array}$ & $\begin{array}{c}\text { Concentração de } \\
\text { proteínas }(\mathbf{m g} / \mathbf{m L})\end{array}$ & $\begin{array}{c}\text { Proteína } \\
\text { total }(\mathbf{m g})\end{array}$ \\
\hline $\mathbf{A 5 0 0 A}$ & 12,5 & 10 & 20 & 0,796 & 9,63 & 0,96 & $-1,04$ \\
\hline $\mathbf{F T}$ & 12,5 & 200 & - & 0,486 & $-1,85$ & $-0,01$ & $-0,12$ \\
\hline Reeq & 25 & 200 & - & 0,485 & $-1,89$ & $-0,01$ & $-0,24$ \\
\hline $\mathbf{2 5 0 m M}$ & 24 & 200 & - & 0,501 & $-1,30$ & $-0,01$ & $-0,16$ \\
\hline $\mathbf{5 0 0 m M}$ & 26 & 200 & - & 0,503 & $-1,22$ & $-0,01$ & $-0,16$ \\
\hline $\mathbf{7 5 0 m M}$ & 27 & 200 & - & 0,482 & $-2,00$ & $-0,01$ & $-0,27$ \\
\hline $\mathbf{1 M}$ & 25 & 200 & - & 0,478 & $-2,15$ & $-0,01$ & $-0,27$ \\
\hline 1M com EDTA & 20 & 10 & 20 & 0,652 & 4,30 & 0,43 & 8,59 \\
\hline
\end{tabular}


ANEXO G - Curvas de calibração utilizadas para determinação de atividade de FVIII e PC e para determinação da concentração de proteínas nas frações da purificação em IMAC-Ni ${ }^{2+}$.

Curva de calibração para determinação de atividade de FVIII.

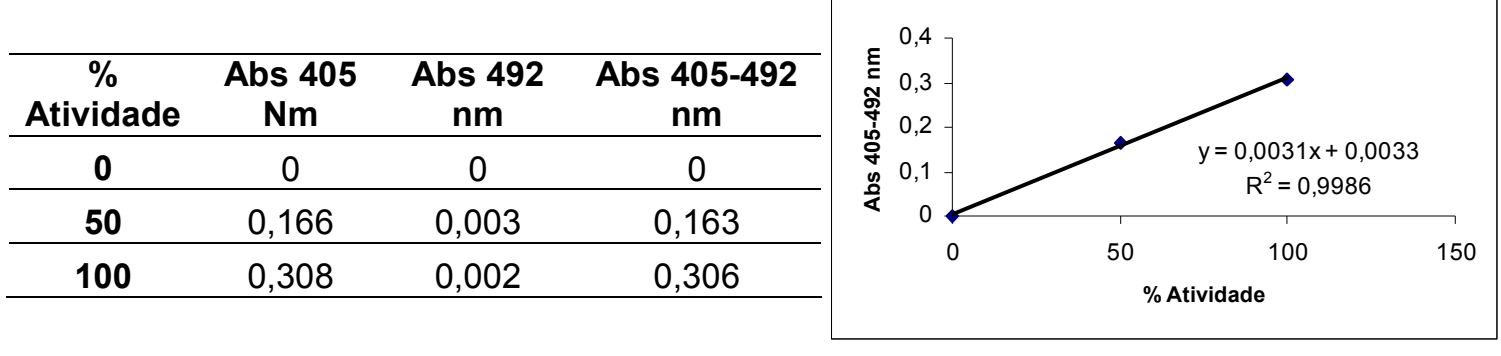

Determinação de atividade de FVIII nas frações da purificação.

\begin{tabular}{cccccc}
\hline Amostras & $\begin{array}{c}\text { Volume da } \\
\text { fração } \mathbf{( m L}\end{array}$ & $\begin{array}{c}\text { Abs } \mathbf{4 0 5 - 4 9 2} \\
\mathbf{n m}\end{array}$ & Atividade & $\begin{array}{c}\text { Atividade } \\
\text { total (U) }\end{array}$ & $\begin{array}{c}\text { \% de atividade } \\
\text { recuperada }\end{array}$ \\
\hline $\mathbf{A 5 0 0}$ & 9,6 & 0,268 & 85,39 & 820 & 100 \\
\hline $\mathbf{F T}$ & 9,6 & 0,012 & 2,81 & 27 & 3,29 \\
\hline $\mathbf{R e e q}$ & 24 & 0,036 & 10,55 & 253 & 30,88 \\
\hline $\mathbf{1 0 M m}$ & 10 & 0,036 & 10,55 & 105 & 12,87 \\
\hline $\mathbf{3 0} \mathbf{m M}$ & 10 & 0,006 & 0,87 & 9 & 1,06 \\
\hline $\mathbf{5 0} \mathbf{m M}$ & 10 & 0,004 & 0,23 & 2 & 0,28 \\
\hline $\mathbf{1 0 0} \mathbf{m M}$ & 10 & 0,005 & 0,55 & 5 & 0,67 \\
\hline $\mathbf{2 0 0} \mathbf{m M}$ & 10 & 0,004 & 0,23 & 2 & 0,28 \\
\hline $\mathbf{5 0 0} \mathbf{m M}$ & 10 & 0,002 & $-0,42$ & -4 & - \\
\hline
\end{tabular}

Curva de calibração para determinação de atividade de PC.

\begin{tabular}{cccc}
$\begin{array}{c}\text { \% } \\
\text { Atividade }\end{array}$ & $\begin{array}{c}\text { Abs 405 } \\
\mathbf{n m}\end{array}$ & $\begin{array}{c}\text { Abs 492 } \\
\mathbf{n m}\end{array}$ & $\begin{array}{c}\text { Abs 405- } \\
\mathbf{4 9 2} \mathbf{~ n m}\end{array}$ \\
\hline $\mathbf{0}$ & 0 & 0 & 0 \\
\hline $\mathbf{1 0}$ & 0,086 & 0,001 & 0,085 \\
\hline $\mathbf{2 0}$ & 0,166 & 0,006 & 0,16 \\
\hline $\mathbf{5 0}$ & 0,419 & 0,015 & 0,404 \\
\hline $\mathbf{7 5}$ & 0,589 & 0,021 & 0,568 \\
\hline $\mathbf{1 0 0}$ & 0,694 & 0,027 & 0,667 \\
\hline
\end{tabular}

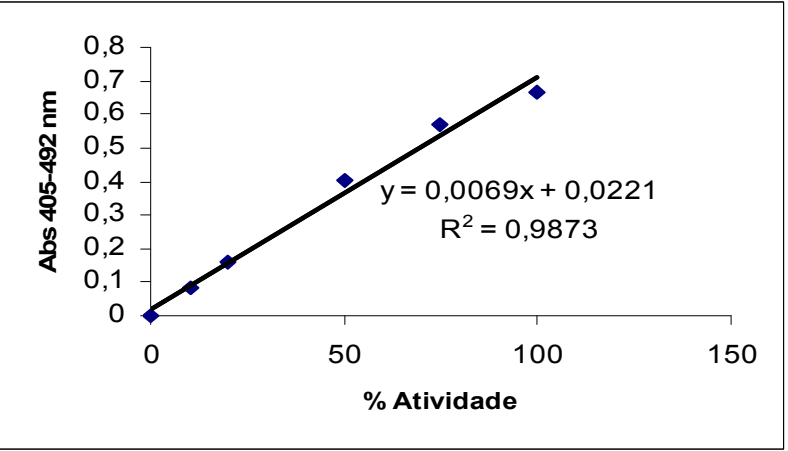

Determinação de atividade de PC nas frações da purificação.

\begin{tabular}{cccccc}
\hline Amostras & $\begin{array}{c}\text { Volume da } \\
\text { fração }(\mathbf{m L})\end{array}$ & $\begin{array}{c}\text { Abs } \mathbf{4 0 5 - 4 9 2} \\
\mathbf{n m}\end{array}$ & Atividade & $\begin{array}{c}\text { Atividade } \\
\text { total (U) }\end{array}$ & $\begin{array}{c}\text { \% de atividade } \\
\text { Recuperada }\end{array}$ \\
\hline $\mathbf{A 5 0 0}$ & 9,6 & 0,943 & 133,46 & 1281 & 100 \\
\hline $\mathbf{F T}$ & 9,6 & 0,15 & 18,54 & 178 & 13,89 \\
\hline $\mathbf{R e e q}$ & 24 & 0,246 & 32,45 & 779 & 60,78 \\
\hline $\mathbf{1 0} \mathbf{m M}$ & 10 & 0,045 & 3,32 & 33 & 2,59 \\
\hline $\mathbf{3 0} \mathbf{m}$ & 10 & 0,005 & $-2,48$ & -25 & - \\
\hline $\mathbf{5 0} \mathbf{m}$ & 10 & $-0,001$ & $-3,35$ & -33 & - \\
\hline $\mathbf{1 0 0} \mathbf{m M}$ & 10 & $-0,001$ & $-3,35$ & -33 & - \\
\hline $\mathbf{2 0 0} \mathbf{m M}$ & 10 & 0 & $-3,20$ & -32 & - \\
\hline $\mathbf{5 0 0} \mathbf{m M}$ & 10 & 0 & $-3,20$ & -32 & - \\
\hline
\end{tabular}


Curva de calibração para determinação da concentração de proteínas nas frações da purificação.

\begin{tabular}{cc}
\hline BSA $(\boldsymbol{\mu g})$ & Abs 595nm \\
\hline $\mathbf{0}$ & 0,329 \\
\hline $\mathbf{5}$ & 0,437 \\
\hline $\mathbf{1 0}$ & 0,48 \\
\hline $\mathbf{1 5}$ & 0,513 \\
\hline $\mathbf{2 0}$ & 0,588 \\
\hline $\mathbf{2 5}$ & 0,671 \\
\hline
\end{tabular}

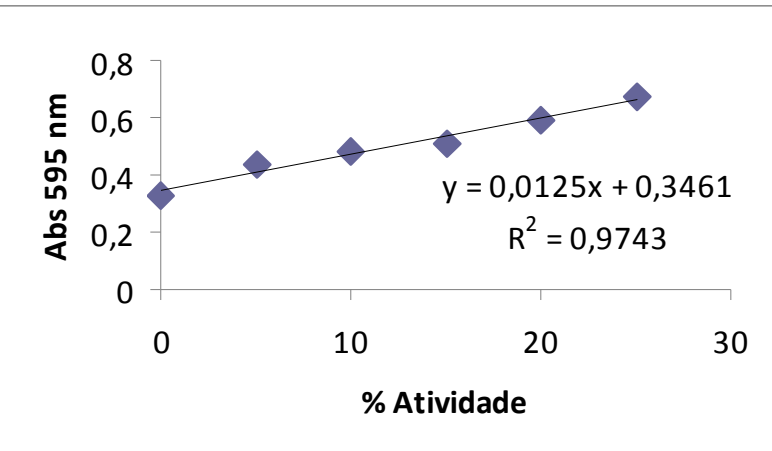

Determinação da concentração de proteínas nas frações da purificação.

\begin{tabular}{cccccccc}
\hline Amostras & $\begin{array}{c}\text { Volume da } \\
\text { fração }(\mathbf{m L})\end{array}$ & $\begin{array}{c}\text { Volume de } \\
\text { amostra }(\boldsymbol{\mu L})\end{array}$ & $\begin{array}{c}\text { Fator de } \\
\text { diluição }\end{array}$ & $\begin{array}{c}\text { Abs 595 } \\
\mathbf{n m}\end{array}$ & $\begin{array}{c}\text { Massa de } \\
\text { proteína }(\boldsymbol{\mu g})\end{array}$ & $\begin{array}{c}\text { Concentração de } \\
\text { proteínas }(\mathbf{m g} / \mathbf{m L})\end{array}$ & $\begin{array}{c}\text { Proteína } \\
\text { total }(\mathbf{m g})\end{array}$ \\
\hline $\mathbf{A 5 0 0 A}$ & 9,6 & 10 & 20 & 0,548 & 16,8 & 1,68 & 16,16 \\
\hline $\mathbf{F T}$ & 9,6 & 200 & - & 0,603 & 21,4 & 0,11 & 1,03 \\
\hline $\mathbf{R e e q}$ & 24 & 30 & 6,6 & 0,551 & 17,1 & 0,57 & 13,67 \\
\hline $\mathbf{1 0} \mathbf{m M}$ & 10 & 50 & 4 & 0,481 & 11,3 & 0,23 & 2,25 \\
\hline $\mathbf{3 0} \mathbf{m M}$ & 10 & 200 & - & 0,517 & 14,3 & 0,07 & 0,71 \\
\hline $\mathbf{5 0} \mathbf{m M}$ & 10 & 200 & - & 0,574 & 19,0 & 0,10 & 0,95 \\
\hline $\mathbf{1 0 0} \mathbf{m M}$ & 10 & 200 & - & 0,549 & 16,9 & 0,08 & 0,85 \\
\hline $\mathbf{2 0 0} \mathbf{m M}$ & 10 & 200 & - & 0,574 & 19,0 & 0,10 & 0,95 \\
\hline $\mathbf{5 0 0} \mathbf{m M}$ & 10 & 200 & - & 0,658 & 26,0 & 0,13 & 1,30 \\
\hline
\end{tabular}


ANEXO H - Curvas de calibração utilizadas para determinação de atividade de FVIII e PC e para determinação da concentração de proteínas nas frações da purificação em IMAC$\mathrm{Zn}^{2+}$ empregando coluna HiTrap IMAC HP de $1 \mathrm{~mL}$ e dessorção com imidazol.

Curva de calibração para determinação de atividade de FVIII.

\begin{tabular}{cccc}
\hline $\begin{array}{c}\text { \% } \\
\text { Atividade }\end{array}$ & $\begin{array}{c}\text { Abs 405 } \\
\mathbf{n m}\end{array}$ & $\begin{array}{c}\text { Abs 492 } \\
\mathbf{n m}\end{array}$ & $\begin{array}{c}\text { Abs 405-492 } \\
\mathbf{n m}\end{array}$ \\
\hline $\mathbf{0}$ & 0 & 0 & 0 \\
\hline $\mathbf{5 0}$ & 0,149 & $-0,004$ & 0,153 \\
\hline $\mathbf{1 0 0}$ & 0,361 & $-0,003$ & 0,364 \\
\hline
\end{tabular}

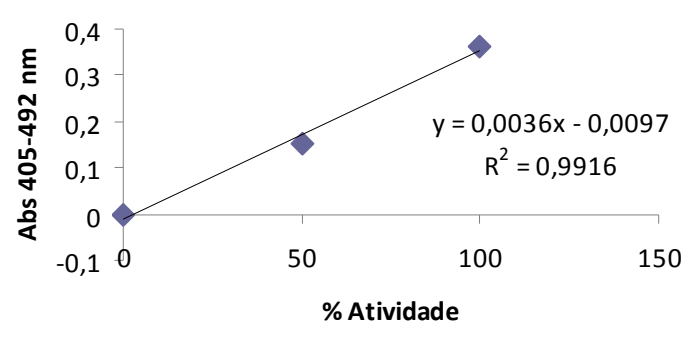

Determinação de atividade de FVIII nas frações da purificação.

\begin{tabular}{cccccc}
\hline Amostra & $\begin{array}{c}\text { Volume da } \\
\text { fração }(\mathbf{m L})\end{array}$ & $\begin{array}{c}\text { Abs } \mathbf{4 0 5 - 4 9 2} \\
\mathbf{n m}\end{array}$ & Atividade & $\begin{array}{c}\text { Atividade } \\
\text { total (U) }\end{array}$ & $\begin{array}{c}\text { \% de atividade } \\
\text { recuperada }\end{array}$ \\
\hline A500 & 25,0 & 0,30 & 101,67 & 2541,67 & 100 \\
\hline FT & 25,0 & 0,01 & 4,67 & 116,67 & 4,59 \\
\hline Reeq & 75 & 0,01 & 5,00 & 375,00 & 14,75 \\
\hline $\mathbf{1 0} \mathbf{m M}$ & 75 & 0,01 & 5,00 & 375,00 & 14,75 \\
\hline $\mathbf{2 0 0} \mathbf{m M}$ & 75 & 0,05 & 18,67 & 1400,00 & 55,08 \\
\hline $\mathbf{5 0 0} \mathbf{m M}$ & 75 & 0,00 & 4,33 & 325,00 & 12,79 \\
\hline
\end{tabular}

Curva de calibração para determinação de atividade de PC.

\begin{tabular}{cccc}
\hline \% Atividade & $\begin{array}{c}\text { Abs 405 } \\
\text { nm }\end{array}$ & $\begin{array}{c}\text { Abs 492 } \\
\text { nm }\end{array}$ & $\begin{array}{c}\text { Abs } \mathbf{4 0 5 - 4 9 2} \\
\mathbf{n m}\end{array}$ \\
\hline $\mathbf{0}$ & 0 & 0 & 0 \\
\hline $\mathbf{1 0}$ & 0,069 & 0 & 0,069 \\
\hline $\mathbf{2 0}$ & 0,134 & 0,003 & 0,131 \\
\hline $\mathbf{5 0}$ & 0,361 & 0,012 & 0,349 \\
\hline $\mathbf{7 5}$ & 0,497 & 0,018 & 0,479 \\
\hline $\mathbf{1 0 0}$ & 0,58 & 0,023 & 0,557 \\
\hline
\end{tabular}

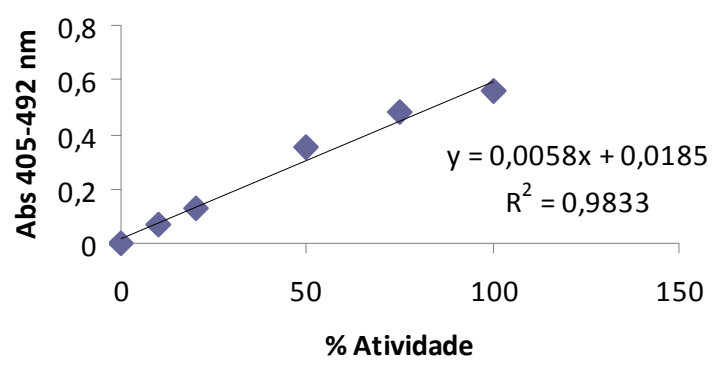

Determinação de atividade de PC nas frações da purificação.

\begin{tabular}{cccccc}
\hline Amostra & $\begin{array}{c}\text { Volume da } \\
\text { fração }(\mathbf{m L})\end{array}$ & $\begin{array}{c}\text { Abs } \mathbf{4 0 5 - 4 9 2} \\
\mathbf{n m}\end{array}$ & Atividade & $\begin{array}{c}\text { Atividade } \\
\text { total (U) }\end{array}$ & $\begin{array}{c}\text { \% de atividade } \\
\text { recuperada }\end{array}$ \\
\hline A500 & 25,0 & 1,01 & 171,64 & 4290,95 & 100 \\
\hline FT & 25,0 & 0,67 & 113,02 & 2825,43 & 65,85 \\
\hline Reeq & 75 & 0,05 & 5,60 & 420,26 & 9,79 \\
\hline $\mathbf{1 0} \mathbf{m M}$ & 75 & 0,00 & $-2,50$ & $-187,50$ & - \\
\hline $\mathbf{2 0 0} \mathbf{m M}$ & 75 & 0,00 & $-2,84$ & $-213,36$ & - \\
\hline $\mathbf{5 0 0} \mathbf{m M}$ & 75 & 0,00 & $-2,84$ & $-213,36$ & - \\
\hline
\end{tabular}


Curva de calibração para determinação da concentração de proteínas nas frações da purificação.

\begin{tabular}{cc}
\hline BSA $(\boldsymbol{\mu g})$ & Abs 595nm \\
\hline $\mathbf{0}$ & 0,508 \\
\hline $\mathbf{5}$ & 0,725 \\
\hline $\mathbf{1 0}$ & 0,905 \\
\hline $\mathbf{1 5}$ & 1,005 \\
\hline $\mathbf{2 0}$ & 1,122 \\
\hline $\mathbf{2 5}$ & 1,206 \\
\hline
\end{tabular}

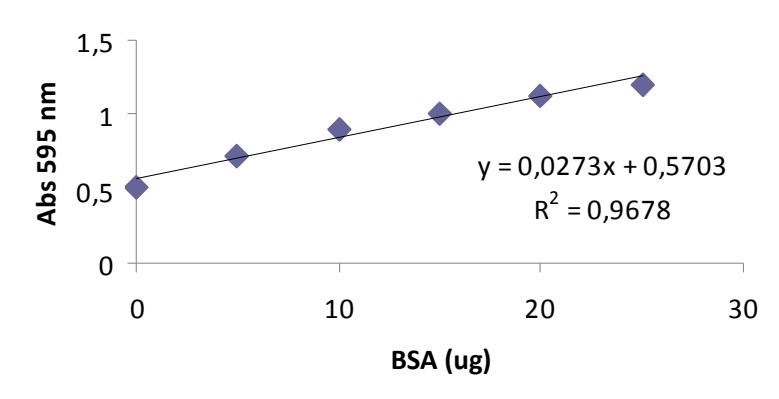

Determinação da concentração de proteínas nas frações da purificação.

\begin{tabular}{cccccccc}
\hline Amostras & $\begin{array}{c}\text { Volume da } \\
\text { fração }(\mathbf{m L})\end{array}$ & $\begin{array}{c}\text { Volume de } \\
\text { amostra }(\boldsymbol{\mu L})\end{array}$ & $\begin{array}{c}\text { Fator de } \\
\text { Diluição }\end{array}$ & $\begin{array}{c}\text { Abs } \\
\mathbf{5 9 5} \mathbf{~ n m}\end{array}$ & $\begin{array}{c}\text { Massa de } \\
\text { proteína }(\boldsymbol{\mu g})\end{array}$ & $\begin{array}{c}\text { Concentração } \\
\text { de proteínas } \\
(\mathbf{m g} / \mathbf{m L})\end{array}$ & $\begin{array}{c}\text { Proteína } \\
\text { total }(\mathbf{m g})\end{array}$ \\
\hline $\mathbf{A 5 0 0}$ & 25,0 & 10 & 20 & 0,857 & 10,6 & 1,06 & 26,57 \\
\hline $\mathbf{F T}$ & 25,0 & 30 & 6,6 & 0,775 & 7,6 & 0,25 & 6,33 \\
\hline $\mathbf{R e e q}$ & $\mathbf{7 5}$ & 10 & 20 & 0,57 & 0,0 & 0,00 & 0,00 \\
\hline $\mathbf{1 0} \mathbf{m M}$ & $\mathbf{7 5}$ & 30 & 6,6 & 0,611 & 1,5 & 0,05 & 3,80 \\
\hline $\mathbf{2 0 0} \mathbf{m M}$ & $\mathbf{7 5}$ & 200 & - & 0,751 & 6,7 & 0,03 & 2,51 \\
\hline $\mathbf{5 0 0} \mathbf{m M}$ & $\mathbf{7 5}$ & 200 & - & 0,539 & $-1,1$ & $-0,01$ & $-0,43$ \\
\hline
\end{tabular}


ANEXO I - Curvas de calibração utilizadas para determinação de atividade de FVIII e PC e para determinação da concentração de proteínas nas frações da purificação em IMAC$\mathrm{Zn}^{2+}$ empregando coluna Chelating Sepharose FF de $10 \mathrm{~mL}$ e dessorção com imidazol.

Curva de calibração para determinação de atividade de FVIII.

\begin{tabular}{cccc}
\hline $\begin{array}{c}\mathbf{\%} \\
\text { Atividade }\end{array}$ & $\begin{array}{c}\text { Abs 405 } \\
\mathbf{n m}\end{array}$ & $\begin{array}{c}\text { Abs 492 } \\
\mathbf{n m}\end{array}$ & $\begin{array}{c}\text { Abs 405-492 } \\
\mathbf{n m}\end{array}$ \\
\hline $\mathbf{0}$ & 0 & 0 & 0 \\
\hline $\mathbf{5 0}$ & 0,149 & $-0,004$ & 0,153 \\
\hline $\mathbf{1 0 0}$ & 0,361 & $-0,003$ & 0,364 \\
\hline
\end{tabular}

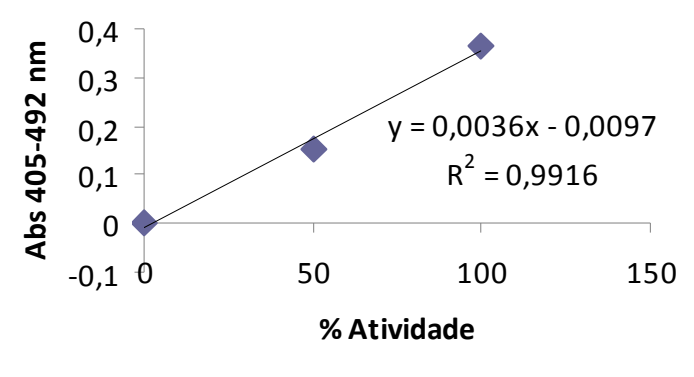

Determinação de atividade de FVIII nas frações da purificação.

\begin{tabular}{cccccc}
\hline Amostra & $\begin{array}{c}\text { Volume da } \\
\text { fração }(\mathbf{m L})\end{array}$ & $\begin{array}{c}\text { Abs } \mathbf{4 0 5 - 4 9 2} \\
\mathbf{n m}\end{array}$ & Atividade & $\begin{array}{c}\text { Atividade } \\
\text { total (U) }\end{array}$ & $\begin{array}{c}\text { \% de atividade } \\
\text { recuperada }\end{array}$ \\
\hline A500A & 50 & 0,38 & 109,08 & 5454,17 & 100 \\
\hline FT & 50 & 0,19 & 56,58 & 2829,17 & 51,9 \\
\hline Reeq & 150 & 0,04 & 14,08 & 2112,50 & 38,7 \\
\hline $\mathbf{1 0} \mathbf{m M}$ & 150 & 0,01 & 4,92 & 737,50 & 13,5 \\
\hline $\mathbf{2 0 0} \mathbf{m M}$ & 150 & 0,01 & 4,92 & 737,50 & 13,5 \\
\hline $\mathbf{5 0 0} \mathbf{m M}$ & 150 & 0,01 & 4,36 & 654,17 & 12,0 \\
\hline
\end{tabular}

Curva de calibração para determinação de atividade de PC.

\begin{tabular}{cccc}
\hline $\begin{array}{c}\text { \% } \\
\text { Atividade }\end{array}$ & $\begin{array}{c}\text { Abs 405 } \\
\mathbf{n m}\end{array}$ & $\begin{array}{c}\text { Abs 492 } \\
\mathbf{n m}\end{array}$ & $\begin{array}{c}\text { Abs } \mathbf{4 0 5 - 4 9 2} \\
\mathbf{n m}\end{array}$ \\
\hline $\mathbf{0}$ & 0 & 0 & 0 \\
\hline $\mathbf{1 0}$ & 0,069 & 0 & 0,069 \\
\hline $\mathbf{2 0}$ & 0,134 & 0,003 & 0,131 \\
\hline $\mathbf{5 0}$ & 0,361 & 0,012 & 0,349 \\
\hline $\mathbf{7 5}$ & 0,497 & 0,018 & 0,479 \\
\hline $\mathbf{1 0 0}$ & 0,58 & 0,023 & 0,557 \\
\hline
\end{tabular}

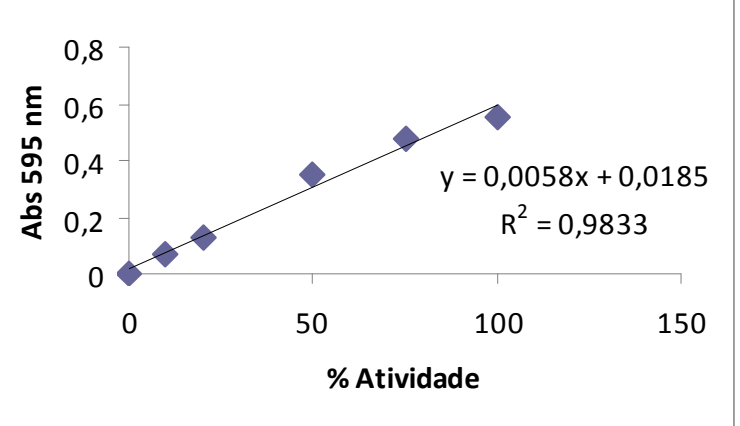

Determinação de atividade de PC nas frações da purificação.

\begin{tabular}{cccccc}
\hline Amostra & $\begin{array}{c}\text { Volume da } \\
\text { fração }(\mathbf{m L})\end{array}$ & $\begin{array}{c}\text { Abs } \mathbf{4 0 5 - 4 9 2} \\
\mathbf{n m}\end{array}$ & Atividade & $\begin{array}{c}\text { Atividade } \\
\text { total (U) }\end{array}$ & $\begin{array}{c}\text { \% de atividade } \\
\text { recuperada }\end{array}$ \\
\hline A500A & 50 & 0,863 & 145,60 & 7280 & 100 \\
\hline FT & 50 & 0,460 & 76,12 & 3806 & 52,3 \\
\hline Reeq & 150 & 0,092 & 12,67 & 1901 & 26,1 \\
\hline $\mathbf{1 0} \mathbf{m M}$ & 150 & 0,003 & $-2,67$ & -401 & - \\
\hline $\mathbf{2 0 0} \mathbf{m M}$ & 150 & 0,002 & $-2,84$ & -427 & - \\
\hline $\mathbf{5 0 0} \mathbf{m M}$ & 150 & 0,003 & $-2,67$ & -401 & - \\
\hline
\end{tabular}


Curva de calibração para determinação da concentração de proteína nas frações da purificação.

\begin{tabular}{cc}
\hline BSA $(\boldsymbol{\mu g})$ & Abs $\mathbf{5 9 5 n m}$ \\
\hline $\mathbf{0}$ & 0,512 \\
\hline $\mathbf{5}$ & 0,753 \\
\hline $\mathbf{1 0}$ & 0,929 \\
\hline $\mathbf{1 5}$ & 1,039 \\
\hline $\mathbf{2 0}$ & 1,155 \\
\hline $\mathbf{2 5}$ & 1,265 \\
\hline
\end{tabular}

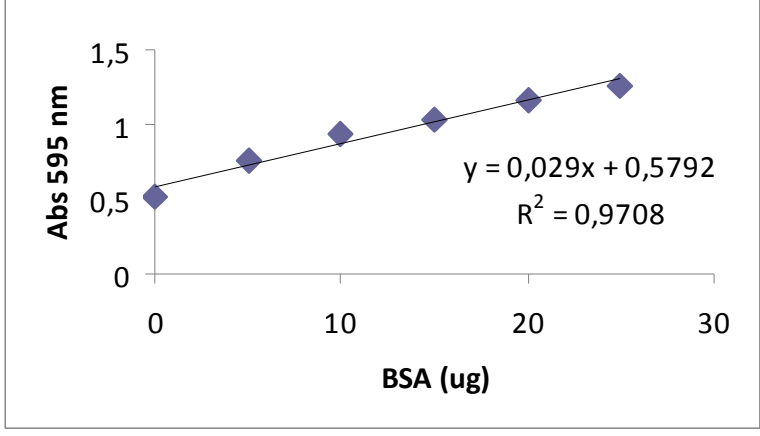

Determinação da concentração de proteínas nas frações da purificação.

\begin{tabular}{cccccccc}
\hline Amostras & $\begin{array}{c}\text { Volume da } \\
\text { fração }(\mathbf{m L})\end{array}$ & $\begin{array}{c}\text { Volume de } \\
\text { amostra } \\
(\boldsymbol{\mu L})\end{array}$ & $\begin{array}{c}\text { Fator de } \\
\text { diluição }\end{array}$ & $\begin{array}{c}\text { Abs 595 } \\
\mathbf{n m}\end{array}$ & $\begin{array}{c}\text { Massa de } \\
\text { proteína } \\
(\boldsymbol{\mu g})\end{array}$ & $\begin{array}{c}\text { Concentração } \\
\text { de proteína } \\
(\mathbf{m g} / \mathbf{m L})\end{array}$ & $\begin{array}{c}\text { Proteína } \\
\text { total (mg) }\end{array}$ \\
\hline $\mathbf{A 5 0 0}$ & 50,0 & 10 & 20 & 0,859 & 9,7 & 0,97 & 48,28 \\
\hline $\mathbf{F T}$ & 50,0 & 10 & 20 & 0,704 & 4,3 & 0,43 & 21,55 \\
\hline $\mathbf{R e e q}$ & 150 & 200 & - & 1,12 & 18,7 & 0,09 & 13,99 \\
\hline $\mathbf{1 0} \mathbf{m M}$ & 150 & 200 & - & 0,516 & $-2,2$ & $-0,01$ & $-1,63$ \\
\hline $\mathbf{2 0 0} \mathbf{m M}$ & 150 & 200 & - & 0,523 & $-1,9$ & $-0,01$ & $-1,45$ \\
\hline $\mathbf{5 0 0} \mathbf{m M}$ & 150 & 200 & - & 0,526 & $-1,8$ & $-0,01$ & $-1,37$ \\
\hline
\end{tabular}


ANEXO J - Curvas de calibração utilizadas para determinação de atividade de FVIII e PC e para determinação da concentração de proteínas nas frações da purificação em IMAC$\mathrm{Zn}^{2+}$ empregando coluna HisTrap HP de $5 \mathrm{~mL}$ e dessorção com imidazol em pH 7,0.

Curva de calibração para determinação de atividade de FVIII.

\begin{tabular}{cccc}
\hline $\begin{array}{c}\% \\
\text { Atividade }\end{array}$ & $\begin{array}{c}\text { Abs 405 } \\
\mathbf{n m}\end{array}$ & $\begin{array}{c}\text { Abs 492 } \\
\mathbf{n m}\end{array}$ & $\begin{array}{c}\text { Abs 405-492 } \\
\mathbf{n m}\end{array}$ \\
\hline $\mathbf{0}$ & 0 & 0 & 0 \\
\hline $\mathbf{5 0}$ & 0,213 & $-0,001$ & 0,214 \\
\hline $\mathbf{1 0 0}$ & 0,453 & 0 & 0,453 \\
\hline
\end{tabular}

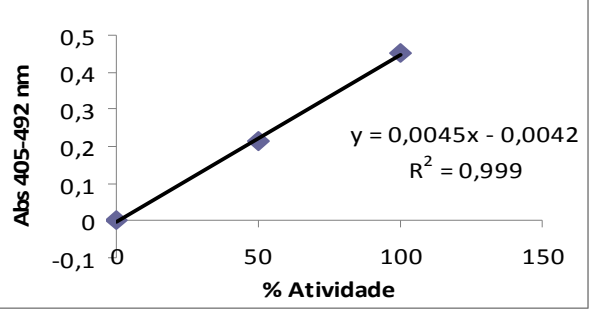

Determinação de atividade de FVIII nas frações da purificação.

\begin{tabular}{cccccc}
\hline Amostra & $\begin{array}{c}\text { Volume da } \\
\text { fração }(\mathbf{m L})\end{array}$ & $\begin{array}{c}\text { Abs } \mathbf{4 0 5 - 4 9 2} \\
\mathbf{n m}\end{array}$ & Atividade & $\begin{array}{c}\text { Atividade } \\
\text { total (U) }\end{array}$ & $\begin{array}{c}\text { \% de atividade } \\
\text { recuperada }\end{array}$ \\
\hline $\mathbf{A 5 0 0}$ & $\mathbf{2 5}$ & 0,660 & 166,00 & 4150,00 & 100,00 \\
\hline $\mathbf{F T}$ & 25 & $-0,012$ & $-2,00$ & $-50,00$ & $-1,20$ \\
\hline Reeq & 75 & $-0,012$ & $-2,00$ & $-150,00$ & $-3,61$ \\
\hline $\mathbf{1 0} \mathbf{m M}$ & 75 & $-0,007$ & $-0,75$ & $-56,25$ & $-1,36$ \\
\hline $\mathbf{3 0} \mathbf{m M}$ & 75 & 0,021 & 6,25 & 468,75 & 11,30 \\
\hline $\mathbf{5 0} \mathbf{m M}$ & $\mathbf{7 5}$ & 0,065 & 17,25 & 1293,75 & 31,17 \\
\hline $\mathbf{1 0 0} \mathbf{m M}$ & $\mathbf{7 5}$ & 0,011 & 3,75 & 281,25 & 6,78 \\
\hline $\mathbf{2 0 0} \mathbf{m M}$ & 75 & $-0,011$ & $-1,75$ & $-131,25$ & $-3,16$ \\
\hline $\mathbf{5 0 0} \mathbf{m M}$ & 75 & $-0,015$ & $-2,75$ & $-206,25$ & $-4,97$ \\
\hline
\end{tabular}

Curva de calibração para determinação da atividade de PC.

\begin{tabular}{cccc}
\hline $\begin{array}{c}\text { \% } \\
\text { Atividade }\end{array}$ & $\begin{array}{c}\text { Abs 405 } \\
\mathbf{n m}\end{array}$ & $\begin{array}{c}\text { Abs 492 } \\
\mathbf{n m}\end{array}$ & $\begin{array}{c}\text { Abs 405-492 } \\
\mathbf{n m}\end{array}$ \\
\hline $\mathbf{0}$ & 0 & 0 & 0 \\
\hline $\mathbf{1 0}$ & 0,088 & 0,003 & 0,085 \\
\hline $\mathbf{2 0}$ & 0,16 & 0,001 & 0,159 \\
\hline $\mathbf{5 0}$ & 0,414 & 0,008 & 0,406 \\
\hline $\mathbf{7 5}$ & 0,568 & 0,01 & 0,558 \\
\hline $\mathbf{1 0 0}$ & 0,693 & 0,018 & 0,675 \\
\hline
\end{tabular}

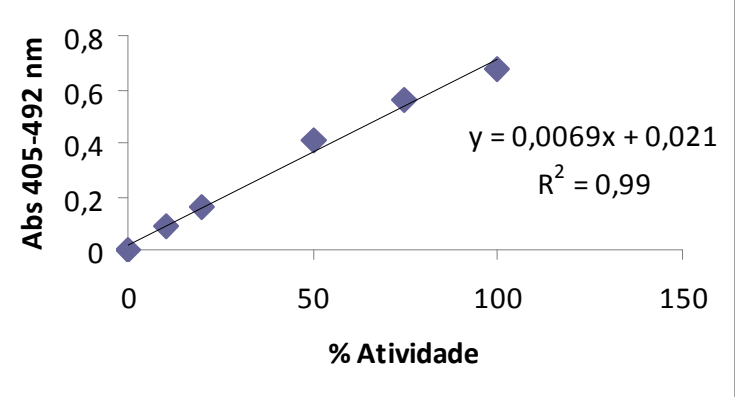

Determinação de atividade de PC nas frações da purificação.

\begin{tabular}{|c|c|c|c|c|c|}
\hline Amostra & $\begin{array}{l}\text { Volume da } \\
\text { fração }(\mathrm{mL})\end{array}$ & $\begin{array}{c}\text { Abs } 405-492 \\
n m\end{array}$ & Atividade & $\begin{array}{c}\text { Atividade } \\
\text { total (U) }\end{array}$ & $\begin{array}{c}\% \text { de atividade } \\
\text { recuperada }\end{array}$ \\
\hline A500 & 25 & 1,194 & 198,83 & 4971 & 100 \\
\hline FT & 25 & 0,052 & 8,50 & 213 & 4,27 \\
\hline Reeq & 75 & 0,144 & 23,83 & 1788 & 35,96 \\
\hline $10 \mathrm{mM}$ & 75 & 0,078 & 12,83 & 963 & 19,36 \\
\hline $30 \mathrm{mM}$ & 75 & $-0,048$ & $-8,17$ & -613 & $-12,32$ \\
\hline $50 \mathrm{mM}$ & 75 & $-0,050$ & $-8,50$ & -638 & $-12,82$ \\
\hline $100 \mathrm{mM}$ & 75 & $-0,052$ & $-8,83$ & -663 & $-13,33$ \\
\hline $200 \mathrm{mM}$ & 75 & $-0,051$ & $-8,67$ & -650 & $-13,08$ \\
\hline $500 \mathrm{mM}$ & 75 & $-0,053$ & $-9,00$ & -675 & $-13,58$ \\
\hline
\end{tabular}


Curva de calibração para determinação da concentração de proteínas nas frações da purificação.

\begin{tabular}{cc}
\hline BSA $(\boldsymbol{\mu g})$ & Abs $595 \mathbf{n m}$ \\
\hline $\mathbf{0}$ & 0,541 \\
\hline $\mathbf{5}$ & 0,812 \\
\hline $\mathbf{1 0}$ & 0,975 \\
\hline $\mathbf{1 5}$ & 1,094 \\
\hline $\mathbf{2 0}$ & 1,225 \\
\hline $\mathbf{2 5}$ & 1,354 \\
\hline
\end{tabular}

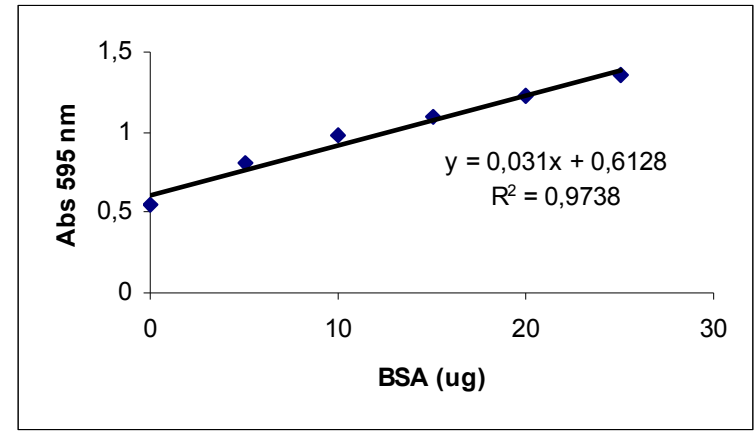

Determinação da concentração de proteínas nas frações da purificação.

\begin{tabular}{cccccccc}
\hline Amostras & $\begin{array}{c}\text { Volume da } \\
\text { fração }(\mathbf{m L})\end{array}$ & $\begin{array}{c}\text { Volume de } \\
\text { amostra }(\boldsymbol{\mu L})\end{array}$ & $\begin{array}{c}\text { Fator de } \\
\text { diluição }\end{array}$ & $\begin{array}{c}\text { Abs 595 } \\
\mathbf{n m}\end{array}$ & $\begin{array}{c}\text { Massa de } \\
\text { proteína }(\boldsymbol{\mu g})\end{array}$ & $\begin{array}{c}\text { Concentração } \\
\text { de proteínas } \\
(\mathbf{m g} / \mathbf{m L})\end{array}$ & $\begin{array}{c}\text { Proteína } \\
\text { Total }(\mathbf{m g})\end{array}$ \\
\hline $\mathbf{A 5 0 0}$ & 25 & 10 & 20 & 1,022 & 13,2 & 1,32 & 33,00 \\
\hline $\mathbf{F T}$ & $\mathbf{2 5}$ & 30 & 6,6 & 0,774 & 5,2 & 0,17 & 4,33 \\
\hline $\mathbf{R e e q}$ & 75 & 200 & - & 0,827 & 6,9 & 0,03 & 2,59 \\
\hline $\mathbf{1 0} \mathbf{m M}$ & 75 & 30 & 6,6 & 0,811 & 6,4 & 0,21 & 15,98 \\
\hline $\mathbf{3 0} \mathbf{m M}$ & 75 & 30 & 6,6 & 0,688 & 2,4 & 0,08 & 6,06 \\
\hline $\mathbf{5 0} \mathbf{m M}$ & 75 & 200 & - & 0,591 & $-0,7$ & 0,00 & $-0,26$ \\
\hline $\mathbf{1 0 0} \mathbf{m M}$ & 75 & 200 & - & 0,551 & $-2,0$ & $-0,01$ & $-0,75$ \\
\hline $\mathbf{2 0 0} \mathbf{m M}$ & 75 & 200 & - & 0,559 & $-1,7$ & $-0,01$ & $-0,65$ \\
\hline $\mathbf{5 0 0} \mathbf{m M}$ & $\mathbf{7 5}$ & $\mathbf{2 0 0}$ & - & 0,577 & $-1,2$ & $-0,01$ & $-0,43$ \\
\hline
\end{tabular}


ANEXO K - Curvas de calibração utilizadas para determinação de atividade de FVIII e PC e para determinação da concentração de proteínas nas frações da purificação em IMAC$\mathrm{Zn}^{2+}$ empregando coluna HisTrap HP de $5 \mathrm{~mL}$ e dessorção com variação de $\mathrm{pH}$ a partir de $\mathrm{pH} 7,0$.

Curva de calibração para determinação de atividade de FVIII.

\begin{tabular}{cccc}
\hline $\begin{array}{c}\boldsymbol{\%} \\
\text { Atividade }\end{array}$ & $\begin{array}{c}\text { Abs 405 } \\
\mathbf{n m}\end{array}$ & $\begin{array}{c}\text { Abs 492 } \\
\mathbf{n m}\end{array}$ & $\begin{array}{c}\text { Abs 405-492 } \\
\mathbf{n m}\end{array}$ \\
\hline $\mathbf{0}$ & 0 & 0 & 0 \\
\hline $\mathbf{5 0}$ & 0,213 & $-0,001$ & 0,214 \\
\hline $\mathbf{1 0 0}$ & 0,453 & 0 & 0,453 \\
\hline
\end{tabular}

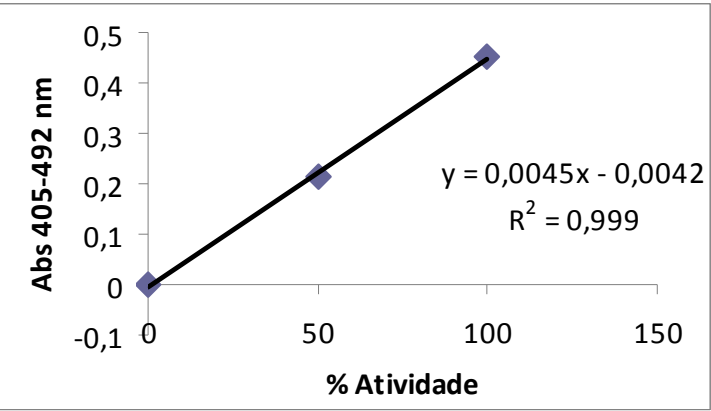

Determinação de atividade de FVIII nas frações da purificação.

\begin{tabular}{cccccc}
\hline Amostras & $\begin{array}{c}\text { Volume da } \\
\text { fração }(\mathbf{m L})\end{array}$ & $\begin{array}{c}\text { Abs 405-492 } \\
\mathbf{N m}\end{array}$ & Atividade & $\begin{array}{c}\text { Atividade } \\
\text { total (U) }\end{array}$ & $\begin{array}{c}\text { \% de atividade } \\
\text { recuperada }\end{array}$ \\
\hline $\begin{array}{c}\text { A500A pH } \\
\mathbf{7 , 0}\end{array}$ & 25 & 0,633 & 159,25 & 3981,25 & 100 \\
\hline FT pH 7,0 & 25 & $-0,011$ & $-1,75$ & $-43,75$ & - \\
\hline Reeq Ph 7,0 & 75 & $-0,009$ & $-1,25$ & $-93,75$ & - \\
\hline pH 6,0 & 75 & $-0,007$ & $-0,75$ & $-56,25$ & - \\
\hline pH 5,0 & 75 & 0,037 & 10,25 & 768,75 & 19,31 \\
\hline pH 4,0 & 75 & $-0,013$ & $-2,25$ & $-168,75$ & - \\
\hline
\end{tabular}

Curva de calibração para determinação da atividade de PC.

\begin{tabular}{cccc}
\hline $\begin{array}{c}\text { \% } \\
\text { Atividade }\end{array}$ & $\begin{array}{c}\text { Abs 405 } \\
\mathbf{n m}\end{array}$ & $\begin{array}{c}\text { Abs 492 } \\
\mathbf{n m}\end{array}$ & $\begin{array}{c}\text { Abs } \mathbf{4 0 5 - 4 9 2} \\
\mathbf{n m}\end{array}$ \\
\hline $\mathbf{0}$ & 0 & 0 & 0 \\
\hline $\mathbf{1 0}$ & 0,088 & 0,003 & 0,085 \\
\hline $\mathbf{2 0}$ & 0,16 & 0,001 & 0,159 \\
\hline $\mathbf{5 0}$ & 0,414 & 0,008 & 0,406 \\
\hline $\mathbf{7 5}$ & 0,568 & 0,01 & 0,558 \\
\hline $\mathbf{1 0 0}$ & 0,693 & 0,018 & 0,675 \\
\hline
\end{tabular}

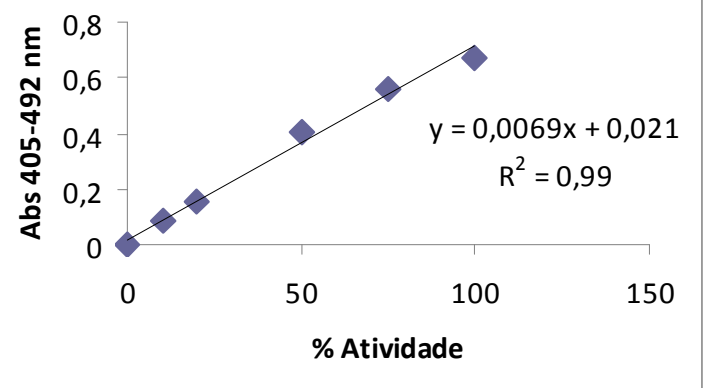

Determinação de atividade de PC nas frações da purificação.

\begin{tabular}{cccccc}
\hline Amostras & $\begin{array}{c}\text { Volume da } \\
\text { Fração (mL) }\end{array}$ & $\begin{array}{c}\text { Abs 405-492 } \\
\text { nm }\end{array}$ & Atividade & $\begin{array}{c}\text { Atividade } \\
\text { total (U) }\end{array}$ & $\begin{array}{c}\text { \% de atividade } \\
\text { Recuperada }\end{array}$ \\
\hline A500A pH 7,0 & 25 & 1,229 & 204,7 & 5116,7 & 100 \\
\hline FT Ph 7,0 & 25 & 0,102 & 16,8 & 420,8 & 8,2 \\
\hline Reeq pH 7,0 & 75 & 0,171 & 28,3 & 2125,0 & 41,5 \\
\hline pH 6,0 & 75 & 0,098 & 16,2 & 1212,5 & 23,7 \\
\hline pH 5,0 & 75 & $-0,002$ & $-0,5$ & $-37,5$ & - \\
\hline pH 4,0 & 75 & $-0,006$ & $-1,2$ & $-87,5$ & - \\
\hline
\end{tabular}


Curva de calibração para determinar a concentração de proteínas nas frações da purificação.

\begin{tabular}{cc}
\hline BSA $(\boldsymbol{\mu g})$ & Abs $595 \mathrm{~nm}$ \\
\hline $\mathbf{0}$ & 0,502 \\
\hline $\mathbf{5}$ & 0,765 \\
\hline $\mathbf{1 0}$ & 0,907 \\
\hline $\mathbf{1 5}$ & 1,046 \\
\hline $\mathbf{2 0}$ & 1,178 \\
\hline $\mathbf{2 5}$ & 1,253 \\
\hline
\end{tabular}

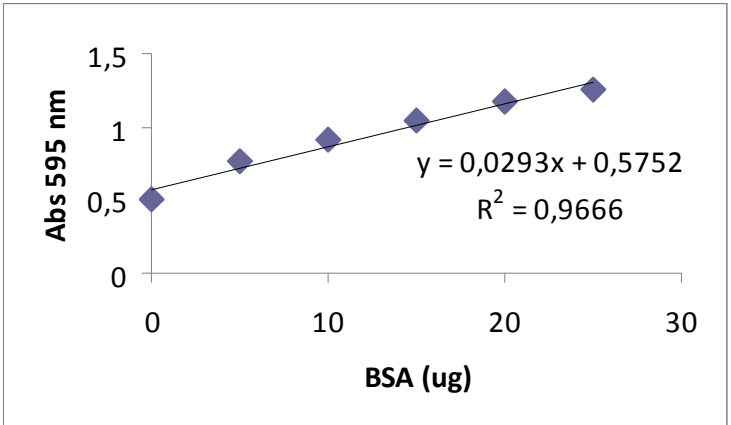

Determinação da concentração de proteínas nas frações da purificação.

\begin{tabular}{ccccccccc}
\hline Amostras & $\begin{array}{c}\text { Volume da } \\
\text { fração }(\mathbf{m L})\end{array}$ & $\begin{array}{c}\text { Volume de } \\
\text { amostra }(\boldsymbol{\mu L})\end{array}$ & $\begin{array}{c}\text { Fator de } \\
\text { diluição }\end{array}$ & $\begin{array}{c}\text { Abs 595 } \\
\mathbf{n m}\end{array}$ & $\begin{array}{c}\text { Massa de } \\
\text { proteína } \\
(\boldsymbol{\mu g})\end{array}$ & $\begin{array}{c}\text { Concentração } \\
\text { de proteínas } \\
\mathbf{( m g / m L})\end{array}$ & $\begin{array}{c}\text { Proteína } \\
\text { total } \\
(\mathbf{m g})\end{array}$ \\
\hline A500A pH 7,0 & 25 & 10 & 20 & 1,013 & 15,1 & 1,51 & 37,76 \\
\hline FT pH 7,0 & 25 & 30 & 6,6 & 0,769 & 6,7 & 0,22 & 5,57 \\
\hline Reeq pH 7,0 & 75 & 200 & - & 0,792 & 7,5 & 0,04 & 2,81 \\
\hline pH 6,0 & 75 & 50 & 4 & 0,727 & 5,2 & 0,10 & 7,86 \\
\hline pH 5,0 & 75 & 50 & 4 & 0,98 & 14,0 & 0,28 & 20,95 \\
\hline pH 4,0 & 75 & 200 & - & 0,582 & 0,2 & 0,00 & 0,09 \\
\hline
\end{tabular}


ANEXO $L$ - Curvas de calibração utilizadas para determinação de atividade de FVIII e PC e para determinação da concentração de proteínas nas frações da purificação em IMAC$\mathrm{Zn}^{2+}$ empregando coluna HisTrap HP de $5 \mathrm{~mL}$ e dessorção com variação de $\mathrm{pH}$ a partir de $\mathrm{pH} 6,0$.

Curva de calibração para determinação de atividade de FVIII.

\begin{tabular}{cccc}
\hline \% Atividade & $\begin{array}{c}\text { Abs 405 } \\
\mathbf{n m}\end{array}$ & $\begin{array}{c}\text { Abs 492 } \\
\mathbf{n m}\end{array}$ & $\begin{array}{c}\text { Abs 405- } \\
\mathbf{4 9 2} \mathbf{~ n m}\end{array}$ \\
\hline $\mathbf{0}$ & 0 & 0 & 0 \\
\hline $\mathbf{5 0}$ & 0,178 & $-0,004$ & 0,182 \\
\hline $\mathbf{1 0 0}$ & 0,347 & 0 & 0,347 \\
\hline
\end{tabular}

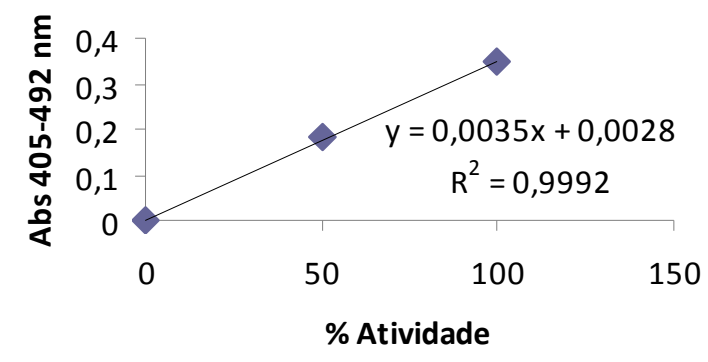

Determinação de atividade de FVIII nas frações da purificação.

\begin{tabular}{cccccc}
\hline Amostra & $\begin{array}{c}\text { Volume da } \\
\text { fração (mL) }\end{array}$ & $\begin{array}{c}\text { Abs 405-492 } \\
\text { nm }\end{array}$ & Atividade & $\begin{array}{c}\text { Atividade } \\
\text { total (U) }\end{array}$ & $\begin{array}{c}\text { \% de atividade } \\
\text { recuperada }\end{array}$ \\
\hline A500 pH 6,0 & 25 & 0,157 & 44 & 1101 & 100 \\
\hline FT pH 6,0 & 25 & $-0,016$ & -5 & -134 & - \\
\hline Reeq pH 6,0 & 75 & $-0,020$ & -7 & -489 & - \\
\hline pH 5,0 & 75 & $-0,013$ & -5 & -339 & - \\
\hline pH 4,0 & 75 & $-0,018$ & -6 & -446 & - \\
\hline
\end{tabular}

Curva de calibração para determinação de atividade de PC.

\begin{tabular}{cccc}
\hline $\begin{array}{c}\text { \% Atividade } \\
\mathbf{0}\end{array}$ & $\begin{array}{c}\text { Abs 405 } \\
\mathbf{n m}\end{array}$ & $\begin{array}{c}\text { Abs 492 } \\
\mathbf{n m}\end{array}$ & $\begin{array}{c}\text { Abs 405-492 } \\
\mathbf{n m}\end{array}$ \\
\hline $\mathbf{1 0}$ & 0,077 & 0 & 0 \\
\hline $\mathbf{2 0}$ & 0,152 & 0,001 & 0,076 \\
\hline $\mathbf{5 0}$ & 0,357 & 0,003 & 0,15 \\
\hline $\mathbf{7 5}$ & 0,507 & 0,009 & 0,354 \\
\hline $\mathbf{1 0 0}$ & 0,715 & 0,011 & 0,798 \\
\hline
\end{tabular}

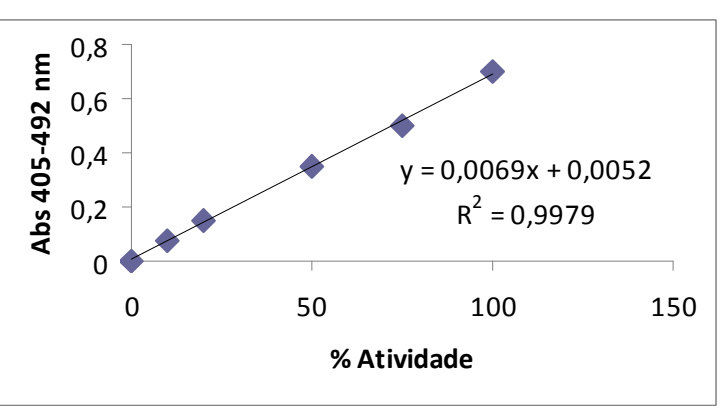

Determinação de atividade de PC nas frações da purificação.

\begin{tabular}{cccccc}
\hline Amostra & $\begin{array}{c}\text { Volume da } \\
\text { fração }(\mathbf{m L})\end{array}$ & $\begin{array}{c}\text { Abs } \mathbf{4 0 5 - 4 9 2} \\
\mathbf{n m}\end{array}$ & Atividade & $\begin{array}{c}\text { Atividade } \\
\text { total (U) }\end{array}$ & $\begin{array}{c}\text { \% de atividade } \\
\text { recuperada }\end{array}$ \\
\hline A500 pH 6,0 & 25 & 0,714 & 103 & 2568 & 100 \\
\hline FT pH 6,0 & 25 & 0,424 & 61 & 1517 & 59,09 \\
\hline Reeq pH 6,0 & 75 & 0,014 & 1 & 96 & 3,72 \\
\hline pH 5,0 & 75 & $-0,028$ & -5 & -361 & - \\
\hline pH 4,0 & 75 & $-0,028$ & -5 & -361 & - \\
\hline
\end{tabular}


Curva de calibração para determinação da concentração de proteínas nas frações da purificação.

\begin{tabular}{cc}
\hline BSA $(\boldsymbol{\mu g})$ & Abs $595 \mathrm{~nm}$ \\
\hline $\mathbf{0}$ & 0,534 \\
\hline $\mathbf{5}$ & 0,743 \\
\hline $\mathbf{1 0}$ & 0,885 \\
\hline $\mathbf{1 5}$ & 1,035 \\
\hline $\mathbf{2 0}$ & 1,157 \\
\hline $\mathbf{2 5}$ & 1,21 \\
\hline
\end{tabular}

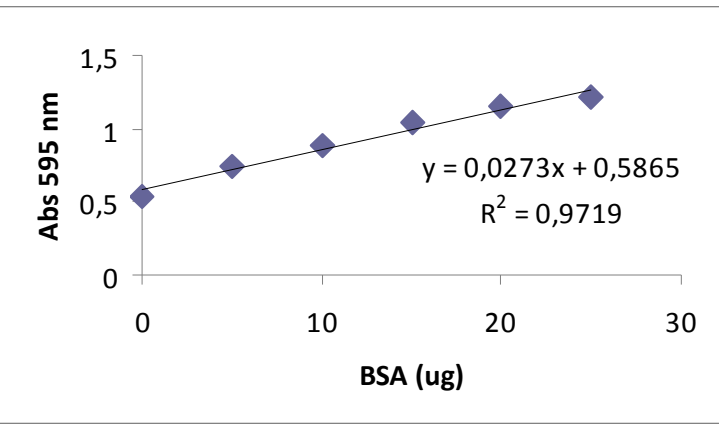

Determinação da concentração de proteínas nas frações da purificação.

\begin{tabular}{ccccccccc}
\hline Amostras & $\begin{array}{c}\text { Volume da } \\
\text { fração }(\mathbf{m L})\end{array}$ & $\begin{array}{c}\text { Volume de } \\
\text { amostra }(\boldsymbol{\mu L})\end{array}$ & $\begin{array}{c}\text { Fator de } \\
\text { diluição }\end{array}$ & $\begin{array}{c}\text { Abs 595 } \\
\mathbf{n m}\end{array}$ & $\begin{array}{c}\text { Massa de } \\
\text { proteina }(\boldsymbol{\mu g})\end{array}$ & $\begin{array}{c}\text { Concentração } \\
\text { de proteína } \\
(\mathbf{m g} / \mathbf{m L})\end{array}$ & $\begin{array}{c}\text { Proteína } \\
\text { total }(\mathbf{m g})\end{array}$ \\
\hline $\mathbf{A 5 0 0 A}$ & 25 & 10 & 20 & 0,797 & 7,8 & 0,78 & 19,54 \\
\hline FT & 25 & 30 & 6,6 & 0,728 & 5,3 & 0,18 & 4,38 \\
\hline Reeq & 75 & 200 & - & 1,047 & 17,1 & 0,09 & 6,40 \\
\hline $\mathbf{p H = 5}$ & 75 & 50 & 4 & 0,692 & 3,9 & 0,08 & 5,89 \\
\hline $\mathbf{p H = 4}$ & 75 & 200 & - & 0,534 & $-1,9$ & $-0,01$ & $-0,72$ \\
\hline
\end{tabular}


ANEXO M - Curvas de calibração utilizadas para determinação de atividade de FVIII e PC e para determinação da concentração de proteínas nas frações da purificação em IMAC- $\mathrm{Zn}^{2+}$ empregando coluna HiTrap IMAC HP de $1 \mathrm{~mL}$ e dessorção com $\mathrm{NH}_{4} \mathrm{Cl}$.

Curva de calibração para determinação de atividade de FVIII.

\begin{tabular}{cccc}
\hline $\begin{array}{c}\text { \% } \\
\text { Atividade }\end{array}$ & $\begin{array}{c}\text { Abs 405 } \\
\mathbf{n m}\end{array}$ & $\begin{array}{c}\text { Abs 492 } \\
\mathbf{n m}\end{array}$ & $\begin{array}{c}\text { Abs 405-492 } \\
\mathbf{N m}\end{array}$ \\
\hline $\mathbf{0}$ & 0 & 0 & 0 \\
\hline $\mathbf{5 0}$ & 0,173 & $-0,005$ & 0,178 \\
\hline $\mathbf{1 0 0}$ & 0,344 & $-0,002$ & 0,346 \\
\hline
\end{tabular}

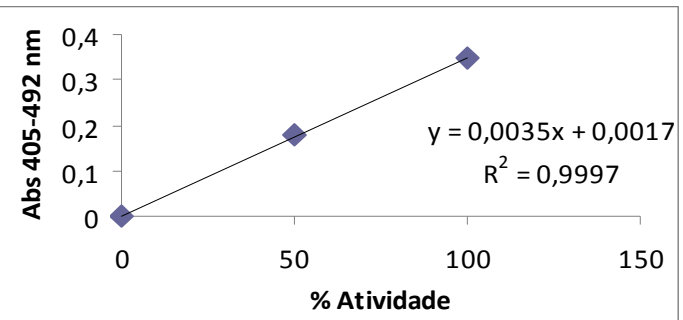

Determinação de atividade de FVIII nas frações da purificação.

\begin{tabular}{cccccc}
\hline Amostra & $\begin{array}{c}\text { Volume da } \\
\text { fração }(\mathbf{m L})\end{array}$ & $\begin{array}{c}\text { Abs } \mathbf{4 0 5 - 4 9 2} \\
\mathbf{n m}\end{array}$ & Atividade & $\begin{array}{c}\text { Atividade } \\
\text { total (U) }\end{array}$ & $\begin{array}{c}\text { \% de atividade } \\
\text { recuperada }\end{array}$ \\
\hline $\mathbf{A 5 0 0}$ & 9,6 & 0,331 & 110 & 1056 & 100 \\
\hline $\mathbf{F T}$ & 9,6 & 0,008 & 2,3 & 22,4 & 2,1 \\
\hline Reeq & 28,8 & 0,021 & 6,7 & 192,0 & 18,2 \\
\hline $\mathbf{0 - 2 0} \%$ & 2 & 0,035 & 11,3 & 22,7 & 2,1 \\
\hline $\mathbf{2 0 - 4 0} \%$ & 2 & 0,038 & 12,3 & 24,7 & 2,3 \\
\hline $\mathbf{4 0 - 6 0} \%$ & 2 & 0,038 & 12,3 & 24,7 & 2,3 \\
\hline $\mathbf{6 0 - 8 0} \%$ & 2 & 0,047 & 15,3 & 30,7 & 2,9 \\
\hline $\mathbf{8 0 - 1 0 0 \%}$ & 2 & 0,069 & 22,7 & 45,3 & 4,3 \\
\hline $\mathbf{1 0 0} \%$ & 18 & 0,07 & 23,0 & 414,0 & 39,2 \\
\hline
\end{tabular}

Curva de calibração para determinação de atividade de PC.

\begin{tabular}{cccc}
\hline $\begin{array}{c}\text { \% } \\
\text { Atividade }\end{array}$ & $\begin{array}{c}\text { Abs 405 } \\
\mathbf{n m}\end{array}$ & $\begin{array}{c}\text { Abs 492 } \\
\mathbf{n m}\end{array}$ & $\begin{array}{c}\text { Abs 405-492 } \\
\mathbf{n m}\end{array}$ \\
\hline $\mathbf{0}$ & 0 & 0 & 0 \\
\hline $\mathbf{1 0}$ & 0,087 & 0,007 & 0,08 \\
\hline $\mathbf{2 0}$ & 0,177 & 0,01 & 0,167 \\
\hline $\mathbf{5 0}$ & 0,415 & 0,027 & 0,388 \\
\hline $\mathbf{7 5}$ & 0,574 & 0,033 & 0,541 \\
\hline $\mathbf{1 0 0}$ & 0,708 & 0,036 & 0,672 \\
\hline
\end{tabular}

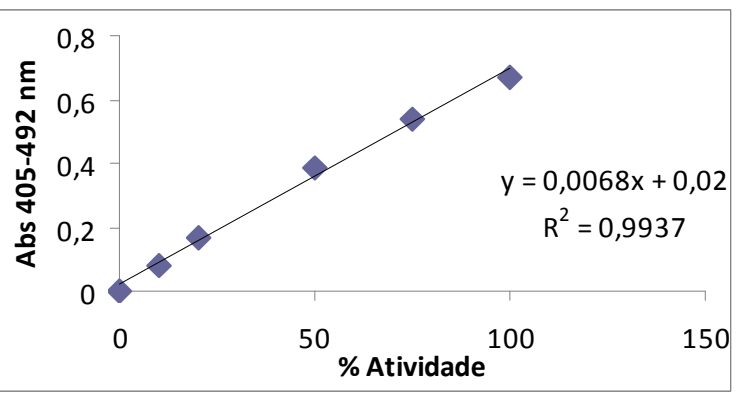

Determinação da atividade de PC nas frações da purificação.

\begin{tabular}{cccccc}
\hline Amostra & $\begin{array}{c}\text { Volume da } \\
\text { fração }(\mathbf{m L})\end{array}$ & $\begin{array}{c}\text { Abs } \mathbf{4 0 5 - 4 9 2} \\
\mathbf{n m}\end{array}$ & Atividade & $\begin{array}{c}\text { Atividade } \\
\text { total (U) }\end{array}$ & $\begin{array}{c}\text { \% de atividade } \\
\text { recuperada }\end{array}$ \\
\hline $\mathbf{A 5 0 0}$ & 9,6 & 1,079 & 176,5 & 1694,4 & 100 \\
\hline $\mathbf{F T}$ & 9,6 & 0,109 & 14,8 & 142,4 & 8,4 \\
\hline Reeq & 28,8 & 0,299 & 46,5 & 1339,2 & 79,0 \\
\hline $\mathbf{0 - 2 0} \%$ & 2 & 0,088 & 11,3 & 22,7 & 1,3 \\
\hline $\mathbf{2 0 - 4 0} \%$ & 2 & 0,079 & 9,8 & 19,7 & 1,2 \\
\hline $\mathbf{4 0 - 6 0} \%$ & 2 & 0,043 & 3,8 & 7,7 & 0,5 \\
\hline $\mathbf{6 0 - 8 0} \%$ & 2 & 0,048 & 4,7 & 9,3 & 0,6 \\
\hline $\mathbf{8 0 - 1 0 0 \%}$ & 2 & 0,034 & 2,3 & 4,7 & 0,3 \\
\hline $\mathbf{1 0 0} \%$ & 18 & 0,019 & $-0,2$ & $-3,0$ & $-0,2$ \\
\hline
\end{tabular}


Curva de calibração para determinação da concentração de proteínas nas frações da purificação.

\begin{tabular}{cc}
\hline BSA $(\boldsymbol{\mu g})$ & $\begin{array}{c}\text { Abs } \\
\mathbf{5 9 5 n m}\end{array}$ \\
\hline $\mathbf{0}$ & 0,772 \\
\hline $\mathbf{5}$ & 1,221 \\
\hline $\mathbf{1 0}$ & 1,469 \\
\hline $\mathbf{1 5}$ & 1,717 \\
\hline $\mathbf{2 0}$ & 1,917 \\
\hline $\mathbf{2 5}$ & 2,063 \\
\hline
\end{tabular}

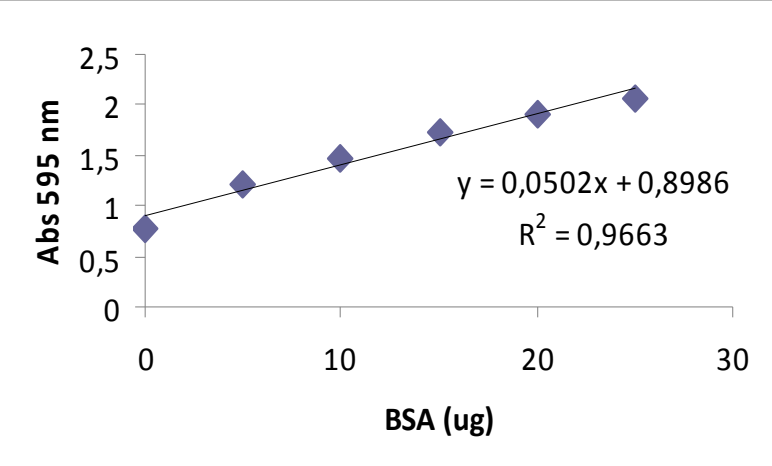

Determinação da concentração de proteínas nas frações da purificação.

\begin{tabular}{cccccccc}
\hline Amostras & $\begin{array}{c}\text { Volume da } \\
\text { fração }(\mathbf{m L})\end{array}$ & $\begin{array}{c}\text { Volume de } \\
\text { amostra }(\boldsymbol{\mu L})\end{array}$ & $\begin{array}{c}\text { Fator de } \\
\text { diluição }\end{array}$ & $\begin{array}{c}\text { Abs 595 } \\
\mathbf{n m}\end{array}$ & $\begin{array}{c}\text { Massa de } \\
\text { proteína } \\
(\boldsymbol{\mu g})\end{array}$ & $\begin{array}{c}\text { Concentração } \\
\text { de proteína } \\
(\mathbf{m g} / \mathbf{m L})\end{array}$ & $\begin{array}{c}\text { Proteína } \\
\text { total }(\mathbf{m g})\end{array}$ \\
\hline $\mathbf{A 5 0 0}$ & 9,6 & 10 & 20 & 1,465 & 11,3 & 1,13 & 10,89 \\
\hline $\mathbf{F T}$ & 9,6 & 60 & 3,3 & 1,203 & 6,1 & 0,10 & 0,98 \\
\hline $\mathbf{R e e q}$ & 28,8 & 30 & 6,6 & 1,371 & 9,5 & 0,32 & 9,08 \\
\hline $\mathbf{0 - 2 0} \%$ & 2 & 200 & - & 1,884 & 19,7 & 0,10 & 0,20 \\
\hline $\mathbf{2 0 - 4 0 \%}$ & 2 & 200 & - & 1,825 & 18,5 & 0,09 & 0,19 \\
\hline $\mathbf{4 0 - 6 0} \%$ & 2 & 200 & - & 1,535 & 12,7 & 0,06 & 0,13 \\
\hline $\mathbf{6 0 - 8 0} \%$ & 2 & 200 & - & 1,517 & 12,4 & 0,06 & 0,12 \\
\hline $\mathbf{8 0 - 1 0 0 \%}$ & 2 & 200 & - & 1,48 & 11,6 & 0,06 & 0,12 \\
\hline $\mathbf{1 0 0} \%$ & 18 & 200 & - & 1,185 & 5,7 & 0,03 & 0,52 \\
\hline
\end{tabular}


ANEXO N - Curvas de calibração utilizadas para determinação de atividade de FVIII e PC e para determinação da concentração de proteínas nas frações da purificação em IMAC$\mathrm{Co}^{2+}$ empregando coluna HiTrap IMAC HP de $1 \mathrm{~mL}$ e tampões citrato $25 \mathrm{mM}$.

Curva de calibração para determinação de atividade de FVIII.

\begin{tabular}{cccc}
\hline $\begin{array}{c}\% \\
\text { Atividade }\end{array}$ & $\begin{array}{c}\text { Abs 405 } \\
\mathbf{n m}\end{array}$ & $\begin{array}{c}\text { Abs 492 } \\
\mathbf{n m}\end{array}$ & $\begin{array}{c}\text { Abs 405- } \\
\mathbf{4 9 2} \mathbf{~ n m}\end{array}$ \\
\hline $\mathbf{0}$ & 0 & 0 & 0 \\
\hline $\mathbf{5 0}$ & 0,145 & 0,004 & 0,141 \\
\hline $\mathbf{1 0 0}$ & 0,254 & 0,004 & 0,25 \\
\hline
\end{tabular}

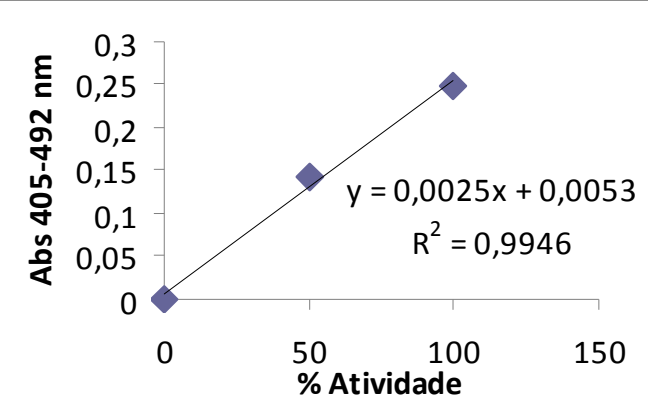

Determinação da atividade de FVIII nas frações da purificação.

\begin{tabular}{cccccc}
\hline Amostras & $\begin{array}{c}\text { Volume da } \\
\text { fração }(\mathbf{m L})\end{array}$ & $\begin{array}{c}\text { Abs } \mathbf{4 0 5 - 4 9 2} \\
\mathbf{n m}\end{array}$ & Atividade & $\begin{array}{c}\text { Atividade } \\
\text { Total (U) }\end{array}$ & $\begin{array}{c}\text { \% de atividade } \\
\text { recuperada }\end{array}$ \\
\hline $\mathbf{A} \mathbf{5 0 0}$ & 9,6 & 0,226 & 110,5 & 1061 & 100 \\
\hline $\mathbf{F T}$ & 9,6 & 0,01 & 2,5 & 24 & 2,26 \\
\hline Reeq & 24 & 0,05 & 22,5 & 540 & 50,90 \\
\hline $\mathbf{1 0} \mathbf{m M}$ & 24 & 0,007 & 1,0 & 24 & 2,26 \\
\hline $\mathbf{3 0} \mathbf{m M}$ & 24 & 0,002 & $-1,5$ & -36 & - \\
\hline $\mathbf{5 0} \mathbf{m M}$ & 24 & 0,002 & $-1,5$ & -36 & - \\
\hline $\mathbf{1 0 0} \mathbf{m M}$ & 24 & 0,001 & $-2,0$ & -48 & - \\
\hline $\mathbf{2 0 0} \mathbf{m M}$ & 24 & 0,003 & $-1,0$ & -24 & - \\
\hline $\mathbf{5 0 0} \mathbf{m M}$ & 24 & 0 & $-2,5$ & -60 & - \\
\hline
\end{tabular}


Curva de calibração para determinação da concentração de proteínas nas frações da purificação.

\begin{tabular}{cc}
\hline BSA $(\boldsymbol{\mu g})$ & Abs $\mathbf{5 9 5 n m}$ \\
\hline $\mathbf{0}$ & 0,716 \\
\hline $\mathbf{5}$ & 1,198 \\
\hline $\mathbf{1 0}$ & 1,446 \\
\hline $\mathbf{1 5}$ & 1,652 \\
\hline $\mathbf{2 0}$ & 1,892 \\
\hline $\mathbf{2 5}$ & 2,063 \\
\hline
\end{tabular}

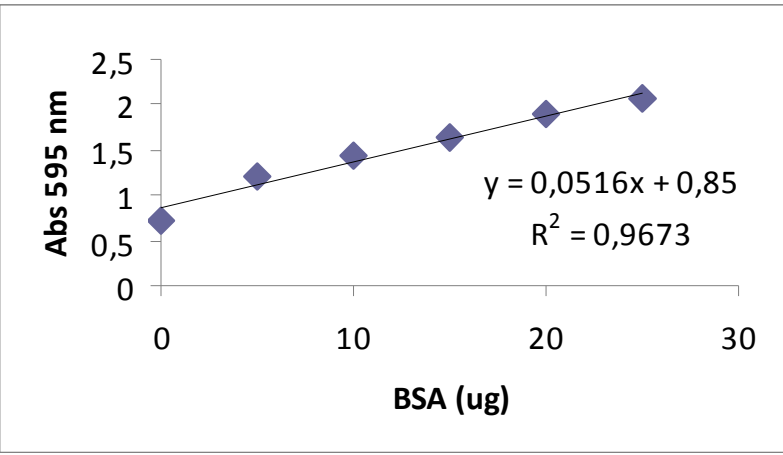

Determinação da concentração de proteínas nas frações da purificação.

\begin{tabular}{cccccccc}
\hline Amostras & $\begin{array}{c}\text { Volume da } \\
\text { fração }(\mathbf{m L})\end{array}$ & $\begin{array}{c}\text { Volume de } \\
\text { amostra }(\boldsymbol{\mu L})\end{array}$ & $\begin{array}{c}\text { Fator de } \\
\text { purificação }\end{array}$ & $\begin{array}{c}\text { Abs 595 } \\
\mathbf{n m}\end{array}$ & $\begin{array}{c}\text { Massa de } \\
\text { proteína } \\
(\boldsymbol{\mu g})\end{array}$ & $\begin{array}{c}\text { Concentração } \\
\text { de proteína } \\
(\mathbf{m g} / \mathbf{m L})\end{array}$ & $\begin{array}{c}\text { Proteína } \\
\text { total } \\
(\mathbf{m g})\end{array}$ \\
\hline $\mathbf{A 5 0 0 A}$ & 9,6 & 10 & 20 & 1,435 & 11,5 & 1,15 & 11,01 \\
\hline $\mathbf{F T}$ & 9,6 & 60 & 3,3 & 1,362 & 10,0 & 0,17 & 1,61 \\
\hline $\mathbf{R e e q}$ & 24 & 30 & 6,6 & 1,315 & 9,1 & 0,30 & 7,29 \\
\hline $\mathbf{1 0} \mathbf{m M}$ & 24 & 50 & 4 & 0,923 & 1,4 & 0,03 & 0,69 \\
\hline $\mathbf{3 0} \mathbf{m M}$ & 24 & 200 & - & 0,833 & $-0,3$ & 0,00 & $-0,04$ \\
\hline $\mathbf{5 0} \mathbf{m M}$ & 24 & 200 & - & 0,72 & $-2,5$ & $-0,01$ & $-0,31$ \\
\hline $\mathbf{1 0 0} \mathbf{m M}$ & 24 & 200 & - & 0,726 & $-2,4$ & $-0,01$ & $-0,29$ \\
\hline $\mathbf{2 0 0} \mathbf{m M}$ & 24 & 200 & - & 0,736 & $-2,2$ & $-0,01$ & $-0,27$ \\
\hline $\mathbf{5 0 0} \mathbf{m M}$ & 24 & 200 & - & 0,743 & $-2,1$ & $-0,01$ & $-0,25$ \\
\hline
\end{tabular}


ANEXO O - Curvas de calibração utilizadas para determinação de atividade de FVIII e PC e para determinação da concentração de proteínas nas frações da purificação em IMAC- $\mathrm{Co}^{2+}$ empregando coluna HisTrap HP de $5 \mathrm{~mL}$ e tampões citrato $10 \mathrm{mM}$.

Curva de calibração para determinação de atividade de FVIII.

\begin{tabular}{cccc}
\hline $\begin{array}{c}\text { \% } \\
\text { Atividade }\end{array}$ & $\begin{array}{c}\text { Abs 405 } \\
\mathbf{n m}\end{array}$ & $\begin{array}{c}\text { Abs 492 } \\
\mathbf{n m}\end{array}$ & $\begin{array}{c}\text { Abs 405- } \\
\mathbf{4 9 2} \mathbf{~ n m}\end{array}$ \\
\hline $\mathbf{0}$ & 0 & 0 & 0 \\
\hline $\mathbf{5 0}$ & 0,149 & $-0,004$ & 0,153 \\
\hline $\mathbf{1 0 0}$ & 0,361 & $-0,003$ & 0,364 \\
\hline
\end{tabular}

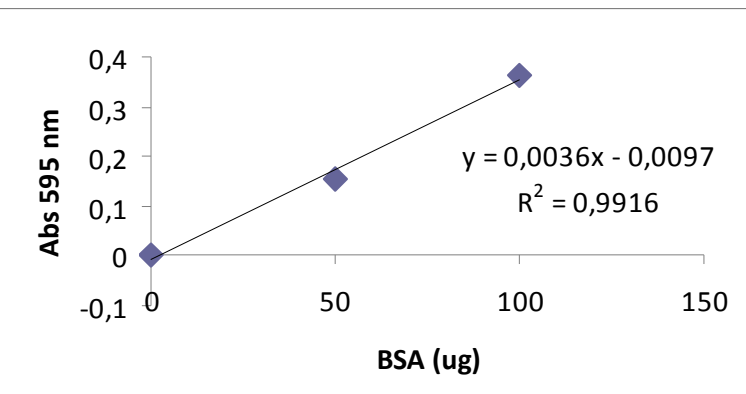

Determinação de atividade de FVIII nas frações da purificação.

\begin{tabular}{cccccc}
\hline Amostras & $\begin{array}{c}\text { Volume } \\
\text { da fração }(\mathbf{m L})\end{array}$ & $\begin{array}{c}\text { Abs } \mathbf{4 0 5 - 4 9 2} \\
\mathbf{n m}\end{array}$ & Atividade & $\begin{array}{c}\text { Atividade } \\
\text { Total (U) }\end{array}$ & $\begin{array}{c}\text { \% de atividade } \\
\text { recuperada }\end{array}$ \\
\hline A500 & 62,0 & 0,175 & 61,3 & 3802,7 & 100 \\
\hline FT & 62,0 & 0,012 & 7,0 & 434,0 & 11,4 \\
\hline Reeq & 74 & 0,002 & 3,7 & 271,3 & 7,1 \\
\hline $\mathbf{1 0 0} \mathbf{m M}$ & 73 & 0,104 & 37,7 & 2749,7 & 72,3 \\
\hline $\mathbf{5 0 0} \mathbf{m M}$ & 75 & 0,001 & 3,3 & 250,0 & 6,6 \\
\hline
\end{tabular}

Curva de calibração para determinação de atividade de PC.

\begin{tabular}{cccc}
\hline $\begin{array}{c}\% \\
\text { Atividade }\end{array}$ & $\begin{array}{c}\text { Abs 405 } \\
\text { nm }\end{array}$ & $\begin{array}{c}\text { Abs 492 } \\
\text { nm }\end{array}$ & $\begin{array}{c}\text { Abs 405- } \\
\mathbf{4 9 2} \mathbf{~ n m}\end{array}$ \\
\hline $\mathbf{0}$ & 0 & 0 & 0 \\
\hline $\mathbf{1 0}$ & 0,069 & 0 & 0,069 \\
\hline $\mathbf{2 0}$ & 0,134 & 0,003 & 0,131 \\
\hline $\mathbf{5 0}$ & 0,361 & 0,012 & 0,349 \\
\hline $\mathbf{7 5}$ & 0,497 & 0,018 & 0,479 \\
\hline $\mathbf{1 0 0}$ & 0,58 & 0,023 & 0,557 \\
\hline
\end{tabular}

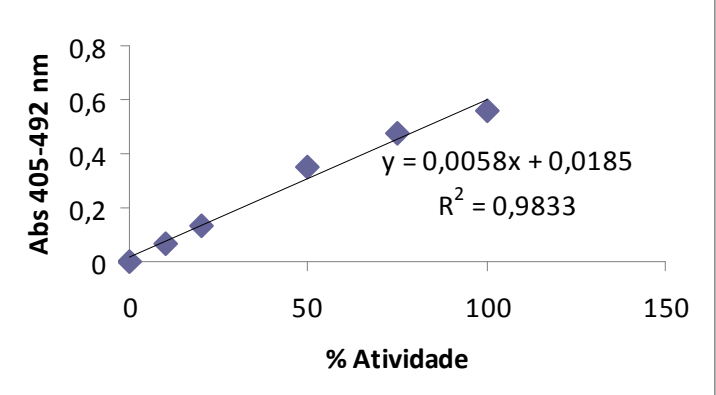

Determinação de atividade de PC nas frações da purificação.

\begin{tabular}{cccccc}
\hline Amostras & $\begin{array}{c}\text { Volume da } \\
\text { fração }(\mathbf{m L})\end{array}$ & $\begin{array}{c}\text { Abs 405-492 } \\
\mathbf{n m}\end{array}$ & Atividade & $\begin{array}{c}\text { Atividade } \\
\text { total (U) }\end{array}$ & $\begin{array}{c}\text { \% de atividade } \\
\text { recuperada }\end{array}$ \\
\hline A500 & 62,0 & 0,369 & 70,2 & 4352,4 & 100 \\
\hline FT & 62,0 & 0,345 & 65,4 & 4054,8 & 93,2 \\
\hline Reeq & 74 & 0,027 & 1,8 & 133,2 & 3,1 \\
\hline $\mathbf{1 0 0} \mathbf{m M}$ & 73 & 0,006 & $-2,4$ & $-175,2$ & - \\
\hline $\mathbf{5 0 0} \mathbf{m M}$ & 75 & 0,006 & $-2,4$ & $-180,0$ & - \\
\hline
\end{tabular}


Curva de calibração para determinação da concentração de proteínas nas frações da purificação.

\begin{tabular}{cc}
\hline BSA $(\boldsymbol{\mu g})$ & Abs $\mathbf{5 9 5 n m}$ \\
\hline $\mathbf{0}$ & 0,521 \\
\hline $\mathbf{5}$ & 0,772 \\
\hline $\mathbf{1 0}$ & 0,838 \\
\hline $\mathbf{1 5}$ & 1,05 \\
\hline $\mathbf{2 0}$ & 1,145 \\
\hline $\mathbf{2 5}$ & 1,269 \\
\hline
\end{tabular}

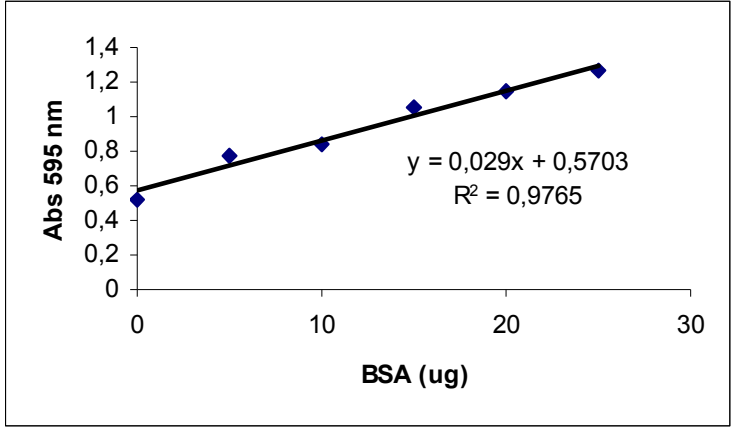

Determinação da concentração de proteínas nas frações da purificação.

\begin{tabular}{cccccccc}
\hline Amostras & $\begin{array}{c}\text { Volume } \\
\text { da fração } \\
(\mathbf{m L})\end{array}$ & $\begin{array}{c}\text { Volume de } \\
\text { amostra } \\
(\boldsymbol{\mu L})\end{array}$ & $\begin{array}{c}\text { Fator de } \\
\text { purificação }\end{array}$ & $\begin{array}{c}\text { Abs 595 } \\
\mathbf{n m}\end{array}$ & $\begin{array}{c}\text { Massa de } \\
\text { proteína } \\
(\boldsymbol{\mu g})\end{array}$ & $\begin{array}{c}\text { Concentração } \\
\text { de proteína } \\
(\mathbf{m g} / \mathbf{m L})\end{array}$ & $\begin{array}{c}\text { Proteína } \\
\text { total } \\
(\mathbf{m g})\end{array}$ \\
\hline $\mathbf{A 5 0 0}$ & 62,0 & 10 & 20 & 0,687 & 4,0 & 0,40 & 24,95 \\
\hline FT & 62,0 & 10 & 20 & 0,638 & 2,3 & 0,23 & 14,47 \\
\hline Reeq & 74 & 200 & - & 0,93 & 12,4 & 0,06 & 4,59 \\
\hline $\mathbf{1 0 0 M m}$ & 73 & 200 & - & 0,666 & 3,3 & 0,02 & 1,20 \\
\hline $\mathbf{5 0 0 M m}$ & 75 & 200 & - & 0,553 & $-0,6$ & 0,00 & $-0,22$ \\
\hline
\end{tabular}


ANEXO P - Curvas de calibração utilizadas para determinação de atividade de FVIII e PC e para determinação da concentração de proteínas nas frações da purificação em IMAC$\mathrm{Co}^{2+}$ empregando coluna Chelating Sepharose FF de $10 \mathrm{~mL}$ e tampões citrato 10 $\mathrm{mM}$.

Curva de calibração para determinação da atividade de FVIII.

\begin{tabular}{cccc}
\hline $\begin{array}{c}\text { \% } \\
\text { Atividade }\end{array}$ & $\begin{array}{c}\text { Abs 405 } \\
\mathbf{n m}\end{array}$ & $\begin{array}{c}\text { Abs 492 } \\
\mathbf{n m}\end{array}$ & $\begin{array}{c}\text { Abs 405- } \\
\mathbf{4 9 2} \mathbf{~ n m}\end{array}$ \\
\hline $\mathbf{0}$ & 0 & 0 & 0 \\
\hline $\mathbf{5 0}$ & 0,141 & 0,002 & 0,139 \\
\hline $\mathbf{1 0 0}$ & 0,278 & 0,002 & 0,276 \\
\hline
\end{tabular}

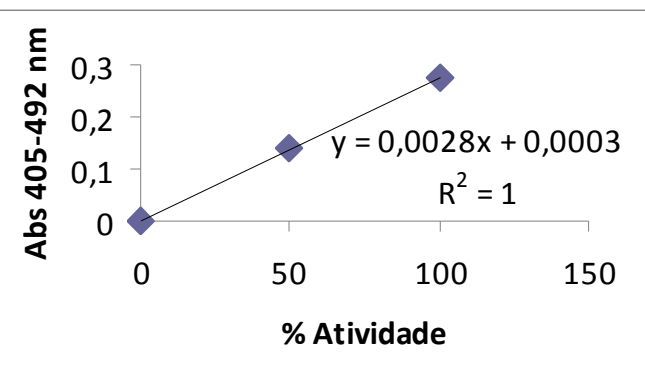

Determinação da atividade de FVIII nas frações da purificação.

\begin{tabular}{cccccc}
\hline Amostra & $\begin{array}{c}\text { Volume da } \\
\text { fração }(\mathbf{m L})\end{array}$ & $\begin{array}{c}\text { Abs } \mathbf{4 0 5}- \\
\mathbf{4 9 2} \mathbf{~} \mathbf{m}\end{array}$ & Atividade & $\begin{array}{c}\text { Atividade } \\
\text { total (U) }\end{array}$ & $\begin{array}{c}\text { \% atividade } \\
\text { recuperada }\end{array}$ \\
\hline A500A & 120 & 0,164 & 58,5 & 7015,7 & 100 \\
\hline FT & 120 & 0,142 & 50,6 & 6072,9 & 86,6 \\
\hline Reeq & 120 & 0,027 & 9,5 & 1430,4 & 20,4 \\
\hline $\mathbf{1 0 0 M m}$ & 150 & 0,028 & 9,9 & 734 & 10,5 \\
\hline $\mathbf{5 0 0 M m}$ & 150 & 0,027 & 9,4 & 698 & 9,9 \\
\hline
\end{tabular}


ANEXO Q - Curvas de calibração utilizadas para determinação de atividade de FVIII e PC e para determinação da concentração de proteínas nas frações da purificação em IMAC-Fe ${ }^{3+}$.

Curva de calibração para determinação da atividade de FVIII.

\begin{tabular}{cccc}
\hline $\begin{array}{c}\text { \% } \\
\text { Atividade }\end{array}$ & $\begin{array}{c}\text { Abs 405 } \\
\mathbf{n m}\end{array}$ & $\begin{array}{c}\text { Abs 492 } \\
\text { nm }\end{array}$ & $\begin{array}{c}\text { Abs 405-492 } \\
\text { nm }\end{array}$ \\
\hline $\mathbf{0}$ & 0 & 0 & 0 \\
\hline $\mathbf{5 0}$ & 0,114 & 0 & 0,114 \\
\hline $\mathbf{1 0 0}$ & 0,223 & 0,004 & 0,219 \\
\hline
\end{tabular}

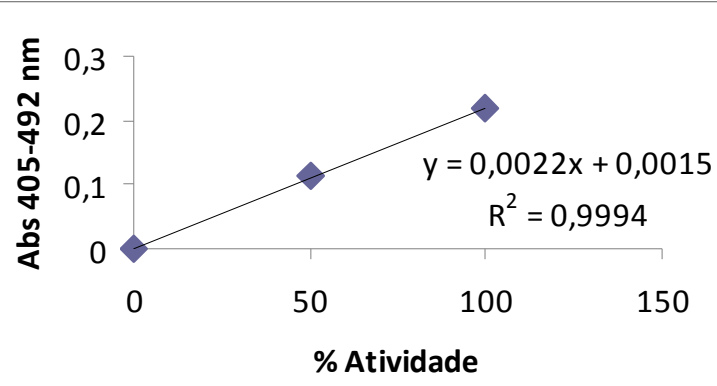

Determinação da atividade de FVIII nas frações da purificação.

\begin{tabular}{cccccc}
\hline Amostras & $\begin{array}{c}\text { Volume da } \\
\text { fração }(\mathbf{m L})\end{array}$ & $\begin{array}{c}\text { Abs } \mathbf{4 0 5 - 4 9 2} \\
\mathbf{n m}\end{array}$ & Atividade & $\begin{array}{c}\text { Atividade } \\
\text { total }(\mathbf{U})\end{array}$ & $\begin{array}{c}\text { \% de atividade } \\
\text { recuperada }\end{array}$ \\
\hline A500 & 9,6 & 0,365 & 165,2 & 1586,2 & 100 \\
\hline FT & 9,6 & 0,271 & 122,5 & 1176,0 & 74,1 \\
\hline Reeq & 24 & 0,006 & 2,0 & 49,1 & 3,1 \\
\hline $\mathbf{1 0 0} \mathbf{m M}$ & 24 & $-0,003$ & $-2,0$ & $-49,1$ & - \\
\hline $\mathbf{5 0 0} \mathbf{m M}$ & 24 & $-0,003$ & $-2,0$ & $-49,1$ & - \\
\hline
\end{tabular}

Curva de calibração para determinação de atividade de PC.

\begin{tabular}{cccc}
\hline $\begin{array}{c}\text { \% } \\
\text { Atividade }\end{array}$ & $\begin{array}{c}\text { Abs 405 } \\
\mathbf{n m}\end{array}$ & $\begin{array}{c}\text { Abs 492 } \\
\mathbf{n m}\end{array}$ & $\begin{array}{c}\text { Abs 405-492 } \\
\mathbf{n m}\end{array}$ \\
\hline $\mathbf{0}$ & 0 & 0 & 0 \\
\hline $\mathbf{1 0}$ & 0,083 & 0,013 & 0,07 \\
\hline $\mathbf{2 0}$ & 0,178 & 0,039 & 0,139 \\
\hline $\mathbf{5 0}$ & 0,357 & 0,039 & 0,318 \\
\hline $\mathbf{7 5}$ & 0,467 & 0,042 & 0,425 \\
\hline $\mathbf{1 0 0}$ & 0,516 & 0,043 & 0,473 \\
\hline
\end{tabular}

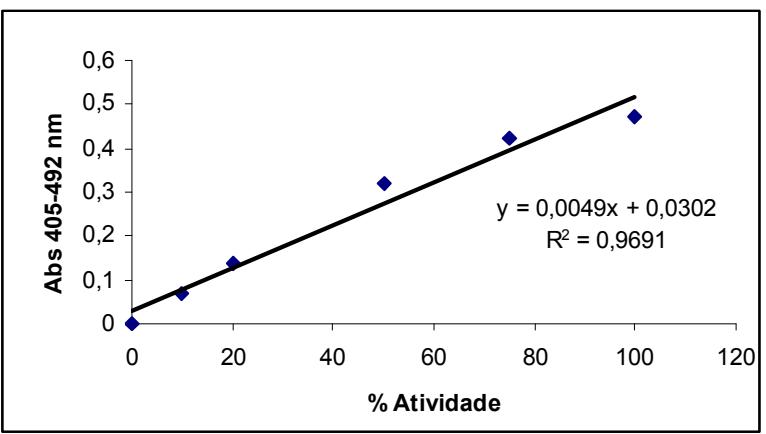

Determinação de atividade de PC nas frações da purificação.

\begin{tabular}{cccccc}
\hline Amostras & $\begin{array}{c}\text { Volume da } \\
\text { fração }(\mathbf{m L})\end{array}$ & $\begin{array}{c}\text { Abs 405-492 } \\
\mathbf{n m}\end{array}$ & Atividade & $\begin{array}{c}\text { Atividade } \\
\text { total (U) }\end{array}$ & $\begin{array}{c}\text { \% de atividade } \\
\text { recuperada }\end{array}$ \\
\hline $\mathbf{A 5 0 0}$ & 9,6 & 0,692 & 135,1 & 1296,6 & 100 \\
\hline FT & 9,6 & 0,493 & 94,4 & 906,7 & 69,9 \\
\hline Reeq & 24 & 0,034 & 0,8 & 18,6 & 1,4 \\
\hline $\mathbf{1 0 0} \mathbf{m M}$ & 24 & 0,006 & $-4,9$ & $-118,5$ & - \\
\hline $\mathbf{5 0 0} \mathbf{m M}$ & 24 & 0,003 & $-5,6$ & $-133,2$ & - \\
\hline
\end{tabular}


Curva de calibração para determinação da concentração de proteínas nas frações da purificação.

\begin{tabular}{cc}
\hline BSA $(\boldsymbol{\mu g})$ & Abs $\mathbf{5 9 5} \mathbf{~ n m}$ \\
\hline $\mathbf{0}$ & 0,54 \\
\hline $\mathbf{5}$ & 0,79 \\
\hline $\mathbf{1 0}$ & 0,892 \\
\hline $\mathbf{1 5}$ & 1,099 \\
\hline $\mathbf{2 0}$ & 1,183 \\
\hline $\mathbf{2 5}$ & 1,284 \\
\hline
\end{tabular}

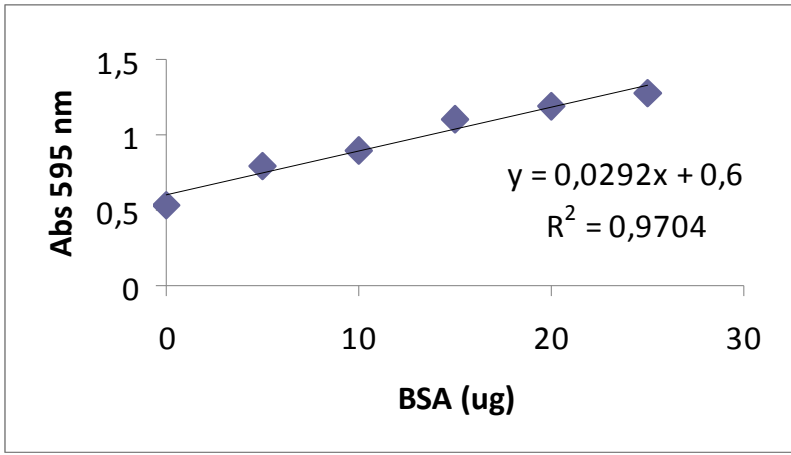

Determinação da concentração de proteínas nas frações da purificação.

\begin{tabular}{cccccccc}
\hline Amostras & $\begin{array}{c}\text { Volume da } \\
\text { fração }(\mathbf{m L})\end{array}$ & $\begin{array}{c}\text { Volume de } \\
\text { amostra }(\boldsymbol{\mu L})\end{array}$ & $\begin{array}{c}\text { Fator de } \\
\text { purificação }\end{array}$ & $\begin{array}{c}\text { Abs 595 } \\
\mathbf{n m}\end{array}$ & $\begin{array}{c}\text { Massa de } \\
\text { proteína } \\
(\boldsymbol{\mu g})\end{array}$ & $\begin{array}{c}\text { Concentração } \\
\text { de proteína } \\
(\mathbf{m g} / \mathbf{m L})\end{array}$ & $\begin{array}{c}\text { Proteína } \\
\text { total } \\
(\mathbf{m g})\end{array}$ \\
\hline $\mathbf{A 5 0 0}$ & 9,6 & 10 & 20 & 1,003 & 13,8 & 1,4 & 13,2 \\
\hline $\mathbf{F T}$ & 9,6 & 10 & 20 & 0,935 & 11,5 & 1,1 & 11,0 \\
\hline $\mathbf{R}$ Reeq & 24 & 30 & 6,6 & 0,592 & $-0,3$ & 0,0 & $-0,2$ \\
\hline $\mathbf{1 0 0 m M}$ & 24 & 200 & - & 0,547 & $-1,8$ & 0,0 & $-0,2$ \\
\hline $\mathbf{5 0 0 m M}$ & 24 & 200 & - & 0,548 & $-1,8$ & 0,0 & $-0,2$ \\
\hline
\end{tabular}

